\title{
USO DO MÉTODO DE REAMOSTRAGEM BOOTSTRAP NA ESTIMAÇÃO DE PARÂMETROS GENÉTICOS POPULACIONAIS
}

\author{
LUCIANA APARECIDA CARLINI-GARCIA \\ Engenheiro Agrônomo
}

Orientador: Prof. Dr. ROLAND VENCOVSKY

Tese apresentada à Escola Superior de Agricultura "Luiz de Queiroz", Universidade de São Paulo, para obtenção do tulo de Doutor em Agronomia, Área de Concentração: Genética e Melhoramento de Plantas.

P I R A I C A B A

Estado de São Paulo - Brasil

Fevereiro - 2001 


\section{Dados Internacionais de Catalogaçāo na Publicaçāo (CIP) DIVISÃO DE BIBLIOTECA E DOCUMENTAÇÃO - Campus "Luiz de QueirOz"/USP}

Carlini-Garcia, Luciana Aparecida

Uso do método de reamostragem bootstrap na estimação de parâmetros genéticos populacionais / Luciana Aparecida Carlini-Garcia. - - Piracicaba, 2001.

$162 \mathrm{p}$.

Tese (doutorado) - Escola Superior de Agricultura Luiz de Queiroz, 2001.

Bibliografia.

1. Genética de população 2. Marcador genético 3. Parâmetro genético 4. Reamostragem I. Título

CDD 575.15

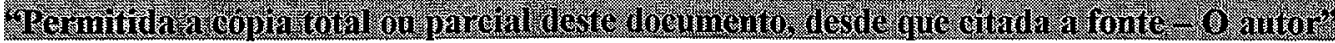


À minha familia, em especial ao meu pai Ebear (in memoriam), a minha mãe Leila $e$ aos meus irmão Marcia e Adilson, pelo amor $e$ compreensão que nunca me foram negados,

\section{DEDICO}

Ao querido Augusto, pelo amor, apoio, dedicação e companheirismo, OFEREÇO 
Ao amigo Cássio van den Berg, pelo auxilio na elaboração do "sumnary".

Ao meu marido Antonio Augusto Franco Garcia, pelo auxilio em parte das análises estatísticas, leitura dos originais e valiosas sugestões.

A toda a minha familia, pelo carinho, apoio e compreensão.

Ao Conselho Nacional de Pesquisa (CNPq), pelo auxilio financeiro. 


\section{SUMÁRIO}

Página

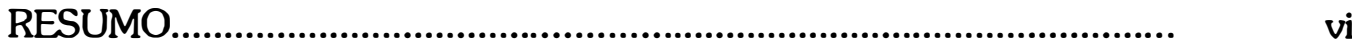

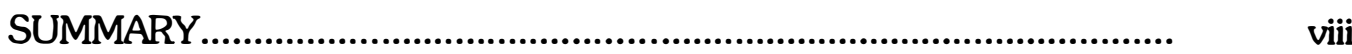

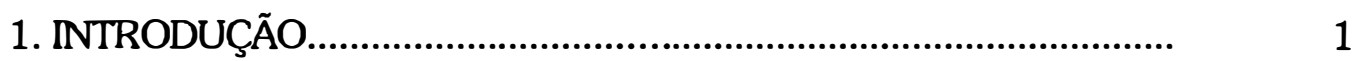

2. REVISÃO DE LITERATURA............................................................

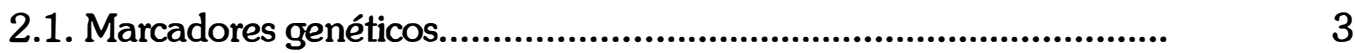

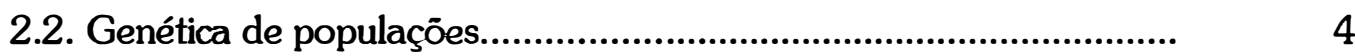

2.2.1. Equilibrio de Hardy-Weinberg e equilibrio de Wright................... 5

2.2.2. Análise de diversidade gênica de Nei............................................. 13

2.2.3. Análise de variância de freqüências gênicas...............................

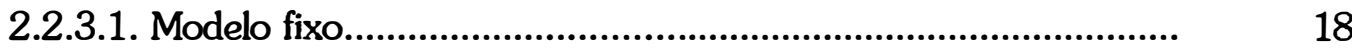

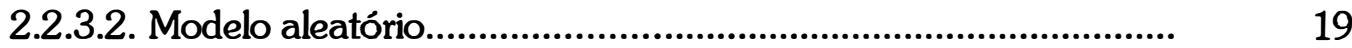

2.2.4. Exemplos de aplicação das estatísticas $F$, da análise de diversidade de Nei e da análise de variância de freqüências gênicas......

2.2.5. Análise molecular de variância (AMOVA).....................................

2.2.6. Medidas de similaridade e de dissimilaridade, métodos de agrupamento e de ordenação.

2.2.7. Análise da estrutura genética populacional através de marcadores dominantes.

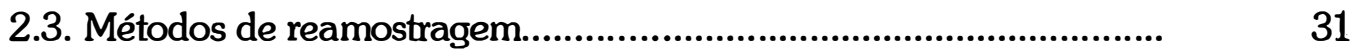

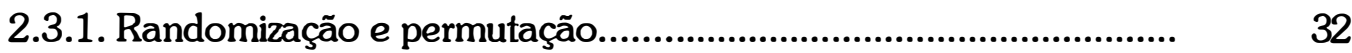

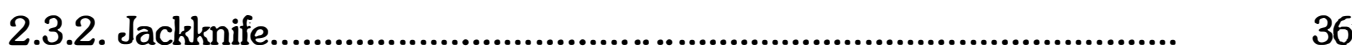

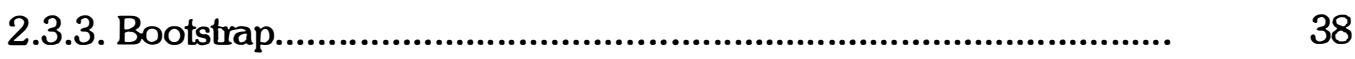

2.3.4. Bootstrap aplicado à Genética......................................................... 44

3. MATERIAL E MÉTODOS..............................................................

3.1. Material..................................................................................... 


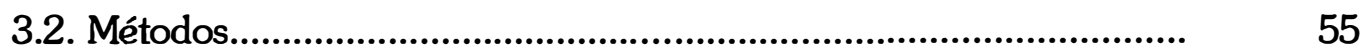

3.2.1. Análise de variância de freqüências gênicas................................. 55

3.2.2. Reamostragem bootstrap............................................................ 56

3.2.2.1. Bootstrap com tamanhos constantes de amostras....................... $\quad 57$

3.2.2.2. Bootstrap com tamanhos variáveis de amostras.......................... 62

3.2.2.2.1. Análise hierárquica das estimativas bootstrap de variância..... 62

3.2.2.2.2. Análise fatorial das estimativas bootstrap de variância............ 65

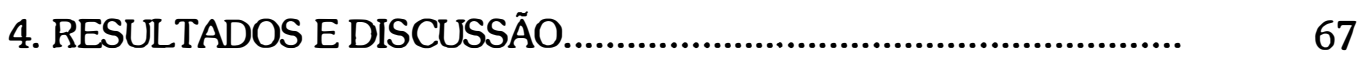

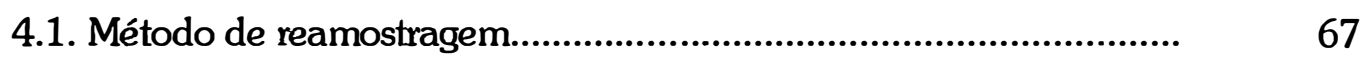

4.2. Bootstrap com tamanhos constantes de amostras............................. 68

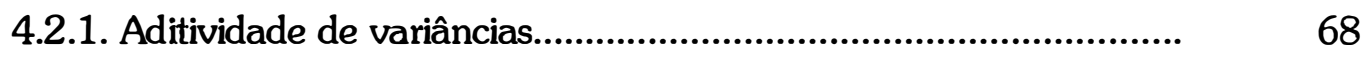

4.2.2. Estimativas dos parâmetros, desvios-padrão $e$ intervalos de confiança associados $e$ testes de normalidade......................................... 77

4.3. Bootstrap com tamanhos variáveis de amostras............................... $\quad 99$

4.3.1. Análise hierárquica das estimativas bootstrap de variância........... 99

4.3.2. Análise fatorial das estimativas bootstrap de variância................... 114

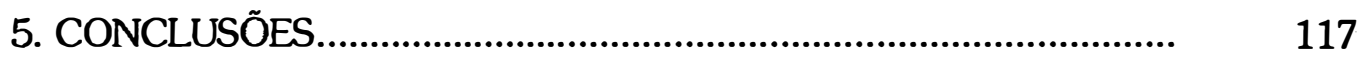

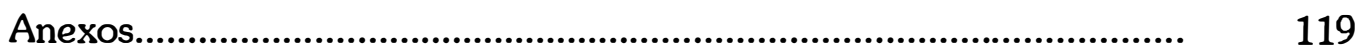

REFERÊNCIAS BIBUOGRÁFICAS................................................... 152 


\title{
USO DO MÉTODO DE REAMOSTRAGEM BOOTSTRAP NA ESTIMAÇÃO DE PARÂMETROS GENÉTICOS POPULACIONAIS
}

\author{
Autora: LUCIANA APARECIDA CARLINI-GARCIA \\ Orientador: Prof. Dr. ROLAND VENCOVSKY
}

\section{RESUMO}

Muitos autores têm utilizado marcadores isoenzimáticos ou moleculares para estudar a estrutura genética e o sistema reprodutivo de populações naturais. Para tanto, parâmetros populacionais de interesse são estimados, mas há pouca informação sobre o erro associado a essas estimativas em função dos diferentes níveis de amostragem. Através dessa informação, estratégias de amostragem poderiam ser estabelecidas de modo a reduzir a magnitude dos erros associados a tais estimativas.

No presente trabalho foram utilizados conjuntos de dados reais, além de dados simulados em algumas situações. Para os dados reais, foram feitas reamostragens bootstrap de locos, indivíduos, populações, e indivíduos e populações concomitantemente. Para os parâmetros índice de fixação total $(F)$, diversidade entre populações ou grau de coancestralidade nas populações $(\theta)$, índice de fixação dentro das populações $(f)$, taxa aparente de cruzamento $\left(t_{a}\right)$, fluxo de genes entre populações $(N m)$ e tamanho efetivo populacional $\left(N_{e}\right)$ foi possível obter, em função das diferentes fontes de reamostragem, os erros associados às estimativas desses parâmetros, a distribuição empírica dessas estimativas e intervalos de confiança para tais parâmetros. Em geral, as menores variâncias estão associadas às estimativas de $\theta$. O contrário foi observado para $F, f$ e $N$ m . Verificou-se que apenas as distribuições empíricas de $\hat{F}$ e $\hat{f}$ tendem à normalidade. Isso ocorreu somente quando foram feitas reamostragens envolvendo indivíduos, possivelmente por serem mais numerosos que populações e locos. 
A partir dos dados reais e simulados, para os parâmetros $F, f$ e $\theta$ individualmente e em conjunto, verificou-se que as estimativas das variâncias devidas à reamostragem de indivíduos $e$ de populações isoladamente são aditivas. Conseqüentemente, pode-se calcular a contribuição relativa destas duas fontes de variação para a variância total das estimativas.

Foi possivel concluir que dois métodos de verificação da importância relativa das causas de variação de populações e de indivíduos, como fonte de erros das estimativas dos parâmetros $F, f$ e $\theta$, em geral, apresentaram resultados concordantes.

Para obter o número necessário de locos, indivíduos e populaçōes, visando atingir uma determinada precisão na estimação de $F, f$ e $\theta$, foram feitas reamostragens com tamanho variável de amostras bootstrap. Para os diversos níveis dos fatores locos, indivíduos e populações, foram estimadas as respectivas variâncias e construídas curvas de regressão entre o número de populações, ou indivíduos ou locos e os erros de estimação associados. Em geral, os tamanhos amostrais utilizados nas pesquisas com populações naturais foram suficientes apenas para estimar $\theta$, considerando a magnitude estabelecida para os erros das estimativas. Observou-se também que a fonte de variação de locos foi responsável pelos maiores erros das estimativas dos parâmetros $F$ e $f$. Portanto, em pesquisas futuras dessa natureza, é recomendável atentar para a necessidade de trabalhar com número adequado de locos. Este número certamente deve ser maior do que o comumente utilizado. A fonte de variação de populações também foi importante na estimação dos parâmetros $F$ e $f$, devendo assim merecer a devida atenção.

Diante dessas informações, evidencia-se a importância da aplicação de bootstrap na mensuração da precisão de estimativas de parâmetros populacionais, em função das diversas fontes de variação. 


\title{
USE OF BOOTSTRAP IN THE ESTIMATION OF POPULATION GENETIC PARAMETERS
}

\author{
Author: LUCIANA APARECIDA CARLINI-GARCIA \\ Adviser: Prof. Dr. ROLAND VENCOVSKY
}

\section{SUMMARY}

Genetic structure and mating system of natural populations have often been studied using molecular markers and isozymes. Specific genetic parameters are therefore being estimated for this purpose. There is little information about errors associated with these estimates due to different possible sampling levels. The knowledge of this information could be used to minimize the magnitude of the errors associated with such estimates.

Real and simulated datasets were used in this study. With the real datasets, bootstrapping over loci, individuals, populations and both individuals and populations simultaneously, was performed. These different resampling strategies produced errors of the estimates, empiric probability distributions and confidence intervals for the following parameters: total fixation index $(F)$, diversity among populations or coancestry index $(\theta)$, fixation index within populations $(f)$, apparent outcrossing rates $\left(t_{a}\right)$, gene flow between populations $(\mathrm{Nm})$, and effective population size $\left(N_{e}\right)$. Generally, smaller variances were associated with estimates of $\theta$, whereas the largest were associated with $\hat{F}, \hat{f}$ and $\hat{N} m$. The only estimates approaching normality were $\hat{F}, \hat{f}$, when individuals were envolved in the resampling process. This was probably caused by the larger number of individuals comparison with the number of loci and populations commonly used.

Resampling both simulated and real datasets for estimation of $F, f$ and $\theta$ jointly and separately showed that the variances due to individuals and due to populations are additive. Consequently, it is possible to calculate the relative contribution of these two sources of variation to the total variance of the estimates. 
There was overall agreement beetwen results obtained when two different methods were applied to assess the relative importance of individuals and populations as source of errors in the estimation of $F, f$ and $\theta$.

Bootstrap samples of variable sizes were used to determine the number of loci, individuals and populations necessary to achieve a given precision in the estimates of $F$, $f$ and $\theta$. Variance estimates with different numbers of loci, individuals and population were obtained and regression analyses performed relating these estimates with the corresponding number of populations, individuals ou loci. The magnitude of errors of the estimates in most real datasets indicated that sample sizes currently used in research involving natural populations would be suitable only for the estimation of $\theta$. The largest errors of the estimates of $F$ and $f$ were associated with sampling error due to loci. Therefore, future studies should use a larger number of loci to improve the estimation of these parameters. Sampling error due to populations was also important and should not be neglected for the estimation of $F$ and $f$.

This study reinforced the importance of bootstrapping as a technique to measure precision of population parameter estimates under different sources of variation. 


\section{INTRODUÇÃO}

A Genética de Populações é fundamental para o desenvolvimento e entendimento dos processos evolutivos e de melhoramento genético. Com o advento dos marcadores bioquímicos e moleculares, houve um salto qualitativo e quantitativo em estudos da estrutura populacional de diversas espécies. Nestes estudos, podem ser estimados vários parâmetros populacionais como freqüências genotípicas e alélicas, grau de endogamia, tamanho efetivo populacional, sistema reprodutivo predominante, entre outros, que são de extrema importância na determinação de estratégias de conservação da variabilidade genética na natureza.

Atualmente, devido ao grande avanço tecnológico, as técnicas de reamostragem têm permitido mensurar a acurácia destas estimativas. Vários são os métodos de reamostragem, com destaque para a técnica bootstrap, que além de permitir a obtenção de estimativas de parâmetros e seus desvios-padrão, permite construir o intervalo de confiança para os parâmetros analisados e obter a distribuição empírica de suas estimativas.

Muitos trabalhos, dissertações $e$ teses têm sido desenvolvidos para estudar a estrututura genética populacional a partir do uso de marcadores moleculares $e$ isoenzimáticos. Nessas pesquisas, vários parâmetros vêm sendo utilizados para descrever os fenômenos genéticos populacionais, destacando-se: o índice de fixação total num conjunto de populações $(F)$, o grau de diversidade entre populações ou de coancestralidade dentro delas $(\theta)$, o índice de fixação dentro das populações $(f)$, a taxa aparente de cruzamento $\left(t_{a}\right)$, o fluxo de genes entre populações $(\mathrm{Nm})$ e o tamanho efetivo populacional $\left(N_{e}\right)$, entre outros. No processo de estimação, nem sempre são fomecidos os erros das estimativas e pouca informação há sobre a natureza da distribuição de probabilidades dessas estimativas. Além disso, quando é utilizado o processo de reamostragem, como o 
bootstrap, freqüentemente não há detalhamento sobre como ele foi aplicado e sobre as principais fontes causadores desse erros. Tendo em vista o exposto, o objetivo geral deste trabalho é:

a) fornecer subsíduos para aplicação mais eficiente do método de reamostragem bootstrap em estudos de populações naturais via marcadores genéticos.

Os objetivos específicos são:

b) demonstrar a necessidade de realizar reamostragens para obtenção dos erros de estimação associados às estimativas dos parâmetros $F, f, \theta, t_{a}, N m$ e $N_{e}$, em função de diversas fontes das variação estudadas, a saber, locos, indivíduos dentro de populações e populações;

c) comparar a grandeza dos erros provenientes dos vários níveis de reamostragem associados às estimativas desses parâmetros;

d) verificar se há aditividade de variâncias quando se utiliza reamostragem bootstrap, considerando as fontes de variação de indivíduos e de populações, no caso dos parâmetros $F, f$ e $\theta$, com dados reais e simulados;

e) comparar dois métodos de verificação da grandeza relativa das causas de variação como fontes de erro nas estimativas desses parâmetros;

f) obter a distribuição de probabilidade empírica das estimativas dos parâmetros $F$, $f, \theta, t_{a}, N m$ e $N_{e}$;

g) comparar intervalos de confiança provenientes das diferentes fontes de variação na estimação dos parâmetros ;

h) verificar a quais parâmetros estão associados os maiores emos de estimação;

i) estabelecer estratégias de amostragem para obter uma determinada precisão na estimação dos parâmetros $F, f$ e $\theta$. 


\section{REVISÃO DE LITERATURA}

\subsection{Marcadores genéticos}

A deteç̧ão de diferenças e semelhanças entre indivíduos (populações, etc.) pode ser feita em diferentes níveis de observação: fenotípico, bioquímico, molecular, entre outros. Para tanto, podem ser utilizados marcadores morfológicos (como os usados por Mendel), marcadores bioquímicos (eletroforese de proteínas e de isoenzimas) e marcadores moleculares (RFLP, RAPD, AFLP, mini e microssatélites, etc.).

Marcadores moleculares são detectados diretamente no material genético, não se restringindo somente às regiões codificadoras do genoma, diferindo neste ponto dos marcadores morfológicos e bioquímicos que, para serem observados, dependem da expressão dos genes.

Os marcadores moleculares podem ser dominantes, como RAPD ("Random Amplified Polymorphic DNA") e AFLP ("Amplified Fragment Length Polymorphism"), ou codominantes, como isoenzimas e RFLP ("Restriction Fragment Length Polymorphism") $e$ micro e minissatélites (que são seqüências repetitivas de DNA arranjadas em tandem, cujos tamanhos variam de 1 a 4 e 15 a 100 bases nitrogenadas, respectivamente) (Griffiths et al, 1996; Weir, 1996). Uma desvantagem dos marcadores dominantes é que, através deles, não é possível diferenciar indivíduos heterozigóticos de indivíduos homozigóticos dominantes, sendo que somente homozigotos recessivos podem ser distintos. Sendo assim, marcadores codominantes são mais informativos (Ferreira \& Grattapaglia, 1996).

Marcadores codominantes, particularmente as isoenzimas e os microssatélites, têm sido amplamente difundidos em estudos de Genética de Populações, pois, ao fornecerem as freqüências genotípicas de indivíduos homo e heterozigóticos, permitem estimar parâmetros tais como freqüências alélicas, índices de fixação $\left(F_{I S}, F_{S T}, F_{I T}\right)$, entre 
outros (Ferreira\& Grattapaglia, 1996). Recentemente, têm sido desenvolvidos modelos estatisticos que permitem estimar tais parâmetros também com a utilização de marcadores dominantes (Lynch \& Milligan, 1994), embora o uso destes modelos seja limitado. No entanto, os marcadores dominantes têm grande aplicação em estudos de divergência genética, permitindo a construção de agrupamentos e ordenações através do uso de similaridades ou dissimilaridades. Como exemplo podem se citar os trabalhos de Bender et al. (1996), Chalwatzis et al. (1996), Chikuni et al. (1995) e Liu et al. (1997).

\subsection{Genética de populações}

Em Genética, muitas áreas de pesquisa têm nos indivíduos a unidade de estudo. No entanto, a transformação de uma espécie no tempo e espaço, tanto por seleção natural quanto por seleção artificial, se dá num conjunto de indivíduos, ou seja, numa população ou ainda num grupo de populações (Griffiths et al., 1996). Assim sendo, a unidade de estudo deixa de ser o indivíduo e passa a ser a população.

Nesse contexto, insere-se a Genética de Populações, que tem por objetivo descrever a variabilidade genética populacional e verificar como esta variabilidade se altera no espaço e no tempo, através de determinações teóricas e experimentais (Griffiths et al., 1996). Esta área da Genética, fundamental para o desenvolvimento e entendimento dos processos envolvidos em estudos evolutivos e de melhoramento (Vencovsky, 1978), é fundamentada em três princípios darwinianos: existência de variabilidade morfológica e/ou fisiológica e/ou comportamental entre indivíduos numa população; hereditariedade; diferença do valor adaptativo entre indivíduos de uma população, sendo que indivíduos mais adaptados em relação ao ambiente em que vivem têm maior capacidade de sobrevivência elou maior sucesso reprodutivo que os demais (Griffiths et al., 1996).

A variabilidade genética das populações pode ser analisada a partir de caracteres morfológicos (cor e textura de sementes, por exemplo), polimorfismos cromossômicos (cromossomos extras, translocaçōes recíprocas, inversōes, etc.), marcadores bioquímicos (eletroforese de proteínas e de isoenzimas) e marcadores moleculares, como RFLP, RAPD, AFLP, mini e microssatélites ou pelo seqüenciamento de DNA (Griffiths et al., 1996; Weir, 1996). 
Em estudos populacionais, além de descrever e quantificar a variabilidade genética, também é necessário saber como ela está estruturada, determinando por exemplo, se há maior variabilidade entre ou dentro de populações. Há diversos parâmetros utilizados para responder a estas questões, tais como freqüências alélicas e genotípicas, índices de fixação, taxa de cruzamento natural, tamanho efetivo populacional, grau de heterozigosidade média, distâncias genéticas intra e interpopulacionais, entre outros, que serão detalhados a seguir.

\subsubsection{Equilíbrio de Hardy-Weinberg e equilíbrio de Wright}

Para descrever a constituição de uma população em relação a um dado gene, é necessário especificar quais são as proporções de cada genótipo pertencente a ela, ou seja, as freqüências genotipicas. Como geneticamente a população não é apenas um grupo de indivíduos, mas um grupo de indivíduos que se reproduzem e deixam descendentes, é necessário não só conhecer a constituição dos indivíduos, mas também como os genes são transmitidos às próximas gerações. Nas progênies, novos genótipos são formados a partir da combinação dos alelos transmitidos pelos gametas dos genitores. A constituição genética da população em relação aos alelos que são transmitidos de geração a geração pode ser descrita pelas freqüências gênicas ou alélicas (Falconer \& Mackay, 1996).

Considere-se um loco com dois alelos $\left(A_{1}\right.$ e $\left.A_{2}\right)$ e uma população com $N$ indivíduos diplóides, na qual as freqüências relativas dos indivíduos homozigóticos dominantes $\left(A_{1} A_{1}\right)$, recessivos $\left(A_{2} A_{2}\right)$ e dos indivíduos heterozigóticos $\left(A_{1} A_{2}\right)$ sejam $P, Q$ e $H$, respectivamente, em que $P+H+Q=1$. Como os $N$ indivíduos têm conjuntamente $2 N$ alelos, tem-se que a freqüência gênica relativa de $A_{1}$ é igual a $(1 / 2)(2 P+H)=f\left(A_{1}\right)=p$ e a de $A_{2}$ igual a $(1 / 2)(2 Q+H)=f\left(A_{2}\right)=1-p=q$, sendo portanto $p+q=1$. Os valores $P, Q$ e $H$ constituem as freqüências genotípicas relativas, enquanto $p$ e $q$ representam as freqüências gênicas ou alélicas. Sob condições de panmixia, ou seja, em populações teoricamente infinitas, cujos indivíduos se cruzam aleatoriamente e onde não existam mecanismos que alterem as freqüências gênicas tais como seleção, deriva; migração e mutação, ocorre o chamado equilíbrio de Hardy- 
Weinberg. Nesse equilibrio, $P=p^{2}, Q=q^{2}$ e $H=2 p q$ e a taxa de autofecundação natural (s) é nula. A ocorrência desse equilíbrio pode ser verificada pelo teste quiquadrado $\left(\chi^{2}\right)$, contrastando-se as freqüências genotípicas esperadas, calculadas a partir das estimativas das freqüências gênicas, contra as freqüências genotípicas observadas. (Falconer \& Mackay, 1996). Há ainda outros testes que podem ser empregados para verificar a condição de equilíbrio, como o da razão de máxima verossimilhança $e$ o teste exato de Fisher (Weir, 1996).

$\mathrm{Na}$ presença de equilibrio de Hardy-Weinberg, pode-se dizer que não existe nenhum nível de estruturação dentro da população, sendo que a transmissão dos alelos se dá de modo aleatório e a ocorrência de um alelo num loco independe da ocorrência de outro alelo no mesmo loco, não havendo assim, correlação entre alelos dentro dos indivíduos de uma população.

Várias são as causas que podem levar a população a se desviar desta condição. Um dos motivos é o sistema de reprodução da espécie. Quando a taxa de autofencundação difere de zero ou quando há cruzamento entre indivíduos aparentados, ocorre a endogamia, a qual conduz a um desvio da condição de equilíbrio de Hardy-Weinberg. Uma medida desse desvio é o coeficiente de endogamia (Wright, 1922), também considerado no modelo de Cockerham (1969). No entanto, mesmo em espécies alógamas, o equilíbrio de Hardy-Weinberg deixa de existir se houver cruzamentos preferenciais entre indivíduos, caracterizando assim uma estruturação dentro da população. Segundo Li (1954, 1976) outro fator que pode causar desvios da panmixia é a ocorrência de deriva genética e, portanto, deve-se atentar para a existência de outras causas que podem levar ao aumento da homozigose na população, além da endogamia. É necessário cautela para não atribuir efeitos à endogamia, que podem, na verdade, ter outra origem. Por isso, é mais adequado utilizar o termo índice de fixação ao invés de coeficiente de endogamia para medir os desvios das proporções do equilîbrio de Hardy-Weinberg.

Historicamente, o coeficiente $F$ foi definido por Wright (1921) como a correlação entre alelos homólogos sob dado padrão de cruzamento, relativo ao conjunto total de alelos da população da qual se originou a população sob estudo. Posteriormente, este coeficiente recebeu o nome de coeficiente de endogamia, quando obtido com base no grau 
de parentesco entre os pais que deram origem a dada progênie (Wright, 1922). No entanto, retomando o conceito inicial, que é mais amplo, Wright (1951) passou a chamar o coeficiente $F$ de índice de fixação, e ainda estabeleceu o índice de panmixia $P$, sendo $P=1-F$.

O cálculo do valor de $F$ como coeficiente de endogamia pode ser determinado através da análise de correlação, pelo método do caminhamento (Wright, 1965). Porém, Malécot (1948) introduziu uma outra interpretação deste coeficiente, baseada em probabilidades e não em correlações. Nesse caso, o coeficiente de endogamia é dado pela probabilidade de dois alelos presentes num loco de um indivíduo serem idênticos por descendência.

A diferença entre estas duas definições de $F$ está na interpretação. Este coeficiente pode ser considerado como a correlação entre dois gametas, relativa à geração parental, ou como a probabilidade de identidade por descendência na geração a qual pertencem. Em termos numéricos, ambos os métodos dão o mesmo resultado. Entretanto, uma diferença importante entre estas interpretações consiste no fato de os coeficientes de correlação variarem no intervalo $[-1 ;+1]$ e probabilidades variarem no intervalo $[0 ;+1]$. Porém, como correlações entre gametas calculadas a partir de genealogia não podem ser negativas, nesse caso elas se assemelham a probabilidades (Wright, 1965).

Ainda segundo esse autor, o método dos caminhamentos foi delineado para determinar correlações em sistemas, cujas variáveis relacionem-se entre si exclusivamente de modo linear. Para calcular correlações fenotípicas entre genitores, referentes a locos com dominância e/ou interação, o uso deste método não é adequado, devendo-se optar pelo o uso de princípios de probabilidade para calcular essas correlações.

Quando o índice de fixação difere de zero, ocorrem desvios do equilíbrio de HardyWeinberg. Porém, mesmo sob esta circunstância, a população pode atingir outro estado de equilibrio, denominado Equilibrio de Wright, ou Equilibrio com Endogamia. Segundo Li (1954), as freqüências genotípicas esperadas neste equilibrio passam a ser $P=p^{2}+F p q$, $Q=q^{2}+F p q$ e $H=2 p q(1-F)$, em que $F$ corresponde ao coeficiente de endogamia, ou, de modo mais geral, ao índice de fixação. No caso extremo, quando se trata de uma 
espécie autógama e a taxa de autofecundação natural $(s)$ é máxima $(s=1)$, as freqüências genotípicas no equilíbrio são dadas por $P=p, Q=q$ e $H=0$.

Em populações naturais podem ocorrer várias restrições aos cruzamentos aleatórios, ou seja, vários níveis de estruturação nas populações. Por exemplo, uma população pode estar subdividida em diversas subpopulações ou demes, sendo mais freqüentes cruzamentos dentro de subpopulações que entre elas. Isso também leva a um desvio da condição de equilíbrio de Hardy-Weinberg. Diante da necessidade de mensurar esses diferentes desvios possíveis, Wright (1951) desenvolveu um sistema para descrever populações naturais com estruturação hierárquica. Considerando a população como um todo $(T)$, suas subdivisões ou subpopulações $(S)$ e indivíduos $(I)$, foram definidos os parâmetros $F_{I T}$ como a correlação entre gametas que se unem para formar os indivíduos, $F_{I S}$ como a média das correlações entre gametas dentro de cada subdivisão, considerando todas as subdivisões e $F_{S T}$ como a correlação entre gametas aleatórios dentro das subdivisões, relativa aos gametas da população inteira. $\mathrm{O}$ número de estatísticas $F$ aumenta com o aumento de complexidade da estrutura populacional.

Além de poderem ser interpretadas como correlações e probabilidades, as estatisticas $F$ podem ser consideradas como quantidades relativas de heterozigosidade, como por exemplo, a heterozigosidade dentro das subpopulações em relação à heterozigosidade populacional total (Wright, 1965).

As estatísticas $F$ relacionam-se pelaa igualdade $\left(1-F_{I T}\right)=\left(1-F_{I S}\right)\left(1-F_{S T}\right)$, sendo que o grau de endogamia dentro da população pode ser expresso como $F_{I S}=\left(F_{I T}-F_{S T}\right) /\left(1-F_{S T}\right)$ (Wright, 1965).

Como mencionado por Weir (1996), verificada a presença do equilibrio com endogamia, a taxa de cruzamento aparente pode ser obtida a partir de $F_{I S}$ pela expressão $t=\left(1-F_{I S}\right) /\left(1+F_{I S}\right)$, para cada loco avaliado, em que $F_{I S}=1-(H / h)$. A heterozigosidade observada $H=H_{o}$ é a soma das freqüências dos indivíduos heterozigóticos e a heterozigosidade esperada $h=H_{e}$ é calculada com base nas freqüências alélicas. Após calcular um $F_{I S}$ médio para cada loco, obtém-se um $F_{I S}$ médio para todos os locos conjuntamente. Verificada a aderência do modelo pelo teste 
$\chi^{2}$, usa-se esse novo valor de $F_{I S}$ para obter a taxa de cruzamento aparente para a população sob estudo.

Uma outra alternativa para calcular a taxa de cruzamento, considerando todos os locos ao mesmo tempo, foi proposta por Ritland \& Jain (1981). Trata-se da taxa de cruzamento multilocos, obtida pelo método da máxima-verossimilhança, a qual pode ser aplicada a marcadores codominantes e dominantes. Estes autores verificaram que esta estimativa é não-viesada se as pressuposições do modelo não forem violadas.

Dois parâmetros a serem também mencionados devido à sua importância na conservação de germoplasma são fluxo gênico $(\mathrm{Nm})$ e tamanho efetivo populacional $\left(N_{e}\right)$. Para entender o significado desses parâmetros, são necessárias algumas considerações sobre migração, deriva genética e endogamia.

Segundo Falconer \& Mackay (1996) numa população panmítica, as freqüências gênicas e genotípicas permanecem constantes no decorrer das gerações, na ausência de agentes que as alterem. No entanto, essas freqüências podem ser modificadas por processos sistemáticos, que são a mutação, a migração e a seleção, e por processo dispersivo, que é a deriva genética. É possível predizer a magnitude e a direção da alteração na freqüências gênicas causada por processos sistemáticos; no entanto, no caso da deriva, a qual ocorre em populações pequenas devido ao efeito de amostragem, as mudanças nas freqüências gênicas podem ser previstas quanto à magnitude, mas não quanto à direção.

Inicialmente, considere-se uma população grande, de tamanho $N$, composta por $m$ indivíduos imigrantes a cada geração e $(1-m)$ indivíduos nativos. Sendo a freqüência de determinado alelo dada por $q_{m}$ entre os indivíduos imigrantes $e q_{o}$ entre os nativos, a freqüência do alelo na população mista é $q_{1}=m\left(q_{m}-q_{o}\right)+q_{o}$ e a mudança na freqüência gênica após uma geração de imigrantes é dada por $\Delta q=q_{1}-q_{o}=m\left(q_{m}-q_{o}\right)$ (Falconer \& Mackay, 1996).

A imigração é responsável por pressão linear sobre as freqüência gênicas (Wright, 1965), ou seja, através do fluxo gênico, a diferenciação entre populações (ou entre outros níveis de subdivisão, como subpopulações) é diminuída, uma vez que populações isoladas, 
sob diferentes pressões de seleção tendem a se diferenciar com o decorrer das gerações. Segundo este autor, sob condição de equilíbrio entre migração e deriva, considerando o modelo de ilhas infinitas, tem-se que $F_{S T}=1 /(4 N m+1)$, em que $N m$ corresponde ao fluxo de genes. Assim, uma estimativa para fluxo gênico seria $\hat{N} m=\left(1-\hat{F}_{S T}\right) / 4 \hat{F}_{S T}$.

Ao se utilizar o modelo de Cockerham (1969), relação semelhante a esta pode ser considerada, substituindo-se $F_{S T}$ por $\theta$, sendo $\theta$ equivalente a $F_{S T}$ nesse modelo, admitido aleatório. Dessa forma, segundo Weir (1996), tem sido sugerido que as taxas de migração podem ser estimadas a partir dos valores $\theta$. Considerando o modelo de infinitas ilhas, a cada geração, qualquer alelo amostrado em uma população tem probabilidade $m$ de ter migrado de qualquer uma das outras infinitas populações. Quando estas várias ilhas são de tamanho $N$, pode-se estabelecer um equilíbrio entre perda de variabilidade devido à deriva dentro de ilhas e um ganho de variação devido à migração entre ilhas. $\mathrm{O}$ equilibrio pode ser expresso por $\theta=1 /(4 N m+1)$. Porém, a estimação do fluxo gênico a partir dessa relação é problemática, uma vez que o modelo de infinitas ilhas não é real, na prática. Com um número $\boldsymbol{n}$ finito de ilhas, há probabilidade diferente de zero de que duas ilhas recebam alelos migrantes de uma mesma ilha $e$ as populações não são independentes. Ao usar $\theta$ ou medidas relacionadas para estimar a taxa de migração, assume-se que o padrão de freqüências alélicas entre populações seja devido ao fluxo de genes. Quando não há medidas diretas de fluxo gênico, esta pode ser a única forma de se estimarem as taxas de migração, o que não significa que qualquer outro padrão evolutivo que resulte no mesmo padrão de freqüências gênicas possa ser desconsiderado (Weir, 1996).

Deve-se mencionar que existem outros modelos de fluxo gênico além do de ilhas infinitas. Futuyma (1992) faz uma breve apresentação dos modelos "continente-ilha", "ilha", "alpondras" ou "stepping-stone" e de "isolamento por distância".

No caso de populações pequenas, mesmo na ausência de seleção, migração e mutação, as freqüências gênicas podem se alterar no decorrer das gerações, sofrendo flutuações aleatórias, devido à amostragem de gametas. Os gametas que transmitem os genes de uma geração para outra carregam uma amostra dos genes parentais e se a amostra for pequena, as freqüências gênicas ficam sujeitas a mudanças de uma geração 
para outra. Estas alterações aleatórias das freqüências gênicas é um processo dispersivo, cujo resultado é denominado deriva genética, que tem como conseqüências: a) a freqüência gênica em uma população pequena pode variar aleatoriamente de geração em geração, não havendo tendência de ela voltar ao seu valor inicial; b) a deriva ocorre de maneira independente entre subpopulações $e$ se as subpopulações foram pequenas, esse processo leva à diferenciação genética entre elas; c) a variação genética dentro de subpopulações torna-se progressivamente reduzida e os indivíduos cada vez mais semelhantes genotipicamente; d) há aumento na homozigosidade e conseqüente perda de fertilidade e viabilidade resultantes, em geral, do processo de endogamia, uma vez que há a tendência de os alelos deletérios serem recessivos (Falconer \& Mackay, 1996).

Segundo esses mesmos autores a deriva genética e suas conseqüências podem ser entendidas como processo de amostragem, descrito em termos de variância amostral, ou como um processo de endogamia, descrito em termos de mudanças genotípicas resultantes de cruzamentos entre indivíduos aparentados.

Assim, considere-se uma população base, suficientemente grande, na ausência de migração, seleção e mutação e na qual os indivíduos se cruzem aleatoriamente e que esta população esteja subdividida em grande número de subpopulações (linhagens). Uma população idealizada deve apresentar as seguintes características: os cruzamentos ocorrem somente dentro das linhagens e em todas as gerações; os cnuzamentos são aleatórios dentro de cada linhagem, incluindo autofertilização em quantidade aleatória; ausência de seleção em todos os estágios; as mutações podem ser desconsideradas. Considere-se ainda que $N$, o tamanho populacional, é o número de indivíduos que deixam descendentes em cada linhagem a cada geração, $t$ é o tempo, medido em gerações, iniciando em $t_{o}$ na população base, $q$ é a freqüência gênica de um dado alelo de determinado loco $e$ $p=1-q$ é a freqüência dos demais alelos nesse loco, sendo que $q_{o} e p_{o}$ são as freqüência alélicas na população base e $q_{1}$ a freqüência gênica média nas diferentes linhagens. Posto isso, a mudança na freqüência gênica $(\Delta q)$, resultante da amostragem genética em na primeira geração, pode se descrita em termos de sua variância, $\sigma_{\Delta q}^{2}=p_{o} q_{o} / 2 N$, em que $\sigma_{\Delta q}^{2}$ expressa a magnitude da mudança das freqüências gênicas resultante da deriva (Falconer \& Mackay, 1996). 
O aumento da diferenciação entre as linhagens é equivalente ao aumento da variância de freqüência gênica $\sigma_{q}^{2}$ entre elas. Numa geração $t$ qualquer, esta variância é $\sigma_{q t}^{2}=p_{o} q_{o}\left[1-(1-1 / 2 N)^{t}\right]$. Há um limite de diferenciação que pode ocorrer entre as linhagens devido ao processo dispersivo, sendo que as freqüência gênicas não podem sair do intervalo $[0 ; 1]$ e, em algum momento, cada linhagem deve atingir um desses limites. Uma vez que isso ocorra, as freqüências não se alteram mais dentro das linhagens. Quando o processo se completa em todas as linhagens, a média das freqüência gênicas permanece constante, sendo igual à freqüência da população inicial; a variância das freqüências gênicas entre linhagens será $p_{o} q_{o}$ (Falconer \& Mackay, 1996).

Suponha-se uma população na qual todos os alelos em todos os locos não são idênticos por descendência. Considerando um único loco, entre os gametas produzidos pela população base há diferentes tipos, em igual número, dos alelos $A_{1}, A_{2}, A_{3}, \ldots$, no loco $A$, de forma que gametas de um mesmo tipos carregam alelos idênticos por descendência e gametas de tipos diferentes carregam alelos de origens independentes. Desta maneira, a probabilidade de se tomar, ao acaso, um par de gametas idênticos por descendência é $1 / 2 N$, que é o coeficiente de endogamia da primeira geração. Nas gerações posteriores, o coeficiente de endogamia passa a ter dois componentes, ou seja, a endogamia referente à geração anterior $(1-1 / 2 N) F_{t-1}$ e o incremento $(\Delta F)$, que é a endogamia resultante da replicação de novos genes. Assim, $F_{t}=(1 / 2 N)+(1-1 / 2 N) F_{t-1}$, em que $F_{t}$ é o coeficiente de endogamia da geração sob estudo e $F_{t-1}$ é o coeficiente de endogamia geração anterior. $\mathrm{O}$ coeficiente de endogamia também pode ser escrito como $F_{t}=\Delta F+(1-\Delta F) F_{t-1}$, onde o incremento $\Delta F$ varia de acordo com o sistema reprodutivo da espécie estudada (Falconer \& Mackay, 1996).

Segundo esses autores a variância da mudança de freqüência gênica em relação a uma geração pode ser expressa em função da taxa de endogamia. Após uma geração, $\sigma_{\Delta q}^{2}=p_{o} q_{o} / 2 N=p_{o} q_{o} \Delta F$ e após $t$ gerações, $\sigma_{q}^{2}=p_{o} q_{o} F_{t}$. A quantidade $\Delta F$ expressa a taxa de dispersão e $F$ o efeito acumulado da deriva genética. 
Se a estrutura reprodutiva não estiver de acordo com a da população idealizada descrita anteriormente, é possível avaliar o processo dispersivo em termos de variância de freqüências gênicas ou da taxa de endogamia. A forma mais conveniente de estudar um desvio particular da estrutura de reprodução idealizada é expressar a situação em termos do número efetivo de indivíduos que se reproduzem, ou seja, o tamanho efetivo populacional $N_{e}$. Assim, como na população idealizada $\Delta F$ é relacionado ao tamanho da população $N$ de acordo com a equação $\Delta F=1 / 2 N, \Delta F$ se relaciona ao tamanho efetivo populacional da mesma forma, $N_{e}=1 / 2 \Delta F$. Conhecendo o tamanho efetivo populacional para uma dada estrutura reprodutiva, a taxa de endogamia pode ser obtida por $\Delta F=1 / 2 N_{e} e$, de maneira análoga à população idealizada, a partir de $\Delta F$ qualquer uma das conseqüências da endogamia pode ser calculada (Falconer \& Mackay, 1996).

Além disso, como mencionado anteriormente, numa população ideal, a variância das freqüências gênicas devido à deriva em urna geração é $\sigma_{\Delta q}^{2}=p_{o} q_{o} / 2 N$ e a taxa de decaimento é $1 / 2 N$. Usa-se esta proporção padrão com a qual outras proporções são comparadas, sendo que o número real de indivíduos que se cruzam é reduzido ao número equivalente de indivíduos na população ideal. Este número é chamado de tamanho efetivo do grupo de indivíduos que se cruzam ( $\mathrm{Li}, 1954)$.

Considerando populações constituídas por indivíduos machos e fêmeas, Li (1954) apresenta estimativas de tamanho efetivo populacional para várias circunstâncias: número desigual de machos e fêmeas, desigualdade reprodutiva entre indivíduos, entre outros. Segundo esse autor, no caso de espécies monóicas, o tamanho efetivo de uma população endogâmica é dado por $N_{e}=N /(1+f)$, em que $N$ é o número de indivíduos que se cruzam na população e $f$ é o coeficiente de endogamia da população.

\subsubsection{Análise de diversidade gênica de Nei}

Nei (1973a) propôs metodologia alternativa para a análise de populações subestruturadas e também medidas absolutas e relativas da diferenciação gênica entre subpopulações. A vantagem dessa abordagem é que ela pode ser aplicada para estudar a 
diversidade gênica (heterozigosidade) em qualquer população, não importando o número de alelos por loco, o padrão das forças evolutivas como seleção, mutação e migração, o nível de ploidia e o sistema reprodutivo dos indivíduos avaliados.

Primeiramente, Nei $(1972 ; 1973 b)$ propôs um método para medir a diferenciação gênica entre pares de populações. Nei (1973a) aplicou este método ao caso de populações com estrutura hierárquica, mostrando que a variação da freqüência gênica em populações estruturadas pode ser analisada em termos de heterozigosidade ou diversidade gênica. $O$ método é baseado no fato de a identidade entre dois alelos retirados aleatoriamente, tanto dentro quanto entre populações, ser independente do número de alelos em determinado loco.

Supondo um loco com $n$ alelos, sendo $x_{k}$ a freqüência do $k$-ésimo alelo numa dada população, Nei (1973a) definiu as probabilidades de identidade e não-identidade entre dois alelos tomados ao acaso da população como $J=\sum_{k} x_{k}^{2}$ e $H=1-J$, respectivamente. A diversidade genética $(H)$, é uma medida de variação genética da população, enquanto seu complemento é dado pela identidade genética $(J)$.

Considerando uma população dividida em $s$ subpopulações, Nei (1973a) estabeleceu a identidade genética da subpopulação $\left(J_{i}\right)$ e da população como um todo $\left(J_{T}\right)$ e a identidade genética entre a $i$-ésima $e j$-ésima subpopulações, dada por $J_{i j}$. A partir desses termos, definiu diversidade genética interpopulacional $\left(D_{i j}\right)$ entre a $i$-ésima e j-ésima populações. Essa diversidade é sempre um valor não negativo, sendo $D_{i j}=H_{i j}-\left(H_{i}+H_{j}\right) / 2=\left(J_{i}+J_{j}\right) / 2-J_{i j}$, em que $H_{i}=1-J_{i}$ e $H_{i j}=1-J_{i j}$. A identidade genética total é dada por $J_{T}=J_{S}-D_{S T}$, em que $J_{S}$ é a identidade genética média dentro de subpopulações e $D_{S T}$ é a diversidade genética média entre subpopulações, incluindo comparações das subpopulações com elas mesmas. Como $H_{T}=1-J_{T}$ e $H_{S}=1-J_{S}$, tem-se que $H_{T}=H_{S}+D_{S T}$, sendo que $H_{T}$ é a diversidade genética populacional total. Quando não se incluem comparações das subpopulações com elas mesmas, Nei (1973a) propôs o termo diversidade genética interpopulacional $\bar{D}_{m}$. 
A diferenciação gênica relativa à população toda é definida como $G_{S T}=D_{S T} / H_{T}$ e depende da população considerada. Assim, a estimativa obtida para uma população não pode ser comparada com outra, a não ser que ambas as populações possuam sistemas reprodutivos similares. Este índice, denominado coeficiente de diferenciação gênica, é equivalente ao parâmetro $F_{S T}$ de Wright. Quando há apenas dois alelos por loco, $G_{S T}=F_{S T}$ e quando há vários alelos por loco, $G_{S T}=\bar{F}_{S T}$. De forma semelhante à equação $1-F_{I T}=\left(1-F_{I S}\right)\left(1-F_{S T}\right)$ obtida por Wright, Nei $\left(1973^{\mathrm{a}}\right)$ obteve $1-J_{S}=\left(1-G_{S T}\right)\left(1-J_{T}\right)$. Segundo este autor, a diferença entre estas duas equações deve-se ao fato de as estatísticas $F_{I S}$ e $F_{I T}$ de Wright medirem desvios das freqüências genotípicas das proporções esperadas sob equilibrio de Hardy-Weinberg, enquanto $J_{S}$ e $J_{T}$ são medidas de identidade genética. Nei (1973a) também obteve o índice $R_{S T}$, que é a diversidade gênica interpopulacional em relação à diversidade gênica intrapopulacional, dado por $R_{S T}=\bar{D}_{m} / H_{S}$.

Segundo Nei (1973a) todos estes índices podem ser estendidos para os diversos níveis de hierarquia populacional. A metodologia proposta é também aplicável a qualquer número de locos, se a diversidade gênica entre locos for substituída pela diversidade gênica média para todos os locos considerados. $\mathrm{O}$ autor ainda salienta que todos estes índices são indicados para medir a diferenciação entre populações geograficamente próximas, mas não são adequados se o grau de diferenciação gênica for grande, bem como no caso de subespécies, pois $J_{T}$ é muito maior que $J_{S}$ e $D_{S T}$ (ou $\bar{D}_{m}$ ). Nestes casos, estimativas melhores são obtidas por $D_{S T}=-\ln \left(J_{T} / J_{S}\right)$ e $G_{S T}=-\ln \left(J_{T} / J_{S}\right) /\left(-\ln J_{T}\right)$.

Nei (1972) propôs uma medida de distância genética $(D)$, usualmente estimada a partir das identidades genéticas amostrais, sobre $r$ locos estudados. No entanto, segundo Nei (1978) quando a heterozigosidade é menor ou igual a 0,2, o viés devido ao pequeno tamanho amostral tem a mesma magnitude tanto na estimativa de heterozigosidade quanto na estimativa de distância genética, sendo que esta tende a ser superestimada e mesmo que ambas as populações sejam geneticamente idênticas entre si, o valor da distância pode ser muito maior que zero. 
Assim, este autor propôs medida não-viesada de distância genética. Esta nova distância, ao contrário da anterior, pode ser negativa devido a deficiências na amostragem, fato que raramente ocorre se os tamanhos amostrais das populações forem elevados. $\mathrm{O}$ autor sugere que valores negativos de distâncias sejam substituídos por zero, para que não ocorram problemas na construção de dendrogramas. Além dessas contribuições, o autor tambémfornece medidas não-viesadas de heterozigosidade para um único loco $e$ para vários locos. Demonstra que o número de indivíduos a ser usado para estimar a heterozigosidade média pode ser muito pequeno se um grande número de locos for considerado $e$ se a heterozigosidade média for baixa. Além disso, verificou que o número de indivíduos usados para estimar a distância genética pode ser bem pequeno se a distância genética for grande $e$ a heterozigosidade média de duas espécies comparadas for baixa.

Weir (1996) apresentou a distância padrão de Nei descrita como $D=-\ln (I)$, em que $I$ é a identidade genética. É adequado assumir que a população ancestral estava em equilibrio entre deriva e mutação e que cada uma das populações permaneça em equilibrio entre estas duas forças no decorrer do tempo. Esta distância tem a vantagem de admitir a ocorrência de mutações e, além disso, aumenta de maneira aproximadamente linear quando o tempo, medido em gerações, se torna moderadamente grande. É apropriada para os casos em que o processo evolutivo esteja ocorrendo há longo tempo, quando as populações divergem por causa da deriva e da mutação.

Por outro lado, essa distância obtida em função da coancestralidade é apropriada para uma divergência devida somente à deriva e nenhuma pressuposição precisa ser feita em relação à população ancestral. Para uma população finita de tamanho $N$ de cruzamentos aleatórios, incluindo uma quantidade aleatória de autofecundações, esta distância pode ser obtida por $d=-\ln (1-\theta)=-t \ln (1-1 / 2 N) \approx t / 2 N$, em que a estimativa de $\theta$ tenha sido obtida a partir de duas ou mais populações de mesmo tamanho e com a mesma história e que estejam divergindo somente devido à deriva no decorrer do tempo (t) (Weir, 1996). 


\subsubsection{Análise de variância de freqüências gênicas}

Cockerham $(1969,1973)$ e Weir \& Cockerham (1984) estabeleceram outra metodologia para se estudar a estrutura genética de populações a partir de marcadores codominantes. Trata-se da análise de variância de freqüências gênicas. $\mathrm{O}$ método pressupõe modelo aleatório, havendo uma população de referência a partir da qual as populações ou subpopulações a serem estudadas se originaram por deriva genética. Além disso, os locos a serem analisados devem ser neutros, ou seja, não podem estar submetidos a nenhuma pressão de seleção. Esta metodologia permite caracterizar a variação genética dentro e entre populações, através da estimação de parâmetros como $F, f$ e $\theta^{\prime} s$, que serão descritos posteriormente. Esta variação também pode ser considerada do ponto de vista de distâncias genéticas.

Segundo Weir (1996), por facilidade, usam-se variáveis indicadoras para realizar a análise de variância de freqüências gênicas. Assim, sendo o alelo $j$ pertencente a uma amostra da população $i$, a variável $x_{i j}$ será definida como:

$$
x_{i j}= \begin{cases}1 & \text { se o alelo é A } \\ 0 & \text { se o alelo não é A }\end{cases}
$$

A média dos valores $x_{i j}$ na população $i$ é a frequêencia alélica do alelo $A$, dada por $p_{A i}$, nesta população. A hipótese de freqüências alélicas iguais entre populações leva à análise de variância dos $x^{\prime} s$. No entanto, esta análise de variância não é adequada como critério para testes, uma vez que não é possivel afirmar que a razão de dois quadrados médios tenha distribuição $F$, caso as variáveis $x_{i j}$ não sejam normalmente distribuídas. (Weir, 1996).

Weir (1990a, 1990b, 1996) descreveu detalhadamente esta metodologia. Primeiramente fez uma distinção dos dois tipos de amostragem envolvidos em estudos populacionais. Segundo esse autor, exceto se a população for invariante para um dado loco, diferentes amostras da população exibirão diferentes niveis de variação genética, pois cada amostra tomada será formada por um grupo diferente de indivíduos. Trata-se da amostragem estatística. Porém, em Genética de Populações, há outro tipo de amostragem 
a ser considerado, a amostragem genética. Isto ocorre pois, do conjunto total de gametas produzido pela população, apenas parte deles são transmitidos à geração seguinte durante o processo reprodutivo, ou seja, apenas uma amostra dos gametas produzidos por uma população em uma geração é transmitida a geração posterior. Desse tipo de amostragem, resulta a deriva genética, que será discutida posteriormente.

A distinção entre amostragem genética e estatística também pode ser feita em termos de efeitos fixos e aleatórios. Se há interesse em apenas uma dada população amostrada, a amostragem genética anterior não tem conseqüência, e somente a amostragem estatística deve ser considerada para amostras repetidas desta única população (fixa). Comparações entre diferentes populações (fixas) podem ser feitas em termos de médias. Permutações e reamostragem numérica podem ser usadas para fazer inferências. No entanto, se a amostra é usada para fazer inferências sobre uma coleção de populações ou sobre uma espécie como um todo, há menos interesse em uma dada população amostrada, a qual pode ser agora considerada como aleatória. Podem-se retirar amostras de outra população diferente, e assim, tanto a variação estatística quanto a genética devem ser consideradas. No modelo genético fixo, somente um grupo específico de médias está sendo comparado enquanto que no modelo genético aleatório tem-se uma população de médias. Neste modelo, cada população é tida como uma repetição amostral do processo evolutivo (Weir, 1996).

\subsubsection{Modelo fixo}

A partir dos dados genotípicos obtidos, os primeiros descritores de uma população são as freqüências genotípicas. Se os indivíduos foram amostrados de maneira independente, ou seja, se cada membro da população teve a mesma probabilidade de ser amostrado, a contagem genotípica tem distribuição multinomial. Na ausência do equilíbrio de Hardy-Weinberg, a populações devem ser comparadas a partir das freqüências genotípicas. No entanto, na presença deste equilibrio, a comparação das freqüências gênicas entre populações já é suficiente para compará-las (Weir, 1996). 
Para comparar populações, é comum usar somente a estatística $F_{S T}$, sendo que este coeficiente será maior quanto maior a divergência entre as freqüências alélicas amostrais, porém, é difícil avaliar a significância desta divergência (Weir, 1996).

Segundo esse autor, através da análise de variância é possível comparar várias médias. Para variáveis com distribuição normal, a razões entre variâncias, como por exemplo a razão entre os quadrados médios entre e dentro de populações, têm distribuição $F$ sob a hipóteses de igualdade entre médias populacionais. Porém, no caso de populações fixas, esta afirmação não é válida.

\subsubsection{Modelo aleatório}

Sob modelo genético aleatório, pode-se considerar que as populações amostradas representam uma determinada espécie ou uma metapopulação e têm uma história evolutiva comum. A análise parte da pressuposição de que há uma única população de referência, a partir da qual as populações se diferenciaram com o decorrer do tempo. Espera-se que todas as populações tenham as mesmas freqüências alélicas na ausência de forças que as alterem, como diferentes pressões de seleção nas diversas populações. Nesse modelo, a amostragem genética faz com que diferentes alelos na população sejam dependentes ou relacionados. Mesmo que indivíduos ou alelos possam ser amostrados aleatoriamente, são dependentes de um ancestral comum, o que deve ser considerado ao se obterem as esperanças matemáticas. Nesse tipo de análise, o objetivo é averiguar o quanto as populações se diferenciam dentro de uma espécie (ou numa metapopulação) no decorrer do tempo. As estatísticas $F$ de Wright ou medidas análogas de Cockerham quantificam a diferenciação intraespecífica causada pela ação das forças evolutivas ou da amostragem genética. Na ausência de seleção, estas medidas quantificam o grau de parentesco entre vários pares de alelos (Weir, 1996).

Considerando indivíduos diplóides, amostrados a partir de várias populações, as três medidas básicas propostas por Cockerham (1969) são:

$F$ ( $F_{I T}$ de Wright): é a correlação entre alelos dentro de indivíduos em todas as populações. É o coeficiente de endogamia que se refere aos indivíduos em relação ao conjunto de populações, reunindo a informação dos índices de fixação $F_{S T}$ e $F_{I S}$; 
$\theta$ ( $F_{S T}$ de Wright): é a correlação de todos os alelos de diferentes indivíduos na mesma população. É o coeficiente de coancestralidade e mede a divengência entre populações;

$f\left(F_{\text {IS }}\right.$ de Wright): correlação dos alelos dentro de indivíduos dentro da população à qual estes indivíduos pertencem.

No modelo aleatório, considerando-se indivíduos diplóides, é possível estimar o grau de identidade por descendência $(F)$ entre alelos dentro de indivíduos e o grau de coancestralidade $\theta$ entre alelos de diferentes indivíduos. $\mathrm{O}$ uso desta metodologia permite medir a diferenciação entre populações em termos de $\theta$, refletindo o parentesco entre indivíduos dentro de populações. A análise também fornece o coeficiente de endogamia geral $F$. O grau de endogamia dentro de populações, $f$, pode ser expresso como $f=(F-\theta) /(1-\theta)$.

As variâncias de populações, de indivíduos dentro de populações e de alelos dentro de indivíduos são estimadas a partir da análise de variância. As somas de quadrados são construídas com base em freqüências alélicas e genotípicas $e$ as esperanças dos quadrados médios são escritas em termos de componentes de variância (Tabela 1) Weir (1996).

Tabela 1. Quadro da análise de variância para dados genotípicos em populações aleatórias.

\begin{tabular}{|c|c|c|c|}
\hline $\begin{array}{l}\text { Fonte de } \\
\text { Variação }\end{array}$ & G.L. & $S . Q$. & $E(Q M)$. \\
\hline $\begin{array}{c}\text { Entre } \\
\text { populações }\end{array}$ & $r-1$ & $2 \sum_{i=1}^{r} n_{i}\left(\widetilde{p}_{A i}-\widetilde{p}_{A .}\right)^{2}=$ & $\begin{array}{l}p_{A}\left(1-p_{A}\right)\left[(1-F)+2(F-\theta)+2 n_{c} \theta\right] \\
=\sigma_{G}^{2}+2 \sigma_{1}^{2}+2 n_{c} \sigma_{P}^{2}\end{array}$ \\
\hline $\begin{array}{l}\text { Indivíduos } \\
\text { dentro de } \\
\text { populações }\end{array}$ & $\sum_{i}\left(n_{i}-1\right)=n \cdot-r$ & $\begin{array}{l}=2(r-1) \bar{n} s_{A}^{2} \\
\sum_{i=1}^{r} n_{i}\left(\widetilde{p}_{A i}+\widetilde{P}_{A A i}-2 \widetilde{p}_{A i}^{2}\right)= \\
=2 r \bar{n} \widetilde{p}_{A}\left(1-\widetilde{p}_{A}\right)-\frac{1}{2} r \bar{n} \widetilde{H}_{A} \\
-2(r-1) \bar{n} s_{A}^{2}\end{array}$ & $\begin{array}{l}p_{A}\left(1-p_{A}\right)[(1-F)+2(F-\theta)] \\
=\sigma_{G}^{2}+2 \sigma_{1}^{2}\end{array}$ \\
\hline $\begin{array}{l}\text { Alelos dentro } \\
\text { de indivíduos }\end{array}$ & $\sum_{i=1}^{r} n_{i}=n$ & $\begin{array}{l}\sum_{i=1}^{r} n_{i}\left(\widetilde{p}_{A i}-\widetilde{P}_{A A i}\right)= \\
=\frac{1}{2} r \bar{n} \widetilde{H}_{A}\end{array}$ & $\begin{array}{l}p_{A}\left(1-p_{A}\right)(1-F) \\
=\sigma_{G}^{2}\end{array}$ \\
\hline
\end{tabular}

Fonte: Weir (1996). 
Na Tabela 1, $n_{c}=\frac{1}{r-1}\left(\sum_{i=1}^{r} n_{i}-\frac{\sum_{i} n_{i}^{2}}{\sum_{i} n_{i}}\right)$, em que $r$ é o número de populações e $n_{i}$ é o tamanho amostral da $i$-ésima população.

Segundo Weir (1996), as esperanças dos quadrados médios podem ser escritas em termos de componentes de variância:

$$
\begin{aligned}
& \sigma_{G}^{2}=p_{A}\left(1-p_{A}\right)(1-F) \text { para alelos dentro de indivíduos; } \\
& \sigma_{I}^{2}=p_{A}\left(1-p_{A}\right)(F-\theta) \text { para indivíduos dentro de populações; } \\
& \sigma_{P}^{2}=p_{A}\left(1-p_{A}\right) \theta
\end{aligned}
$$

Para populações, e pelo método dos momentos, estimativas não-tendenciosas destes componentes de variância são obtidas a partir de funções dos quadrados médios observados de populações $(Q M P)$, indivíduos $(Q M I)$ e alelos $(Q M G)$ :

$\hat{\sigma}_{G}^{2}=Q M G$ para alelos dentro de indivíduos;

$\hat{\sigma}_{I}^{2}=\frac{1}{2}(Q M I-Q M G)$ para indivíduos dentro de populações;

$\hat{\sigma}_{P}^{2}=\frac{1}{2 n_{c}}(Q M P-Q M I)$ para populações.

Ainda segundo esse autor, os parâmetros mencionados podem ser estimadas como:

$$
\begin{aligned}
& \hat{F}=\frac{\hat{\sigma}_{P}^{2}+\hat{\sigma}_{I}^{2}}{\hat{\sigma}_{P}^{2}+\hat{\sigma}_{I}^{2}+\hat{\sigma}_{G}^{2}}=1-\frac{2 n_{c} Q M G}{Q M P+\left(n_{c}-1\right) Q M I+n_{c} Q M G} \\
& \hat{\theta}=\frac{\hat{\sigma}_{P}^{2}}{\hat{\sigma}_{P}^{2}+\hat{\sigma}_{I}^{2}+\hat{\sigma}_{G}^{2}}=\frac{Q M P-Q M I}{Q M P+\left(n_{c}-1\right) Q M I+n_{c} Q M G},
\end{aligned}
$$

Destas duas estimativas pode-se obter a estimativa do coeficiente $f$ dentro de populações, por meio de $\hat{f}=(\hat{F}-\hat{\theta}) /(1-\hat{\theta})$.

Tais estimativas foram apresentadas para um dado alelo $A$, mas na prática, há diversos alelos em vários locos e cada um fomece uma estimativa para parâmetros populacionais que estão sendo estudados se o modelo for estritamente neutro. No entanto, é possivel obter as estimativas de $\hat{F}$ e $\hat{\theta}$ considerando todos os alelos e locos conjuntamente (Weir, 1996). 
A reamostragem bootstrap sobre locos fornece os intervalos de confiança para os parâmetros $F$ e $\theta$, e sobre várias populações permite fazer comparações entre locos. Testes de permutação também podem ser feitos para indivíduos entre populações ou para alelos entre indivíduos e populações, dependendo da hipótese a ser testada (Weir, 1996).

Segundo este autor o método da análise de variâncias de freqüências gênicas pode ser usado para quaisquer níveis de hierarquia que ocorram dentro de populações e a análise de variância deve seguir modelo hierárquico. Assim, Vencousky (1992) usou procedimento semelhante para estimar tais parâmetros considerando a seguinte hierarquia: populações, familias dentro de populações, indivíduos dentro de familias e genes dentro de indivíduos. Obteve estimativas dos parâmetros $F, f$ e de dois $\theta$ 's, um interpopulacional e outro entre progênies. Com base nestas estimativas estimou os componentes de variância associados a cada fonte de variação, o tamanho efetivo amostral e também a taxa de fertilização cruzada, esta última com base em $\hat{f}$. O autor salientou o fato de que é conveniente testar a validade da suposição do equilibrio de Wright através do teste do quiquadrado.

A análise de variâncias de freqüências gênicas apresenta algumas vantagens quando comparadas às estatísticas $F$ de Wright $e$ a análise de diversidade de Nei. A metodologia de Wright pode ser aplicada a qualquer nível hierárquico considerado, porém, em princípio, a aplicação das formas paramétricas como estimadores implica na presença de viéses nas estimativas das estatísticas $F$. Nei (1977) introduziu estimadores para tais estatísticas que, embora sejam corrigidos para viés devido ao pequeno tamanho amostral, contém viés devido ao processo de amostragem. A metodologia de Nei (1973a) pode ser aplicada a diversas situações, como mencionado anterioramente, porém, o viés só é corrigido para pequeno tamanho de amostra. Além disso, não fornece os índices de fixação intrapopulacional e total. Já a metodologia propostas por Weir \& Cockerham (1984) pode ser empregada em qualquer nível hierárquico, com a vantagem de produzir estimativas não influenciadas por efeitos de níveis hierárquicos superiores, como mencionado por Reis (1996). Além disso, as estimativas são corrigidas para viés devido a pequenos tamanhos amostrais e devido ao processo de amostragem em si. Portanto, como este método produz estimativas menos viesadas que os demais, deve ser preferido sempre que as pressuposições para seu uso forem obedecidas. No entanto, deve-se mencionar que no 
caso em que grandes tamanhos amostrais são considerados, as diferenças entre os resultados obtidos por estas três metodologias não são relevantes.

\subsubsection{Exemplos de aplicação das estatísticas $F$, da análise de diversidade de Nei e da análise de variância de freqüências gênicas.}

A seguir, como exemplos de aplicação, serão mencionadas várias dissertações $e$ teses que foram desenvolvidas em diversas universidades. Em tais pesquisas, os autores empregaram essas metodologias para estudar a estrutura genética de populações naturais.

Marcon (1988) estudou, através de isoenzimas, vinte e cinco populações de Stylosanthes humilis, cujas sementes foram coletadas em duas transeções (Norte-Sul e Leste-Oeste) ao longo de três regiões ecogeográficas de Pernambuco (agreste, mata $e$ sertão). Determinou a taxa de cruzamento nestas populações naturais e também a diversidade genética.

Barros (1991) caracterizou sessenta e sete acessos do banco de germoplasma de cajueiro da EMBRAPA/Centro Nacional de Pesquisa do Caju. Para tanto, utilizou descritores botânico-agronômicos e também freqüências de bandas isoenzimáticas. Também estudou a divergência genética através de análise de componentes principais, a distância euclidiana e o agrupamento de Tocher.

Santos (1994) utilizou o modelo multiloco de cruzamento misto para analisar o sistema reprodutivo de Bauhinia forficata. Estimou a taxa de cruzamento para locos individuais e multilocos e também o coeficiente de endogamia e a taxa de cruzamento aparente, concluindo tratar-se de espécie de fecundação cruzada, predominantemente, mas com baixos níveis de endogamia. Utilizou eletroforese de isoenzimas.

Faraldo (1994) estimou parâmetros populacionais e de variabilidade genética entre e dentro de populações de mandioca (Manihot esculenta). Construiu dendrogramas a partir de medidas de similaridade (concordância simples e Jaccard). $\mathrm{O}$ estudo baseou-se em dados de isoenzimáticos.

Reis (1996) estudou, através de isoenzimas, a distribuição e a dinâmica de alelos em oito subpopulações de três populações naturais de palmiteiro nos Estados de São Paulo e Santa Catarina. Caracterizou os níveis e a distribuição de variabilidade genética e a 
estrutura populacional destas populações e também o sistema reprodutivo $e$ o fluxo gênico das mesmas. Estimou, entre outros, as estatísticas $F$ de Wright, as heterozigosidades observada e esperada, o coeficiente de coancestralidade $(\theta)$ de Cockerham, a taxa multilocos de cruzamento $e$ o fluxo gênico.

Sebbenn (1997) estimou as estatísticas $F$ de Wright, o coeficiente $\theta$ de Cockerham, a heterozigosidade média esperada e taxa de cruzamento multilocos, entre outros, em duas subpopulações naturais de Genipa americana no Estado de São Paulo. Para tanto, utilizou marcadores isoenzimáticos. Telles (2000) estudou a diversidade genética e a estrutura populacional de cagaiteira no Estado de Goiás a partir de isoenzimas. Moraes (1997) estudou a estrutura genética de quatro populações de indivíduos adultos de Cryptocaria moschata em quatro parques estaduais do Estado de São Paulo. Também analisou três populações de indivíduos juvenis e 35 progênies. Para tanto, utilizou análise isoenzimática. Ciampi (1999) estudou a estrutura populacional de quatro populações de copaíba no Cerrado usando marcadores microssatélites. Amostrou 24 indivíduos por população $e$ analisou oito locos microssatélites.

\subsubsection{Análise molecular de variância (AMOVA)}

Excoffier et al. (1992) apresentaram uma alternativa para o estudo da variação molecular dentro de uma única espécie. Incorporaram informações sobre divergência de DNA de dados provenientes de haplótipos ao formato da análise de variância convencional; para tanto, empregaram uma matriz de distâncias quadradas entre todos os pares de haplótipos. Esta análise de variância, denominada de AMOVA, produz estimativas dos componentes de variância e estatísticas análogas às estatísticas $F$ de Wright, que os autores chamaram de estatísticas $\Phi$, os quais refletem a correlação da diversidade dos haplótipos em diferentes níveis de subdivisão hierárquica. $\mathrm{O}$ método acomoda diversos tipos de matrizes de entrada, fornecidas por diversos tipos de marcadores moleculares, $e$ diferentes tipos de pressuposições evolutivas, sem modificar a estrutura básica da análise. A significância dos componentes de variância e das estatísticas $\Phi$ são testadas através do uso de permutações. Com isso, não há necessidade da presença de normalidade requerida pelos testes tradicionais. Isso é vantajoso, pois dados provenientes de marcadores 
moleculares não apresentam seus erros normalmente distribuídos. Uma outra vantagem é que este método pode ser facilmente empregado em diferentes situações e possui estrutura coerente e flexível para análise estatística de dados moleculares. Esta metodologia foi adaptada também para quando se utilizam marcadores dominantes como RAPD.

A base da análise apresentada por estes autores é que as somas de quadrados convencionais (SQ) podem ser escritas na forma de somas de quadrados de diferenças entre pares de observações. Assim, eles construíram uma análise de variância molecular hierárquica, partindo diretamente da matriz das distâncias quadradas de todos os pares de haplótipos. O método possui também a vantagem de que diferentes pressuposiçōes podem ser impostas ao processo de diferenciação dos haplótipos, cada um dos quais traduzidos em uma matriz de distância diferente, sem mudar a estrutura da análise subseqüente. Adicionalmente, para obter testes de significância para cada componente de variância molecular e suas estatísticas $F$ análogas relacionadas, são feitas permutações sobre a matriz de distâncias quadradas entre indivíduos.

Os autores aplicaram a metodologia a dez populações humanas, já bastante estudadas, as quais representam cinco grupos regionais, com duas populações cada. Para analisar o $\mathrm{mtDNA}$ destas populações, utilizaram cinco enzimas de restrição. Foram feitas análises de variância hierárquicas para quatro diferentes matrizes de distâncias quadradas entre haplótipos. A partir da análise de variância hierárquica, algumas conclusões que puderam obter foram que a subdivisão entre populações é significativa, porém com grande variação dentro de populações ( $>74 \%$ ), e que grupos regionais exibiram alto nível de divergência e populações dentro de regiões diferiram significativamente (mas de forma mínima) entre si.

É importante salientar que esta análise pode ser aplicada para para estimar o grau de subdivisão genética em nível intraespecífico (Excoffier et al., 1992). Como exemplo de aplicação, pode-se citar o trabalho de Huff et al. (1993) que estudaram a variação genética entre e dentro de populações naturais alógamas de Buchloë dactyloides (Nutt.) Engelm.. Baseando-se em dados de presença/ausência de bandas RAPD, calcularam uma matriz de distâncias genéticas para quatro populações naturais de tal espécie, com doze indivíduos cada uma. Dessas quatro populações, duas foram provenientes do México e duas provenientes do Texas (EUA). Utilizaram a técnica de AMOVA para dividir a variação entre 
indivíduos dentro de populações, entre populações dentro de regiões adaptativas e entre regiões. Notaram considerável variação dentro de cada uma das quatro populações consideradas, sendo que cada indivíduo foi geneticamente diferente. As maiores diferenças genéticas foram observadas entre os dois ecótipos regionais. Os padrões de variação genética foram muito diferentes dos encontrados em espécies endógamas.

Travis et al. (1996) analisaram a variação genética em três populações de Astragalus cremnophylax var. cremnophylax, através de marcadores AFLP's e AMOVA. As análises permitiram o cálculo de parâmetros genéticos populacionais, como diversidade genética. Os resultados obtidos pela AMOVA foram corroborados por aqueles obtidos por análise de agrupamento (UPGMA) e de coordenadas principais.

Como outros exemplos de aplicação, podem-se citar o trabalho de Huff et al (1993), já mencionado anteriormente, e o trabalho de Buso et al. (1998), que utilizaram AMOVA para analisar a variabilidade genética de populações Sul-Americanas de arroz selvagem (Oryza glumaepatula) com isoenzimas e marcadores RAPD.

Slatkin (1995) propôs uma nova medida de diversidade $\left(R_{S T}\right)$ para avaliar a diferença entre populações, que é função das diferenças entre tamanhos de alelos microssatélite. É uma medida análoga ao $G_{S T}$, porém para dados de microssatélites provenientes de um só loco. Pode ser calculada como $R_{S T}=\left(\bar{S}-S_{W}\right) /(\bar{S})$, em que $S_{W}$ e $\bar{S}$ são, respectivamente, a diferença quadrática média entre tamanhos de alelos entre pares de genes dentro de populações e entre pares de genes tomados de várias populações.

Michalakis \& Excoffier (1996) estudaram uma estimativa genérica da subdivisão de populaçōes. Considerando uma definição particular da distância entre haplótipos, mostraram que a AMOVA pode ser aplicada a dados de microssatélites para obter uma medida análoga ao $R_{S T}$ de Slatkin (1995). Dessa maneira, a AMOVA fornece uma forma geral para analisar a estrutura genética de populações, sendo que as pressuposições evolutivas de polimorfismo podem ser enquadradas na definição de uma matriz de distância euclidiana sem afetar a estrutura essencial da AMOVA. 


\subsubsection{Medidas de similaridade e dissimilaridade, métodos de agnupamento e de ordenação}

No caso dos marcadores dominantes, como não é possível distinguir os indivíduos heterozigóticos dos homozigóticos dominantes, em geral, empregam-se técnicas multivariadas as quais consideram diversas variáveis (no caso, marcadores) simultaneamente, sendo possível descrever o padrão de relação entre os objetos (genótipos, populações, etc.) por ordenação, que consiste na redução da dimensão de uma matriz de distâncias ou similaridades entre os atributos ou entre os objetos. Outra opção é a análise de agrupamento, que é uma classificação de objetos em categorias hierárquicas com base em matriz de similaridade entre objetos (James \& McCulloch, 1990). Salienta-se que esta metodologia pode ser aplicada aos marcadores codominantes também, porém, neste caso, com medidas de similaridade ou dissimilaridade mais informativas, como as distâncias de Nei e de Rogers.

Os marcadores bioquímicos e moleculares são considerados variáveis qualitativas binários, caracterizadas por dois estados: presença ou ausência da marca (banda no gel), que, por conveniência, são designados por zeros e uns (Dunn \& Everitt, 1980). Existem muitas medidas de similaridade e de dissimilaridade para variáveis binárias, contínuas e multiestados (Dunn \& Everitt, 1980; Manly, 1994) mas, para o caso de variáveis binárias como marcadores moleculares, entre as medidas mais usadas estão os coeficientes de similaridade de Jaccard e de concordância simples, entre outros.

Embora haja ampla variedade de medidas de similaridade e de dissimilaridade propostas, relativamente poucas estão em uso, pois muitos índices são variantes de outros já existentes, alguns tendo propriedades semelhantes, outros propriedades desfavoráveis, principalmente quando próximos de seus limites. Alguns são altamente especializados, sendo baseados em hipóteses prévias acerca da natureza do material a ser estudado (Clifford \& Stephenson, 1975).

A partir dos dados obtidos com marcadores, procede-se à análise da dissimilaridade ou similaridade dos genótipos estudados: genótipos que possuam maior coincidência de presenças e/ou ausências de bandas são mais similares ou menos distantes entre si. A partir destas medidas pode-se observar, por exemplo, como os indivíduos dentro de 
subpopulações, subpopulações dentro de populações, populações dentro de espécies, etc., estão relacionados. Calculadas estas dissimilaridades ou similaridades, diversos tipos de dendrogramas e ordenações podem ser construídos $e$ interpretados. Esta interpretação deve se dar também com base no conhecimento do conjunto biológico sob avaliação. Revisões bastante aprofundadas sobre medidas de similaridade e dissimilaridade podem ser encontradas em Sneath \& Sokal (1973) e Clifford \& Stephenson (1975) entre outros.

Assim como no caso das medidas de similaridade e dissimilaridade, há muitos métodos de agrupamento disponíveis na literatura. De modo análogo, não existe um método mais correto, mas sim o mais adequado a determinada situação, dependendo do tipo de dados disponível e do objetivo do estudo. Descrições destes métodos podem ser encontradas em Andenberg (1973), Sneath \& Sokal (1973), Clifford \& Stephenson (1975), Morrison (1976), Mardia et al. (1979), Chatfield \& Collins (1980), Dunn \& Everitt (1980), Bussab et al. (1990), Johnson \& Wichem (1992), Manly (1994), entre outros.

Os métodos de ordenação mais comumente utilizados são os pertencentes ao grupo SAHN. (métodos seqüenciais, aglormerativos, hierárquico e sem sobreposição), como os métodos de ligação simples (vizinho mais próximo), de ligação completa (vizinho mais distante) e de ligação média, tais como UPGMA, WPGMA entre outros. (Sneath \& Sokal, 1973).

Métodos de ordenação também são bastante úteis em estudos da estrutura populacional usando marcadores moleculares. Uma das metodologias mais difundidas é a Análise de Componentes Principais (PCA), da qual os demais métodos de ordenação se originaram. Segundo James \& McCulloch (1990) a análise de componentes principais tem por objetivo descrever os dados, reduzindo a poucas dimensões a matriz de distâncias entre os objetos.

Segundo Sneath \& Sokal (1973) um avanço importante nas técnicas de ordenação se deu com da Análise de Coordenadas Principais, através da qual é possível obter coordenadas principais a partir da matriz de distância Euclidiana, sem necessidade de se possuir, como no caso do PCA, a matriz dos dados originais ou a matriz de variânciascovariâncias dos caracteres dos objetos sob análise. É também aplicável a outras distâncias além da Euclidiana,. Bem como a coeficientes de associação. Entretanto, neste caso, a solução é apenas uma aproximação do método de componentes principais. Quando os 
caracteres estão estandardizados, os resultados da PCO são idênticos aos da PCA utilizando matriz de correlação.

Tostain (1994) analisou as principais raças locais nigerianas de Pennisetum glaucum (Poaceae), quanto à estrutura genética. Para tanto, utilizou-se de oito sistemas isoenzimáticos, codificados para doze locos e 46 alelos, identificando três grupos: um grupo de material precoce (entre $8^{\circ}$ e $13^{\circ}$ de longitude leste), o grupo com maior diversidade; outro grupo precoce (entre $1^{\circ}$ e $8^{\circ}$ de longitude leste); um grupo tardio. $\mathrm{O}$ autor usou análise de agrupamento (UPGMA) com base na distância de Rogers modificada, análise de componentes principais e análise discriminante, entre outras.

Gang \& Weber (1995) utilizaram RAPD para analisar a variabilidade genética $e$ as relações entre dez populações de Chrysothamnus nauseosus ssp. hololeucus. Os autores usaram coeficiente de Jaccard, de concordância simples $e$ a distância genética $\left[\frac{1-2 a}{2 a+b+c}\right]$ entre cada par de populações e o método de agrupamento UPGMA. Observaram nível elevado de variação entre populações, sendo que $63,3 \%$ das bandas foram polimórficas.

Gillies et al. (1997) estudaram a diversidade genética dentro e entre dez populações de Cedrela odorata L., distribuídas pela Costa Rica, através de marcadores RAPD. Com dados de presença $e$ ausência de bandas, calcularam o coeficiente de Jaccard, fizeram análise de agnupamento destas distâncias e também aplicaram AMOVA, para avaliar os níveis de diversidade entre populações $e$ entre regiões. Os resultados indicaram diferenciação genética significativa entre populações do Pacífico Norte e Atlântico/Pacífico Sul da Costa Rica e pouca diferenciação entre populações dentro de regiões.

\subsubsection{Análise da estrutura genética populacional através de marcadores dominantes}

Uma nova abordagem surgiu com o trabalho de Lynch \& Milligan (1994), que propuseram uma metodologia de estudo da estrutura populacional a partir de marcadores dominantes, como RAPD. Apresentaram fórmulas para estimação de medidas convencionais de estrutura populacional e de parentesco entre indivíduos, bem como as 
expressões de sua variância. Todos os estimadores consideraram o viés devido ao pequeno tamanho amostral. Além disso, devido à dominância, a informação genotípica é incompleta. Nesse caso, a variância amostral associada a um único loco é maior e as estimativas dos parâmetros de interesse são tendenciosas.

Embora não seja possível obter estimativas de parâmetros sem algum viés, os autores sugeriram vários passos para que este viés se tome desprezível. Verificaram que, para obter o mesmo poder estatístico conseguido com marcadores codominantes, é necessário amostrar de duas a dez vezes mais indivíduos por loco dominante. Também, para evitar o viés, os alelos marcadores da maioria dos locos devem estar em freqüência relativamente baixa. Como é necessário descartar locos com baixa freqüência de alelos nulos, é preciso amostrar maior número de locos RAPD em relação aos marcadores convencionais. Mesmo assim, alguns problemas de viés não podem ser totalmente eliminados.

Como pressuposições do método, assume-se que a interpretação dos padrões de bandas no gel pode ser feita sem ambigüidade e cada loco é tratado como um sistema de dois alelos, sendo que somente um alelo por loco é amplificado pela reação PCR ("Polymerase Chain Reaction"). Porém, sem análise de segregação, é difícil validar tal pressuposição. Todas estas estimações ficam muito mais complexas se a população é localmente endógama. Diferentemente da situação onde os três genótipos são observáveis, não há como avaliar se $F_{I S}=0$, através da análise com marcadores RAPD para uma única geração Lynch \& Milligan (1994).

Para esta situação, os autores sugerem que se obtenha uma geração de cruzamentos aleatórios, para que se atinja o equilíbrio de Hardy-Weinberg na população sob análise e, com base nas diferenças das freqüências gênicas e genotípicas das duas populações que se estimem, por exemplo, as estatísticas $F$ da população de interesse, como medida do desvio da população em relação à panmixia. Portanto, nesse método, assume-se que a população, de alguma forma, tenha sido analisada, quando as freqüências genotípicas estavam em equilibrio de Hardy-Weinberg.

Os autores fornecem expressões para obter estimativas de freqüências alélicas, diversidade genética dentro de uma população, diversidade genética média dentro de população, diversidade genética média estimada por loco entre as populações, a 
diversidade genética média estimada entre as populações, estatísticas $F$, estimador nãotendencioso da distância de Nei e estimativas de medidas de parentesco. Sugerem que as estimativas de parentesco sejam obtidas usando a média considerando todos os locos $e$ não com base em um único loco. $\mathrm{Na}$ verdade, esta análise pode ser aplicada somente a locos polimórficos. Observaram que marcadores RAPD são limitados na estimação do grau de parentesco, e que estimativas de parâmetros populacionais com marcadores dominantes são sempre menos precisas que aquelas obtidas com marcadores codominantes, apresentando sempre, por menor que seja, algum viés.

Embora o trabalho desenvolvido por Lynch \& Milligan (1994) tenha contribuições relevantes, apresenta sérias restrições que limitam sua aplicação. O principal problema é a obtenção de geração de cnuzamentos aleatórios a partir de populações naturais, principalmente se a espécie considerada não for anual. Alternativas mais adequadas seriam obter, a partir da população sob estudo, familias maternas ou ainda progênies provenientes de autofecundações $e$ a seguir, as estimativas dos parâmetros populacionais de interesse poderiam ser obtidas em relação a estas progênies. Por exemplo, ao invés de calcular os desvios das freqüências gênicas e genotípicas em relação ao equilỉbrio de Hardy-Weinberg, como sugerido, poder-se-iam calcular desvios em relação às proporçōes do equilíbrio com endogamia de gerações $S_{1}$ ou de meio-irmãos maternos, no caso de espécies alógamas, pois, no caso de espécies mistas, cruzamentos manuais também seriam necessários, o que seria trabalhoso. Segundo Vencousky ${ }^{1}$ outro problema apresentado pelo método ocorre se houver ligações gênicas, uma vez que poderiam ser necessárias várias gerações de cruzamentos aleatórios para que tais ligações fossem quebradas $e$ o equilíbrio de ligação fosse atingido.

\subsection{Métodos de reamostragem}

Algumas técnicas de reamostragem existem há muitos anos, mas não eram tão difundidas por exigirem grande quantidade de cálculos. No entanto, com o desenvolvimento dos computadores, métodos estatísticos computacionalmente intensivos

\footnotetext{
' VENCOSKY, R. (Departamento de Genética da Escola Superior de Agricultura "Luiz de Queiroz"). Comunicação pessoal, 2000.
} 
tornaram-se disponiveis para uso geral, modificando a forma de análise de dados de origem ecológica e evolutiva (Crowley, 1992).

Nos estudos de populações naturais, não se usam repetições como no caso da experimentação. Trabalham-se com amostras das populações existentes na natureza. Nesse contexto, o uso de técnicas de reamostragem pode ser bastante útil, representando uma tentativa para contornar o problema da falta de repetições. Além disso, muitas estimativas de parâmetros populacionais não têm distribuição de probabilidade conhecida. Também nessa situação, o uso de métodos de reamostragem pode ser útil, pois permite a obtenção de estimativas, de erros associados a essas estimativas, de intervalos de confiança para os parâmetros $e$ testes de hipótese e, em alguns casos, até mesmo da distribuição de estimativas de parâmetros de interesse. A seguir, serão destacadas as principais técnicas de reamostragem empregadas em estudos genéticos. No entanto, maior enfoque será dado ao método bootstrap, utilizado neste trabalho.

\subsubsection{Randomização e permutação}

$\mathrm{Na}$ década de trinta, quando Fisher introduziu a idéia do teste de permutação ou randomização, não tinha por objetivo propor um novo método estatístico, mas sim mostrar que o teste $t$ de Student poderia ser aplicado mesmo na ausência de normalidade. $\mathrm{O}$ procedimento proposto era simples e livre de pressuposições matemáticas (Efron \& Tibishirani, 1993). Os termos permutação e randomização em geral são usados como sinônimos, mas uma distinção pode ser feita, sendo o termo teste de permutação aplicado quando amostras aleatórias justificam os cálculos e o termo teste de randomização usado quando o delineamento experimental fornece esta justificativa (Kempthome \& Doerfler, 1969).

O procedimento de randomização é muito utilizado em testes de hipóteses, e é bastante simples. Primeiramente, os testes de randomização requerem mistura dos dados de todos os niveis de tratamento a serem comparados, isto é, grupos experimentalmente estabelecidos ou observados. Em seguida, a redistribuição dos dados nos níveis de tratamento é feita de forma aleatória e sem reposição, sendo que o número de observações por nível de tratamento deve ser igual ao dos dados originais. Este procedimento é repetido 
diversas vezes e, a cada rearnostragem, calcula-se a estatística de interesse. Na seqüência, compara-se o valor original observado da estatística com a distribuição da mesma, obtida aleatoriamente pela reordenação dos dados. Se a hipótese da nulidade for verdadeira, todas as ordens possiveis para os dados ocorrem com mesma freqüência. Assim, a ordem observada dos dados é uma das possíveis ordens.

Esse é um método de reamostragem de dados para obter o $p$-valor (" $p$-value"), ou seja, a probabilidade de erro tipo I sob a hipótese da nulidade. O $p$-valor é simplesmente a proporção de todos os arranjos de dados que produzem valores da estatística de interesse pelo menos tão extremos em magnitude quanto o valor resultante do arranjamento real observado. De acordo com o $p$-valor obtido, rejeita-se ou não a hipótese da nulidade (Crowley, 1992; Efron \& Tibishirani, 1993; Manly, 1997). Por exemplo, se $p \leq 0,05$, rejeita-se a hipótese de nulidade. Segundo Crowley (1992), quando todas as possíveis redistribuições dos dados nos níveis de tratamento são consideradas, o teste de randomização é dito exato.

Segundo Efron \& Tibishirani (1993) a principal aplicação dos testes de permutação é verificar se duas distribuições, $F$ e $G$, diferem entre si, ou seja, a hipótese da nulidade a ser testada é $H_{o}: F=G$. Em outras palavras, se a hipótese da nulidade for verdadeira, isso significa que os elementos pertencentes à distribuição $F$ têm o mesmo comportamento probabilístico que os elementos pertencentes à distribuição $G$.

Considerando-se duas amostras $X=X_{1}, X_{2}, \cdots, X_{m}$ e $Y=Y_{1}, Y_{2}, \cdots, Y_{n}$, provenientes de duas distribuições de probabilidade $(F$ e $G$ ) possivelmente diferentes, agrupam-se as $N=m+n$ observações e dessas observações sorteia-se, sem reposição, uma amostra de tamanho $m$ para representar a distribuição $F$, sendo que as $n$ observações restantes representam a distribuição $G$. O processo é repetido $B$ vezes (usualmente, $B \geq 1.000$ ), tendo-se, portanto, $B$ vetores independentes, cada qual constituído por $m+n$ observações, selecionado aleatoriamente do grupo de todas as $n\left(\begin{array}{l}N \\ n\end{array}\right)$ possiveis combinações de vetores. 
Calcula-se a estatistica de interesse $(\hat{\theta})$ para cada uma das $B$ permutações, obtendo-se $\hat{\theta}^{*}(b)$, com $b=1,2, \cdots, B$. Em seguida, calcula-se o $p$-valor, que é simplesmente a proporção de todos os arranjos de dados para os quais a estatística de interesse apresentou magnitude tão ou mais extremas em relação ao o valor resultante do arranjamento real observado (Crowley, 1992). Quanto menor o $p$-valor obtido, haverá maior evidência contra $H_{o}$. É interessante notar que o $p$-valor encontrado por este método é muito próximo do valor obtido pelo teste $t$ (Efron \& Tibishirani, 1993).

As principais vantagens dos testes de randomização em relação aos métodos estatísticos convencionais são: a possibilidade dessa técnica poder ser aplicada mesmo que as amostras não sejam aleatórias, o fato de ser relativamente fácil considerar as peculiaridades da situação de interesse, e o fato de poderem ser usados testes estatísticos não convencionais. No entanto, não se pode generalizar as conclusões obtidas pelos testes de permutação. Tais testes são completamente específicos para os dados sob análise, o que é uma desvantagem (Manly, 1997).

Outra vantagem dos testes de randomização é sua exatidão. Se forem feitas 99 randomizações, estarão disponíveis 100 conjuntos de dados, considerando o conjunto observado. Cada conjunto fornece um valor para a estatística de interesse, como por exemplo, valores de $t$ ou de $F$. Assim, é possível construir uma distribuição com estes valores, sendo que cada um deles tem a mesma probabilidade de ocorrer $(0,01)$. O teste é considerado significativo a $5 \%$ se o valor observado estiver entre os cinco maiores valores, caso não ocorram empates. No caso de empates, a probabilidade de o valor observado estar entre os cinco maiores é menor ou igual a 5\%, dependendo da posição do empate na distribuição. Este processo pode ser generalizado para qualquer número de randomizaçōes e também para testes bilaterais (Manly, 1997).

Segundo este autor, existe boa concordância entre testes convencionais e testes de randomização quando ambos os tipos de testes usam estatísticas equivalentes. Se o conjunto de dados estiver em conformidade com as pressuposições exigidas pelos testes clássicos, há uma tendência de os resultados obtidos por estes testes serem muito semelhantes aos obtidos com testes de randomização, porém, se o conjunto de dados tiver um ou dois valores anômalos, os resultados podem não ser concordantes. Devido a essa 
concordância quando o conjunto de dados é bom, justifica-se o uso de métodos estatísticos clássicos em casos de amostras não aleatórias. No entanto, os testes clássicos são considerados uma aproximação dos testes de randomização (Manly, 1997).

Outra limitação é que os testes de randomização só podem ser usados para testar hipóteses com comparações entre dois ou mais grupos, para testar a aleatoriedade das observações em um grupo. Não podem ser aplicados para testar hipóteses sobre valores absolutos de parâmetros populacionais. No entanto, Fisher criou um teste para verificar se a amostra pode ter vindo de uma população com média igual a um determinado valor $\boldsymbol{\mu}$. Trata-se do teste de randomização de Fisher para uma amostra. Nesse teste, calculam-se as diferenças entre os valores observados do caráter e a média hipotética do mesmo. Em seguida, comparam-se as somas dessas diferenças com a distribuição obtida pela randomização dos seus sinais. Somam-se os valores das diferenças obtidas e esta soma é comparada com a distribuição de probabilidade completa obtida por randomização para obter a probabilidade de significância. Em determinados casos, também é possível construir intervalos de confiança (Manly, 1997).

Segundo Weir (1996) uma das aplicações dos testes de permutação em Genética é verificar se as freqüências alélicas entre duas populações podem ser consideradas iguais. A proporção de permutações, em que a diferença de freqüência do alelo $A_{i}$ entre duas amostras é tão grande ou maior que o valor original observado, formece o nível de significância para a rejeição da hipótese da nulidade, ou seja, a hipótese de que a freqüência deste alelo é igual nas duas populaçōes consideradas, que é equivalente aos alelos serem amostrados independentemente nas duas amostras.

Keightley \& Knott (1999) desenvolveram um teste de permutação da correspondência entre testes estatísticos obtidos em dois experimentos com QTL's para testar se os mesmos QTL's estão segregando no par de experimentos. Demonstraram por simulação, que testes de permutação têm as propriedades desejadas se cromossomos são do mesmo comprimento, mas viéses podem ocorrer se os cromossomos são de tamanhos diferentes, devido a problemas relacionados à autocorrelação de valores de testes estatísticos. Aplicaram os testes num exemplo real $e$ o resultado foi não significativo, indicando a falta de concordância entre os QTL's segregando nos experimentos considerados. 


\subsubsection{Jackknife}

Este método foi introduzido em 1949, por Quenouille, para estimar o viés de um estimador (Shao \& Tu, 1995). O termo jackknife foi introduzido por Tukey (1958), referindo-se aos canivetes de bolso com múltiplas funções, que embora fáceis de carregar, raramente realizam alguma das funções de modo ideal. Esta analogia foi proposta com intuito de descrever uma abordagem geral para testar hipóteses e construir intervalos de confiança quando outros métodos melhores não podem ser empregados com facilidade. No entanto, esse procedimento produz melhores estimativas amostrais de alguns parâmetros, como a média e a curtose, e fornecem freqüentemente variância $e$ intervalos de confiança aproximados para estas estimativas. Estes intervalos são usados algumas vezes em testes de hipóteses (Crowley, 1992).

É um processo de reamostragem, em que o parâmetro de interesse $(\theta)$, em uma amostra com $n$ observações, é estimado apropriadamente como $\hat{\theta}$. Pseudovalores $\hat{\theta}_{j}$, associados a cada observação $j$, são obtidos como $\hat{\theta}_{j}=\hat{\theta}-(n-1)\left(\hat{\theta}_{-j}-\hat{\theta}\right)$, em que $\hat{\theta}_{-j}$ é o cálculo do parâmetro com a $j$-ésima observação excluída da amostra. $\mathrm{O}$ lado direito da expressão é a estimativa do parâmetro amostral menos um termo de tendenciosidade, refletindo o desvio da $j$-ésima estimativa $\hat{\theta}_{-j}$ desconsiderada da estimativa $\hat{\theta}$ da amostra total. A média dos pseudovalores $\hat{\theta}_{(.)}$é a estimativa jackknife de $\theta$. A diferença $\hat{\theta}-\hat{\theta}_{(.)}$mede o viés amostral geral da estimativa original $\hat{\theta}$ (Crowley, 1992). Para o parâmetro de interesse $\theta$, é possível obter com jackknife a estimativa do parâmetro e de sua variância e seu intervalo de confiança. A variância jackknife é calculada considerandose nulas as correlações entre pseudovalores, no entanto, não se sabe sob que condições esse pressuposto é válido. $\mathrm{O}$ intervalo de confiança obtido é paramétrico, pois parte-se da pressuposição de que as estimativas jackknife estão baseadas em erros com distribuição normal. Esta pressuposição é justificada pelo Teorema Central do Limite se as amostras forem grandes, mas nos caso de tamanho amostral pequeno é difícil avaliar a validade desse pressuposto (Crowley, 1992). 
Uma das vantagens do método é transformar muitos problemas de estimação no simples problema de estimar a média. Basta que o estimador convencional seja função de $n$ valores amostrais. Como já mencionado, correlações entre pseudovalores são prejudiciais, causando viés na estimativa da variância, podendo esta ser sub ou superestimada (Manly, 1997).

Outra vantagem é que ao substituir o estimador usual pelo estimador jackknife há uma redução de ordem 1/n no viés (Efron \& Tibishirani, 1993; Weir, 1996). Esta idéia pode ser generalizada, sendo que jacklenife de $p$-ésima ordem pode ser usado para remover viés da ordem $1 / n^{p}$ (Manly, 1997).

Além disso, ao estimar o parâmetro de interesse sem uma observação de cada vez, o método jackknife permite identificar as observações mais divergentes na amostra, pois, é possivel verificar quais observações promovem maiores alterações na estimativa quando são retiradas.

A rapidez do método jackknife em relação ao bootstrap quando o número $\boldsymbol{n}$ de observações na amostra for menor que 100 ou 200 (número de amostras bootstrap necessárias para calcular o desvio-padrão), hoje não se constitui numa vantagem importante por causa do grande desenvolvimento da informática. No entanto, nesse cálculo, o método jackknife pode ser visto como uma aproximação do bootstrap, pois considerando as $n$ possiveis amostras jacknnife, este método usa informação limitada sobre a estatística de interesse. Assim, o bootstrap pode ser mais eficiente que o jackknife neste ponto. Também no caso do cálculo do viés, o jackknife é uma aproximação do bootstrap. De maneira geral, este comportamento ocorre para estatísticas do tipo não-linear (Efron \& Tibishirani, 1993).

Segundo esses autores, uma falha importante do método jackknife refere-se a estatísticas dadas por funções não-diferenciáveis, ou seja, aquelas que são pouco influenciadas por pequenas mudanças no conjunto de dados, como a mediana. Como conseqüência, o estimador jackknife do erro-padrão dessas estatísticas é inconsistente. Para contornar esse problema, ao invés de remover apenas uma observação por reamostragem jackknife, removem-se $d$ observações. De modo aproximado, toma-se $\sqrt{n} \leq d \leq n$, em que $n$ é o número de observações da amostra. Outra desvantagem importante consiste no 
fato de o método não fornecer a distribuição da estimativa do parâmetro. Alguns exemplos de aplicação serão considerados a seguir.

Roff \& Preziosi (1994) avaliaram a utilidade do método da média de famílias e de um procedimento mais geral usando jackknife para calcular correlações genéticas. Verificaram que o método de médias de familia pode ser muito tendencioso a menos que os tamanho das familias seja grande, aproximadamente 20. Observaram também que o método jackknife produz estimativas válidas para correlações genotípicas e fenotípicas $e$ seus erros-padrão.

Korman et al. (1993), ao estudarem a estrutura populacional $e$ o fluxo gênico de Heliothis virenscens, usaram jackknife para construir intervalos de confiança para a estatística $F_{S T}$. Zhu \& Weir (1996), propuseram um modelo genético para cruzamentos dialélicos modificados, no qual se utilizam do procedimento jackknife na estimação de componentes de variância de efeitos aditivos e de dominância.

Mitchell et al. (1999) descreveram um procedimento jackknife para identificar indivíduos que contribuem desproporcionalmente para a ligação entre marcador e QTL. Após detectar a ligação com um QTL, a estratégia é remover cada indivíduo (ou familia) de cada análise e recalcular o "lod score" associado a cada região de ligação, usando os dados dos indivíduos (ou familias) restantes. Este procedimento pode ser usado para verificar se determinadas observações têm grande impacto na evidência da ligação.

\subsubsection{Bootstrap}

A técnica bootstrap foi definida por Efron (1979) tendo sido desenvolvida para fazer certos tipos de inferências estatísticas. Segundo Crowley (1992), assim como randomização e jackknife, o método bootstrap é baseado na reamostragem de dados reais para revelar algum padrão neles presente. A noção básica é de que os dados em si, vistos como distribuição de freqüências, representam a melhor imagem disponível da distribuição de freqüências da qual eles são amostrados. A metáfora bootstrap refere-se ao fato de os dados serem usados em sua própria análise estatística.

Para exemplificar o processo bootstrap, pode-se citar o trabalho de Efron (1979), que propôs a estimativa bootstrap do erro-padrão de uma estimativa $\hat{\theta}$ de um parâmetro 
$\theta$ qualquer. $\mathrm{O}$ procedimento consiste em obter $B$ amostras bootstrap independentes $x^{* 1}, x^{* 2}, \cdots, x^{* B}$, cada qual constituída por $n$ valores de observações reamostradas com reposição a partir de um conjunto de pontos observados dado por $x=x_{1}, x_{2}, \ldots, x_{n}$. Para cada repetição bootstrap, calcula-se o valor correspondente de $\hat{\theta}$, dado por $\hat{\theta}^{* b}$, com $b=1,2, \cdots, B$. Estima-se o erro padrão $s_{B}(\hat{\theta})$ através do desvio-padrão amostral das $B$ repetições $\operatorname{se}_{B}(\hat{\theta})=\left\{\sum_{b=1}^{B}\left[\hat{\theta}^{* b}-\hat{\theta}^{*}(.)\right]^{2} /(B-1)\right\}^{1 / 2}$, em que $\hat{\theta}^{*}()=.\sum_{b=1}^{B} \hat{\theta}^{* b} / B$ (Figura 1). Deve-se salientar que para estimar o erro-padrão, o número de amostras bootstrap deve variar entre 25 de 200 (Efron \& Tibishirani, 1993).

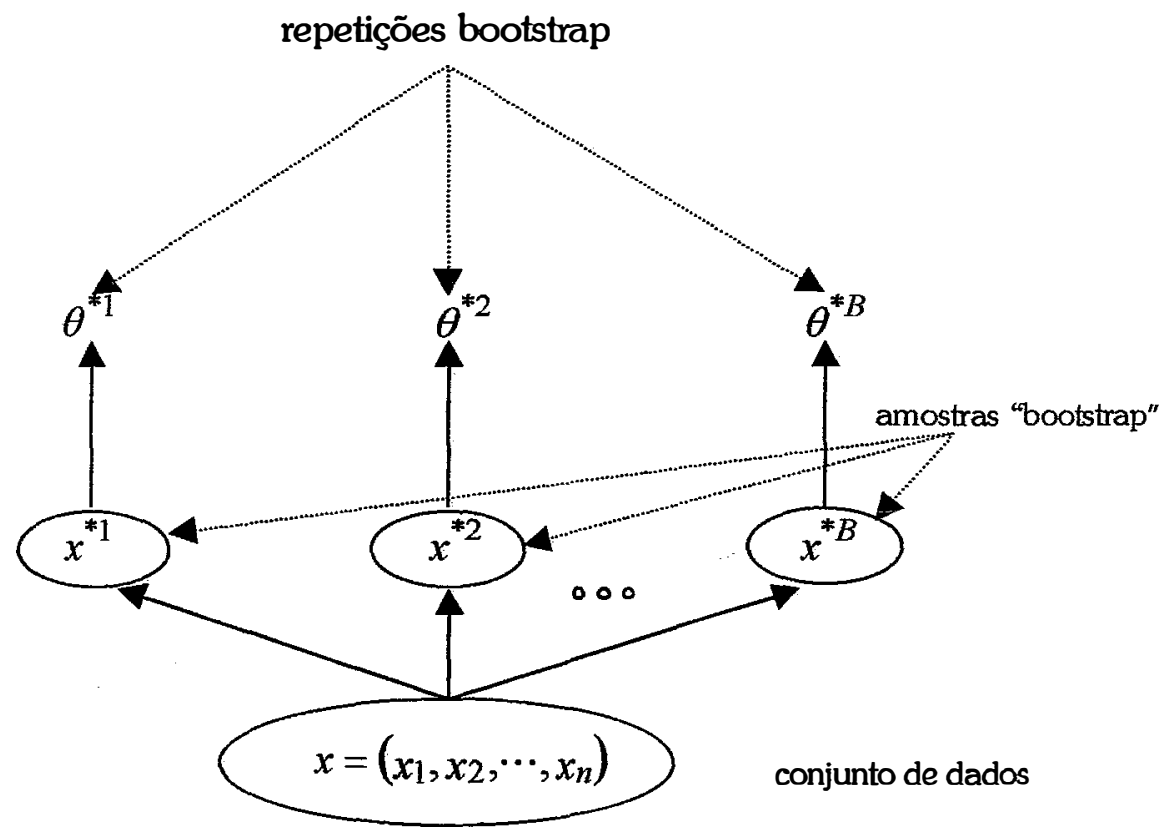

Figura 1. Esquema do processo "bootstrap" para estimar o erro-padrão ( $\left.s e_{B}\right)$ de uma estimativa $(\hat{\theta})$ de um parâmetro $\theta$ qualquer. O erro-padrão dos valores $\theta^{* 1}, \theta^{* 2}, \cdots, \theta^{* B}$ é a estimativa bootstrap do erro-padrão de $\left(\hat{\theta}_{(.)}\right)$, a estimativa bootstrap de $\theta$. (Fonte: Efron \& Tibishirani, 1993.)

Segundo Efron e Tibishirani (1993), o método bootstrap é baseado no princípio "plug-in", um método simples de estimar parâmetros a partir de amostras. Considerando o parâmetro $\theta$ e uma função $t$ de probabilidade de uma distribuição $F$ qualquer de uma 
variável aleatória, a estimativa "plug-in" do parâmetro $\theta=t(F)$ é dada por $\hat{\theta}=t(\hat{F})$. $O$ circunflexo indica estimativa. Portanto, estima-se a função $\theta=t(F)$ da distribuição de probabilidades $F$ pela mesma função da distribuição empírica $\hat{F}, \hat{\theta}=t(\hat{F})$.

O método bootstrap é uma aplicação do princípio "plug-in" e sua virtude está em produzir tendências e erros-padrões de forma automática, não importando quão complicada $\theta=t(F)$ possa ser. Este princípio é adequado se a informação disponível sobre $F$ é proveniente de uma amostra $x$. Nesta circunstância, $\hat{\theta}=t(\hat{F})$ não pode ser melhorada como um estimador de $\theta=t(F)$. Porém, é menos indicado em situações onde há informação sobre $F$, além das fornecidas pela amostra $x$. Neste caso, pode-se assumir que $F$ é um membro da familia paramétrica. Mesmo quando os dados a serem analisados pertencem a uma determinada distribuição, o método bootstrap pode ser aplicado e, neste caso, ele é dito paramétrico. O bootstrap é denominado não-paramétrico quando os dados pertencem a uma distribuição desconhecida a ser estimada de forma empírica no próprio procedimento bootstrap (Efron e Tibishirani, 1993).

O bootstrap também pode ser usado em testes de hipóteses, por exemplo, com dados de cada nível de tratamento (ou grupos de dados a serem comparados), amostrados separadamente, com reposição. Testes podem ser formulados de acordo com a extensão de sobreposição entre intervalos de confiança ou por combinar amostras bootstrap para calcular um teste estatístico (Crowley, 1992).

Muitos autores referem-se à possibilidade de se estimar o viés apresentado por um estimador a partir da técnica bootstrap (Efron \& Tibishirani, 1993; Shao \& Tu, 1995; Manly, 1997; Davidson \& Hinkley, 1997). Considere-se uma amostra aleatória $x=\left(x_{1}, x_{2}, \cdots, x_{n}\right)$ tomada de uma distribuição de probabilidade $F$ e suponha-se que se deseje estimar o valor real do parâmetro $\theta=t(F)$. Considere-se também como estimador $\theta$ a estatística $\hat{\theta}=s(x)$, cujo viés é definido como sendo a diferença entre a esperança de $\hat{\theta}$ e o valor do parâmetro $\theta$. Estimativas "plug-in" $\hat{\theta}=t(\hat{F})$ podem ser viesadas, mas tendem a ter viéses pequenos se comparados à magnitude de seus erros-padrão. Assim, sugere-se que o método bootstrap possa ser usado para estimar o viés de um estimador 
$\hat{\theta}=s(x)$ qualquer, mesmo que $\hat{\theta}$ não seja uma estimativa "plug-in" de $\theta$ (Efron \& Tibishirani, 1993).

Para verificar se esse viés é importante ou não, esses autores sugerem que seja obtida a razão entre a estimativa bootstrap do viés e o emo-padrão bootstrap. Se o viés for menor que 0,25 vezes o erro-padrão, pode ser ignorado, a menos que se deseje obter intervalos de confiança com acurácia.

A construção de intervalos de confiança bootstrap é outra questão a ser discutida. $\mathrm{Na}$ literatura, existem vários tipos de intervalos de confiança que podem ser obtidos a partir de reamostragens bootstrap, alguns dos quais serão mencionados a seguir.

Intervalos de confiança baseados nas distribuições normal padronizada e $t$ podem ser construídos desde que as pressuposições usuais necessárias para tanto sejam respeitadas. Com intervalos baseados nas distribuições normal e $t$, os pontos poncentuais são simétricos em relação ao zero $e$, conseqüentemente, os intervalos de confiança resultantes são simétricos em relação à estimativa pontual $\hat{\theta}$. Porém, os percentis obtidos com esse tipo de intervalo podem ser assimétricos em relação ao zero, fazendo com que os intervalos sejam mais deslocados à direita ou à esquerda. Deve-se salientar que este procedimento pode ser aplicado para estimar intervalos de confiança de estatísticas de posição, mas não é confiável quando usado em casos mais gerais como na construção de intervalos de confiança para coeficiente de correlação, por exemplo. Além disso, podem fornecer resultados errôneos e podem ser muito influenciados por valores discrepantes (Efron \& Tibishirani, 1993).

Os intervalos de confiança mais amplamente difundidos quando se usa bootstrap são os chamados intervalos percentis. Segundo Manly (1997) o uso desse tipo de intervalo é uma tentativa de aproximar os percentis da distribuição de um estimador usando percentis gerados por bootstrap. Há vários tipos deles e o mais simples é o intervalo de confiança percentil simples, descrito por Efron (1979). Nesse intervalo, os dois limites para a estimativa do parâmetro são fornecidos de forma que contenham $100(1-\alpha) \%$ das estimativas obtidas por bootstrap a partir da amostra original. A justificativa para isso é a existência de uma transformação que converta a distribuição do estimador em uma distribuição normal. Assim, se o objetivo for encontrar o intervalo de confiança 
$100(1-\alpha) \%$ para um parâmetro $\theta$, estimado como $\hat{\theta}$ a partir de amostras aleatórias da população sob estudo, assume-se que há uma transformação monotônica crescente de forma que valores transformados de $\hat{\theta}$, dados por $f(\hat{\theta})$, têm distribuição normal, com média $f(\theta)$ e desvio-padrão 1. A transformação não precisa ser conhecida. Somente sua existência já é suficiente para se construir o intervalo. Em conseqüência, há probabilidade $1-\alpha$ de que $f(\hat{\theta})-z_{\alpha / 2} \sigma<f(\theta)<f(\hat{\theta})+z_{\alpha / 2} \sigma$ seja verdadeiro (Manly, 1997).

Se a função de transformação $f$ for conhecida, é possivel transformar o intervalo de confiança obtido para $f(\theta)$ num intervalo para $\theta$, mantendo o mesmo nível de significância de $100(1-\alpha) \%$. Esse fato constitui uma das vantagens deste método. Para tanto, basta apenas aplicar a função inversa de $f$ aos limites do intervalo de $f(\theta)$ para obter limites do intervalo de confiança de $\theta$. Porém, a transformação geralmente não é conhecida (Efron \& Tibishirani, 1993; Manly, 1997). Entretanto, como a transformação tem natureza monotônica, a ordem das estimativas $f(\hat{\theta})$ obtidas por bootstrap, da menor para a maior, corresponde à ordem das estimativas bootstrap $\hat{\theta}$. Assim, os limites para $\theta$ correspondentes ao intervalo de confiança são simplesmente o valor que excede a fração $\alpha / 2$ das estimativas bootstrap desse parâmetro $e$ o valor que excede a fração $(1-\alpha / 2)$ das estimativas bootstrap do parâmetro. Portanto, não é necessário conhecer a transformação para encontrar esses limites (Manly, 1997).

O segundo tipo de intervalo percentil foi proposto por Hall (1992). É praticamente idêntico ao anterior, porém, o intervalo não é para a estimativa do parâmetro, mas para o erro associado a ela. Baseia-se na pressuposição de que a distribuição do erro em $\hat{\theta}$, $(\varepsilon=\hat{\theta}-\theta)$, pode ser aproximada pela distribuição bootstrap do erro $\left(\varepsilon_{B}=\hat{\theta}_{B}-\theta\right)$ (Manly, 1997).

É importante salientar que, para intervalos percentis, é necessário número maior de amostras bootstrap em relação aos intervalos baseados na distribuição normal padronizada ou $t$ para que se obtenham estimativas acuradas dos pontos percentis da distribuição bootstrap (Manly, 1997). Efron (1987) verificou que, para obter a média e o desviopadrão, 100 amostras bootstrap são suficientes, no entanto, para se construir intervalos de 
confiança pelos métodos percentis, são necessárias pelo menos 1000 reamostragens. Buckland (1984) estudou a amplitude coberta por intervalos de confiança construídos pelo primeiro método percentil. Supondo que se deseje obter intervalo com $95 \%$ de confiança, se forem realizadas 200,1.000, 10.000 reamostragens bootstrap, o nível de confiança real varia, respectivamente, de (92 a 98)\%, (93,6 a 96,4)\% e (94,6 a 95,4)\%, respectivamente.

Um dos problemas do primeiro método percentil é que nem sempre existe uma transformação que faça com que a variável transformada $f(\hat{\theta})$ tenha distribuição normal com média $f(\theta)$. Por conseguinte, se o número de amostras bootstrap for suficiente para representar a verdadeira distribuição bootstrap, parece ser útil modificar o primeiro método percentil para remover qualquer viés que possa existir devido ao fato de o verdadeiro valor do parâmetro não ser a mediana da distribuição das estimativas. Para contomar este problema, foram incorporadas modificações no método percentil para construir intervalos de confiança corrigidos, como o intervalo de confiança percentil corrigido para viés ("biascorrected percentile confidence limits") e o intervalo de confiança percentil acelerado corrigido para viés ("accelerated bias-corrected percentile confidence limits"). Detalhes sobre estas metodologias podem ser encontrados em Efron \& Tibishirani, 1993 e Manly, 1997.

Além de ser utilizado na construção de intervalos de confiança, o método bootstrap também pode ser usado para fazer testes de significância. Para testar a hipótese de que um parâmetro $\theta$ assume um determinado valor $\theta_{o}$ basta simplesmente calcular o intervalo de confiança para $\theta$ e verificar se este intervalo contém o valor $\theta_{o}$. Porém, embora o procedimento seja simples, deve-se obter estimativas acuradas de valores críticos do teste de significância, mesmo quando a hipótese da nulidade não for verdadeira para a população da qual a amostra original procede. Trata-se de decidir exatamente como a hipótese de nulidade que está sendo testada pode influenciar na escolha da estatística a ser reamostrada. Para qualquer teste estatístico $S$ usado, o teste bootstrap requer que seja verificado se o valor de $S$ para os dados disponíveis é suficientemente extremo se comparado com a distribuição bootstrap de $S$, para garantir que a hipótese da nulidade seja rejeitada (Manly, 1997). 
O teste pode ser realizado de modo similar ao teste de randomização. Suponha-se que altos valores de $S$ forneçam evidência contra a hipótese da nulidade e que os dados resultaram num valor $S_{1}$ de $S$, e que a rearnostragem bootstrap produziu $B-1$ valores $S_{2}, S_{3}, \cdots, S_{B}$. Todos os $B$ testes estatísticos pertencem à mesma distribuição se a hipótese da nulidade é verdadeira. Logo, $S_{1}$ é significativamente maior, com nível de significância de $100 \alpha \%$, se for um dos $100 \alpha \%$ valores maiores de $B$ testes obtidos, ou ainda, o nível de significância é $p=m / B$, sendo $m$ o número de vezes em que o valor dos testes foi maior ou igual a $S_{1}$ (Manly, 1997).

\subsubsection{Bootstrap aplicado à Genética}

Uma questão importante em Genética de Populações e ainda não resolvida na literatura é que nível hierárquico do modelo considerado deve ser reamostrado. Ou seja, considerando que foram amostradas na natureza várias populações, várias progênies dentro de populações, vários indivíduos dentro de progênies $e$ vários locos, não está definido qual é o nível que deve ser reamostrado para obter estimativas bootstrap de parâmetros populacionais, como estatísticas $F$, suas respectivas distribuições, intervalos de confiança, etc..

Van Dongen (1995) estudou o uso de bootstrap para estimar a distribuição de estatísticas de dados alozimáticos, propondo reamostragem de genótipos individuais, evitando a reamostragem de locos, que é a mais usada. $\mathrm{O}$ autor argumenta que a reamostragem de genótipos individuais seria uma abordagem alternativa válida, uma vez que a interpretação $e$ a validade do bootstrap são afetadas pela unidade de reamostragem e que a reamostragem de locos muitas vezes não respeita as três premissas básicas, que são: independência das freqüências alélicas entre diferentes locos; mesma distribuição de freqüências alélicas em diferentes locos; tamanho efetivo $\left(N_{e}\right)$ relativamente grande. $\mathrm{O}$ autor propõe a estimação do intervalo de confiança para estatísticas $F$ e distâncias genéticas através da reamostragem de genótipos bem como estimar a distribuição do índice de fixação médio ou fazer separadamente análises para cada loco diferente e combinar os resultados posteriormente. Porém, sob modelo aleatório definido para a análise de 
variância de freqüências gênicas, a reamostragem de genótipos individuais não é válida, uma vez que os indivíduos não podem ser considerados independentes. $\mathrm{O}$ autor ainda sugere o uso de jackknife para detectar locos discrepantes.

Van Dongen \& Backeljau (1995) propuseram dois procedimentos bootstrap para avaliação do coeficiente de endogamia, para um único loco, através da reamostragem de genótipos. O primeiro procedimento compara estatisticamente os índices de fixação observado e esperado, obtido por simulações Monte Carlo. O segundo compara dois índices de fixação observados. Simulações Monte Carlo mostraram a probabilidade de estes testes se comportarem satisfatoriamente desde que o número de reamostragens bootstrap seja maior ou igual a 2500 e o tamanho da amostra seja maior ou igual a 20, para o caso de dois alelos. Quanto mais extrema a localização do índice de fixação na distribuição, maiores tamanhos de amostra são necessários para obter testes confiáveis. Duas fórmulas explícitas do poder dos dois testes foram obtidas e avaliadas a partir das simulações Monte Carlo. Foi feita comparação com o teste clássico de qui-quadrado.

Petit \& Pons (1998) avaliaram qual a unidade a ser reamostrada para estudos de diversidade. Propuseram novos estimadores dos parâmetros populacionais de diversidade e diferenciação genética e suas variâncias para locos haplóides em população subdividida em grande número de subpopulações, com amostragens de populações e indivíduos. Eles foram comparados com estimadores bootstrap. Três formas de rearnostragem foram avaliadas: populações; indivíduos dentro de populações; populações e indivíduos conjuntamente. Utilizaram simulações e um exemplo real, em que estudaram 81 populações européias de carvalho (Quercus petrea (Matt.) Liebl.) através de isoenzimas. Resultados teóricos do exemplo numérico mostraram que os estimadores de variância mais apropriados são obtidos através da reamostragem de populações somente, e não pela amostragem de indivíduos e populações. Entretanto, os autores concluíram que os métodos bootstrap apresentaram certa tendenciosidade e que estimadores diretos, propostos previamente por Pons \& Petit (1995), devem ser preferidos para os parâmetros considerados no trabalho. Outro ponto interessante a ser considerado é que tanto pela comparação das variâncias obtidas por bootstrap quanto pelas estimativas diretas, os autores verificaram que o bootstrap feito em dois passos (populações e indivíduos) produz a soma das variâncias total e intrapopulacional e não a variância total somente, fato que é 
concordante com a teoria por eles desenvolvida. Com base no trabalho de Van Dongen (1995), não foram realizadas reamostragem de locos.

No entanto, quando possivel, é interessante reamostrar todos os níveis hieráquicos presentes no conjunto de dados sob estudo, pois assim se obtêm estimativas de variâncias decorrentes de cada fonte de variação. Isto é importante, porque, onde houver maior variância, haverá um indicativo de que a amostragem deva ser melhorada em estudos futuros para tal nível, ou seja, o processo permite determinar estratégias de amostragem.

Outra questão a ser considerada é sobre a existência da aditividade das estimativas das variâncias das estimativas dos parâmetros, obtidas através de bootstrap, a partir de diferentes níveis de reamostragem. Vários autores vêm se preocupando com a questão da aditividade de variâncias no estudo de populações. Segundo Nei (1987), na estimação da diversidade genética média, há dois processos de amostragem envolvidos, que são a amostragem de locos do genoma $e$ o enro associado à amostragem de alelos. Este autor notou que a heterozigosidade observada para um dado loco pode ser escrita como $\hat{h}_{j}=h_{j}+s_{j}$, sendo $h_{j}$ a heterozigosidade populacional e $s_{j}$ o erro amostral com média zero e variância $V_{s j}(h)$. Como $h_{j}$ e $s_{j}$ são independentes, a variância de $\hat{h}_{j}$ sobre todos os locos é $V(\hat{h})=V(h)+V_{s}(h)$, sendo $V(h)$ a variância de $h$ (variância interlocos, associada com a reamostragem de locos no genoma) e $V_{s}(h)$ a média de $V_{s j}(h)$ sobre todos os locos (variância intralocos, associada com a amostragem de indivíduos por loco). $\mathrm{Na}$ análise de variância de freqüências gênicas, observa-se, como mencionado anteriormente, que a soma das variâncias das diferentes fontes de variação resulta na variância total.

Há diversos exemplos de aplicação da técnica de bootstrap em Genética, mostrando a grande utilidade desse método. A seguir, alguns desses exemplos serão considerados.

Segundo Weir (1996) uma alternativa às tabelas de contingência seria a reamostragem numérica, o que significa fazer inferências sobre freqüências alélicas populacionais a partir de freqüências amostrais. Podem-se estimar variâncias e construir intervalos de confiança, ambos a partir de reamostragem das mesmas populações que estão sendo analisadas. Aplicar bootstrap dentro de cada uma das $r$ amostras fornece 
intervalos de confiança para a população de freqüências alélicas, sem precisar do teorema binomial e sem assumir o equilibrio de Hardy-Weinberg. Considera-se que duas populações têm freqüências alélicas diferentes se as freqüências alélicas estimadas para cada população não apresentarem intervalos de confiança sobrepostos.

Vencovsky et al. (1997) utilizaram bootstrap para obter as distribuições das estimativas do índice de fixação $\hat{f}$ e da taxa de cruzamento $\hat{t}$, para obter as estimativas da variância desses estimadores e os intervalos de confiança para $f$ e $t$ e para estudar a validade dos critérios para testes de hipótese. Para tanto, foram usados dados de Santos (1991), obtidos de aproximadamente 100 plantas de dendê e nove locos isoenzimáticos. Os autores realizaram 1.000 amostras bootstrap e obtiveram estimativas de $f$ e $t$ tanto pelo método das freqüências quanto pelo método das variâncias. Observaram que $\hat{f}$ apresentou distribuição normal para oito locos enquanto $\hat{t}$ não apresentou esse tipo de distribuição. Além disso, verificaram que os valores obtidos para $\hat{f}$ e $\hat{t}$ são praticamente iguais pelos dois métodos de estimação, considerando um número elevado de plantas (97). Os intervalos de confiança para $f$ diferiram entre locos.

Ao estimar a distância genética entre genótipos a partir de dados obtidos com marcadores moleculares é importante conhecer a variância amostral associada a esses marcadores para determinar quantas marcas são necessárias para obter um dado nível de precisão na estimativa de distância genética. Assim, Tivang et al. (1994) calcularam a variância amostral entre 37 linhagens endogâmicas de milho, considerando 1202 marcas RFLP, geradas a partir de 251 combinações enzima/sonda. A reamostragem foi feita de forma que as amostras produzidas variassem de tamanho $e$, para cada tamanho de amostra, foi calculado um coeficiente de variação médio entre todas as distâncias entre as linhagens. $O$ processo foi aplicado tanto para o número de marcas quanto para combinações sonda/enzima. Ao realizar bootstrap sobre bandas polimórficas individuais, verificaram que a taxa de redução no $\mathrm{CV}$ médio com aumento do tamanho amostral foi a mesma, independentemente da enzima de restrição usada. Entretanto, apesar de a taxa de redução ser a mesma, os interceptos dos CVs médios foram diferentes quando combinações enzima/sonda foram reamostradas. 
Halldén et al. (1994) avaliaram e compararam marcadores RAPD e RFLP quanto à capacidade de determinar as relações genéticas num grupo de três linhagens endogâmicas de Brassica napus. Para tanto, estimaram a similaridade genética entre estas linhagens a partir de mais de 500 bandas RFLP e 400 bandas RAPD. Foram estimadas freqüências relativas de locos com diferenças alélicas. Foram feitas 300 amostras bootstrap com tamanhos variando de 1 ao número máximo de sondas e primers. Para estimar o erro, com diferentes números de marcadores, foram feitas 5.000 amostras bootstrap e o coeficiente de variação foi estimado para diferentes números de marcadores. Além disso, o processo bootstrap também foi usado para estimar as probabilidades de dois tipos de erro, um causado pela perda de resolução e outro pela ordem reversa. Observaram que grupos de marcadores RAPD e RFLP apresentaram alta similaridade nas relações entre as três linhagens endogâmicas, o que demonstra a consistência da genealogia. Verificaram que com mais de vinte sondas e primers, a probabilidade de qualquer um dos dois tipos de erro é muito baixa.

Fanizza et al (1999) utilizaram 320 primers e 932 bandas polimórficas de RAPD para estudar a variabilidade em dez genótipos de Vitis vinifera. Usaram bootstrap para avaliar o coeficiente de variação (CV) das distâncias genéticas em função do aumento do número de bandas. Observaram que o $\mathrm{CV}$ diminuiu com o aumento do número de bandas e que agrupamentos de genótipos no dendrograma foram estáveis quando grande número de bandas polimórficas (400 ou mais) é usado.

Visscher et al. (1996) compararam intervalos de confiança obtidos pelos métodos "lod score" e bootstrap, tendo por objetivo testar, através de simulações, a aplicação de boostrap na determinação de intervalos de confiança aproximados para a posição de QTL's. Estes intervalos foram calculados através de reamostragem bootstrap em populações retrocruzadas, derivadas de linhagens endogâmicas. Foram obtidas amostras de tamanhos igual a duzentos e a quinhentos indivíduos e o QTL explicou $1 \%, 5 \%$, ou $10 \%$ da variância fenotípica. O método funcionou bem pois a proporção de intervalos de confiança empíricos que continham o QTL simulado foi próxima à proporção esperada. Correlações entre testes estatísticos e a amplitude do intervalo de confiança foram fortemente negativas; assim, quanto mais forte a evidência de um QTL segregante, menor o intervalo de confiança empírico para sua localização. Concluíram que diferentes números 
de amostras causam diferenças pequenas no intervalo de confiança e na proporção de IC que contém o QTL e que um intervalo de confiança é menor em populações maiores, sendo que para $\mathrm{N}=500$, o intervalo de confiança empírico parece ser não-tendencioso para herdabilidades de 0,05 e 0,10. O tamanho médio do intervalo de confiança depende muito do tamanho populacional e do efeito do QTL. O espaçamento entre marcadores tem efeito pequeno sobre o intervalo de confiança empírico médio e a posição do QTL não afeta o intervalo de confiança bootstrap.

Remington et al. (1999) construíram um mapa genético completo de Pinus taeda L. usando AFLP em megagametófitos haplóides. Usaram 21 primers AFL e obtiveram 521 fragmentos polimórficos, dos quais 508 foram mapeados em 12 grupos de ligação, que é o número de cromossomos de Pinus taeda em estado haplóide. A partir de bootstrap de locos, foram selecionados 184 estruturas de marcadores.

Felsenstein (1985) propôs uma maneira de reamostrar filogenias, permitindo verificar se um grupo particular é monofilético. O método fomece intervalo de confiança dentro do qual está contida a filogenia que poderia ser estimada em repetidas amostragens. Para tanto, propôs construir uma tabela do tipo espécies $\mathrm{x}$ sítios de seqüências moleculares e em seguida é feita a reamostragem dos caracteres (sítios). A independência dos processos evolucionários para cada caráter garante que os caracteres sejam independentes $e$ identicamente distribuídos, validando o bootstrap.

Keeley \& Jansen (1994) estudaram a filogenia da tribo Vernonieae (Asteraceae) através da variação de sítios de restrição em DNA cloroplastidial: Examinaram 35 taxa nesta tribo e em quatro outras tribos, usando dezessete enzimas de restrição. Encontraram 139 mutações geneticamente informativas. Árvores filogenéticas foram construídas e posteriormente avaliadas por bootstrap e por análise de decaimento. Concluíram haver padrão complexo de relação entre Vernonieae do Velho e Novo Mundos e que a monofilia dos taxa baseada em dois hemisférios não foi sustentada.

Dopazo (1995) propôs o uso de bootstrap para estimar erros e intervalos de confiança para a medida do comprimento de ramos em árvores filogenéticas. $\mathrm{O}$ método também pode ser utilizado para testar se a distância internodal difere de zero. Por se tratar de um procedimento de reamostragem, o autor considera o método vantajoso, pois independe do número de espécies sob estudo e pode ser usado para qualquer estimador 
de distância genética, sem que o nível de complexidade dos cálculos aumente. Porém, reconhece que o bootstrap por si só não dá uma estimativa acurada do parâmetro. Concluiu ainda que a reamostragem é uma abordagem mais geral que os procedimentos baseados em fórmulas para a estimação da confiabilidade dos comprimentos de ramos. 


\section{MATERIAL E MÉTODOS}

\subsection{Material}

Dentre os vários conjuntos de dados fornecidos por diversos pesquisadores que analisaram a estrutura genética populacional, através do uso de marcadores isoenzimáticos e microssatélites, foram selecionados os seis conjuntos que mais se adaptaram aos objetivos deste estudo. A seguir, será fornecida uma breve descrição desse material, devendo-se salientar que os dados de progênies obtidos por Reis (1996), Seoane (1998) e Sebbenn et al. (2000) não foram considerados neste estudo.

Reis (1996) estudou, através de isoenzimas, a distribuição e a dinâmica de alelos em oito populaçōes naturais de palmiteiro em duas regiões geográficas distintas, sendo a primeira localizada no Médio Vale do Rio Itajaí-Açu (Blumenau, SC) e a segunda no Vale do Rio Ribeira do Iguape (Sete Barras, SP). Na primeira região, foram analisadas três populações de palmiteiro pertencentes à Fazenda Faxinal. As populações foram estabelecidas com base em altitudes e denominadas SC450 (Santa Catarina, $450 \mathrm{~m}$ de altitude média), SC550 (Santa Catarina, $550 \mathrm{~m}$ de altitude média) e SC650 (Santa Catarina, $650 \mathrm{~m}$ de altitude média). Na segunda região foram amostrados dois locais de estudo: Saibadela, localizado na Bacia do Rio Saibadela, com três áreas de coletas situadas a 100, 250 e 350m de altitude média e denominadas SPS100 (São Paulo/Saibadela, 100m de altitude), SPS250 e SPS350, respectivamente; Limão, situado no Vale do Rio São Pedro, com duas áreas de coleta definidas a 350 e $700 \mathrm{~m}$ de altitude, denominadas SPL350 (São Paulo/Limão, 350m de altitude) e SPL700. Nas oito populações estabelecidas foram coletadas amostras foliares e sementes (progênies) de individuos adultos tomados aleatoriamente (Tabela 2). 
Folíolos de indivíduos adultos $e$ de progênies foram submetidos a análises isoenzimáticas. De todos os locos avaliados, sete apresentaram boa resolução $e$ foram considerados nas análises (Reis, 1996). O autor caracterizou os níveis e a distribuição de variabilidade genética e a estrutura genética dessas populações e também o sistema reprodutivo e o fluxo gênico das mesmas. Estimou, entre outros, as estatísticas $F$ de Wright, as heterozigosidades observada e esperada, os coeficientes de coancestralidade $\left(\theta^{\prime} s\right)$ de Cockerham, a taxa de cruzamento e o fluxo gênico.

Seoane (1998) avaliou, por análise isoenzimática, adultos e progênies de Esenbeckia leiocarpa (guarantã) em dois fragmentos florestais, um de 2.178 ha, na Estação Ecológia de Caetetus (E.E.C.), e outro de 76 ha, na Estação Ecológica de Ibicatu (E.E.I.). Foram consideradas duas subpopulações no fragmento E.C.C., denominadas de $\mathrm{C} 1$ e $\mathrm{C} 2$, e duas subpopulações no fragmento E.E.I., chamadas de I1 e I2 (Tabela 2). De cada subpopulação foram coletados os vinte indivíduos adultos, que estavam mais próximos ao indivíduo localizado no centro da subpopulação. Foram obtidas dez progênies na subpopulação $\mathrm{C} 2$ e dez na subpopulação I1. Cada progênie foi compostas por vinte plântulas. Dos onze locos avaliados, oito foram polimórficos. Calcularam-se estimativas das estatísticas $F$, da taxa de cruzamento uni $e$ multilocos e do fluxo gênico. Também realizou análise de autocorrelação espacial.

Telles \& Coelho (1998) estudaram a magnitude e a distribuição da variabilidade genética de seis populações (Tabela 2) de Araticum (Anonna crassiflora) provenientes de duas regiões do Estado de Goiás. Foram amostrados 30 indivíduos por população, os quais foram avaliados através do uso de quatro marcadores isoenzimáticos. Com base nos resultados, os autores puderam concluir que existe elevada variabilidade genética desta espécie em Goiás e elevada divergência genética entre as populações. Detectaram também a presença de estruturação populacional, sendo que o parentesco entre indivíduos dentro de populações e a endogamia total dos indivíduos foram significativos. Não se detectou estruturação genética significativa entre regiões. Houve indícios da presença de efeito da distribuição espacial sobre a magnitude da similaridade entre as populações. Concluíram ainda que a espécie se reproduz preferencialmente por alogamia.

Ciampi (1999) estudou quatro populações de copaíba (Copaifera langsdorffii) no Cerrado, usando marcadores microssatélites. Foram amostrados 24 indivíduos por 
população (Tabela 2) e foram analisados oito locos microssatélites. Estimou parâmetros de estutura genética populacional $e$ a patemidade nessas populações.

Auler (2000) caracterizou a estrutura genética de nove populações naturais de Araucaria angustifolia em Santa Catarina. As populações consideradas e sua localização foram: Fazenda Amola Faca (F.A.F.), em Lages; Parque Municipal (P.M.), em Lages; Fazenda Rancho Alegre (F.R.A.), em Lages; Fazenda Guamirim Gateados (F.G.G.), em Campo Belo do Sul; Reserva do Caraguatá (R.C.), em Antonio Carlos; FLONA Fazenda Três Barras, em Três Barras; EPAGRI Caçador, em Caçador; Urupema, em Urupema; ARIE Victor Meirelles, em Victor Meirelles (Tabela 2). Foram analisados 15 locos isoenzimáticos e estimadas as estatísticas $F$ de Wright, os índices de coancestralidade $\theta$ de Cockerham e foi realizada a análise de diversidade de Nei.

Sebbenn et al. (s.d.) e Sebbenn et al. (2000) estudaram a estrutura genética, o sistema reprodutivo, a distribuição genética espacial, o fluxo de genes e o tamanho efetivo populacional de duas populações de Tabebuia cassinoides, uma não manejada, situada na localidade de Juréia e outra manejada localizada em Iguape. Sebbenn et al. (s.d.) coletaram aleatoriamente 45 indivíduos da população de Juréia e 47 da população de Iguape e Sebbenn et al. (2000) obtiveram oito progênies contendo dez indivíduos em Juréia e nove progênies com dez indivíduos em Iguape. Avaliaram os indivíduos adultos $e$ as progênies por análise isoenzimática, considerando 12 locos para adultos e 15 para progênies (Tabela 2). 
Tabela 2. Origem dos dados utilizados nesta pesquisa: autores, nomes ou locais de coleta $e$ tamanhos amostrais das populações e progênies consideradas.

\begin{tabular}{|c|c|c|c|c|c|}
\hline Autor & $\begin{array}{c}\text { Nome ou } \\
\text { Localização } \\
\text { da populacáo }\end{array}$ & $\begin{array}{c}\text { Tamanho } \\
\text { amostral da } \\
\text { população }\end{array}$ & $\begin{array}{c}\text { Nome ou } \\
\text { Localização } \\
\text { da Progênie }\end{array}$ & $\begin{array}{l}\text { Número de } \\
\text { progênies/ } \\
\text { população }\end{array}$ & $\begin{array}{c}\text { Tamanho } \\
\text { amostral médio } \\
\text { das progênies }\end{array}$ \\
\hline \multirow[t]{8}{*}{ Reis (1996) } & Blumenau, SC & 23 & Blumenau, SC & 17 & 14,65 \\
\hline & Blumenau, SC & 27 & Blumenau, SC & 11 & 14,73 \\
\hline & Blumenau, SC & 23 & Blumenau, SC & 12 & 13,67 \\
\hline & Saibadela, SP & 26 & Saibadela, SP & 16 & 19,69 \\
\hline & Saibadela, SP & 26 & Saibadela, SP & 11 & 19,82 \\
\hline & Saibadela, SP & 26 & Saibadela, SP & 18 & 19,72 \\
\hline & Limão, SP & 22 & Limão, SP & 22 & 19,82 \\
\hline & Limão, SP & 25 & & - & \\
\hline \multirow[t]{4}{*}{ Seoane (1998) } & E.E.C. (C1) & 26 & & & \\
\hline & E.E.C. (C2) & 20 & E.E.C. (C2) & 10 & 20 \\
\hline & E.E.I. (I1) & 23 & E.E.I. (I1) & 10 & 20 \\
\hline & E.E.I. (12) & 19 & & & \\
\hline \multirow{6}{*}{$\begin{array}{c}\text { Telles \& Coelho } \\
\text { (1998) }\end{array}$} & Pop1 & 30 & - & - & - \\
\hline & Pop2 & 30 & - & - & - \\
\hline & Pop3 & 30 & - & - & - \\
\hline & Pop4 & 30 & - & - & - \\
\hline & Pop5 & 30 & - & - & - \\
\hline & Pop6 & 30 & - & - & - \\
\hline \multirow[t]{4}{*}{ Ciampi (1999) } & Mata Onça & 24 & - & - & - \\
\hline & Mata Tamanduá & 24 & - & - & - \\
\hline & $\begin{array}{c}\text { Mata Cabeça do } \\
\text { Veado }\end{array}$ & 24 & - & - & - \\
\hline & Mata Acudinho & 24 & - & - & - \\
\hline \multirow[t]{9}{*}{ Auler (2000) } & F.A.F. & 30 & - & - & - \\
\hline & P.M. & 25 & - & - & - \\
\hline & F.R.A. & 34 & - & - & - \\
\hline & F.G.G. & 42 & - & - & - \\
\hline & R.C. & 41 & - & - & - \\
\hline & FLONA & 28 & - & - & - \\
\hline & EPAGRI & 45 & - & - & - \\
\hline & U & 37 & - & - & - \\
\hline & ARIE & 43 & - & - & - \\
\hline \multirow{2}{*}{$\begin{array}{l}\text { Sebbenn et al. } \\
\text { (s.d.) Sebbenn et } \\
\text { al. (2000) }\end{array}$} & $\begin{array}{l}\text { Juréia (não } \\
\text { manejada) }\end{array}$ & 45 & $\begin{array}{l}\text { Juréia (não } \\
\text { manejada) }\end{array}$ & 8 & 10 \\
\hline & $\begin{array}{c}\text { Iguape } \\
\text { (manejada) }\end{array}$ & 47 & $\begin{array}{c}\text { Iguape } \\
\text { (manejada) }\end{array}$ & 9 & 10 \\
\hline
\end{tabular}




\subsection{Métodos}

\subsubsection{Análise de variância de freqüências gênicas}

A análise da estrutura populacional foi feita a partir da análise de variância de freqüências gênicas (Cockerham, 1969; Cockerham, 1973; Weir \& Cockerham, 1984; Weir, 1996). Esta análise foi realizada para cada conjunto de dados, visando a obtenção das estimativas das variâncias genéticas total, populacional, de indivíduos dentro de populações e de genes dentro de indivíduos $\left(\hat{\sigma}_{T}^{2}, \hat{\sigma}_{P}^{2}, \hat{\sigma}_{I}^{2}\right.$, e $\hat{\sigma}_{G}^{2}$, respectivamente) e das estimativas dos parâmetros populacionais $F, f$ e $\theta$ e seus respectivos desvios-padrão.

Assim, para cada conjunto de dados, assumiu-se modelo aleatório, ou seja, a existência de uma população de referência a partir da qual as populações avaliadas se originaram por deriva genética, na ausência de seleção, e os locos foram considerados seletivamente neutros. A estrutura hierárquica considerada incluiu as seguintes fontes de variação: populações (P), indivíduos dentro de populações (I) e genes dentro de indivíduos (G) (Tabela 3).

Tabela 3. Análise de variância para dados genotípicos em populações aleatórias.

\begin{tabular}{clcll}
\hline Fonte de Variação & \multicolumn{1}{c}{$G L$} & $S Q$ & $Q M$ & \multicolumn{1}{c}{$E(Q M)^{\cdot}$} \\
\hline Entre populaçóes & $r-1$ & $S Q P$ & $Q M P$ & $\sigma_{G}^{2}+2 \sigma_{I}^{2}+2 n_{c} \sigma_{P}^{2}$ \\
$\begin{array}{c}\text { Indivíduos dentro de } \\
\text { populaçöes }\end{array}$ & $\sum_{i}\left(n_{i}-1\right)=n .-r$ & $S Q I$ & $Q M I$ & $\sigma_{G}^{2}+2 \sigma_{I}^{2}$ \\
$\begin{array}{c}\text { Genes dentro de } \\
\text { indivíduos }\end{array}$ & $\sum_{i=1}^{r} n_{i}=n$. & $S Q G$ & $Q M G$ & $\sigma_{G}^{2}$ \\
\hline
\end{tabular}

Fonte: Weir (1996).

$n_{c}=\frac{1}{r-1}\left(\sum_{i=1}^{r} n_{i}-\frac{\sum_{i} n_{i}^{2}}{\sum_{i} n_{i}}\right)$.

Da Tabela 3, têm-se, pelo método dos momentos, estimativas não-viesadas destes componentes de variância, obtidas através de funções dos quadrados médios observados, $Q M P, Q M I$ e $Q M G$ para populações, indivíduos dentro de populações e genes dentro de indivíduos, respectivamente. Assim: 
$\hat{\sigma}_{T}^{2}=\hat{\sigma}_{P}^{2}+\hat{\sigma}_{I}^{2}+\hat{\sigma}_{G}^{2}$ é a variância genética total;

$\hat{\sigma}_{P}^{2}=\frac{1}{2 n_{c}}(Q M P-Q M I)$ para populações;

$\hat{\sigma}_{I}^{2}=\frac{1}{2}(Q M I-Q M G)$ para indivíduos dentro de populações;

$\hat{\sigma}_{G}^{2}=Q M G$ para genes dentro de indivíduos.

A partir dessas estimativas, podem ser obtidas as seguintes estimativas:

$\hat{F}=\frac{\hat{\sigma}_{P}^{2}+\hat{\sigma}_{I}^{2}}{\hat{\sigma}_{P}^{2}+\hat{\sigma}_{I}^{2}+\hat{\sigma}_{G}^{2}}$, o índice de fixação total;

$\hat{\theta}=\frac{\hat{\sigma}_{P}^{2}}{\hat{\sigma}_{P}^{2}+\hat{\sigma}_{I}^{2}+\hat{\sigma}_{G}^{2}}$, a diversidade entre populações ou a coancestria dentro de populações;

$$
\hat{f}=\frac{\hat{F}-\hat{\theta}}{1-\hat{\theta}}, \text { o índice de fixação intrapopulacional. }
$$

\subsubsection{Reamostragem bootstrap}

O método de reamostragem bootstrap foi aplicado com diversas finalidades. A primeira foi a obtenção de estimativas bootstrap dos parâmetros $f, F$ e $\theta$ e de seus respectivos desvios-padrão, em função das fontes de variação locos, indivíduos, populações $e$ indivíduos e populações simultaneamente. A partir das estimativas desses parâmetros, estimaram-se também os parâmetros $t_{a}$ (taxa aparente de cruzarnento), $N m$ (fluxo gênico) e $N_{e}$ (tamanho efetivo populacional). Nesse caso, as reamostragens foram realizadas para verificar quais as principais fontes de erro associadas às estimativas desses seis parâmetros, obter intervalos de confiança para tais parâmetros e as distribuições de probabilidade empíricas de suas estimativas. Para tanto, foram realizadas reamostragens como descrito no item 3.2.2.1.

Para determinar o número de populações, indivíduos e locos necessários, visando obter os erros associados às estimativas dos parâmetros $F, f$ e $\theta$ dentro do limite de 
desvio-padrão estipulado neste trabalho, foram feitas reamostragens bootstrap de acordo com a metodologia descrita no item 3.2.2.2.1. Neste item foram feitas considerações sobre estratégias de amostragem.

Uma outra forma de verificar a contribuição relativa das fontes de variação sobre os erros amostrais das estimativas dos parâmetros $F, f$ e $\theta$, foi realizar reamostragens de populações e indivíduos concomitantemente, obtendo estimativas de variância associadas aos parâmetros estimados em função dessas diferentes fontes de variação. Obtiveram-se cinco estimativas dessas variâncias para cada conjunto de dados, e essas foram submetidas a análise de variância sob estrutura fatorial. Em seguida, calculou-se o coeficiente de determinação para cada fonte de variação. Fontes de variação que apresentaram coeficientes de determinação com magnitudes mais elevadas para um dado parâmetro são responsáveis por maiores erros associados à estimação de tal parâmetro. Maiores detalhes são encontrados no item 3.2.2.2.2.

\subsubsection{Bootstrap com tamanhos constantes de amostras}

Nesse tipo de reamostragem, cada amostra bootstrap foi tomada com o mesmo tamanho que a amostra original. Por exemplo, se o número de populações de um conjunto de dados era originalmente cinco, cada amostra bootstrap foi constituída de cinco populações obtidas pela reamostragem com reposição do conjunto original de populações.

Assim, de modo semelhante ao utilizado por Petit \& Pons (1998), foram feitas reamostragens de populações, de indivíduos $e$ de populações $e$ indivíduos simultaneamente. Também foi realizada reamostragem de locos. Para cada nível de reamostragem, foram obtidas 100.000 amostras bootstrap. Para cada uma delas, calcularam-se, pelo método da análise de variância de frequuências gênicas, estimativas bootstrap dos parâmetros $f, F$ e $\theta$, bem como de suas variâncias (Tabela 4). A média dessas estimativas, por parâmetro, é a estimativa bootstrap do parâmetro e a variância dessas estimativas é a estimativa da variância associada à estimativa bootstrap do parâmetro. Uma informação importante extraída desses resultados é sobre qual fonte de variação é responsável pelas maiores variâncias associadas às estimativas dos parâmetros. Essa informação pode ser utilizada na determinação de estratégias de amostragem. Assim, 
por exemplo, se na estimação de um dado parâmetro num conjunto de dados, a maior variância associada a sua estimativa é decorrente da amostragem de locos, em pesquisas futuras dessa natureza o número de locos deve merecer atenção especial, de preferência atentando-se para a necessidade de ser aumentado.

A partir de cada estimativa destes parâmetros mencionados em cada amostra bootstrap, obtiveram-se estimativas dos parâmetros: tava de cruzamento aparente $\left(t_{a}\right)$, fluxo de genes $(\mathrm{Nm})$ e tamanho efetivo populacional $\left(N_{e}\right)$. Esses últimos foram estimados de acordo coam as seguintes expressões: $\hat{t}_{a}=(1-\hat{f}) /(1+\hat{f}), \quad \hat{N} m=(1-\hat{\theta}) / 4 \hat{\theta} \quad$ e $\hat{N}_{e}=\bar{N} /(1+\hat{f})$. Na estimativa do tamanho efetivo, $\bar{N}$ foi aproximado como a média aritmética entre os tamanhos amostrais das populações para cada conjunto de dados. Esta aproximação foi usada pois os tamanhos das populações não variaram muito dentro de cada conjunto, exceto para os dados de Auler (2000). Mesmo neste caso, $\hat{N}_{e}$ foi obtido como descrito acima para que houvesse uniformidade entre as metodologias aplicadas aso diferentes conjuntos. Além disso, para os parâmetros $t_{a}, N m$ e $N_{e}$, buscou-se apenas ter uma noção geral do comportamento da distribuição de probabilidades de suas estimativas e de quais as fontes de variação conferem maiores erros associados a tais estimativas.

Para cada conjunto de dados, foram construídos histogramas com as estimativas dos seis parâmetros obtidas pelos diferentes tipos de reamostragem e também obtiveram-se intervalos de confiança percentil simples para os mesmos. Foram realizados teste de normalidade em cada uma das distribuições das estimativas obtidas. Como o número de reamostragens por nível (ou combinação de níveis) foi de 100.000, o teste de normalidade aplicado foi o de Kolmogorov-Smimov (Sokal \& Rohlf, 1995). O número 100.000 foi adotado por vários motivos: existência de números muito elevados de possíveis amostras bootstrap; aumento da precisão das estimativas com o aumento do número de amostras; obtenção dos pontos percentis dos intervalos de confiança com maior acurácia (Buckland, 1984; Manly, 1997). 
Tabela 4. Estimativas dos parâmetros índice ${ }^{\mathrm{a}} F,{ }^{\mathrm{b}} f,{ }^{\mathrm{c}} \theta,{ }^{\mathrm{d}} \boldsymbol{t}_{a},{ }^{\mathrm{e}} N m$ e ${ }^{\mathrm{f}} N_{e}$ e suas respectivas estimativas de variância

\begin{tabular}{|c|c|}
\hline $\begin{array}{l}\text { Estimativas dos } \\
\text { parâmetros }\end{array}$ & Estimativa da variância das estinativas dos parâmetros \\
\hline$\hat{F}$ & $\hat{\operatorname{Var}}(\hat{F} ; P):$ estimativa da variância de $\hat{F}$, devida a populações \\
\hline & imativa da variância de $\hat{F}$, devida a indivíduos \\
\hline & $\hat{V} a r(\hat{F} ; L):$ estimativa da variância de $\hat{F}$, devida a locos \\
\hline & $\hat{V} a r(\hat{F} ; P, I):$ estimativa da variância de $\hat{F}$, devida a populações $e$ indivíduos \\
\hline$\hat{f}$ & $\hat{\operatorname{Var}}(\hat{f} ; P):$ estimativa da variância de $\hat{f}$, devida a populações \\
\hline$\hat{\theta}$ & $\hat{\operatorname{Var}}(\hat{\theta} ; P):$ estimativa da variância de $\hat{\theta}$, devida a populações \\
\hline & $\hat{\operatorname{Var}}(\hat{\theta} ; I):$ estimativa da variância de $\hat{\theta}$, devida a indivíduos \\
\hline & timativa da variância de $\hat{\theta}$, devida a locos \\
\hline & $\hat{\operatorname{Var}}(\hat{\theta} ; P, I):$ estimativa da variância de $\hat{\theta}$, devida a populações e indivíduos \\
\hline$\hat{t}_{a}$ & $\hat{\operatorname{Var}}\left(\hat{t}_{a} ; P\right):$ estimativa da variância de $\hat{t}_{a}$, devida a populações \\
\hline & $\hat{V} a r\left(\hat{t}_{a} ; I\right):$ estimativa da variância de $\hat{t}_{a}$, devida a indivíduos \\
\hline & $\hat{\operatorname{Var}}\left(\hat{\boldsymbol{t}}_{a} ; L\right):$ estimativa da variância de $\hat{t}_{a}$, devida a locos \\
\hline & $\hat{V} a r\left(\hat{t}_{a} ; P, I\right):$ estimativa da variância de $\hat{t}_{a}$, devida a populações e indivíduos \\
\hline$\hat{N} m$ & $\hat{\operatorname{Var}}(\hat{N} m ; P):$ estimativa da variância de $\hat{N} m$, devida a populaçōes \\
\hline & $\hat{\operatorname{Var}}(\hat{N} m ; I):$ estimativa da variância de $\hat{N} m$, devida a indivíduos \\
\hline & $\hat{\operatorname{Var}}(\hat{N} m ; L):$ estimativa da variância de $\hat{N} m$, devida a locos \\
\hline & $\hat{\operatorname{Var}}(\hat{N} m ; P, I):$ estimativa da variância de $\hat{N} m$, devida a populações e indivíduos \\
\hline$\hat{N}_{e}$ & $\hat{\operatorname{Var}}\left(\hat{N}_{e} ; P\right):$ estimativa da variância de $\hat{N}_{e}$, devida a populações \\
\hline & $\hat{\operatorname{Var}}\left(\hat{N}_{e} ; I\right):$ estimativa da variância de $\hat{N}_{e}$, devida a indivíduos \\
\hline & $\hat{\operatorname{Var}}\left(\hat{N}_{e} ; L\right):$ estimativa da variância de $\hat{N}_{e}$, devida a locos \\
\hline
\end{tabular}

ándice de fixação total; 'índice de fixação intrapopulacional; 'divergência entre populaçōes; 'taxa de cruzamento aparente; 'fluxo de genes entre populaçōes;'tamanho efetivo populacional.

Deve-se esclarecer que apenas os locos polimórficos foram considerado na reamostragem de locos. Todas estas análises foram realizadas usando programa computacional EG (Coelho, 2000a). 
Para cada um dos parâmetros $F, f$ e $\theta$ e para estes três parâmetros conjuntamente verificou-se se há existência aditividade de variâncias quando se utiliza a abordagem bootstrap. Assim, por exemplo, para o parâmetro $F$, foi verificado se $\hat{\operatorname{Var}}(\hat{F} ; P)+\hat{\operatorname{Var}}(\hat{F} ; I)=\hat{\operatorname{Var}}(\hat{F} ; P, I)$. Tendo sido comprovada a aditividade das estimativas da variância, além da facilidade prática de não se ter que fazer a reamostragem conjunta de populações e indivíduos, pode-se calcular a contribuição relativa das estimativas da variância decorrente de cada nível de reamostragem em relação à estimativa da variância total, dada pela soma das estimativas das variâncias obtidas a partir de cada nível de reamostragem considerado. Esta contribuição relativa seria um indicativo de onde estariam ocorrendo as maiores deficiências na amostragem. Assim, por exemplo, se um determinado parâmetro apresentar maior variância quando estimado a partir de reamostragem de indivíduos, isso indicaria que nas próximas amostragens, um número maior de indivíduos deva ser considerado para obter estimativa mais acurada de tal parâmetro.

O estudo da aditividade foi realizado a partir dos conjuntos reais descritos anteriormente e também a partir de simulação. Na simulação, foram construídos 25 conjuntos com 30 populações cada um, constituídas por cem indivíduos e avaliadas para cinco locos, com três alelos em cada loco ${ }^{2}$ (Tabela 5).

\footnotetext{
${ }^{2}$ COELHO, A.S.G. (Universidade Federal de Goiás, Instituto de Ciências Biológicas, Departamento de Biologia Geral). Comunicação pessoal, 2000.
} 
Tabela 5. Populações simuladas e respectivas taxas de autofecundação $(s)$ e número de gerações decorridas $(t)$.

\begin{tabular}{ccc}
\hline População & Taxa da autofecundação $(s)$ & Tempo em número de geraçōes $(t)$ \\
\hline 1 & 0,00 & 100 \\
2 & 0,20 & 100 \\
3 & 0,40 & 100 \\
4 & 0,60 & 100 \\
5 & 0,80 & 100 \\
6 & 0,00 & 200 \\
7 & 0,20 & 200 \\
8 & 0,40 & 200 \\
9 & 0,60 & 200 \\
10 & 0,80 & 200 \\
11 & 0,00 & 300 \\
12 & 0,20 & 300 \\
13 & 0,40 & 300 \\
14 & 0,60 & 300 \\
15 & 0,80 & 300 \\
16 & 0,00 & 400 \\
17 & 0,20 & 400 \\
18 & 0,40 & 400 \\
19 & 0,60 & 400 \\
20 & 0,80 & 400 \\
21 & 0,00 & 500 \\
22 & 0,20 & 500 \\
23 & 0,40 & 500 \\
24 & 0,60 & 500 \\
25 & 0,80 & 500 \\
\hline
\end{tabular}

Foram feitas regressões lineares tanto para os resultados obtidos com dados reais quanto para os obtidos a partir das populações simuladas, para cada um dos parâmetros estimados $(\hat{F}, \hat{f}$ e $\hat{\theta})$ e para todos eles conjuntamente. No modelo de regressão $Y=\beta X+\alpha$, no qual $Y$ é a variável dependente, $X$ a variável independente, $\beta$ é o coeficiente de inclinação de reta e $\alpha$ é o intercepto, ou seja, o valor de $Y$ quando $X$ for zero (Sokal \& Rohlf, 1995). Nessas regressōes, a variável $X$ correspondeu à variância obtida pela reamostragem concomitante de indivíduos (I) e populações (P). A variável $Y$, por sua vez, correspondeu à soma das variâncias $[\hat{\operatorname{Var}}(\hat{F} ; P)+\hat{\operatorname{Var}}(\hat{F} ; I)]$ estimadas através da reamostragem de indivíduos e populações separadamente.

Foram feitos testes $t$ para verificar se as estimativas dos parâmetros $\beta$ e $\alpha$ ( $b$ e $a$, respectivamente) diferiram de zero $e$ foram construídos intervalos de confiança para $\beta$, com a finalidade de verificar se tal parâmetro diferiu de 1 (Sokal \& Rohlf, 1995). Se $a=0$, se $b \neq 0$ e se $b=1$, a equação de regressão se reduz a $Y=X$ e a aditividade de 
variâncias estimadas pela reamostragem de indivíduos e populações isoladamente fica comprovada.

Como as duas variáveis envolvidas na regressão são aleatórias, poder-se-ia empregar a análise de regressão para modelo aleatório, conhecida como análise de regressão do tipo média geométrica (Sokal \& Rohlf, 1995). No entanto, esses autores mencionam a existência controvérsias quanto ao emprego dessa metodologia. Desse modo, foi empregada a análise de regressão como descrito acima, em concordância com Neter et al. (1990).

\subsubsection{Bootstrap com tamanhos variáveis de amostras}

Nesse caso, as amostras bootstrap tiveram tamanhos variáveis, podendo ser menores ou iguais ao tamanho amostral original. Assim, se por exemplo for considerado um conjunto com cinco populações, foram obtidas amostras bootstrap com tamanhos variando entre duas e cinco populações para verificar a influência do tamanho amostral sobre a magnitude dos desvios-padrão das estimativas dos parâmetros provenientes da reamostragem de populações.

\subsection{Análise hierárquica das estimativas bootstrap de variâncias}

As estimativas das variâncias de $\hat{F}, \hat{f}$ e $\hat{\theta}$, são compostas por vários fatores. Muniz (1994) apresentou estimadores de $F, f, \theta$ e $t$ e de suas respectivas variâncias. No entanto, tais estimadores, além de viesados, apresentaram resultados satisfatórios somente quando as frequuências gênicas são intermediárias $e$ os tamanhos amostrais foram elevados. Weir \& Cockerham (1984) também apresentaram estimadores para $F, f$ e $\theta$ e suas variâncias, porém, considerando apenas um loco.

Assim, dada a dificuldade de obter expressões explícitas das variâncias das estimativas desses parâmetros, no presente trabalho foi adotada metodologia semelhante àquela utilizada por Tivang et al. (1994) e por Halldén et al. (1994) visando determinar quais os número mínimos de locos, indivíduos e populações que seriam necessários para obter uma dada magnitude de desvio-padrão dessas estimativas, para cada conjunto de 
dados avaliados. Esse procedimento foi empregado com o objetivo de inferir sobre estratégias de amostragem. Assim, foram realizadas reamostragens bootstrap com tamanhos de amostra variando de 1 ao número máximo de locos por conjunto, de dois ao número máximo de indivíduos da menor população em cada conjunto $e$ de dois ao número máximo de populações em cada conjunto. $\mathrm{O}$ número mínimo de populações $e$ indivíduos considerados na reamostragem variável foi dois, uma vez que com menos de dois indivíduos e de duas populações os parâmetros de $F, f$ e $\theta$ não podem ser estimados.

Portanto, foram realizados três tipos de reamostragem bootstrap variando tamanhos amostrais: variando o número de locos, sendo fixos o número de populações $e$ o número de indivíduos por população; variando o número de indivíduos, sendo fixos os números de locos e de populações; variando o número de populações, sendo que o número de locos e indivíduos se mantiveram fixos. Deve-se esclarecer que, quando fixos, o número de locos, o número de populações e o número de indivíduos foram, respectivamente, o número total de locos, o número total de populações e o número máximo de indivíduos da menor população do conjunto de dados sob estudo.

Diferindo dos trabalhos de Tivang et al. (1994) e de Hállden et al. (1994), ao invés de calcular o coeficiente de variação associado às estimativas dos parâmetros para cada tamanho de amostra, foram obtidos os desvios-padrão. Optou-se por utilizar esta medida uma vez que o coeficiente de variação depende da média e da variância amostrais (Sokal \& Rohlf, 1995), o que pode ser desvantajoso. Por exemplo, estimativas de parâmetros como $\theta$ tendem a ser baixas, às vezes próximas de zero. Nesse caso, o coeficiente de variação tenderia ao infinito $e$ assim, sua aplicação não seria adequada neste estudo.

O número de amostras bootstraps para cada tamanho de amostra foi de 1.000 . Dessa forma, para um conjunto com 41 indivíduos, foram obtidas 40.000 amostras bootstrap, 1.000 para cada tamanho de amostra, o qual variou de 2 a 41 indivíduos.

A partir destas reamostragens os parâmetros $F, f$ e $\theta$, bem como suas variâncias foram estimados em função da fonte de variação reamostrada. Em seguida, foram construídos gráficos cujo eixo das abscissas representou o número de populações (ou de indivíduos ou de locos) e o das ordenadas o desvio-padrão associado a cada estimativa do 
parâmetro. A Figura 2 mostra, como ilustração, um gráfico desse tipo quando foram reamostradas populações e o parâmetro estudado foi $F$.

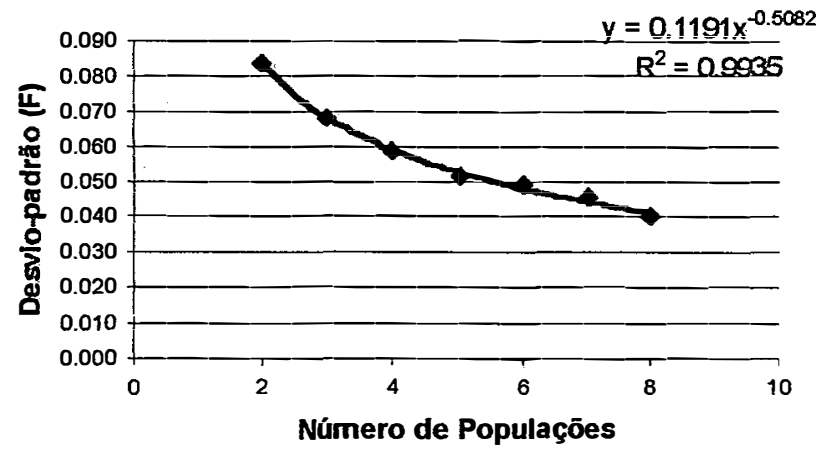

Figura 2. Estimativas do desvio-padrão de $\hat{F}$, obtidas a partir de 1.000 amostras bootstrap, para cada número de populações avaliado.

Para cada estimativa de parâmetro foi admitido erro máximo de 0,02 a ela associada. Este valor foi determinado em função das magnitudes de $\hat{F}, \hat{f}$ e $\hat{\theta}$ freqüentemente encontradas na literatura. Dessa forma, se forem feitas reamostragens de populaçōes, por exemplo, o número suficiente de populações a serem amostradas em estudos futuros é aquele a partir do qual o desvio-padrão da estimativa do parâmetro de interesse é menor ou igual a 0,02 . Este número pode ser estimado a partir da equação de regressão do tipo potência obtida em cada caso, substituindo a variável resposta $y$ pelo valor 0,02 .

Para o exemplo da Figura 1, observa-se que, mesmo usando o número máximo de populações (8) a estimativa do desvio-padrão associado a $\hat{F}$ foi superior a 0,02 . Ou seja, o número de populações amostrado não foi suficiente para obter estimativas de $F$ com a magnitude de erro desejável. A partir da equação de regressão deste exemplo, o número de populações necessário para obter estimativa de desvio-padrão menor ou igual ao valor estipulado é 34. Embora devam ser considerados os riscos decorrentes de extrapolações, esta é uma maneira de se ter uma razoável aproximação do número de populações que deveria ser amostrado. Obviamente, nem sempre é possível aumentar o tamanho da 
amostra, sendo que o número de populações na natureza, às vezes, é bem menor do que o valor que deveria ser amostrado.

Com base na metodologia proposta, foi possivel determinar estratégias de amostragem adequadas para cada um dos conjuntos de dados avaliados.

As reamostragens $e$ cálculos das estimativas dos parâmetros $e$ de suas variâncias associadas foram realizadas usando o programa computacional EGBV (Coelho, 2000b).

\subsubsection{Análise fatorial das estimativas bootstrap de variâncias}

Uma outra abordagem utilizada para a determinação de estratégias de amostragem foi realizar reamostragens variando o número de níveis dos fatores populações $e$ indivíduos ao mesmo tempo e, para cada estimativa dos parâmetros de interesse, obter estimativas de variância para as diversas combinações entre os níveis desses fatores. Assim, foram feitas 1.000 reamostragens para estimar os parâmetros $e$ a suas estimativas de variância associadas, dentro de cada combinação possível entre números de populações $e$ indivíduos. Para cada conjunto, tais combinações variaram desde a combinação entre duas populações e dois indivíduos por população até a combinação dada pelo número máximo de populações e o número máximo de indivíduos da menor população. Foram feitas cinco repetições desse processo, de modo que foram obtidas cinco estimativas das variâncias das estimativas dos parâmetros para cada combinação. Para que o conjunto fosse avaliado de acordo com essa metodologia, teve que apresentar no mínimo três populações $e$ três indivíduos por população.

Os níveis dos fatores variaram de dois ao número máximo de indivíduos para a menor população de cada conjunto de dados e de dois ao número máximo de populações por conjunto de dados. As reamostragens e estimativas dos parâmetros e de suas variâncias associadas foram realizadas usando o programa computacional EGBV (Coelho, 2000b).

A análise de variância foi realizada de acordo com uma estrutura fatorial, para $\hat{F}$, $\hat{f}$ e $\hat{\theta}$, em todos os conjuntos de dados reais utilizados, exceto o de Sebbenn et al. (s.d.), por apresentar somente duas populações. Como o desdobramento da soma de quadrados não é ortogonal, as estimativas de quadrados médios não são independentes. No entanto, 
segundo Sokal \& Rohlf (1995), é possível obter o coeficiente de determinação $\left(R^{2}\right)$ para cada fonte de variação, bastando dividir a soma de quadrados $(S Q)$ da fonte de variação de cada fator, e também da interação entre fatores, pela soma de quadrados total $\left(S Q_{\text {Total }}\right)$. Fontes de variação com valores mais elevados de $R^{2}$ são mais influentes na estimação do parâmetro sob estudo, ou seja, se a fonte de variação de indivíduos, por exemplos, apresentar maior $R^{2}$ que populações, isso indica que um número maior de indivíduos deve ser considerado em amostragens posteriores para tal espécie, pois maiores erros associados às estimativas dos parâmetros são provenientes dessa fonte de variação.

No quadro da análise de variância (Tabela 6), para um dado parâmetro ( $F$, por exemplo), as fontes de variação são população $(\mathrm{P})$, indivíduos (I), interação entre populações e indivíduos $(\mathrm{PxI})$ e o resíduo. O número de tamanhos de populações e de indivíduos e o número de repetições são $p, i$ e $r$, respectivamente.

Tabela 6. Análise de variância de $\hat{\operatorname{Var}}(\hat{F} ; P, I)$ no esquema fatorial.

\begin{tabular}{cccc}
\hline Fonte de Variação & $G L$ & $S Q$ & $R^{2}$ \\
\hline $\mathrm{P}$ & $(p-1)$ & $S Q_{P}$ & $S Q_{P} / S Q_{\text {Total }}$ \\
$\mathrm{I}$ & $(i-1)$ & $S Q_{I}$ & $S Q_{I} / S Q_{\text {Total }}$ \\
PxI & $(p-1)(i-1)$ & $S Q_{P x I}$ & $S Q_{P x I} / S Q_{\text {Total }}$ \\
Resíduo & $p i(r-1)$ & $S Q_{\text {Residuo }}$ & - \\
\hline TOTAL & pir-1 & $S Q_{\text {Total }}$ & - \\
\hline
\end{tabular}




\section{RESULTADOS E DISCUSSÃO}

\subsection{Método de reamostragem}

$\mathrm{Na}$ literatura, há pouca informação sobre como reamostrar dados genéticos, considerando vários níveis amostrais. Assim, o primeiro resultado obtido nesta pesquisa refere-se aos métodos de reamostragem propostos no item 3.2.2. O mais comum na literatura é encontrar reamostragens bootstrap apenas sobre locos, ou sobre indivíduos (Van Dongen, 1995) ou, raramente sobre dois níveis, como no caso de Petit \& Pons (1998) que reamostraram populações e indivíduos, de maneira separada e conjuntamente.

Neste trabalho, no entanto, obtiveram-se, pelo método de reamostragem bootstrap, as estimativas dos parâmetros populacionais de interesse $e$ de seus erros-padrão associados, em função dos níveis de reamostragem considerados. Com isso, foi possivel identificar quais fontes mais contribuíram para a magnitude das estimativas dos parâmetros estudados para os conjuntos de dados avaliados.

Também foram obtidas amostras bootstrap variando o número de níveis dos fatores reamostrados, de modo semelhante aos procedimentos adotados por Tivang et al. (1994) e Hállden et al. (1994). No entanto, estes autores variaram o número de marcas apenas, enquanto neste trabalho, foram feitos bootstraps variando o número de locos, indivíduos $e$ populações isoladamente, permitindo inferir sobre estratégias de amostragem. Realizaramse também reamostragens variando concomitantemente o número de indivíduos $e$ de populações, sendo que as estimativas das variâncias associadas aos parâmetros de interesse puderam ser analisadas sob esquema fatorial. Nesse ponto, deve ficar claro que a reamostragem em si obedeceu à estrutura hierárquica presente na natureza, ou seja, populações $e$ indivíduos dentro de populações. Apenas as estimativas das variâncias dos parâmetros é que foram analisadas sob esquema fatorial. 


\subsection{Bootstrap com tamanhos constantes de amostras}

Como descrito no item 3.2.2.1., as amostras bootstrap foram obtidas, inicialmente, respeitando o tamanho amostral original. Com isso, puderam ser obtidas as estimativas pontuais dos parâmetros populacionais de interesse e de suas variâncias, além do intervalo de confiança para os mesmos.

\subsubsection{Aditividade de variâncias}

Considerando os dados reais e visando verificar se as estimativas das variâncias de

$\dot{\hat{F}}, \hat{f}$ e $\hat{\theta}$, obtidas em função da reamostragem de indivíduos e de populaçōes, podem ser somadas, foram comparadas as estimativas observadas e esperadas dessas variância, de acordo com o item 3.2.2.1., para esses parâmetros, considerados individualmente ou em conjunto. Verificou-se que os valores observados e esperados dessas variâncias estimadas foram bastante próximos entre si (Tabela 7). No caso dos dados de Seoane (1998), o descarte de bootstraps não deve ter contibuído de maneira significativa no aumento da diferença entre tais estimativas pois foi muito pequeno $(1,1 \%$ e $1,4 \%$, para a reamostragem de indivíduos e de indivíduos e populações conjuntamente). No entanto, a ocorrência desses descartes deve ter alterado a precisão das estimativas dos parâmetros e de suas variâncias em comparação com as obtidas na ausência de descarte. Esses descartes ocorrem porque algumas amostras bootstrap possuem configuração de elementos que impede que os parâmetros sejam estimados. Por exemplo, pode haver um denominador igual a zero. 
Tabela 7. Valores das estimativas das variâncias bootstrap das estimativas de ${ }^{\mathrm{a}} F,{ }^{\mathrm{b}} f e^{\mathrm{c}} \theta$, oriundas da reamostragem de locos $(\mathrm{L})$, indivíduos $(\mathrm{I})$, populações $(\mathrm{P})$, indivíduos $e$ populações concomitantemente (I e $\mathrm{P}$ ) e de indivíduos e populações isoladamente (I+P), para os diversos autores.

\begin{tabular}{|c|c|c|c|c|c|}
\hline Autor & $\begin{array}{c}\text { Níveis de } \\
\text { reamostragem }\end{array}$ & n.d.b. ${ }^{+}$ & $\overline{\hat{V}(\hat{F})}$ & $\hat{V}(\hat{f})$ & $\hat{V}\left(\hat{\theta}_{P}\right)$ \\
\hline \multirow[t]{5}{*}{ Reis (1996) } & $\mathrm{L}$ & 0 & 0,001642 & 0,001492 & 0,000046 \\
\hline & I & 0 & 0,000538 & 0,000598 & 0,000050 \\
\hline & $\mathrm{P}$ & 0 & 0,001603 & 0,001369 & 0,000037 \\
\hline & I, P (observ.) & 0 & 0,002164 & 0,001974 & 0,000088 \\
\hline & $\mathrm{I}+\mathrm{P}$ (esper.) & - & 0,002141 & 0,001967 & 0,000087 \\
\hline \multirow[t]{5}{*}{ Seoane (1998) } & $\mathrm{L}$ & 0 & 0,006780 & 0,009041 & 0,002209 \\
\hline & I & 11 & 0,002099 & 0,002923 & 0,000595 \\
\hline & $\mathrm{P}$ & 0 & 0,003597 & 0,003056 & 0,000973 \\
\hline & I, P (observ.) & 14 & 0,005836 & 0,005931 & 0,001419 \\
\hline & $\mathrm{I}+\mathrm{P}$ (esper.) & - & 0,005696 & 0,005979 & 0,001569 \\
\hline Telles \& Coelho & $\mathrm{L}$ & 0 & 0,006047 & 0,003330 & 0,001543 \\
\hline \multirow[t]{4}{*}{ (1998) } & I & 0 & 0,001255 & 0,001839 & 0,000334 \\
\hline & $\mathrm{P}$ & 0 & 0,003538 & 0,001662 & 0,001971 \\
\hline & I, P (observ.) & 0 & 0,004931 & 0,003534 & 0,002281 \\
\hline & $\mathrm{I}+\mathrm{P}$ (esper.) & - & 0,004793 & 0,003501 & 0,002306 \\
\hline \multirow[t]{5}{*}{ Ciampi (1999) } & $\mathrm{L}$ & 0 & 0,000899 & 0,001037 & 0,000013 \\
\hline & I & 0 & 0,000148 & 0,000183 & 0,000029 \\
\hline & $\mathrm{P}$ & 0 & 0,000425 & 0,000357 & 0,000168 \\
\hline & I e $\mathrm{P}$ (observ.) & 0 & 0,000578 & 0,000533 & 0,000186 \\
\hline & $\mathrm{I}+\mathrm{P}$ (esper.) & - & 0,000573 & 0,000540 & 0,000197 \\
\hline \multirow[t]{5}{*}{ Auler (2000) } & $\mathrm{L}$ & 0 & 0,003428 & 0,003553 & 0,000011 \\
\hline & I & 0 & 0,000851 & 0,000819 & 0,000080 \\
\hline & $\mathrm{P}$ & 0 & 0,002636 & 0,002673 & 0,000058 \\
\hline & I e $\mathrm{P}$ (observ.) & 0 & 0,003491 & 0,003478 & 0,000139 \\
\hline & $\mathrm{I}+\mathrm{P}$ (esper.) & - & 0,003487 & 0,003492 & 0,000139 \\
\hline \multirow[t]{5}{*}{ Sebbenn et al. (s.d.) } & $\mathrm{L}$ & 0 & 0,003290 & 0,002273 & 0,000608 \\
\hline & I & 0 & 0,000930 & 0,000695 & 0,000340 \\
\hline & $\mathrm{P}$ & 0 & 0,001636 & 0,000070 & 0,001813 \\
\hline & Ie $\mathrm{P}$ (observ.) & 0 & 0,002453 & 0,000788 & 0,001945 \\
\hline & I+P (esper.) & -- & 0,002566 & 0,000765 & 0,002153 \\
\hline
\end{tabular}

${ }^{+}$número de bootstraps descartedos; 'índice de fixação total; 'índice de fixação dentro das populaçóes; 'Grau de divergência entre populações.

Regressōes lineares entre os valores observados e esperados das estimativas das variâncias foram feitas $e$ o ajuste dessas regressões foi testado através de análises de variância. Verificou-se que, em todos as situações, o modelo de regressão linear se ajustou bem ao dados. Em todos os casos, as estimativas dos coeficientes de inclinação das retas foram significativos, mas as dos interceptos não diferiram de zero (Tabela 8, Figura 3). 
Nota-se que, para todas as regressōes, os coeficientes de inclinação da reta não diferiram de 1 , o que pode ser observalo pelos intervalos de confiança para $\beta$ (Tabela 8).

Tabela 8. Análises da regressão entre os valores observados e esperados das estimativas das variâncias de ${ }^{\mathrm{a}} \hat{F},{ }^{\mathrm{b}} \hat{f} \mathrm{e}^{\mathrm{c}} \hat{\boldsymbol{\theta}}$, individual e conjuntamente. Coeficientes de regressão linear $(\beta)$ e seus respectivos intervalos de confiança (I.C.) e intercepto $(\alpha)$. Dados de diversos autores.

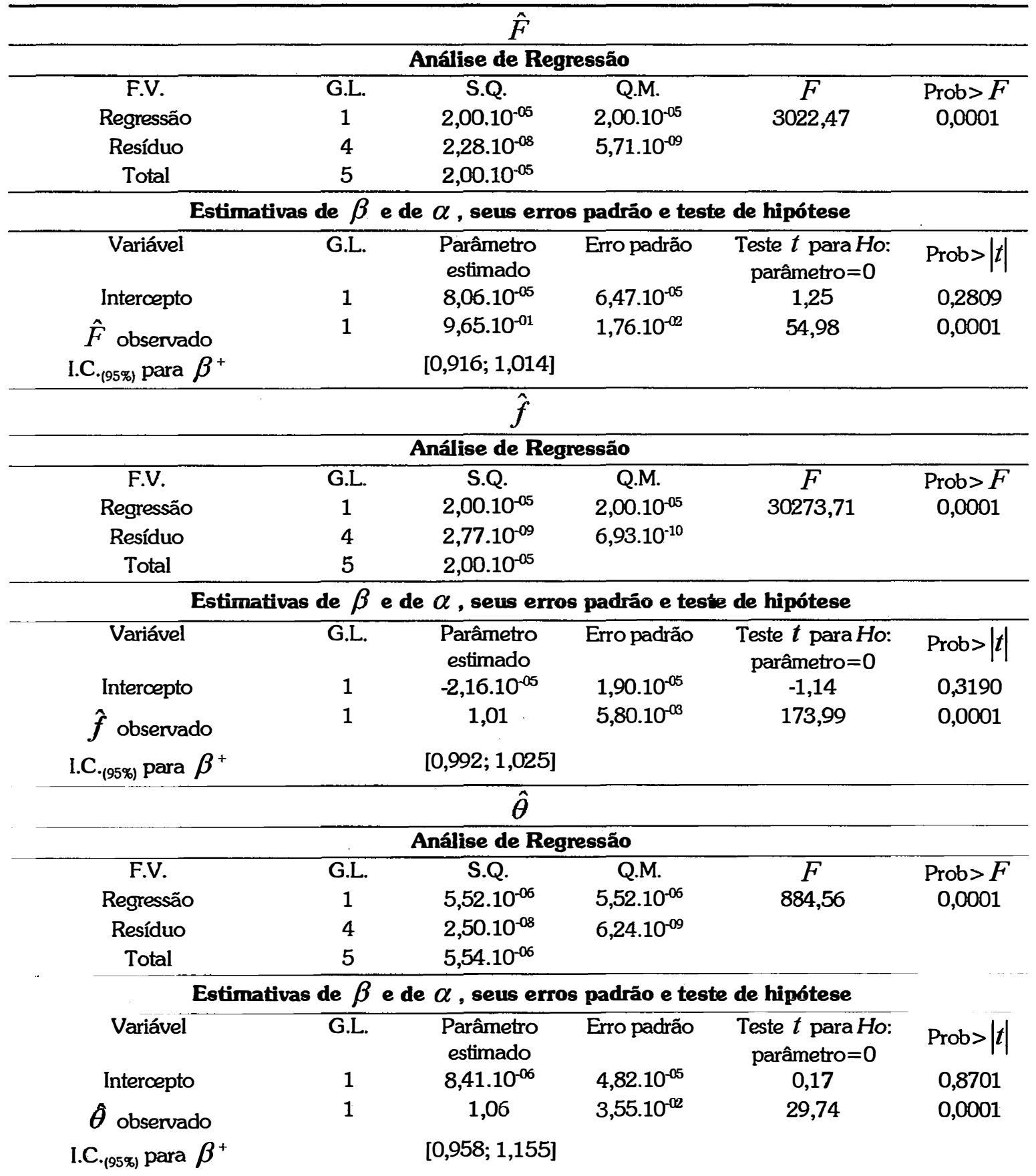


Continuação da Tabela 8. Análises da regressão entre os valores observados e esperados das estimativas das variâncias $\mathrm{de}^{\mathrm{a}} \hat{\boldsymbol{F}},{ }^{\mathrm{b}} \hat{\boldsymbol{f}} \mathrm{e}^{\mathrm{c}} \hat{\boldsymbol{\theta}}$, individual $e$ conjuntamente. Coeficientes de regressão $(\beta)$ e seus respectivos intervalos de confiança (I.C.) e intercepto $(\alpha)$. Dados de diversos autores.

\begin{tabular}{|c|c|c|c|c|c|}
\hline \multicolumn{6}{|c|}{$\hat{F}, \hat{f}$ e $\hat{\theta}$ conjuntamente } \\
\hline \multicolumn{6}{|c|}{ Análise de Regressão } \\
\hline F.V. & G.L. & S.Q. & Q.M. & $F$ & Prob $>F$ \\
\hline Regressão & 1 & $6,00.10^{-05}$ & $6,00.10^{-05}$ & 8740,26 & 0,0001 \\
\hline Resíduo & 16 & $1,07.10^{-07}$ & $6,71 \cdot 10^{-09}$ & & \\
\hline Total & 17 & $6,00 \cdot 10^{-05}$ & & & \\
\hline \multicolumn{6}{|c|}{ Estimativas de $\beta$ e de $\alpha$, seus erros padrão e teste de hipótese } \\
\hline Variável & G.L. & $\begin{array}{l}\text { Parâmetro } \\
\text { estimado }\end{array}$ & Erro padrão & $\begin{array}{c}\text { Teste } t \text { para Ho: } \\
\text { parâmetro }=0\end{array}$ & Prob $>|t|$ \\
\hline Intercepto & 1 & $4,54.10^{-05}$ & $3,12 \mathrm{E}^{05}$ & 1,46 & 0,1641 \\
\hline$(\hat{F}, \hat{f}$ e $\hat{\theta})$ observado & 1 & $9,85 \cdot 10^{-01}$ & $1,05.10^{-02}$ & 93,49 & 0,0001 \\
\hline I.C. ${ }_{(95 \%)}$ para $\beta^{+}$ & & {$[0,963 ; 1,008$} & & & \\
\hline
\end{tabular}

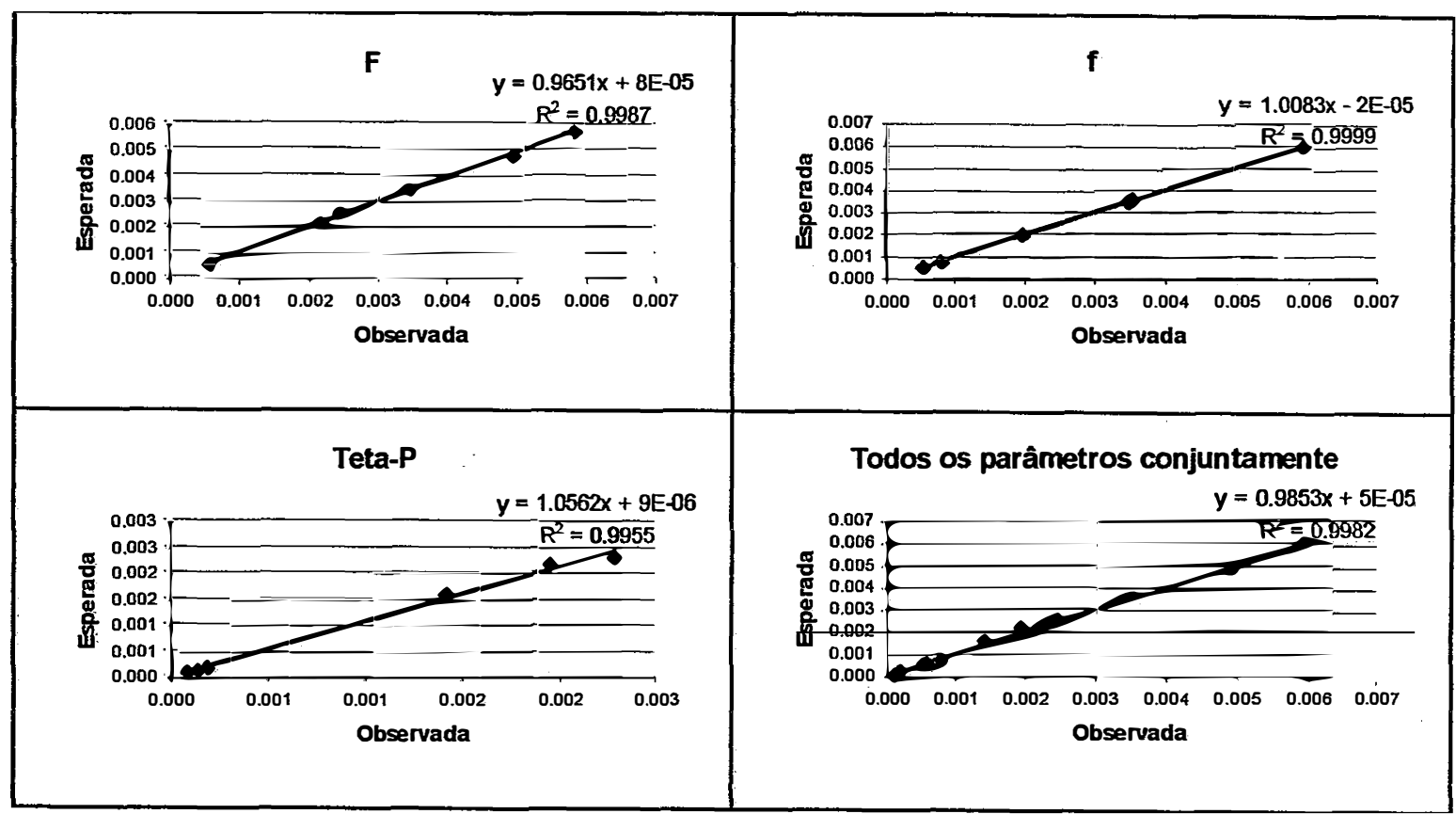

Figura 3. Regressōes lineares entre as estimativas das variâncias observadas e esperadas das estimativas do índice de fixação geral $(F)$, do índice de fixação dentro de populações $(f)$ e da divergência entre populações $(\theta)$, considerados de forma individual $e$ conjuntamente. Dados de diversos autores. 
Em vista dos resultados obtidos, para todos os três parâmetros em questão, avaliados isolada e conjuntamente, pode-se concluir que as estimativas das variâncias das estimativas desses parâmetros oriundas da reamostragem de indivíduos e de populações, podem ser somadas para obter a variância total devida a essas duas fontes de variação conjuntamente, sendo portanto confirmada a aditividade de variâncias. Desse modo, as equações de regressão podem ser escritas como $Y=X$, e a aditividade das variâncias fica comprovada para os conjuntos de dados reais estudados.

Esse mesmo comportamento foi observado quando foram analisados os conjuntos de dados simulados. Nesse caso, os valores observados $e$ esperados das estimativas das variância de $\hat{F}, \hat{f}$ e $\hat{\theta}$, avaliados isoladamente e em conjunto, foram ainda mais semelhantes do que nos dados reais (Tabela 9). Isso provavelmente ocorreu por causa do elevado número de populações (30 por conjunto) e de indivíduos (100 por população) considerados. Além disso, em nenhum dos tipos de reamostragem realizados nestes conjuntos ocorreram descartes de bootstrap. 
Tabela 9. Valores das estimativas das variâncias bootstrap das estimativas de ${ }^{\mathrm{a}} \boldsymbol{F},{ }^{\mathrm{b}} f \mathrm{e}^{\mathrm{c}} \boldsymbol{\theta}$, oriundas da reamostragem de locos $(\mathrm{L})$, indivíduos $(\mathrm{I})$, populações $(\mathrm{P})$, indivíduos $e$ populações concomitantemente (I e P) e de indivíduos e populações isoladamente (I+P). Dados simulados. (Valores devem ser multiplicados por $10^{-5}$ ).

\begin{tabular}{|c|c|c|c|c|c|c|c|c|c|c|c|c|c|}
\hline \multicolumn{2}{|c|}{ Populaçōes } & \multicolumn{4}{|c|}{$F$} & \multicolumn{4}{|c|}{ 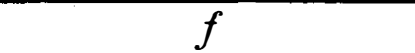 } & \multicolumn{4}{|c|}{$\theta$} \\
\hline$s^{+}$ & $t^{++}$ & $\mathbf{P}$ & I & P e I & $\mathbf{P}+\mathbf{I}$ & $\mathbf{P}$ & I & P eI & $P+I$ & $\mathbf{P}$ & I & P e I & $\overline{\mathbf{P}+I}$ \\
\hline 0,0 & 100 & 5,34 & 3,48 & 8,85 & 8,82 & 3,96 & 3,44 & 7,49 & 7,40 & 1,29 & 0,33 & 1,64 & 1,62 \\
\hline 0,0 & 200 & 7,61 & 3,54 & 11,14 & 11,15 & 3,29 & 3,80 & 7,13 & 7,09 & 4,83 & 0,56 & 5,38 & 5,38 \\
\hline 0,0 & 300 & 5,47 & 3,57 & 9,11 & 9,04 & 2,78 & 4,00 & 6,76 & 6,79 & 4,57 & 0,63 & 5,09 & 5,20 \\
\hline 0,0 & 400 & 18,36 & 3,58 & 22,61 & 21,95 & 3,51 & 4,13 & 7,63 & 7,64 & 14,68 & 0,76 & 15,78 & 15,44 \\
\hline 0,0 & 500 & 20,80 & 3,65 & 23,11 & 24,45 & 4,48 & 4,36 & 8,53 & 8,84 & 18,91 & 0,84 & 18,70 & 19,75 \\
\hline 0,2 & 100 & 5,11 & 4,72 & 10,15 & 9,83 & 3,98 & 5,13 & 9,44 & 9,11 & 1,79 & 0,40 & 2,21 & 2,20 \\
\hline 0,2 & 200 & 7,25 & 4,66 & 11,92 & 11,92 & 4,95 & 5,34 & 10,26 & 10,29 & 4,35 & 0,64 & 4,98 & 4,99 \\
\hline 0,2 & 300 & 13,17 & 4,42 & 17,75 & 17,59 & 6,28 & 5,60 & 11,82 & 11,89 & 8,98 & 0,72 & 9,62 & 9,70 \\
\hline 0,2 & 400 & 22,20 & 4,52 & 26,64 & 26,73 & 6,17 & 6,15 & 12,33 & 12,33 & 23,44 & 0,85 & 24,03 & 24,29 \\
\hline 0,2 & 500 & 42,02 & 4,23 & 46,91 & 46,25 & 5,74 & 6,39 & 12,18 & 12,13 & 43,38 & 0,96 & 44,48 & 44,35 \\
\hline 0,4 & 100 & 8,02 & 6,10 & 14,38 & 14,12 & 7,03 & 6,84 & 14,26 & 13,86 & 1,22 & 0,51 & 1,68 & 1,73 \\
\hline 0,4 & 200 & 8,88 & 5,76 & 14,65 & 14,65 & 6,43 & 7,16 & 13,31 & 13,59 & 7,27 & 0,81 & 8,06 & 8,08 \\
\hline 0,4 & 300 & 12,93 & 5,36 & 19,29 & 18,30 & 10,67 & 7,35 & 18,59 & 18,03 & 11,17 & 1,01 & 12,59 & 12,18 \\
\hline 0,4 & 400 & 13,23 & 5,58 & 5,58 & 18,81 & 7,84 & 8,16 & 8,16 & 16,00 & 19,17 & 0,95 & 0,95 & 20,11 \\
\hline 0,4 & 500 & 23,98 & 4,97 & 28,19 & 28,95 & 9,26 & 7,72 & 16,97 & 16,98 & 28,64 & 1,05 & 28,68 & 29,69 \\
\hline 0,6 & 100 & 8,99 & 6,77 & 15,68 & 15,75 & 9,24 & 7,74 & 17,18 & 16,98 & 3,67 & 0,66 & 4,30 & 4,33 \\
\hline 0,6 & 200 & 6,72 & 6,23 & 13,16 & 12,95 & 5,91 & 8,40 & 14,26 & 14,30 & 10,50 & 1,00 & 11,44 & 11,50 \\
\hline 0,6 & 300 & 10,24 & 5,74 & 16,22 & 15,98 & 10,95 & 8,52 & 19,63 & 19,47 & 9,81 & 1,11 & 10,57 & 10,92 \\
\hline 0,6 & 400 & 15,32 & 5,26 & 20,58 & 20,59 & 11,45 & 8,58 & 19,86 & 20,03 & 27,29 & 1,20 & 29,04 & 28,49 \\
\hline 0,6 & 500 & 15,95 & 4,67 & 21,39 & 20,62 & 7,23 & 8,64 & 16,53 & 15,87 & 33,59 & 1,31 & 34,94 & 34,90 \\
\hline 0,8 & 100 & 5,92 & 5,15 & 11,31 & 11,07 & 6,91 & 6,33 & 13,62 & 13,24 & 3,98 & 0,94 & 5,01 & 4,91 \\
\hline 0,8 & 200 & 6,10 & 5,13 & 11,05 & 11,22 & 6,27 & 7,25 & 13,26 & 13,52 & 7,89 & 1,30 & 9,11 & 9,19 \\
\hline 0,8 & 300 & 4,77 & 4,30 & 9,29 & 9,08 & 4,35 & 7,38 & 11,74 & 11,72 & 21,83 & 1,51 & 23,66 & 23,34 \\
\hline 0,8 & 400 & 9,50 & 3,84 & 13,55 & 13,34 & 8,82 & 8,00 & 16,95 & 16,82 & 37,43 & 1,62 & 38,75 & 39,05 \\
\hline 0,8 & 500 & 7,46 & 3,14 & 10,91 & 10,60 & 8,77 & 7,85 & 16,84 & 16,62 & 41,64 & 1,62 & 42,01 & 43,26 \\
\hline
\end{tabular}

+Taxa natural de autofecundação $(s) ;{ }^{++}$Número de gerações $(t)$; 'indice de fixação total; bíndice de fixação dentro das populações; 'Grau de divergência entre populações.

Os resultados com as populações simuladas foram semelhantes aos obtidos com dados reais. Em todas as situações, o modelo de regressão linear se ajustou aos dados (Tabela 10 e Figura 4) e as estimativas do coeficiente de inclinação da reta diferiram significativamente de zero, enquanto que $e$ as estimativas dos interceptos não diferiram desse valor. Além disso, ao observar os intervalos de confiança construídos para os coeficiente de inclinação das retas, verificou-se que esse coeficiente não diferiu de $1 \mathrm{em}$ nenhum dos casos (Tabela 10). Assim, as equações de regressão podem ser reduzidas a $Y=X$ e a aditividade de variâncias fica comprovada também a partir de simulações. 
Tabela 10. Análises da regressão entre os valores observados e esperados das estimativas das variâncias de ${ }^{\mathrm{a}} \hat{F},{ }^{\mathrm{b}} \hat{\boldsymbol{f}} \mathrm{e}^{\mathrm{c}} \hat{\boldsymbol{\theta}}$, individual e conjuntamente. Coeficientes de regressão linear $(\beta)$ e seus respectivos intervalos de confiança (I.C.) e intercepto $(\alpha)$. Dados simulados.

\begin{tabular}{|c|c|c|c|c|c|}
\hline \multicolumn{6}{|c|}{$\hat{F}$} \\
\hline \multicolumn{6}{|c|}{ Análise de Regressão } \\
\hline F.V. & G.L. & S.Q. & Q.M. & $F$ & Prob $>F$ \\
\hline Regressão & 1 & $1,66.10^{-7}$ & $1,66.10^{-7}$ & 7365,17 & 0,0001 \\
\hline Resíduo & 23 & $5,17 \cdot 10^{-10}$ & $2,25.10^{-11}$ & & \\
\hline Total & 24 & $1,66.10^{-7}$ & & & \\
\hline \multicolumn{6}{|c|}{ Estimativas de $\beta$ e de $\alpha$, seus erros padrão e teste de hipótese } \\
\hline Variável & G.L. & Parâmetro estimado & Erro padrão & $\begin{array}{c}\text { Teste } t \text { para Ho: } \\
\text { parâmetro }=0\end{array}$ & Prob $>|t|$ \\
\hline Intercepto & 1 & $-1,06.10^{-6}$ & $2,20.10^{-6}$ & $-0,48$ & 0,6360 \\
\hline$\hat{F}$ observado & 1 & $9,98.10^{-1}$ & $1,16.10^{-2}$ & 85,82 & 0,0001 \\
\hline I.C. ${ }_{(95 \%)}$ para $\beta^{+}$ & & {$[0,974 ; 1,022]$} & & & \\
\hline \multicolumn{6}{|c|}{$\hat{f}$} \\
\hline \multicolumn{6}{|c|}{ Análise de Regressão } \\
\hline F.V. & G.L. & S.Q. & Q.M. & $F$ & Prob $>F$ \\
\hline Regressão & 1 & $3,72.10^{-8}$ & $3,72.10^{-8}$ & 7032,53 & 0,0001 \\
\hline Resíduo & 23 & $1,22.10^{-10}$ & $5,29.10^{-12}$ & & \\
\hline Total & 24 & $3,73.10^{-8}$ & & & \\
\hline \multicolumn{6}{|c|}{ Estimativas de $\beta$ e de $\alpha$, seus erros padrão e teste de hipótese } \\
\hline Variável & G.L. & Parâmetro estimado & Erro padrão & $\begin{array}{l}\text { Teste } t \text { para } H o: \\
\text { parâmetro }=0\end{array}$ & Prob $>|t|$ \\
\hline Intercepto & 1 & $1,67.10^{-6}$ & $1,62.10^{-6}$ & 1,03 & 0,3152 \\
\hline$\hat{f}$ observado & 1 & $9,81 \cdot 10^{-1}$ & $1,17.10^{-2}$ & 83,86 & 0,0001 \\
\hline I.C. ${ }_{(95 \%)}$ para $\beta^{+}$ & & {$[0,957 ; 1,005]$} & & & \\
\hline \multicolumn{6}{|c|}{$\hat{\theta}$} \\
\hline \multicolumn{6}{|c|}{ Análise de Regressão } \\
\hline F.V. & G.L. & S.Q. & Q.M. & $F$ & Prob $>F$ \\
\hline Regressão & 1 & $4,34.10^{-7}$ & $4,34.10^{-7}$ & 24118,22 & 0,0001 \\
\hline Resíduo & 23 & $4,14 \cdot 10^{-10}$ & $1,80.10^{-11}$ & & \\
\hline Total & 24 & $4,35.10^{-7}$ & & & \\
\hline
\end{tabular}

Estimativas de $\beta$ e de $\alpha$, seus erros padrão e teste de hipótese

\begin{tabular}{|c|c|c|c|c|c|}
\hline Variável & G.L. & Parâmetro estimado & Erro padrão & $\begin{array}{c}\text { Teste } t \text { para } H o: \\
\text { parâmetro }=0\end{array}$ & Prob $>|t|$ \\
\hline Intercepto & 1 & $-4,71.10^{-7}$ & $1,37.10^{-6}$ & $-0,35$ & 0,7336 \\
\hline$\hat{\theta}$ observado & 1 & 1,01 & $6,50.10^{3}$ & 155,30 & 0,0001 \\
\hline I.C. ${ }_{(95 \%)}$ para $\beta^{+}$ & & {$[0,997 ; 1,023]$} & & & \\
\hline
\end{tabular}


Continuação da Tabela 10. Análises da regressão entre os valores observados e esperados das estimativas das variâncias de ${ }^{\mathrm{a}} \hat{F},{ }^{\mathrm{b}} \hat{f} \mathrm{e}^{\mathrm{c}} \hat{\theta}$, individual e conjuntamente. Coeficientes de regressão $(\beta)$ e seus respectivos intervalos de confiança (I.C.) e intercepto $(\alpha)$. Dados simulados.

\begin{tabular}{cccccc}
\hline \multicolumn{5}{c}{$\hat{F}, \hat{f}$ e $\hat{\theta}$ conjuntamente } \\
\hline Análise de Regressão (xy) \\
\hline F.V. & G.L. & S.Q. & Q.M. & $F$ & Prob $>F$ \\
Regressão & 1 & $6,58.10^{-7}$ & $6,58.10^{-7}$ & 40594,57 & 0,0001 \\
Resíduo & 73 & $1,18.10^{-9}$ & $1,62.10^{-11}$ & \\
Total & 74 & $6,59.10^{-7}$ & & \\
\hline
\end{tabular}

Estimativas de $\beta$ e de $\alpha$, seus erros padráo e teste de hipótese

\begin{tabular}{|c|c|c|c|c|c|}
\hline Variável & G.L. & Parâmetro estimado & Erro padrão & $\begin{array}{c}\text { Teste } t \text { para Ho: } \\
\text { parâmetro }=0\end{array}$ & Prob $>|t|$ \\
\hline Intercepto & 1 & $-1,18.10^{-6}$ & $9,10 \cdot 10^{-7}$ & $-1,30$ & 0,1969 \\
\hline$\hat{F}, \hat{f}$ e $\hat{\theta}$ & 1 & 1,01 & $4,99 \cdot 10^{-3}$ & 201,48 & 0,0001 \\
\hline I.C. ${ }_{(95 \%)}$ para $\beta^{+}$ & & {$[0,995 ; 1,015]$} & & & \\
\hline
\end{tabular}

+Intervalo de confiança para $\beta$ com 0,95 de probabilidade; ${ }^{a}$ estimativa do índice de fixação total; 'estimativa do índice de fixação dentro das populações; 'estimativa do grau de divergência entre populações.

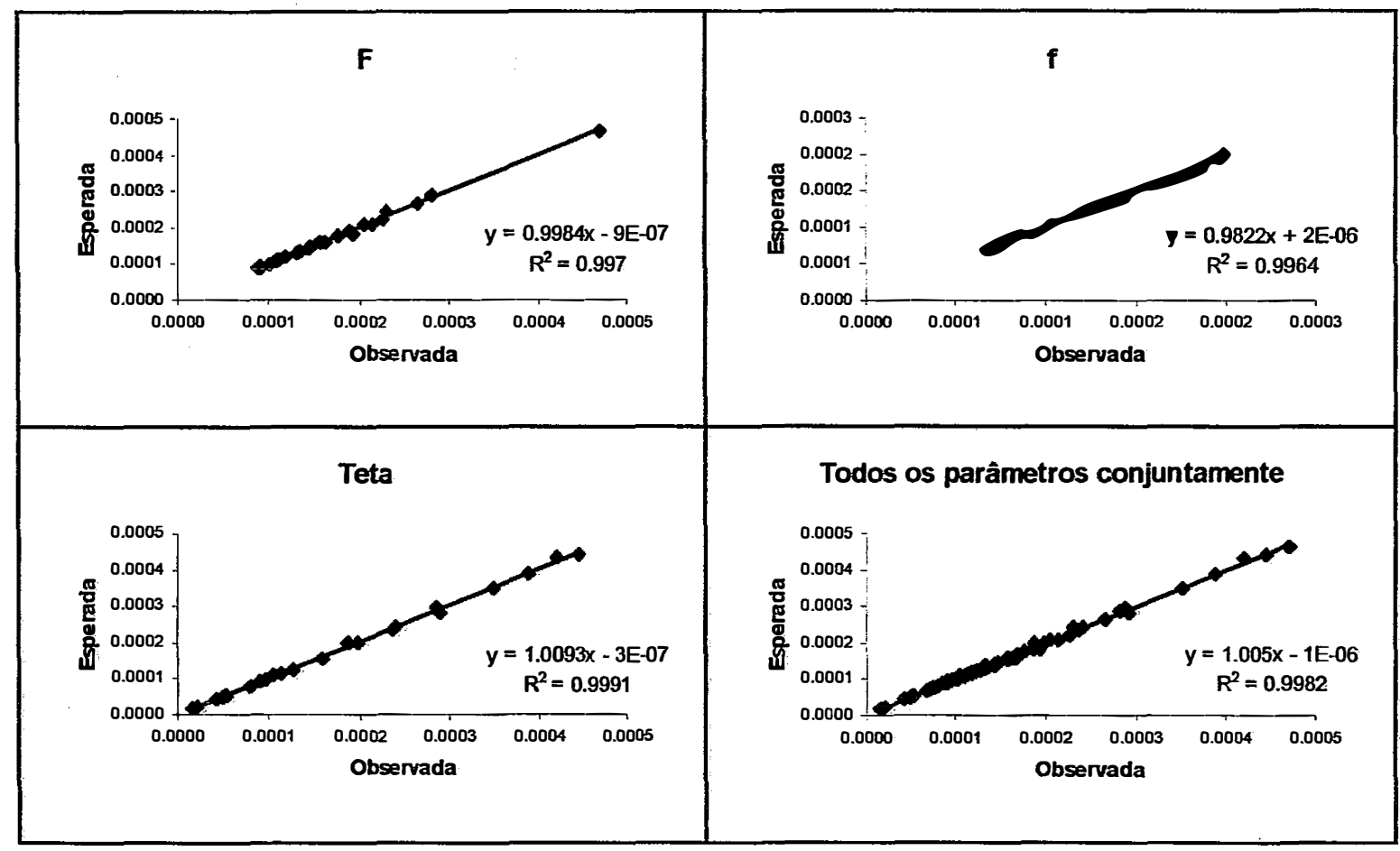

Figura 4. Regressões linear entre as estimativas das variâncias observadas e esperadas das estimativas do índice de fixação geral $(F)$, do índice de fixação dentro de populações $(f)$ e da divergência entre populações $(\theta)$, considerados individual e conjuntamente. Dados simulados. 
Essa aditividade encontrada é vantajosa, por ser muito mais simples trabalhar com modelos aditivos. Uma outra vantagem de ordem prática é a não necessidade de realizar reamostragens simultâneas de indivíduos e populações para obter estimativas de desviospadrão para esses dois níveis de reamostragem simultaneamente. Assim, considerando um conjunto composto por populações e indivíduos, ao somar as estimativas de variância das estimativas dos parâmetros de interesse, calculadas a partir da reamostragem de populações e de indivíduos isoladamente, obtém-se a estimativa da variância de tais parâmetros estimados em função da reamostragens de populações $e$ indivíduos concomitantemente. No entanto, se mesmo assim houver interesse em obter as estimativas pontuais dos parâmetros $e$ de seus intervalos de confiança reamostrando indivíduos $e$ populações conjuntamente, a reamostragem dessas duas fontes de variação concomitantemente é necessária.

Em pesquisas futuras deve-se buscar encontrar os componentes das variâncias intrapopulacional (entre indivíduos) e interpopulacional que compõem as variâncias bootstrap, quando são reamostrados indivíduos e populações ao mesmo tempo. Petit \& Pons (1998), ao estudarem medidas de diversidade de Nei com locos haplóides, verificaram que a variância obtida pela reamostragem conjunta de indivíduos e populações é constituída pelas variâncias total (variâncias intra e interpopulacionais) $e$ intrapopulacional e não somente pela variância total. Isso não pôde ser verificado no presente estudo, pois para tanto, seriam necessárias as expressões explícitas dos componentes das variâncias bootstrap dos parâmetros avaliados.

Ao observar a Tabela 7 , nota-se que, em aproximadamente $78 \%$ dos casos entre as estimativas da variância devida a populações foi superior à estimada para a fonte de variação de indivíduos. Com os conjuntos simulados, esse percentual aumentou para $91 \%$ (Tabela 9). Esses resultados parecem corroborar a pesquisa de Petit \& Pons (1998), ou seja, que as estimativas das variâncias, obtidas quando foram reamostradas populações, devem conter os componentes variância intra e interpopulacionais. Nesse caso, o número de indivíduos deve influenciar na proporção com que o componente de variância de indivíduos participa da composição da variância devida à reamostragem de populações.

Esse comportamento é pertinente, uma vez que ao reamostrar populações, os indivíduos a elas pertencentes também são reamostrados em grupos. Assim, por exemplo, 
se um conjunto de dados é formado pelas populações $1,2,3$ e 4, e se, ao aplicar o método bootstrap para reamostrar populações, uma das amostras obtidas for $1,1,2$ e 4, os indivíduos da população 1 foram considerados duas vezes mas o da população três foram descartados, ficando evidente que, quando são reamostradas populações, os indivíduos a elas pertencentes também o são, porém de forma diferente de quando se faz reamostragem especificamente de indivíduos. No último caso são mantidas as populações originais e os indivíduos são reamostrados sem levar em conta a quais populações eles pertencem.

Porém, ao considerar as variâncias oriundas da reamostragens como quadrados médios e não em termos de seus componentes, comprovou-se que a estimativa da variância de indivíduos e populações concomitantemente é equivalente à soma das variâncias devidas às reamostragens de indivíduos e de populações independentemente.

De qualquer forma, fica evidente a necessidade de especificar claramente que tipo de reamostragem se planeja fazer numa pesquisa, ao empregar a técnica bootstrap. Parece claro, também, que reamostrar somente indivíduos, fixando as populações, não leva a desvios-padrão capazes de mensurar convenientemente os diferentes tipos de erros amostrais inerentes a investigações dessa natureza.

\subsubsection{Estimativas dos parâmetros, desvios-padrão e intervalos de confiança associados e testes de normalidade}

As estimativas bootstrap dos parâmetros $F, f$ e $\theta$ e de suas variâncias foram obtidas a partir da reamostragem de locos, indivíduos, populações $e$ indivíduos $e$ populações conjuntamente (Tabela 11), conforme já exposto na metodologia.

Como a adilividade de variâncias foi comprovada para estes parâmetros, os resultados oriundos da reamostragem conjunta de indivíduos e populações, embora apresentado na referida tabela, não foram considerados na discussão. 
Tabela 11. Estimativas dos parâmetros ${ }^{\mathrm{a}} F,{ }^{\mathrm{b}} f \mathrm{e}^{\mathrm{c}} \boldsymbol{\theta}$ e de suas variâncias bootstrap oriundas da reamostragem de locos (L), indivíduos (I), populações (P), indivíduos $e$ populações concomitantemente (I e P) e variância total $(\mathrm{I}+\mathrm{P})$. Entre parênteses, porcentagem da variância total $(\mathrm{I}+\mathrm{P})$, para os diversos autores.

\begin{tabular}{|c|c|c|c|c|c|c|c|}
\hline \multicolumn{8}{|c|}{ Reis (1996) } \\
\hline & & \multicolumn{3}{|c|}{$\hat{F}$} & \multicolumn{3}{|c|}{$\hat{f}$} \\
\hline Nivel & $\mathrm{nbd}^{+}$ & Estimativa & Variância & I.C. & Estimativa & Variância & I.C. \\
\hline Original & & $-0,028$ & & & $-0,046$ & & \\
\hline L & 0 & $-0,031$ & 0,001642 & {$[-0,110 ; 0,050]$} & $-0,048$ & 0,001492 & {$[-0,120,0,029]$} \\
\hline I & 0 & $-0,028$ & $\begin{array}{l}0,000538 \\
(25,12 \%)\end{array}$ & {$[-0,073 ; 0,018]$} & $-0,067$ & $\begin{array}{l}0,000598 \\
(30,42 \%)\end{array}$ & {$[-0,115 ;-0,019]$} \\
\hline $\mathrm{P}$ & 0 & $-0,033$ & $\begin{array}{l}0,001603 \\
(74,88 \%)\end{array}$ & {$[-0,110 ; 0,047]$} & $-0,046$ & $\begin{array}{l}0,001369 \\
(69,58 \%)\end{array}$ & {$[-0,116 ; 0,029]$} \\
\hline $\mathrm{I}+\mathrm{P}$ & & & $\begin{array}{c}0,002141 \\
(100 \%)\end{array}$ & & & $\begin{array}{c}0,001967 \\
(100 \%)\end{array}$ & \\
\hline Ie $\mathrm{P}$ & 0 & $-0,032$ & 0,002164 & {$[-0,122 ; 0,060]$} & -0.066 & 0,001974 & {$[-0,152 ; 0,023]$} \\
\hline \multicolumn{8}{|c|}{$\hat{\theta}$} \\
\hline Original & & 0,017 & & & & & \\
\hline $\mathrm{L}$ & 0 & 0,017 & 0,000046 & {$[0,005 ; 0,031]$} & & & \\
\hline I & 0 & 0,036 & $\begin{array}{l}0,000050 \\
(57,81 \%)\end{array}$ & {$[0,023 ; 0,051]$} & & & \\
\hline$P$ & 0 & 0,013 & $\begin{array}{l}0,000037 \\
(42,19 \%)\end{array}$ & {$[-0,001 ; 0,022]$} & & & \\
\hline $\mathrm{I}+\mathrm{P}$ & 0 & & $\begin{array}{c}0,000087 \\
(100 \%)\end{array}$ & & & & \\
\hline le $\mathrm{P}$ & 0 & 0,032 & 0,000088 & {$[0,015 ; 0,051]$} & & & \\
\hline & & \multicolumn{5}{|c|}{ Seoane (1998) } & \\
\hline \multicolumn{8}{|c|}{$\hat{F}$} \\
\hline $\begin{array}{l}\text { Nivel } \\
\text { Original }\end{array}$ & nbd & $\begin{array}{c}\text { Estimativa } \\
0.085\end{array}$ & Variância & I.C. & Estimativa & Variância & I.C. \\
\hline $\begin{array}{l}\text { Original } \\
\mathrm{L}\end{array}$ & & 0,085 & & & $-0,018$ & & \\
\hline $\mathrm{L}$ & 0 & 0,090 & 0,006780 & {$[-0,067 ; 0,236]$} & $-0,011$ & 0,009041 & {$[-0,149 ; 0,205]$} \\
\hline I & 11 & 0,084 & $\begin{array}{l}0,002099 \\
(36,85 \%)\end{array}$ & {$[-0,006 ; 0,174]$} & $-0,045$ & $\begin{array}{l}0,002923 \\
(48,89 \%)\end{array}$ & {$[-0,152 ; 0,059]$} \\
\hline$P$ & 0 & 0,055 & $\begin{array}{l}0,003597 \\
(63,15 \%)\end{array}$ & {$[-0,082 ; 0,162]$} & $-0,017$ & $\begin{array}{l}0,003056 \\
(51,11 \%)\end{array}$ & {$[-0,128 ; 0,087]$} \\
\hline $\mathrm{I}+\mathrm{P}$ & & & $\begin{array}{c}0,005696 \\
(100 \%)\end{array}$ & & $\cdot$ & $\begin{array}{c}0,005979 \\
(100 \%)\end{array}$ & \\
\hline IeP & 14 & 0,055 & 0,005836 & {$[-0,101 ; 0,197]$} & $-0,043$ & 0,005931 & {$[-0,194 ; 0,107]$} \\
\hline \multicolumn{8}{|c|}{$\hat{\theta}$} \\
\hline Original & & 0,101 & & & & & \\
\hline L & 0 & 0,099 & 0,002209 & {$[0,017 ; 0,194]$} & & & \\
\hline I & 11 & 0,123 & $\begin{array}{l}0,000595 \\
(37,95 \%)\end{array}$ & {$[0,078 ; 0,174]$} & & & \\
\hline$P$ & 0 & 0,071 & $\begin{array}{l}0,000973 \\
(62,05 \%)\end{array}$ & {$[-0,012 ; 0,102]$} & & & \\
\hline $\mathrm{I}+\mathrm{P}$ & & & $\begin{array}{c}0,001569 \\
(100 \%)\end{array}$ & & & & \\
\hline IeP & 14 & 0,094 & 0,001418 & {$[0,006 ; 0,161]$} & & & \\
\hline
\end{tabular}


Continuação da Tabela 11. Estimativas dos parâmetros ${ }^{\mathrm{a}} F,{ }^{\mathrm{b}} f \mathrm{e}^{\mathrm{c}} \boldsymbol{\theta}$ e de suas variâncias bootstrap oriundas da reamostragem de locos $(\mathrm{L})$, indivíduos $(\mathrm{I})$, populações $(\mathrm{P})$, indivíduos e populaçōes concomitantemente (I e P) e variância total $(I+P)$. Entre parênteses, porcentagem da variância total $(I+P)$, para os diversos autores.

\begin{tabular}{|c|c|c|c|c|c|c|c|}
\hline \multicolumn{8}{|c|}{ Telles \& Coelho (1998) } \\
\hline & & \multicolumn{3}{|c|}{$\hat{F}$} & \multicolumn{3}{|c|}{$\hat{f}$} \\
\hline $\begin{array}{l}\text { Nivel } \\
\text { Original }\end{array}$ & $n b d$ & $\begin{array}{c}\text { Estimativa } \\
0,231\end{array}$ & Variância & I.C. & $\begin{array}{l}\text { Estimativa } \\
0,017\end{array}$ & Variância & I.C. \\
\hline $\mathrm{L}$ & 0 & 0,229 & 0,006047 & {$[0,083 ; 0,372]$} & 0,020 & 0,003330 & {$[-0,081 ; 0,141]$} \\
\hline I & 0 & 0,231 & $\begin{array}{l}0,001255 \\
(26,19 \%)\end{array}$ & {$[0,162 ; 0,300]$} & $-0,001$ & $\begin{array}{l}0,001839 \\
(52,53 \%)\end{array}$ & {$[-0,084 ; 0,083]$} \\
\hline $\mathrm{P}$ & 0 & 0,198 & $\begin{array}{l}0,003538 \\
(73,81 \%)\end{array}$ & {$[0,079 ; 0,310]$} & 0,017 & $\begin{array}{l}0,001662 \\
(47,47 \%)\end{array}$ & {$[-0,062 ; 0,094]$} \\
\hline $\mathrm{I}+\mathrm{P}$ & & & $\begin{array}{c}0,004793 \\
(100 \%)\end{array}$ & & & 0,003501 & \\
\hline IeP & 0 & 0,198661 & 0,004931 & {$[0,058061 ; 0,33008]$} & 0,000637 & 0,003534 & {$[-0,11552 ; 0,11720]$} \\
\hline \multicolumn{8}{|c|}{$\hat{\theta}$} \\
\hline Original & & 0,218 & & & & & \\
\hline $\mathrm{L}$ & 0 & 0,215 & 0,001543 & {$[0,148 ; 0,294]$} & & & \\
\hline $\bar{I}$ & 0 & 0,231 & $\begin{array}{l}0,000334 \\
(14,49 \%)\end{array}$ & {$[0,197 ; 0,268]$} & & & \\
\hline$P$ & 0 & 0,185 & $\begin{array}{l}0,001971 \\
(85,51 \%)\end{array}$ & {$[0,096 ; 0,268]$} & & & \\
\hline $\mathrm{I}+\mathrm{P}$ & & & $\begin{array}{c}0,002306 \\
(100 \%)\end{array}$ & & & & \\
\hline IeP & 0 & 0,198393 & 0,002281 & {$[0,10125 ; 0,28442]$} & & & \\
\hline
\end{tabular}

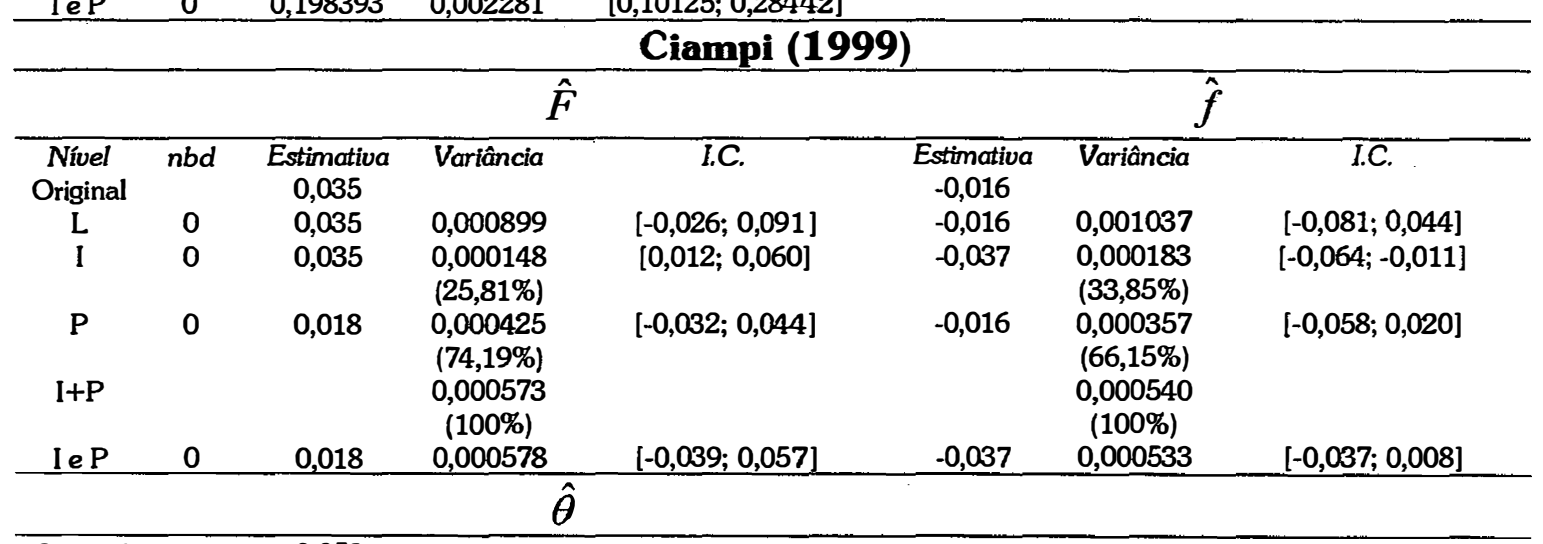

\begin{tabular}{ccccc}
\hline Original & & 0,050 & & \\
L & 0 & 0,050 & 0,000013 & {$[0,043 ; 0,058]$} \\
I & 0 & 0,070 & 0,000029 & {$[0,060 ; 0,081]$} \\
P & 0 & 0,033 & $\begin{array}{c}(14,57 \%) \\
0,000168\end{array}$ & {$[0,009 ; 0,050]$} \\
& & & $\begin{array}{c}(85,43 \%) \\
0,000197\end{array}$ & \\
I+P & & & $(100 \%)$ & \\
I e P & 0 & 0,053 & 0,000186 & {$[0,026 ; 0,074]$}
\end{tabular}


Continuação da Tabela 11. Estimativas dos parâmetros ${ }^{a} F,{ }^{b} f \mathrm{e}^{\mathrm{c}} \boldsymbol{\theta}$ e de suas variâncias bootstrap oriundas da reamostragem de locos (L), indivíduos (I), populações (P), indivíduos e populações concomitantemente (I e P) e variância total (I+P). Entre parênteses, porcentagem da variância total $(\mathrm{I}+\mathrm{P})$, para os diversos autores.

\begin{tabular}{|c|c|c|c|c|c|c|c|}
\hline \multicolumn{8}{|c|}{ Auler (2000) } \\
\hline & & \multicolumn{3}{|c|}{$\hat{F}$} & \multicolumn{3}{|c|}{$\hat{f}$} \\
\hline $\begin{array}{l}\text { Nivel } \\
\text { Original }\end{array}$ & $n b d$ & $\begin{array}{c}\text { Estimativa } \\
0,175\end{array}$ & Variância & I.C. & $\begin{array}{c}\text { Estimativa } \\
0.148\end{array}$ & Variância & I.C. \\
\hline L & 0 & 0,182 & 0,003428 & {$[0,091 ; 0,327]$} & 0,155 & 0,003553 & {$[0,061 ; 0,303]$} \\
\hline I & 0 & 0,174 & $\begin{array}{l}0,000851 \\
(24,42 \%)\end{array}$ & {$[0,117 ; 0,231]$} & 0,134 & $\begin{array}{l}0,000819 \\
(23,45 \%)\end{array}$ & {$[0,077 ; 0,189]$} \\
\hline $\mathrm{P}$ & 0 & 0,173 & $\begin{array}{l}0,002636 \\
(75,58 \%)\end{array}$ & {$[0,073 ; 0,272]$} & 0,151 & $\begin{array}{l}0,002673 \\
(76,55 \%)\end{array}$ & {$[0,052 ; 0,251]$} \\
\hline $\mathrm{I}+\mathrm{P}$ & & & $\begin{array}{c}0,003487 \\
(100 \%)\end{array}$ & & & $\begin{array}{c}0,003492 \\
(100 \%)\end{array}$ & \\
\hline Ie P & 0 & 0,173 & 0,003491 & {$[0,060 ; 0,289]$} & 0,137 & 0,003478 & {$[0,024 ; 0,253]$} \\
\hline \multicolumn{8}{|c|}{$\hat{\theta}$} \\
\hline Original & & 0,031 & & & & & \\
\hline $\mathrm{L}$ & 0 & 0,032 & 0,000011 & {$[0,026 ; 0,039]$} & & & \\
\hline I & 0 & 0,047 & $\begin{array}{l}0,000080 \\
(58,03 \%)\end{array}$ & {$[0,031 ; 0,066]$} & & & \\
\hline $\mathbf{P}$ & 0 & 0,026 & $\begin{array}{l}0,000058 \\
(41,97 \%)\end{array}$ & {$[0,012 ; 0,042]$} & & & \\
\hline $\mathrm{I}+\mathrm{P}$ & & & $\begin{array}{c}0,000139 \\
(100 \%)\end{array}$ & & & & \\
\hline I e P & 0 & 0,042 & 0,000139 & {$[0,022 ; 0,068]$} & & & . \\
\hline
\end{tabular}

\begin{tabular}{|c|c|c|c|c|c|c|c|}
\hline Ie P & 0 & 0,042 & 0,000139 & {$[0,022 ; 0,068]$} & & & \\
\hline \multicolumn{8}{|c|}{ Sebbenn et al. (s.d.) } \\
\hline & & \multicolumn{3}{|c|}{$\hat{F}$} & \multicolumn{3}{|c|}{$\hat{f}$} \\
\hline $\begin{array}{l}\text { Nivel } \\
\text { Original }\end{array}$ & $n b d$ & Estimativa & Variância & I.C. & Estimativa & Variância & I.C. \\
\hline Original & & 0,107 & & & 0,037 & & \\
\hline $\mathrm{L}$ & 0 & 0,108 & 0,003290 & {$[-0,008 ; 0,215]$} & 0,037 & 0,002273 & {$[-0,060 ; 0,126]$} \\
\hline I & 0 & 0,106626 & $\begin{array}{l}0,000930 \\
(36,23 \%)\end{array}$ & {$[0,046 ; 0,165]$} & 0,025 & $\begin{array}{l}0,000695 \\
(90,87 \%)\end{array}$ & {$[-0,028 ; 0,076]$} \\
\hline$P$ & 0 & 0,068 & $\begin{array}{l}0,001636 \\
(63,77 \%)\end{array}$ & {$[0,016 ; 0,107]$} & 0,038 & $\begin{array}{c}0,000070 \\
(9,13 \%)\end{array}$ & {$[0,028 ; 0,051]$} \\
\hline $\mathrm{I}+\mathrm{P}$ & & & $\begin{array}{c}0,002566 \\
(100 \%)\end{array}$ & & & $\begin{array}{c}0,000765 \\
(100 \%)\end{array}$ & \\
\hline le P & 0 & 0,067 & 0,002453 & {$[-0,019 ; 0,156]$} & 0,026 & 0,000788 & {$[-0,028 ; 0,083]$} \\
\hline \multicolumn{8}{|c|}{$\hat{\theta}$} \\
\hline Original & & 0,073 & & & & & \\
\hline L & 0 & 0,074 & 0,000608 & {$[0,028 ; 0,125]$} & & & \\
\hline I & 0 & 0,084 & $\begin{array}{l}0,000340 \\
(15,80 \%)\end{array}$ & {$[0,052 ; 0,124]$} & & & \\
\hline$P$ & 0 & 0,030 & $\begin{array}{l}0,001813 \\
(84,20 \%)\end{array}$ & {$[-0,013 ; 0,073]$} & & & \\
\hline $\mathrm{I}+\mathrm{P}$ & & & $\begin{array}{c}0,002153 \\
(100 \%)\end{array}$ & & & & \\
\hline I e P & 0 & 0,042 & 0,001945 & {$[-0,008 ; 0,116]$} & & & \\
\hline
\end{tabular}


No caso do parâmetro $F$, observou-se que as estimativas $\hat{F}$ obtidas, quando se reamostraram indivíduos, foram as que mais se aproximam da estimativa original, estimada pelo método da análise de variância das freqüências gênicas, porém sem a realização de bootstrap. Isso ocorreu em todos os conjuntos de dados. Por outro lado, as estimativas de $F$ que menos se aproximam da estimativa original foram as obtidas pela reamostragem de populações, que sempre foram subestimadas em comparação à original. Exceção a essa regra ocorreu com o conjunto de Auler (2000), em que a estimativa mais discrepante foi obtida pela reamostragem de locos, sendo superestimada. Esse resultado está relacionado ao fato de este conjunto apresentar número elevado de populações em comparação aos demais.

O que se nota é que, quando o número de populações não é grande, as estimativas dos parâmetros oriundas da reamostragem de populações são subestimadas. Isso é inerente ao procedimento bootstrap. Para exemplificar, considere-se o parâmetro $\theta$ e um conjunto qualquer de dados com somente duas populações, $\mathrm{A}$ e $\mathrm{B}$, e suponha-se ainda que a estimativa original de $\theta$ difira estatisticamente de zero. Quando o método de reamostragem bootstrap é aplicado sobre a fonte de variação de populações, somente três combinações entre populações são possiveis; A e A; A e B; B e B, cujas probabilidades de ocorrência são, 0,25, 0,50 e 0,25, respectivamente. Sabendo-se que amostras bootstrap do tipo $\mathrm{A}$ e $\mathrm{A}$ ou $\mathrm{B}$ e $\mathrm{B}$ produzem estimativas nulas de $\theta$ e que a probabilidade conjunta de ocorrência dessas amostras é 0,50 , conclui-se que em metade das amostras bootstrap a divergência entre populações será nula e conseqüentemente, a estimativa bootstrap de $\theta$ será subestimada, e neste caso, será a metade da estimativa obtida originalmente. Este raciocínio aplica-se a qualquer outro parâmetro estimado a partir de qualquer nível de reamostragem. Como exemplo prático, considere-se o conjunto de Sebbenn et al. (s.d.), para o qual todos os parâmetros foram subestimados quando foram realizadas reamostragens envolvendo a fonte de variação de populações.

Para o parâmetro $f$, as estimativas $\hat{f}$ mais próximas da original foram obtidas pela reamostragem de locos com os dados de Sebbenn et al. (s.d.) e de populações para os demais conjuntos de dados. As estimativas mais discrepantes em comparação às estimativas originais, ocorreram quando foram reamostrados indivíduos, sendo todas subestimativas. Esse comportamento se repetiu em todos os conjuntos. 
No caso de $\theta$, as estimativas mais parecidas com a estimativa original ocorreram quando locos foram reamostrados. Isso ocorreu com todos os conjuntos de dados. Em geral, as estimativas $\hat{\theta}$ mais discordantes em relação à original ocorreram quando foram reamostradas populações, sendo sempre subestimativas, como esperado devido ao problema referido anteriormente. Para os conjuntos de Reis (1996) e de Auler (2000), o coeficiente $\theta$ foi superestimado quando foram reamostrados indivíduos.

$\mathrm{O}$ fato de ser observada tendência a um padrão de comportamento das estimativas oriundas de diferentes tipos de reamostragem em relação às estimativas originais dos parâmetros, pode sugerir a presença de algum viés nas estimativas bootstrap, o que é esperado, pois como mencionado anteriormente, estimativas "plug-in" não estão livres de viéses. No entanto, com o aumento do tamanho amostral, espera-se que o viés tenda a diminuir. Coelho ${ }^{3}$ simulou uma população com freqüências gênicas e genotípicas $e$ índice de fixação $(f)$ conhecidos. Com diferentes tamanhos de amostra, obteve o valor de $\hat{f}$ usando um estimador não-viesado e também o estimador bootstrap. Verificou que para este parâmetro, as estimativas bootstrap apresentaram algum viés, principalmente quando se consideram tamanhos amostrais pequenos. Esse viés diminuiu com o aumento do tamanho amostral.

Assim, sugere-se que pesquisas futuras devam ser conduzidas para verificar se esses padrões de comportamento observados neste trabalho são de fato caracterizados como viéses e, em caso afirmativo, estudar a importância desses viéses na estimação de parâmetros populacionais e a partir de que tamanhos amostrais eles são despreziveis.

Para as estimativas dos parâmetros $F$ e $f$ as maiores variâncias foram obtidas quando foram reamostrados locos. A segunda maior fonte de erro está associada a. populações, exceto para $\hat{f}$, nos conjuntos de Telles \& Coelho (1998) e Sebbenn et al. (s.d.), nos quais a segunda maior fonte de erro foi devida à reamostragem de indivíduos. No caso das estimativas do parâmetro $\theta$, as variâncias máximas obtidas em função dos níveis de reamostragem variaram entre os diferentes conjuntos de dados, não havendo um padrão aparente para essa variação. Dessas observaçōes, sugere-se que um maior número

${ }^{3}$ COEL HO, A.S.G. (Universidade Federal de Goiás, Instituto de Ciências Biológicas, Departamento de Biologia Geral). Comunicação pessoal, 2000. 
de populações e principalmente de locos seja considerado em pesquisas futuras com populações naturais. Deve-se lembrar que, nos dados do presentes estudo, o número de locos variou de quatro a quinze e o de populações de duas a nove.

No entanto, muitas vezes não é possível aumentar o número de populações, pois pode haver um limite para esse número na natureza. $\mathrm{O}$ número de locos isoenzimáticos também é relativamente difícil de ser ampliado e, nesse ponto, o emprego de marcadores microssatélites, por exemplo, pode ser favorável. Porém, uma outra observação a ser feita é que, ao aumentar o número de indivíduos, mesmo sem alterar o número de populações $e$ locos, deve haver redução nos erros associados a essas duas últimas fontes de variação.

Da Tabela 11, observou-se que, em geral, as maiores variâncias estão associadas às estimativas de $F$ e $f$. A magnitude dos erros de $\hat{\theta}$ foram relativamente menores, mesmo quando as estimativas pontuais de $\theta$ foram maiores, como ocorre nos conjuntos de Seoane (1998) e Ciampi (1999), por exemplo. Portanto, para uma mesma magnitude de erros de tais estimativas, tamanhos amostrais maiores seriam necessários para estimar $F e$ $f$ em comparação $\operatorname{com} \theta$.

Nos dados de Reis (1996) observou-se, pelos intervalos de confiança relativos a $f$, que este parâmetro não diferiu de zero, exceto quando foram reamostrados indivíduos. Neste caso, os extremos do intervalo de confiança foram menores que zero, indicando excesso de heterozigotos nas populações. Para o parâmetro $\theta$, os intervalos foram todos positivos, exceto quando foram reamostrada populações, sendo que neste caso, $\theta$ não diferiu de zero. Isto pode ter ocorrido porque a estimativa de $\theta$ com a reamostragem de populações foi subestimada. Para $F$, todos os intervalos contiveram o zero, indicando que este parâmetro não diferiu estatisticamente desse valor. Essa discrepância entre os intervalos de confiança obtidos para um mesmo parâmetro, indica que, com diferentes niveis de reamostragens, os resultados podem não coincidir. Deve-se investigar futuramente quais as causas dessas discrepâncias e determinar qual nível de reamostragem deve ser aplicado na estimação dos erros associados aos diferentes parâmetros, embora talvez o mais adequado seja construir tais intervalos para as diversas fontes de variação, tendo-se assim conhecimento mais completo sobre os dados analisados $e$ podendo-se, assim, obter conclusões mais acertadas. 
A partir dos resultados obtidos com os dados de Seoane (1998), observou-se que os parâmetros $F$ e $f$ não diferiram estatisticamente de zero, enquanto $\theta$ somente não diferiu de zero quando foram feitas reamostragens de populações, sendo positivo quando se realizaram outros tipos de reamostragens (Tabela 11). Como $F$ e $f$ não diferiram de zero e como $F$ se relaciona com $f$ e $\theta$ de acordo com a expressão $(1-F)=(1-f) \cdot(1-\theta)$, era esperado que $\theta$ também não diferisse de zero, o que só foi confirmado quando foram feitas reamostragens de populações. Embora isso pareça um indício de que a melhor maneira de estimar este parâmetro, sua variância e calcular seu intervalo de confiança seja com reamostragem de populações, novamente deve-se atentar para o fato de que $\theta$ foi subestimatimado quando foram reamostradas populações, o que deve ter ocorrido porque nesse conjunto somente quatro populações foram consideradas. Como conseqüência, o intervalo de confiança $\theta$ pode ter se deslocado para a esquerda.

Da Tabela 11, verifica-se que para os dados de Telles \& Coelho (1998), $f$ não diferiu de zero, $\theta$ foi positivo e relativamente elevado e $F$ também foi positivo. Esse comportamento foi observado em todos os níveis de reamostragem. Isso confirma os resultados obtidos por esses autores que concluíram que existe estruturação entre populações devido somente à deriva e não à endogamia ou ainda a outros fatores como cruzamentos preferenciais, e que os valores positivos de $F$ resultam da divergência entre populações ( $\theta$ positivo).

Com os dados de Ciampi (1999) verificou-se que os intervalos de confiança de $\theta$ foram sempre positivos, indicando divergência entre populações devida à deriva genética. Como o intervalo de confiança para $f$ tem somente valores negativos quando se reamostraram indivíduos, e não diferente de zero quando foram feitas reamostragens nos outros níveis, era de se esperar que os intervalos para $F$ fossem positivos, exceto talvez quando fossem reamostrados indivíduos. No entanto, verificou-se que o intervalo para $F$ foi positivo somente quando este tipo de reamostragem foi realizado e que pelos demais intervalos, $F$ não diferiu de zero.

No caso de Auler (2000), $F, f$ e $\theta$ apresentaram intervalos de confiança positivos em todos os tipos de reamostragem, indicando, como o próprio autor sugeriu, que devem ter ocorrido cruzamentos entre indivíduos aparentados dentro de populações 
$(f>0)$, uma vez que a espécie é dióica, e que deve ter havido deriva genética entre as populações $(\theta>0)$, fazendo com que elas se diferenciassem no decorrer das gerações (Tabela 11).

No conjunto de Sebbenn et al. (s.d.), observou-se pelos intervalos de confiança, que $f$ diferiu de zero, sendo positivo, somente quando foram feitas reamostragens de populações e que $\theta$ foi positivo quando foram feitas reamostragens de locos e indivíduos, não diferindo de zero quando foram realizadas reamostragens de populações $e$ de indivíduos e populações. Como $\hat{f}=(\hat{F}-\hat{\theta}) /(1-\hat{\theta})$, sendo $\theta$ subestimado, como deve ter ocorrido neste conjunto que possui apenas duas populações, $\hat{f}$ é superestimado. Provavelmente por isso, quando foram reamostradas populações, o intervalo de confiança para este parâmetro foi positivo $e$ o intervalo de confiança para $\theta$ foi deslocado para a esquerda, sendo que $\theta$ não diferiu de zero para esta fonte de variação. $F$ diferiu estatisticamente de zero quando foram feitas reamostragem de indivíduos e de populações, isoladamente.

Como dito anteriormente, os parâmetros taxa de cruzamento aparente $\left(t_{a}\right)$, fluxo de genes entre populações $(\mathrm{Nm})$ e tamanho efetivo populacional $\left(N_{e}\right)$ foram estimados a partir de $\hat{F}, \hat{f}$ e $\hat{\theta}$. Por essa razão, não foi feito o estudo sobre a aditividade de variâncias no caso das estimativas de $t_{a}, N m$ e $N_{e}$. Assim, os resultados obtidos pela reamostragem simultânea de indivíduos e de populações foram incluídos na discussão. As estimativas bootstrap desses parâmetros, suas variâncias $e$ intervalos de confiança em função dos diferentes níveis de reamostragem encontram-se na Tabela 12. 
Tabela 12. Estimativas dos parâmetros ${ }^{\mathrm{a}} \boldsymbol{t}_{a},{ }^{\mathrm{b}} \mathrm{Nm} e{ }^{\mathrm{c}} N_{e}$ e de suas variâncias bootstrap oriundas da reamostragem de locos $(\mathrm{L})$, indivíduos $(\mathrm{I})$, populações $(\mathrm{P})$, indivíduos $e$ populações concomitantemente (I e P), para os diversos autores.

\section{Reis (1996)}

\begin{tabular}{|c|c|c|c|c|c|c|c|}
\hline & & \multicolumn{3}{|c|}{$\hat{t}_{a}$} & \multicolumn{3}{|c|}{$\hat{N} m$} \\
\hline Nivel & $n b d^{+}$ & Estimativa & Variância & I.C. & Estimativa & Variância & I.C. \\
\hline Original & & 1,097 & & & 14,438 & & \\
\hline $\mathrm{L}$ & 0 & 1,105 & 0,007285 & {$[0,944 ; 1,273]$} & 18,948 & 4735,67557 & {$[7,906 ; 54,383]$} \\
\hline I & 0 & 1,145 & 0,003176 & {$[1,039 ; 1,259]$} & 6,948 & 2,283364 & {$[4,655 ; 10,524]$} \\
\hline $\mathrm{P}$ & 0 & 1,099 & 0,006622 & {$[0,944 ; 1,261]$} & 67,401 & 5312131,71 & {$[-42,767 ; 158,279]$} \\
\hline I eP & 0 & 1,147 & 0,010503 & {$[0,956 ; 1,359]$} & 8,401 & 1187,35999 & {$[4,642 ; 16,946]$} \\
\hline \multicolumn{8}{|c|}{$\hat{N}_{e}$} \\
\hline Original & & 25,945 & & & & & \\
\hline $\mathrm{L}$ & 0 & 26,050 & 1,115649 & {$[24,051 ; 28,134]$} & & & \\
\hline I & 0 & 26,539 & 0,486375 & {$[25,230 ; 27,953]$} & & & \\
\hline $\mathrm{P}$ & 0 & 25,972 & 1,014079 & {$[24,060 ; 27,986]$} & & & \\
\hline IeP & 0 & 26,568 & 1,608449 & {$[24,205 ; 29,187]$} & & & \\
\hline \multicolumn{8}{|c|}{ Seoane (1998) } \\
\hline & & \multicolumn{3}{|c|}{$\hat{t}_{a}$} & \multicolumn{3}{|c|}{$\hat{N} m$} \\
\hline $\begin{array}{l}\text { Nivel } \\
\text { Original }\end{array}$ & $n b d$ & Estimativa & Variância & I.C. & Estimativa & Variância & I.C. \\
\hline $\begin{array}{l}\text { Uriginal } \\
\text { L }\end{array}$ & 0 & $\begin{array}{l}1,036 \\
1,041\end{array}$ & & $10660 \cdot 13501$ & $\begin{array}{l}2,238 \\
7072\end{array}$ & & \\
\hline I & 11 & 1,100 & 0,014525 & {$[0,889 ; 1,359]$} & 1,868 & 0,203746 & {$[1,037.24039]$} \\
\hline $\mathrm{P}$ & 0 & 1,041 & 0,013532 & {$[0,840 ; 1,293]$} & 1,274 & 73,028406 & {$[-25,597 ; 7,361]$} \\
\hline IeP & 0 & 1,104 & 0,029823 & {$[0,806 ; 1,482]$} & 1,406 & 241835,11 & {$[1,199 ; 17,933]$} \\
\hline \multicolumn{8}{|c|}{$\hat{N}_{e}$} \\
\hline Original & & 22,395 & & & & & \\
\hline L & 0 & 22,447 & 4,119171 & {$[18,259 ; 25,849]$} & & & \\
\hline I & 0 & 23,105 & 1,757516 & {$[20,776 ; 25,948]$} & & & \\
\hline $\mathrm{P}$ & 0 & 22,448 & 1,637337 & {$[20,245 ; 25,224]$} & & & \\
\hline I eP & 0 & 23,147 & 3,608610 & {$[19,865 ; 27,290]$} & & & \\
\hline
\end{tabular}

Telles \& Coelho (1998)

\begin{tabular}{cccccccc}
\hline \multicolumn{9}{c}{$\hat{\boldsymbol{t}}_{a}$} & \multicolumn{3}{c}{$\hat{N} m$} \\
\hline Nível & nbd & Estimativa & Variância & I.C. & Estimativa & Variância & I.C. \\
Original & & 0,967 & & 0,895 & & \\
L & 0 & 0,967 & 0,012320 & {$[0,755 ; 1,176]$} & 0,955 & 0,053012 & {$[0,600 ; 1,442]$} \\
I & 0 & 1,004 & 0,007488 & {$[0,847 ; 1,185]$} & 0,837 & 0,007480 & {$[0,682 ; 1,020]$} \\
P & 0 & 0,969 & 0,006310 & {$[0,828 ; 1,133]$} & 1,160 & 25,848450 & {$[0,682 ; 2,362]$} \\
I e P & & 1,006 & 0,014504 & {$[0,790 ; 1,261]$} & 1,098 & 19,277711 & {$[0,629 ; 2,218]$} \\
\hline \multicolumn{9}{c}{$\hat{N}_{e}$} \\
\hline \multicolumn{9}{c}{}
\end{tabular}

\begin{tabular}{cllll}
\hline Original & & 29,502 & & \\
L & 0 & 29,508 & 2,772101 & {$[26,304 ; 32,642]$} \\
I & 0 & 30,066 & 1,684716 & {$[27,701 ; 32,769]$} \\
P & 0 & 29,537 & 1,419693 & {$[27,416 ; 31,999]$} \\
I e P & 0 & 30,088 & 3,263366 & {$[26,853 ; 33,918]$}
\end{tabular}


Continuação da Tabela 12. Estimativas dos parâmetros ${ }^{\mathrm{a}} t_{a},{ }^{\mathrm{b}} \mathrm{Nm} e{ }^{\mathrm{c}} N_{e}$ e de suas variâncias bootstrap oriundas da reamostragem de locos $(\mathrm{L})$, indivíduos $(\mathrm{I})$, populações $(\mathrm{P})$, indivíduos e populações concomitantemente (I e P), para os diversos autores.

\begin{tabular}{|c|c|c|c|c|c|c|c|}
\hline \multicolumn{8}{|c|}{ Ciampi (1999) } \\
\hline & & \multicolumn{3}{|c|}{$\hat{t}_{a}$} & \multicolumn{3}{|c|}{$\hat{N} m$} \\
\hline Nivel & $n b d$ & Estimativa & Variância & I.C. & Estimativa & Variância & I.C. \\
\hline & & 1,032 & & & & & \\
\hline $\mathrm{L}$ & 0 & 1,035 & 0,004510 & {$[0,915 ; 1,177]$} & 4,739 & 0,132171 & {$[4,085 ; 5,503]$} \\
\hline I & 0 & 1,077 & 0,000853 & {$[1,022 ; 1,136]$} & 3,349 & 0,074985 & {$[2,831 ; 3,902]$} \\
\hline $\mathrm{P}$ & 0 & 1,033 & 0,001543 & {$[0,960 ; 1,122]$} & 8,223 & 31,248438 & {$[4,712 ; 27,44]$} \\
\hline LeP & 0 & 1,078 & 0,002493 & {$[0,984 ; 1,179]$} & 4,305 & 123961,66 & {$[3,062 ; 8,730]$} \\
\hline \multicolumn{8}{|c|}{$\hat{N}_{e}$} \\
\hline Original & & 24,384 & & & & & \\
\hline $\mathrm{L}$ & 0 & 24,417 & 0,649378 & {$[22,986 ; 26,124]$} & & & \\
\hline I & 0 & 24,927 & 0,122811 & {$[24,260 ; 25,632]$} & & & \\
\hline $\mathrm{P}$ & 0 & 24,397 & 0,222206 & {$[23,525 ; 25,469]$} & & & \\
\hline Ie $P$ & 0 & 24,942 & 0,359060 & {$[23,812 ; 26,153]$} & & & \\
\hline \multicolumn{8}{|c|}{ Auler (1999) } \\
\hline & & \multicolumn{3}{|c|}{$\hat{t}_{a}$} & \multicolumn{3}{|c|}{$\hat{N} m$} \\
\hline $\begin{array}{l}\text { Nível } \\
\text { Original }\end{array}$ & $n b d$ & $\begin{array}{c}\text { Estimativa } \\
0.742\end{array}$ & Variância & I.C. & $\begin{array}{c}\text { Estimativa } \\
7780\end{array}$ & Variância & I.C. \\
\hline L & 0 & 0,736 & 0,007271 & {$[0,535 ; 0,885]$} & 7,734 & 0,672233 & {$[6,181: 9,284]$} \\
\hline I & 0 & 0,765 & 0,001997 & {$[0,6824 ; 0,857]$} & 5,249 & 1,193655 & {$[3,529 ; 7,786]$} \\
\hline $\mathrm{P}$ & 0 & 0,741 & 0,006174 & {$[0,599 ; 0,902]$} & 10,345 & 1376,55743 & {$[5,673 ; 19,957$} \\
\hline leP & 0 & 0,764 & 0,008445 & {$[0,596 ; 0,953]$} & 6,180 & 86,461574 & {$[3,408 ; 10,978]$} \\
\hline \multicolumn{8}{|c|}{$\hat{N}_{e}$} \\
\hline Original & & 31,451 & & & & & \\
\hline L & 0 & 31,339 & 2,370143 & {$[27,722 ; 34,036]$} & & & \\
\hline I & 0 & 31,874 & 0,650964 & {$[30,371 ; 33,530]$} & & & \\
\hline$\dot{\mathrm{P}}$ & 0 & 31,442 & 2,012533 & {$[28,869 ; 34,336]$} & & & \\
\hline IeP & 0 & 31,858 & 2,752900 & {$[28,824 ; 35,253]$} & & & \\
\hline \multicolumn{8}{|c|}{ Sebbenn et al. (s.d.) } \\
\hline & & \multicolumn{3}{|c|}{$\hat{\boldsymbol{t}}_{a}$} & \multicolumn{3}{|c|}{$\hat{N} m$} \\
\hline Nivel & $n b d$ & Estimativa & Variância & I.C. & Estimativa & Variância & I.C. \\
\hline Original & & 0,929 & & & 2,085 & & \\
\hline $\mathrm{L}$ & 0 & 0,9326 & 0,008118 & {$[0,777 ; 1,127]$} & 3,702 & 42,734469 & {$[1,752 ; 8,543]$} \\
\hline $\bar{I}$ & 0 & 0,953 & 0,002544 & {$[0,859 ; 1,057]$} & 2,882 & 0,524730 & {$[1,772 ; 4,596]$} \\
\hline $\mathrm{P}$ & 0 & 0,926 & 0,000238 & {$[0,902 ; 0,945]$} & $-8,827$ & 144,913574 & {$[-21,972 ; 3,176]$} \\
\hline IeP & 0 & 0,950 & 0,002843 & {$[0,847 ; 1,057]$} & $-13,971$ & 6166747,91 & {$[-343,657 ; 309,156]$} \\
\hline \multicolumn{8}{|c|}{$\hat{N}_{e}$} \\
\hline Original & & 44,367 & & & & & \\
\hline $\mathrm{L}$ & 0 & 44,449 & 4,294321 & {$[40,860 ; 48,926]$} & & & \\
\hline$\vec{I}$ & 0 & 44,915 & 1,345936 & {$[42,751 ; 47,316]$} & & & \\
\hline $\mathrm{P}$ & 0 & 44,306 & 0,12615 & {$[43,748 ; 44,738]$} & & & \\
\hline IeP & 0 & 44,853 & 1,504070 & {$[42,482 ; 47,304]$} & & & \\
\hline
\end{tabular}

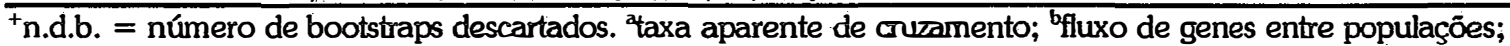
${ }^{c}$ tamanho efetivo populacional.

Os mesmos cuidados tomados quanto a tamanhos pequenos das amostras e sua implicação nas estimativas bootstrap devem ser observados para estes parâmetros. 
Observa-se que para $t_{a}$, as estimativas que mais se aproximaram da original foram obtidas pela reamostragem de locos com os dados de Seoane (1998) e Telles \& Coelho (1998) e pela reamostragem de populações nos demais conjuntos de dados. Nos conjuntos de Auler (2000) e Sebbenn et al. (s.d.), as estimativas mais discrepantes foram obtidas quando se reamostraram indivíduos e, para os demais conjuntos, isso ocorreu quando indivíduos e populações foram amostrados conjuntamente. Tais valores foram superestimados.

Quanto ao parâmetro $N m$, as estimativas mais próximas da original ocorreram quando foram reamostrados locos, para os dados de Reis (1996), Ciampi (1999) e Auler (2000), e quando foram reamostrados indivíduos nos demais conjuntos de dados. As que mais divergiram da original foram todas superestimadas e ocorreram com a reamostragem de locos nos dados de Seoane (1998), indivíduos e populações nos de Sebbenn et al. (s.d.) e populações nos demais conjuntos.

No que se refere ao parâmetro $N_{e}$, o comportamento de suas estimativas foi idêntico ao observado para $t_{a}$, exceto pelo fato de a estimativa mais próxima da original ter ocorrido com a reamostragem de populações com os dados de Seoane (1998). Era esperado que esses dois parâmetros tivessem comportamento semelhante, pois ambos são estimados em função da estimativa de um único parâmetro $(f)$.

Essa mesma coincidência repete-se em termos das variâncias, sendo que as maiores variâncias associadas a esses parâmetros foram encontradas quando foram reamostrados indivíduos e populações conjuntamente para os dados de Reis (1996), Telles \& Coelho (1998) e Auler (2000) e quando foram feitas reamostragens de locos, nos demais conjuntos. Quanto ao parâmetro $N m$, as maiores variâncias foram encontradas com a reamostragem de populações, com os conjuntos de Reis (1996), Telles \& Coelho (1998) e Auler (2000) e com reamostragens de populações e indivíduos simultaneamente, para os demais autores.

Mesmo quando as estimativas pontuais de $N m$ apresentaram magnitudes semelhantes às das estimativas de $t_{a}$ e menores que as de $N_{e}, N m$ apresentou a tendência de ter emos maiores, como no caso dos dados de Telles \& Coelho (1998) (Tabela 12). Esse comportamento é acentuado quando as reamostragens envolveram 
populações. Isso era esperado pois este parâmetro é função de $\theta$, a divergência entre populações e ao fazer reamostragens envolvendo a fonte de variação de populações, as estimativas de $\theta$ devem variar mais entre as amostras bootstrap do que quando se reamostram indivíduos ou locos. Pequenas varições nas estimativas de $\theta$ podem causar grandes variações nas estimativas de $\mathrm{Nm}$, o que pode justificar a maior variância das estimativas desse parâmetro quando a fonte de variação de populações está envolvida na reamostragem.

Em alguns casos, quando são reamostrados locos ou indivíduos, $N_{e}$ apresentou variâncias maiores em comparação com os demais parâmetros. Por outro lado, as menores variâncias estã́o sempre associadas às estimativas de $\boldsymbol{t}_{\boldsymbol{a}}$, exceto para os dados de Telles \& Coelho (1998), em que $\mathrm{Nm}$ apresentou menor variância quando foram feitas reamostragens de indivíduos. Esse comportamento indica que menores tamanhos amostrais são necessários para estimar $t_{a}$ e que, para obter boas estimativas de $\mathrm{Nm}$, é necessário número maior de populações. Isso pode ser um problema, pois muitas vezes o número de populações da espécie as quais se tem acesso na natureza é pequeno. Novamente, ressalta-se que o aumento do número de locos e indivíduos analisados pode compensar a impossibilidade de aumentar o número de populações avaliadas. Weir (1996) sugere uso de maior número de locos para simular populações.

Para o conjunto de Reis (1996), a taxa aparente de cnuzamento não diferiu de 1 exceto na reamostragem de indivíduos, quando foi superior a este valor, sendo o limite inferior do intervalos de confiança próximo de 1 (Tabela 12). Embora a taxa aparente de cruzamento não possa ser superior a 1 , isso ocorreu porque, para esse nível de reamostragem, $f$ foi negativo (Tabela 11) e com o estimador de $t_{a}$ utilizado, obteve-se estimativa superior a 1 para tal parâmetro. Sendo assim, assumiu-se que $t_{a}$ também não diferiu de 1 quando foram reamostrados indivíduos. Comportamento idêntico foi encontrado com os dados de Ciampi (1999). Com esses resultados, confirmou-se a conclusão obtida por esses autores de que essas duas espécies são alógamas.

Com os dados de Seoane (1998) e Telles \& Coelho (1998), observou-se que, para todos os níveis de reamostragem considerados, $t_{a}$ não diferiu de 1 , o que era esperado 
uma vez que $f$ não diferiu de zero em nenhum dos intervalos de confiança calculados para esse parâmetro. Também essas espécies podem ser consideradas alógamas, de acordo com o que esses autores concluíram:

Embora a espécie estudada por Auler (2000) seja dióica e, portanto, fosse esperado que a taxa de cruzamento não diferisse de 1 , observou-se que, para todos os níveis reamostrados, $t_{a}$ foi menor que 1 . Isso ocorreu porque $f$ foi maior que zero também em todos os níveis de reamostragem, indicando, como o autor sugeriu, a presença de cruzamentos entre indivíduos aparentados. Para os dados de Sebbenn et al. (s.d.), $t_{a}$ foi menor do que 1 somente quando foram feitas reamostragens de populações. Novamente, isso ocorreu porque, para esse nivel de reamostragem, $f$ foi estatisticamente maior que zero. No entanto, ressalta-se que neste conjunto de dados, apenas duas populações foram amostradas e que, portanto, deve-se tomar cuidado quando as reamostragens envolverem poucas populações, numa situação como essa.

Em geral, para o parâmetro $N m$, observaram-se intervalos de confiança com grandes amplitudes, principalmente quando as reamostragens envolveram populações. Essas amplitudes eram esperadas uma vez que, nesses casos, as variâncias foram altas. Essas variâncias tendem a ser elevadas devido à natureza do estimador de $\mathrm{Nm}$, sendo que pequenas variações em $\theta$ resultam em grandes variações na estimativa do fluxo de genes. Assim, por exemplo, com valores de $\hat{\theta}$ iguais a 0,010, 0,011 e 0,012, os respectivos valores de $\hat{N} m$ são $24,75,22,48$ e 20,58. Além disso, estimativas negativas de $N m$ são possíveis, uma vez que as estimativas de $\theta$ também podem ser menores que zero. Em relação a $\mathrm{Nm}$, quando foram reamostradas populações, ocorreram intervalos de confiança muito amplos, que continham o zero, para os dados de Reis (1996), Seoane (1998) e Sebbenn et al. (s.d.). Para este último conjunto de dados, o intervalo obtido pela: reamostragem concomitante de populações $e$ indivíduos também conteve o zero, sendo o mais amplo de todos os intervalos obtidos, em todos os níveis de reamostragem, em todos os conjuntos. Talvez isso tenha ocorrido porque somente duas populações foram amostradas.

Deve-se ter a devida cautela com intervalos de confiança para $\mathrm{Nm}$ que contenham o zero. Segundo Steel \& Torrie (1980), correlações intraclasse podem variar dentro do 
intervalo $[-1 /(n-1) ; 1]$, em que $n$ é o número de observações dentro das classes. Assim, considerando que $\hat{N} m=(1-\hat{\theta}) / 4 \hat{\theta}$ e lembrando que $\theta$ é uma correlação intraclasse, suponha-se que haja 11 indivíduos por população (11 observações dentro de cada classe), de modo que o intervalo para $\theta$ seja $[-0,10 ; 1]$. Então, poder-se-ia pensar que o intervalo de confiança para $\mathrm{Nm}$ seria $[-2,25 ;+\infty)$. No entanto, ao observar a Figura 5 , vê-se que quando $\hat{\theta}$ tende a zero pela esquerda $\hat{N} m$ tende a $-\infty$, e quando $\hat{\theta}$ tende a zero pela direita $\hat{N m}$ tende a $+\infty$. Assim, considerando-se o intervalo de $\theta$ como $[-0,10 ; 1]$, o

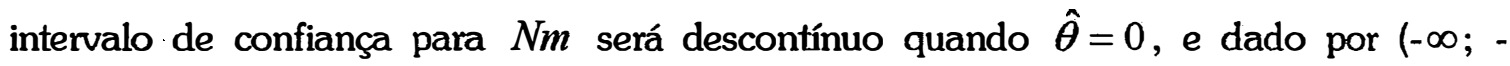
$2,25] \mathrm{U}[0 ;+\infty)$.

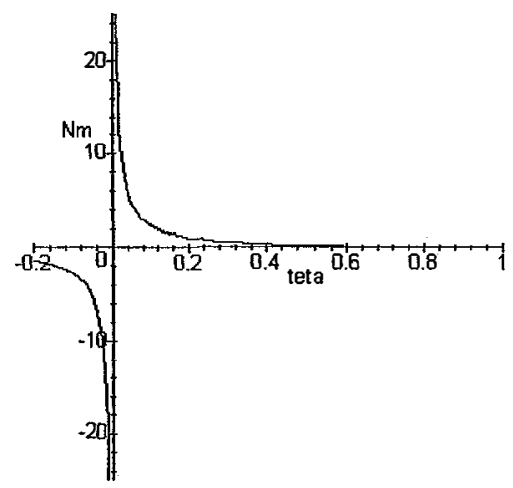

Figura 5. Comportamento do parâmetro $\mathrm{Nm}$ em função do parâmetro $\theta$.

Note-se que, por definição, o parâmetro $\theta$ deve ser necessariamente um valor não negativo e assim, o intervalo de $\mathrm{Nm}$ seria dado por $[0 ;+\infty)$. No entanto, se $\theta$ for estimado a partir da análise de variância das freqüências gênicas, sua estimativa pode ser negativa. Assim, intervalos de confiança para $\theta$ podem conter o zero, o que leva à descontinuidade do intervalo de confiança de $\mathrm{Nm}$.

Portanto, para intervalos de confiança de $\mathrm{Nm}$ que contenham o zero, deve-se encontrar as estimativas máxima e mínima de $\theta$ e compor o o intervalo real de $\mathrm{Nm}$. Considere-se novamente o intervalo percentil [-42,767; 158,279] obtido para os dados de Reis (1996) quando foram reamostradas populações. Como mencionado, este intervalo 
deve ter uma descontinuidade que ocorre em função das estimativas $\hat{\theta}$, a qual deve ser considerada. O menor e o maior valores de $\hat{\theta}$ foram $-0,013$ e 0,025 , quando feita reamostragem de populações. As estimativas de $\mathrm{Nm}$ encontradas para esses $\hat{\theta}$ 's foram 19,394 e 9,625. Assim, o intervalo de confiança para $\mathrm{Nm}$ fica sendo [-42,767; $19,394] \mathrm{U}[9,625 ; 158,279]$. Utilizando o mesmo raciocínio, os intervalos de confiança para Seoane (1998) e Sebbenn et al. (s.d.) quando foram reamostradas populações, respectivamente, são [-25,597; -8,404]U[2,194; 7,361] e [-21,972; -19,729]U[3,176], uma vez que como há apenas duas populações, existem somente três estimativas de $\theta$. Quando reamostrados indivíduos $e$ populações concomitantemente, o intervalo para o fluxo de genes considerando os dados de Sebbenn et al. foi [-21,233; -0,012]U[0,968; 309,156]. Com os dados deste autor, as estimativas pontuais do fluxo de genes foram negativas quando se reamostraram populações e indivíduos e populações. Isso mostra a fraqueza do estimador de $\mathrm{Nm}$.

Com os resultados obtidos, ficou evidente que se deve tomar cuidado com as estimativas de $t_{a}$ e de $\mathrm{Nm}$, pois seus estimadores não são muito eficientes e conclusões incorretas podem ser tomadas se os intervalos de confiança não forem considerados. Mesmo assim, quando se trata do parâmetro $\mathrm{Nm}$ a atenção deve ser ainda maior em situações como a de Reis (1996), por exemplo, em que o intervalo obtido inclui o zero, como ocorreu quando foram reamostradas populações.

Com os dados de Reis (1996) e Ciampi (1999) intervalos de confiança obtidos para $\mathrm{Nm}$ com a reamostragem de indivíduos não contiveram a estimativa original desse parâmetro, sendo que a magnitude dessas estimativas foi maior do que os limites superiores de tais intervalos. Além disso, com o conjunto de Ciampi (1999), a estimativa original de $\mathrm{Nm}$ correspondeu ao limite inferior do intervalo de confiança obtido para esse parâmetro, quando foram reamostradas populações. Para esse conjunto de dados, esse comportamento é justificado pelo fato de o intervalo de confiança de $\theta$, obtido pela reamostragem de indivíduos, não conter a estimativa original $\theta$ e o intervalo obtido quando foram reamostradas populações ter como limite superior a estimativa original desse parâmetro. 
Em geral, para o parâmetro $N_{e}$, os intervalos de confiança não foram tão amplos $e$ em todos os conjuntos e em todos os níveis de reamostragens contiveram a estimativa original. A maior diminuição do tamanho efetivo populacional, em comparação ao tamanho médio das populações, foi verificada para o conjunto de Auler (2000). O tamanho populacional médio nas populações amostradas por esse autor foi 36,11 e o tamanho efetivo estimado, para os vários níveis de reamostragem, ficou em torno de 31,5. Isso pode ser explicado pelo fato de ser esse o conjunto com o maior nível de endogamia. (Tabelas 11 e 12).

Nesse ponto, deve-se chamar a atenção para a importância da reamostragem bootstrap na estimação dos erros das estimativas dos parâmetros populacionais. É relevante conhecer a magnitude desses erros, pois se ela for elevada, a precisão das estimativas dos parâmetros é pequena, o que pode ser prejudicial no que se refere, por exemplo, a planos de conservação da variabilidade genética na natureza. A preservação de populações em condições naturais, muitas vezes baseia-se nas medidas de diversidade intra e interpopulacionais, quantificadas pelas estimativas dos parâmetros populacionais. Assim, se eles forem estimados com baixa precisão, decisões errôneas podem ser tomadas quanto à manutenção ou não de populações na natureza, o que pode acarretar em perda da variabilidade genética, ou ter outras conseqüências.

Para exemplificar o que foi discutido até o momento, considerem-se os conjuntos de Reis (1996) e Telles \& Coelho (1998) (Tabela 13). Nos dados de Reis (1996) quando foram reamostrados locos, os erros das estimativas dos parâmetros $F, f$ e $\mathrm{Nm}$ foram os mais elevados quando comparados à magnitude de tais estimativas. No caso de $F$ e $\mathrm{Nm}$, as estimativas dos erros apresentaram até maior magnitude que as próprias estimativas desses parâmetros. Nesse mesmo conjunto, esse comportamento ocorreu também quando estimativas de $F, f$ e $\mathrm{Nm}$ quando foram obtidas com a reamostragem de populações e no caso de $\mathrm{Nm}$ estimado com a reamostragem concomitante de indivíduos e populações.

Ocorreu ainda esse mesmo comportamento no conjunto de Telles \& Coelho (1998) com as estimativas de $f$ obtidas através da reamostragem de locos e de populações, com $\hat{F}$ proveniente da reamostragem de indivíduos, com $\hat{N} m$ obtida com a reamostragem de populações e de indivíduos e populações e com $N_{e}$ estimado quando foram realizadas 
reamostragens de locos e de indivíduos. Com essas ocorrências, ficou evidente que tais estimativas não são precisas, o que deve ser levado em conta ao se tirar conclusões a partir delas, como já enfatizado anteriormente. Assim, a contribuição dos erros varia de acordo com a fonte de variação reamostrada, sendo, portanto, necessário indicar que fonte de variação está sendo reamostrada. Nesses dois conjunto, em geral, notou-se que as fontes de variação de locos e de populações foram responsáveis pelos maiores erros associados às estimativas dos parâmetros.

A necessidade de construir intervalos de confiança para os parâmetros de interesse em função das várias fontes de variação fica evidente. Assim, se fossem realizadas somente reamostragens de indivíduos, poder-se-ia concluir que $\hat{f}$ era negativo, havendo excesso de heterozigotos dentro de populações. No entanto, ao observar os demais intervalos, vê-se que $\hat{f}$ não diferiu de zero e que as populações estariam nas proporções do equilíbrio de Hardy-Weinberg. Esse tipo de conflito, evidentemente, é prejudicial em pesquisas genéticas com populações naturais.

Uma outra consideração a ser feita refere-se à natureza das diferentes fontes de variação. Observou-se que a reamostragem conforme essas diferentes fontes fornecem informações diversas sobre os dados. Neste ponto, deve-se ressaltar que a fonte de variação de locos é uma grandeza ortogonal às demais. Isso é facilmente compreensível ao pensar na própria matriz de dados. Nas linhas encontram-se os indivíduos pertencentes às diversas populações e nas colunas, as informações sobre os genótipos desses indivíduos para cada loco. Ao reamostrar populações, automaticamente os indivíduos também estão sendo reamostrados, como mencionado anteriormente e ao reamostrar indivíduos a estrutura das populações também está sendo alterada. Ou seja, não existe independência entre populações $e$ indivíduos. Com esses tipos de reamostragem, no entanto, a estrutura de locos não se altera, ou seja, os locos incluídos nessas reamostragens são sempre os mesmos. Isso é válido também para a reamostragem de indivíduos e populações conjuntamente. Sendo reamostrados locos, aqueles incluídos nas diferentes amostras podem variar, mas os indivíduos e populações são sempre os mesmos. $\mathrm{O}$ que se deseja esclarecer com esta argumentação é que, biometricamente, a informação devida a locos é independente (ortogonal) das devidas a populações e indivíduos e que portanto a natureza da informação proveniente da reamostragem de locos é diferente da natureza das 
informações provenientes dos outros tipos de reamostragens aqui estudadas. Estas, por sua vez, não são independentes entre si.

Seria interessante verificar futuramente se existem fontes de variação mais apropriadas para serem reamostradas em função dos diversos parâmetros de interesse. No momento, o mais aconselhável é considerar os resultados provenientes das diversas fontes de variação para obter conclusões com maior segurança.

Nesse ponto, é conveniente uma consideração mais geral que possa servir como orientação em pesquisas como as abordadas aqui. Foi visto que as diferentes fontes de variação podem levar a intervalos de confiança conflitantes entre si. Em tais situações, querendo-se fazer inferências a respeito de um dado parâmetro, um critério que pode ser adotado é o seguinte: a) o parâmetro é considerado maior do que zero se todos os intervalos forem positivos; b) o parâmetro é considerado menor do que zero se todos os intervalos forem negativos; c) o parâmetro é admitido como nulo se pelo menos um intervalo contiver o zero. Dessa forma, as inferências terão considerável margem de segurança.

Este mesmo raciocínio pode ser aplicado para o parâmetro taxa de cruzamento aparente. No entanto, o valor de referência passa a ser o 1 e não o zero, quando se quer investigar se a espécie é alógama. Quanto ao fluxo gênico, o referencial também é o 1 , pois, como mencionado por Futuyma (1992), um fluxo de genes igual a 1 é suficiente para contrabalançar o efeito de deriva. Assim, para tal parâmetro, os intervalos de confiança decorrentes das várias fontes de variação devem conter o 1 ou serem maiores que 1 para que se possa afirmar com segurança que existe fluxo de genes entre populações. Com relação ao tamanho efetivo populacional, não há um valor de referência, porém, é desejável que esse valor seja elevado. 
Tabela 13. Estimativas dos parâmetros ${ }^{\mathrm{a}} F,{ }^{\mathrm{b}} f,{ }^{\mathrm{c}} \theta,{ }^{\mathrm{d}} t_{a},{ }^{e} N m$ e ${ }^{\mathrm{f}} N_{e} e$ seus desviospadrão $e$ intervalos de confiança percentil, em função das diferentes fontes de variação. Dados de Reis (1996) e Telles \& Coelho (1998).

\begin{tabular}{|c|c|c|c|c|c|c|}
\hline \multirow{3}{*}{$\begin{array}{c}\text { Reis } \\
\text { (1996) } \\
\text { Parâmetro }\end{array}$} & \multicolumn{6}{|c|}{ Fontes de variação } \\
\hline & \multicolumn{3}{|c|}{ Locos } & \multicolumn{3}{|c|}{ Indivíduos } \\
\hline & Estimativa & Desvio-padrão & I.C. $.95 \%$ & Estimativa & Desvio-padrão & I.C.95\% \\
\hline$F$ & $-0,031$ & $\overline{0,041}$ & {$[-0,110 ; 0,050]$} & $-0,028$ & 0,023 & {$[-0,073 ; 0,018]$} \\
\hline$f$ & $-0,048$ & 0,039 & {$[-0,120,0,029]$} & $-0,067$ & 0,024 & {$[-0,115 ;-0,019]$} \\
\hline$\theta$ & $-0,033$ & 0,007 & {$[-0,110 ; 0,047]$} & $-0,046$ & 0,007 & {$[-0,116 ; 0,029]$} \\
\hline$t_{a}$ & 1,105 & 0,085 & {$[0,944 ; 1,273]$} & 1,145 & 0,056 & {$[1,039 ; 1,259]$} \\
\hline$N m$ & 18,948 & 68,816 & {$[7,906 ; 54,383]$} & 6,948 & 1,511 & {$[4,655 ; 10,524]$} \\
\hline$N_{e}$ & 26,050 & 1,056 & {$[24,051 ; 28,134]$} & 26,539 & 0,697 & {$[25,230 ; 27,953]$} \\
\hline \multicolumn{7}{|c|}{ Populaçóes } \\
\hline Parâmetro & Estimativa & Desvio-padrão & I.C. $.95 \%$ & & & \\
\hline$F$ & 0,017 & 0,040 & {$[0,005 ; 0,031]$} & & & \\
\hline$f$ & 0,036 & 0,037 & {$[0,023 ; 0,051]$} & & & \\
\hline$\theta$ & 0,013 & 0,006 & {$[-0,001 ; 0,022]$} & & & \\
\hline & \multicolumn{3}{|c|}{ Populações } & \multicolumn{3}{|c|}{ Indivíduos e Populações } \\
\hline Parâmetro & Estimativa & Desvio-padrão & I.C. $95 \%$ & Estimativa & Desvio-padrão & I.C. $25 \%$ \\
\hline$t_{a}$ & 1,098738 & 0,081 & {$[0,94424 ; 1,26147]$} & 1,147 & 0,102 & {$[0,956 ; 1,359]$} \\
\hline$N m$ & 67,400716 & 2304,806 & {$[-42,7670 ; 158,279]$} & 8,401 & 34,458 & {$[4,642 ; 16,946]$} \\
\hline$N_{e}$ & 25,971881 & 1,007 & {$[24,0600 ; 27,9857]$} & 26,568 & 1,268 & {$[24,205 ; 29,187]$} \\
\hline Telles \& & \multicolumn{6}{|c|}{ Fontes de Variação } \\
\hline $\begin{array}{l}\text { Coelho } \\
\text { (1998) }\end{array}$ & \multicolumn{3}{|c|}{ Locos } & \multicolumn{3}{|c|}{ Indivíduos } \\
\hline Parâmetro & Estimativa & Desvio-padrão & I.C. $.95 \%$ & Estimativa & Desvio-padrāo & I.C. $.95 \%$ \\
\hline$F$ & 0,229 & 0,078 & {$[0,083 ; 0,372]$} & 0,231 & 0,035 & {$[0,162 ; 0,300]$} \\
\hline$f$ & 0,020 & 0,058 & {$[-0,081 ; 0,141]$} & $-0,001$ & 0,043 & {$[-0,084 ; 0,083]$} \\
\hline$\theta$ & 0,215 & 0,039 & {$[0,148 ; 0,294]$} & 0,231 & 0,018 & {$[0,197 ; 0,268]$} \\
\hline$t_{a}$ & 0,967 & 0,111 & {$[0,755 ; 1,176$} & 1,004 & 0,087 & {$[0,847 ; 1,185]$} \\
\hline$N m$ & 0,955 & 0,230 & {$[0,600 ; 1,442]$} & 0,837 & 0,086 & {$[0,682 ; 1,020]$} \\
\hline$N_{e}$ & 0,967 & 1,665 & {$[0,755 ; 1,176]$} & 30,066 & 1,298 & {$[27,701 ; 32,769]$} \\
\hline \multicolumn{7}{|c|}{ Populações } \\
\hline Parâmetro & Estimativa & Desvio-padrão & I.C. $25 \%$ & & & \\
\hline$F$ & 0,198 & 0,059 & {$[0,079 ; 0,310]$} & & & \\
\hline$f$ & 0,017 & 0,041 & {$[-0,062 ; 0,094]$} & & & \\
\hline$\theta$ & 0,185 & 0,044 & {$[0,096 ; 0,268]$} & & & \\
\hline
\end{tabular}


Continuação da Tabela 13. Estimativas dos parâmetros ${ }^{\mathrm{a}} F,{ }^{\mathrm{b}} f,{ }^{\mathrm{c}} \theta,{ }^{\mathrm{d}} t_{a},{ }^{\mathrm{e}} \mathrm{Nm}$ e ${ }^{\mathrm{f}} N_{e} e$ seus desvios-padrão $e$ intervalos de confiança percentil, em função das diferentes fontes de variação. Dados de Reis (1996) e Telles \& Coelho (1998).

\begin{tabular}{ccccccc}
\hline & \multicolumn{3}{c}{ Populaçóes } & \multicolumn{3}{c}{ Indivíduos e Populações } \\
\hline Parâmetro & Estimativa & Desvio-padrão & I.C.95\% & Estimativa & Desvio-padrão & I.C.95\% \\
\hline$t_{a}$ & 0,969 & 0,079 & {$[0,828 ; 1,133]$} & 1,006 & 0,120 & {$[0,790 ; 1,261]$} \\
$N m$ & 1,160 & 5,084 & {$[0,682 ; 2,362]$} & 1,098 & 4,391 & {$[0,629 ; 2,218]$} \\
$N_{e}$ & 29,537 & 1,192 & {$[27,416 ; 31,999]$} & 30,088 & 1,806 & {$[26,853 ; 33,918]$} \\
\hline
\end{tabular}

aestimativa do índice de fixação total; ${ }^{b}$ estimativa do índice de fixação dentro das populaçóes; ${ }^{\text {eestimativa do }}$ grau de divergência entre populações; taxa de cruzamento aparente; 'fluxo de genes entre populações; tamanho efetivo populacional.

Pelo teste de normalidade de Kolmogorov-Smirnov, verificou-se que a estimativa de $F$ apresentou distribuição normal somente quando foram reamostados indivíduos, para os dados de Seoane (1998) e Auler (2000). Quanto à estimativa de $f$, por outro lado, o teste de normalidade foi não significativo apenas na reamostragem de indivíduos, com os dados de Telles \& Coelho (1998) e para a reannostragem concomitante de indivíduos e populações nos dados de Ciampi (1999) (Tabela 14). Para os demais parâmetros, nos diversos níveis de reamostragem, todos os testes foram significativos, no mínimo com 0,05 de probabilidade, e portanto, a hipótese da normalidade foi rejeitada. 
Tabela 14. p-valores do teste de Kolmogorov-Smimov para os parâmetros ${ }^{\mathrm{a}} F,{ }^{\mathrm{b}} f,{ }^{\mathrm{c}} \boldsymbol{\theta}$, ${ }^{\mathrm{d}} t_{a},{ }^{\mathrm{e}} \mathrm{Nm} e{ }^{\mathrm{f}} N_{e}$ estimados a partir da reamostragem de locos (L), indivíduos (I), populações $(\mathrm{P})$ e indivíduos e populações conjuntamente ( $\mathrm{P}$ e I).

\begin{tabular}{|c|c|c|c|c|c|c|}
\hline $\begin{array}{c}\text { Nivel } \\
\text { Reamostrado }\end{array}$ & Reis (1996) & $\begin{array}{l}\text { Seoane } \\
\text { (1998) }\end{array}$ & $\begin{array}{c}\text { Telles \& } \\
\text { Coelho(1998) }\end{array}$ & $\begin{array}{l}\text { Ciampi } \\
\text { (1999) }\end{array}$ & Auler (2000) & $\begin{array}{l}\text { Sebbenn et al. } \\
\text { (2000) }\end{array}$ \\
\hline & \multicolumn{6}{|c|}{$\hat{F}$} \\
\hline L & $<0,0100$ & $<0,0100$ & $<0,0100$ & $<0,0100$ & $<0,0100$ & $<0,0100$ \\
\hline I & 0,0357 & $>0,1500$ & 0,0310 & $<0,0100$ & 0,1272 & $<0,0100$ \\
\hline $\mathrm{P}$ & $<0,0100$ & $<0,0100$ & $<0,0100$ & $<0,0100$ & $<0,0100$ & $<0,0100$ \\
\hline I e P & $<0,0100$ & $<0,0100$ & $<0,0100$ & $<0,0100$ & $<0,0100$ & $<0,0100$ \\
\hline & & & & & & \\
\hline L & $<0,0100$ & $<0,0100$ & $<0,0100$ & $<0,0100$ & $<0,0100$ & $<0,0100$ \\
\hline I & 0,0225 & $<0,0100$ & $>0,1500$ & 0,0347 & $<0,0100$ & $<0,0100$ \\
\hline $\mathrm{P}$ & $<0,0100$ & $<0,0100$ & $<0,0100$ & $<0,0100$ & $<0,0100$ & $<0,0100$ \\
\hline \multirow[t]{2}{*}{ I eP } & $<0,0100$ & 0,0231 & $<0,0100$ & $>0,1500$ & $<0,0100$ & $<0,0100$ \\
\hline & & \multicolumn{4}{|c|}{$\hat{\theta}$} & \\
\hline $\mathrm{L}$ & $<0,0100$ & $<0,0100$ & $<0,0100$ & $<0,0100$ & $<0,0100$ & $<0,0100$ \\
\hline I & $<0,0100$ & $<0,0100$ & $<0,0100$ & $<0,0100$ & $<0,0100$ & $<0,0100$ \\
\hline $\mathrm{P}$ & $<0,0100$ & $<0,0100$ & $<0,0100$ & $<0,0100$ & $<0,0100$ & $<0,0100$ \\
\hline \multirow[t]{2}{*}{ I e P } & $<0,0100$ & $<0,0100$ & $<0,0100$ & $<0,0100$ & $<0,0100$ & $<0,0100$ \\
\hline & & \multicolumn{4}{|c|}{$\hat{t}_{a}$} & \\
\hline L & $<0,0100$ & $<0,0100$ & $<0,0100$ & $<0,0100$ & $<0,0100$ & $<0,0100$ \\
\hline I & $<0,0100$ & $<0,0100$ & $<0,0100$ & $<0,0100$ & $<0,0100$ & $<0,0100$ \\
\hline $\mathrm{P}$ & $<0,0100$ & $<0,0100$ & $<0,0100$ & $<0,0100$ & $<0,0100$ & $<0,0100$ \\
\hline \multirow[t]{2}{*}{ IeP } & $<0,0100$ & $<0,0100$ & $<0,0100$ & $<0,0100$ & $<0,0100$ & $<0,0100$ \\
\hline & & \multicolumn{4}{|c|}{$\hat{N} m$} & \\
\hline $\mathrm{L}$ & $<0,0100$ & $<0,0100$ & $<0,0100$ & $<0,0100$ & $<0,0100$ & $<0,0100$ \\
\hline 1 & $<0,0100$ & $<0,0100$ & $<0,0100$ & $<0,0100$ & $<0,0100$ & $<0,0100$ \\
\hline $\mathrm{P}$ & $<0,0100$ & $<0,0100$ & $<0,0100$ & $<0,0100$ & $<0,0100$ & $<0,0100$ \\
\hline \multirow[t]{2}{*}{ Ie P } & $<0,0100$ & $<0,0100$ & $<0,0100$ & $<0,0100$ & $<0,0100$ & $<0,0100$ \\
\hline & & \multicolumn{4}{|c|}{$\hat{N}_{e}$} & \\
\hline $\mathrm{L}$ & $<0,0100$ & $<0,0100$ & $<0,0100$ & $<0,0100$ & $<0,0100$ & $<0,0100$ \\
\hline I & $<0,0100$ & $<0,0100$ & $<0,0100$ & $<0,0100$ & $<0,0100$ & $<0,0100$ \\
\hline $\mathrm{P}$ & $<0,0100$ & $<0,0100$ & $<0,0100$ & $<0,0100$ & $<0,0100$ & $<0,0100$ \\
\hline I e P & $<0,0100$ & $<0,0100$ & $<0,0100$ & $<0,0100$ & $<0,0100$ & $<0,0100$ \\
\hline
\end{tabular}

ao índice de fixação total; "índice de fixação dentro das populações; 'Grau de divergência entre populações; taxa aparente de cruzamento; 'fluxo de genes entre populaçôes; 'tamanho efetivo populacional.

Disso pôde-se concluir que os parâmetros $F$ e $f$ tendem à̀ normalidade quando o tamanho amostral é grande. Isso deveu-se ao número de indivíduos amostrados nas pesquisas, que foi maior do que o de locos e de populações. Assim, quando indivíduos estão incluídos na reamostragem, parece que tais estimativas tendem à normalidade. Vencovsky et al. (1997) obtiveram resultados semelhantes. Verificaram que, com oito de nove locos analisados, as estimativas de $f$ foram normalmente distribuídas, quando feitas 
reamostragens de indivíduos e o número de indivíduos considerados por loco foi próximo de 100. Esses autores observaram também que as estimativas de $t_{a}$ não tinham distribuição normal quando este mesmo tipo de reamostragem foi realizado.

A questão da normalidade é importante quando se trata de testes de hipóteses. Parâmetros cujas estimativas tenham distribuição normal podem ser facilmente testados quanto à significância de suas estimativas, através dos testes usuais. Quando isso não ocorre, a significância das estimativas dos parâmetros deve ser testada através de métodos de reamostragem, como os testes de randomização, ou através do uso de bootstrap e obtenção dos intervalos de confiança para tais estimativas, como feito aqui.

Os histogramas das estimativas de cada um dos seis parâmetros estudados, em função dos diversos níveis de reamostragem, podem ser visualizados no Anexo B.

\subsection{Bootstrap com tamanhos variáveis de amostras}

Nesse item, as amostras bootstrap obtidas foram de tamanhos variáveis, ou seja, foram feitas análises mantendo fixo o número de populações da amostra e variando o número de indivíduos, ou fixando o número de indivíduos e variando o de populações ou ainda, variando ambos.

\subsubsection{Análise hierárquica das estimativas bootstrap de variância}

A partir das análises realizadas como descrito no item 3.2.2.2.1., construíram-se, para cada nível de reamostragem das estimativas de $F, f$ e $\theta$, curvas de regressão do tipo potência, cujos gráficos, equações de regressão e coeficientes de determinação $\left(R^{2}\right)$ podem ser observados nas Figura 6 a 11, para todos os conjuntos de dados avaliados.

$\hat{E}$ importante esclarecer que, em alguns conjuntos, houve elevado número de bootstraps descartados quando poucos indivíduos foram reamostrados (Anexo A). Nesses casos, estabeleceu-se que o número mínimo de indivíduos a ser considerado nas análises de regressão seria aquele a partir do qual houvesse menos de $10 \%$ de descartes. Assim, para os dados de Seoane (1998), Auler (2000) e Sebbenn et al. (s.d.), as regressōes foram 
realizadas considerando número mínimo de seis, cinco e três indivíduos, respectivamente, quando se reamostraram indivíduos. Quando foram reamostradas populaçōes, nenhum boostrap foi descartado em nenhum dos conjuntos. Deve ser mencionado que, para os dados de Sebbenn et al. (s.d.), a reamostragem com número variável de populações não foi realizada, uma vez que somente duas populações foram amostradas.

Em nenhum dos conjuntos estudados ocorreu descarte de bootstraps quando realizada a reamostragem com número variável de locos. Na reamostragem de locos, foi possível obter bootstraps com amostras de tamanho um (Anexo A). A estimativa da variância com um só loco reamostrado é uma medida interessante, uma vez que representa a estimativa do componente da variância de locos, informação que não foi possível obter quando foram feitas reamostragens de indivíduos ou populações, pois nesses casos, o número mínimo de populações e/ou indivíduos a serem reamostrados tem que ser dois, para que as correlações entre alelos dentro de indivíduos e dentro de populações $e$ de indivíduos dentro de populações pudessem ser calculadas. Do Anexo A, observa-se que com um único loco, as estimativas das variâncias de $\hat{F}$ e de $\hat{f}$ continuam maiores que as de $\hat{\theta}$ em todos os conjuntos de dados. 


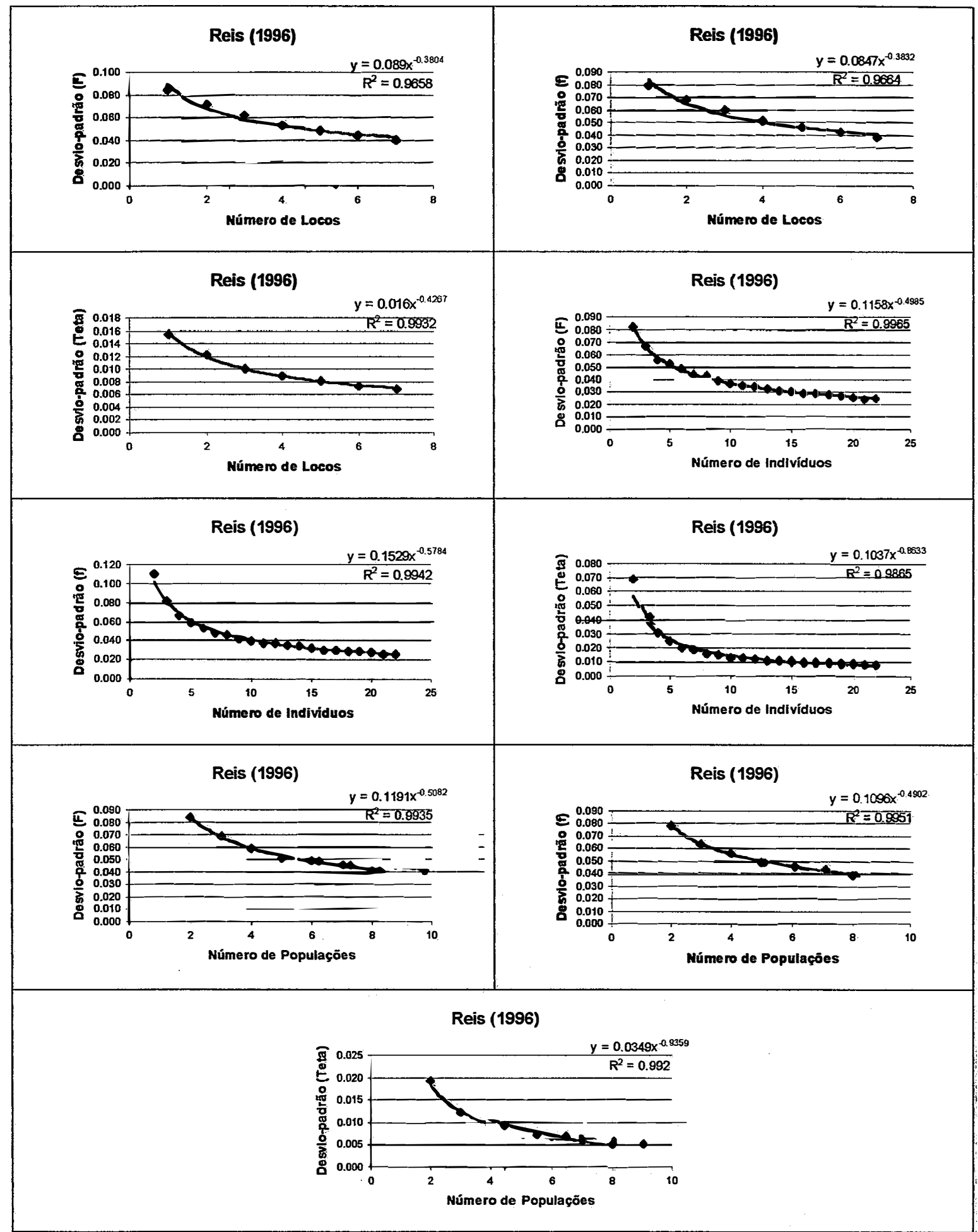

Figura 6. Análise de regressão entre as estimativas do desvios-padrão das estimativas dos parâmetros índice de fixação total $(F)$, índice de fixação dentro de populações $(f)$ e divergência entre populações $(\theta)$ e o número de locos, o número de indivíduos por população e o número de populaçōes, para os dados de Reis (1996). 


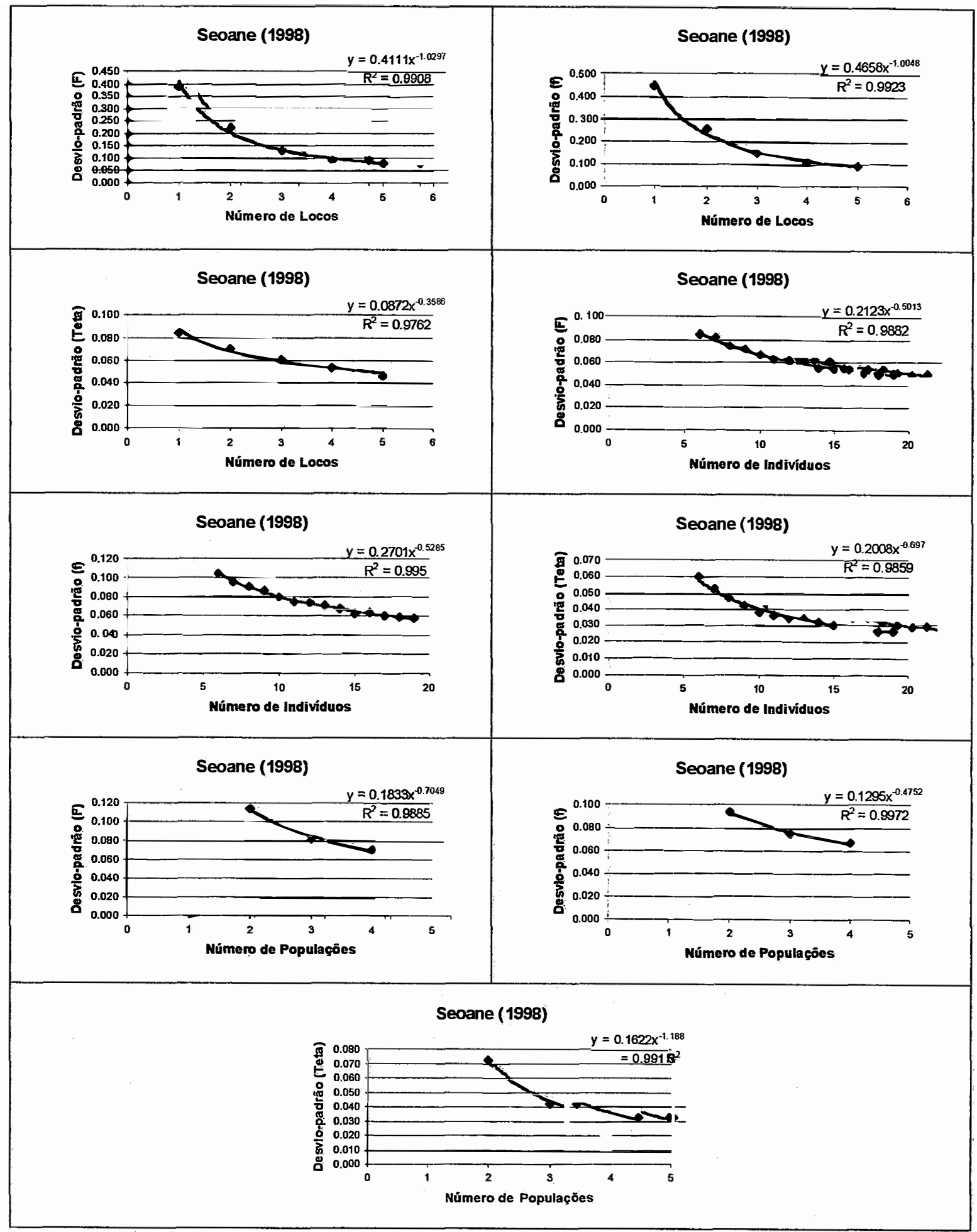

Figura 7. Análise de regressão entre as estimativas do desvios-padrão das estimativas dos parâmetros índice de fixação total $(F)$, índice de fixação dentro de populações $(f)$ e divergência entre populações $(\theta)$ e o número de locos, o número de indivíduos por população e o número de populações, para os dados de Seoane (1998). 


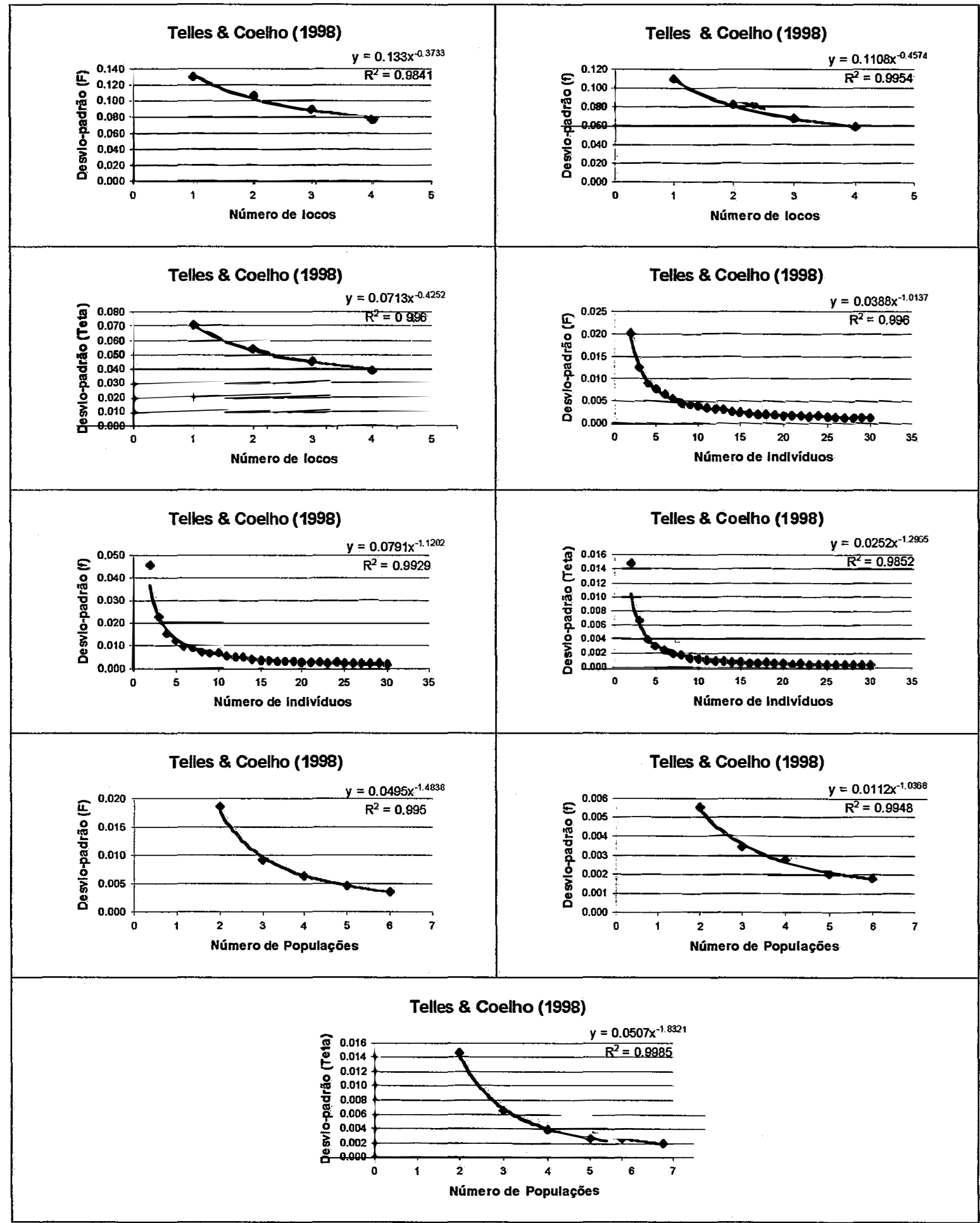

Figura 8. Análise de regressão entre as estimativas do desvios-padrão das estimativas dos parâmetros índice de fixação total $(F)$, índice de fixação dentro de populaçōes $(f)$ e divergência entre populações $(\theta)$ e o número de locos, o número de indivíduos por população e o número de populaçōes, para os dados de Telles \& Coelho (1998). 


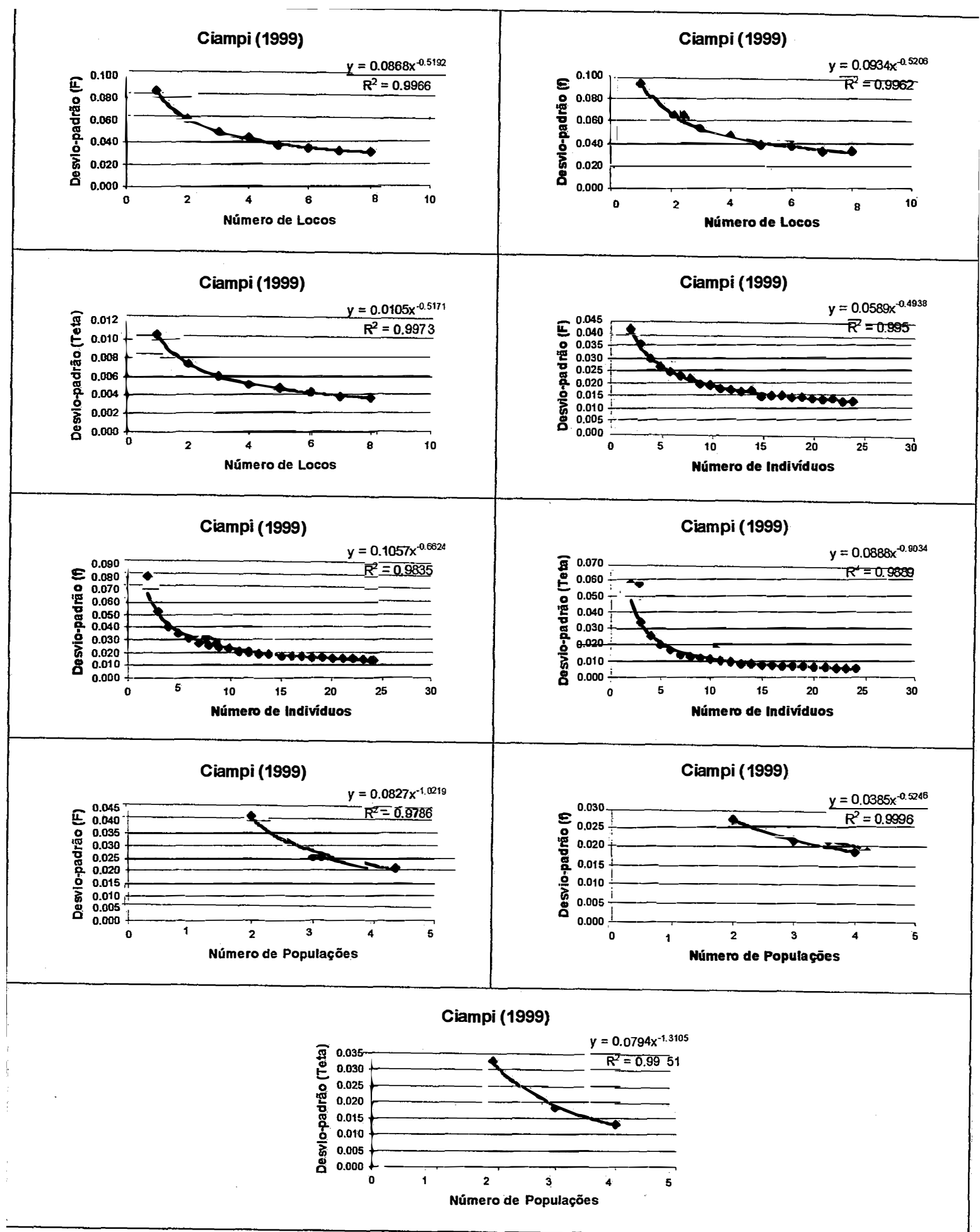

Figura 9. Análise de regressão entre as estimativas do desvios-padrão das estimativas dos parâmetros índice de fixação total $(F)$, índice de fixação dentro de populações $(f)$ e divergência entre populações $(\theta)$ e o número de locos, o número de indivíduos por população e o número de populações, para os dados de Ciampi (1999). 


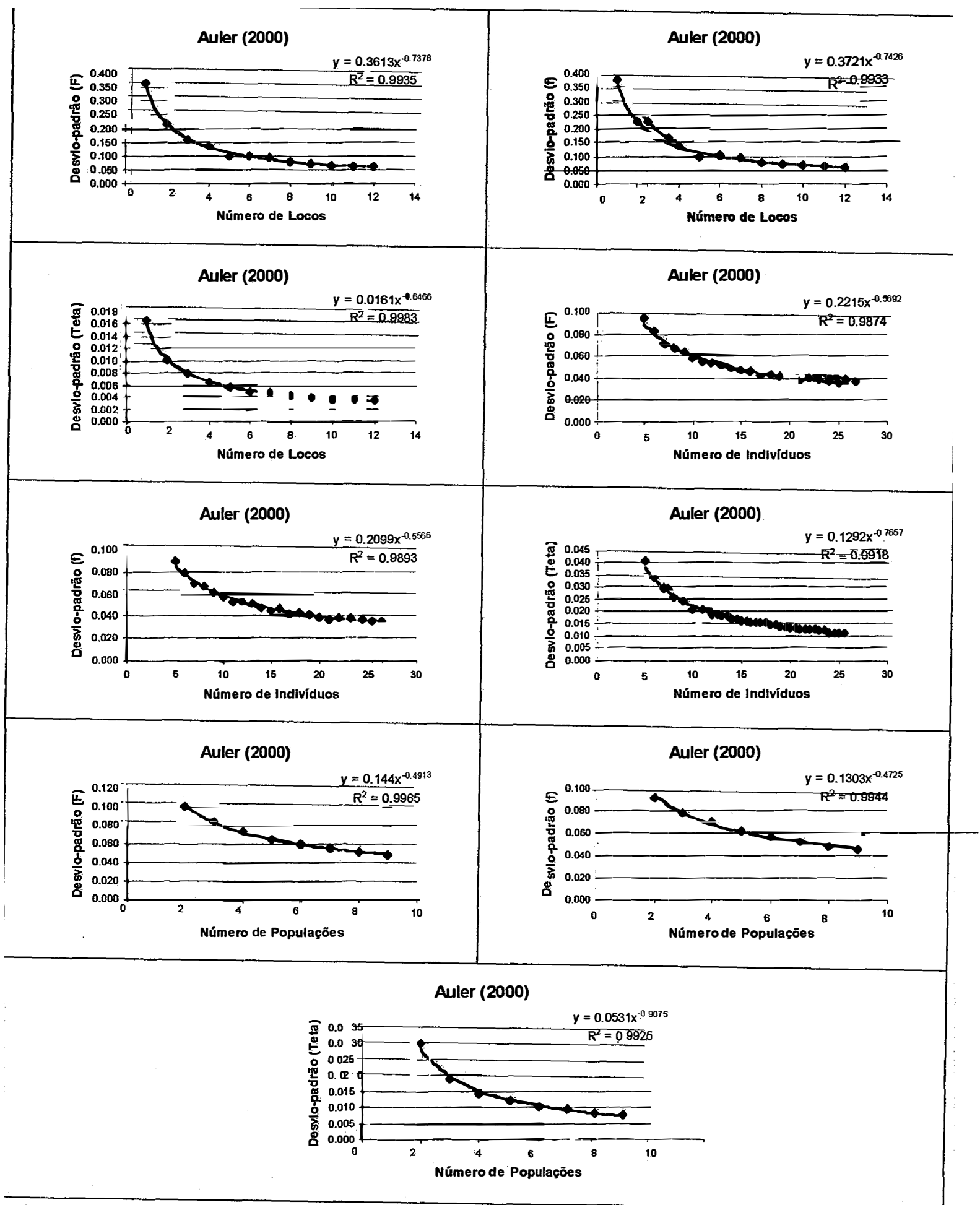

Figura 10. Análise de regressão entre as estimativas do desvios-padrão das estimativas dos parâmetros índice de fixação total $(F)$, índice de fixação dentro de populações $(f)$ e divergência entre populações $(\theta)$ e o número de locos, o número de indivíduos por população e o número de populações, para os dados de Auler (2000). 


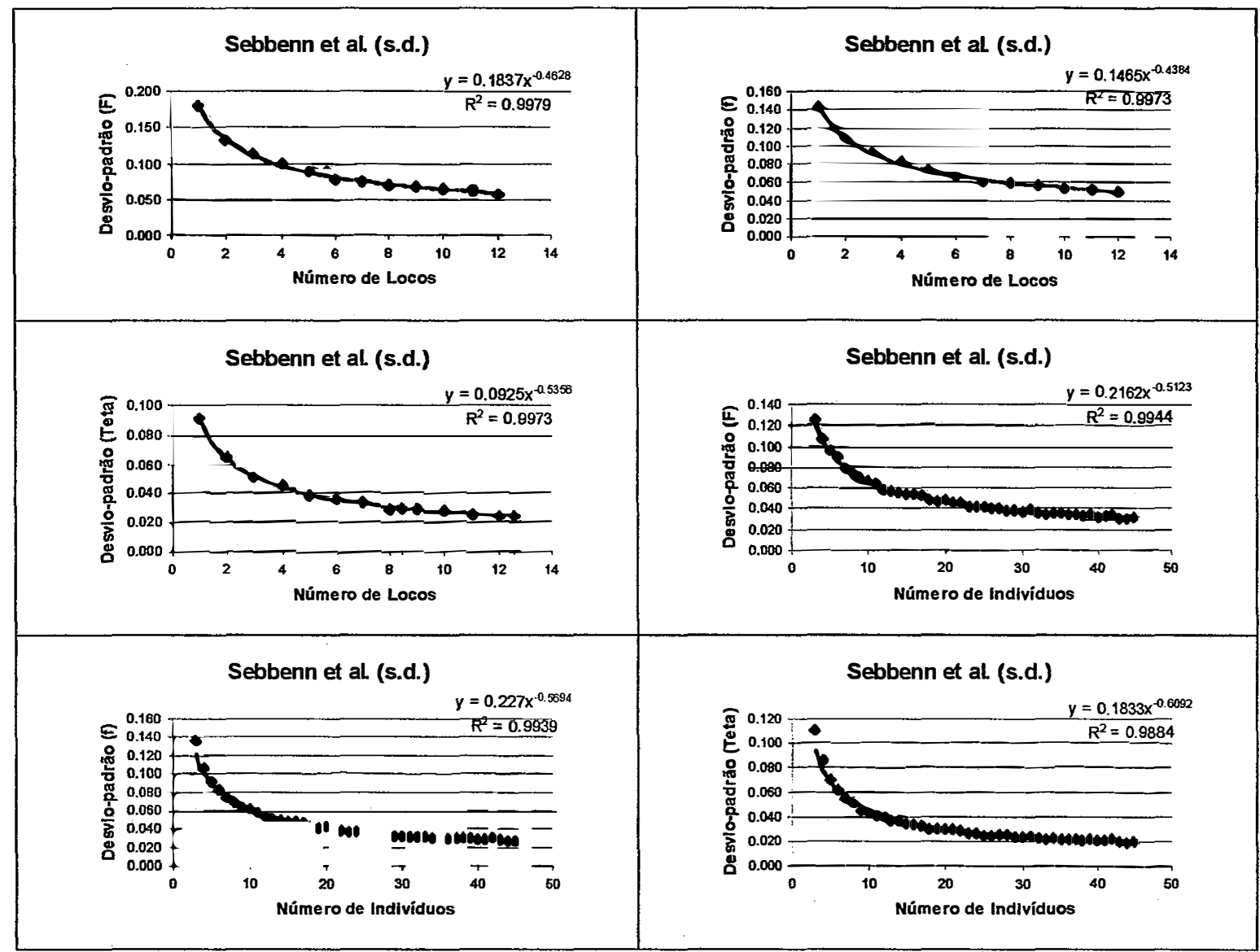

Figura 11. Análise de regressão entre as estimativas do desvios-padrão das estimativas dos parâmetros índice de fixação total $(F)$, índice de fixação dentro de populaçōes $(f)$ e divergência entre populações $(\theta)$ e o número de locos e o número de indivíduos por população, para os dados de Sebbenn et al. (s.d.).

Observa-se que em todos os casos o ajuste das curvas foi adequado, apresentando elevados coeficientes de determinação, sendo que o menor deles $\left(R^{2}=0,9664\right)$ foi encontrado, quando foram reamostrados locos para estimar o parâmetro $f$ no conjunto de Reis (1996) (Figura 6).

A partir das equações de regressão, foi possivel obter o número mínimo de locos, indivíduos e populações a serem considerados como orientação em pesquisas futuras, para atingir desvios-padrão menores ou iguais a 0,02 associados às estimativas de $F, f$ e $\theta$. Em geral, nota-se que, para obter erros dessa magnitude, os parâmetros $F$ e $f$, para serem estimados, requereriam número maior de locos, de indivíduos e de populações do que o que vem sendo em geral utilizados em pesquisas com populações naturais (Tabela 
15). Isso já era esperado, pois, como discutido no item 4.2.2. as estimativas de $F$ e $f$ tiveram variâncias maiores do que as de $\theta$.

Tabela 15. Número de locos (L), indivíduos (I) e populações (P) necessários para obter erros-padrão de ${ }^{\mathrm{a}} \hat{F},{ }^{\mathrm{b}} \hat{f} e^{\mathrm{c}} \hat{\boldsymbol{\theta}}$ iguais ou menores a 0,02 . Dados de diversos autores.

\begin{tabular}{|c|c|c|c|c|c|c|c|c|c|}
\hline \multirow[b]{2}{*}{ Nível } & \multicolumn{3}{|c|}{ Reis (1996) } & \multicolumn{3}{|c|}{ Seoare (1998) } & \multicolumn{3}{|c|}{ Telles \& Coelho (1998) } \\
\hline & $\hat{F}$ & $\hat{f}$ & $\hat{\theta}$ & $\hat{F}$ & $\hat{f}$ & $\hat{\theta}$ & $\hat{F}$ & $\hat{f}$ & $\hat{\theta}$ \\
\hline $\mathrm{L}$ & 51 & 44 & 1 & 19 & 23 & 61 & 160 & 43 & 20 \\
\hline I & 34 & 34 & 7 & 112 & 138 & 38 & 2 & 4 & 2 \\
\hline $\mathrm{P}$ & 34 & 33 & 2 & 24 & 51 & 6 & 2 & 1 & 2 \\
\hline & \multicolumn{3}{|c|}{ Ciampi (1999) } & \multicolumn{3}{|c|}{ Auler (2000) } & \multicolumn{3}{|c|}{ Sebbenn et al. (s.d.) } \\
\hline Nível & $\hat{F}$ & $\hat{f}$ & $\hat{\theta}$ & $\hat{F}$ & $\hat{f}$ & $\hat{\theta}$ & $\hat{F}$ & $\hat{f}$ & $\hat{\theta}$ \\
\hline $\mathrm{L}$ & 17 & 20 & 1 & 51 & 52 & 1 & 121 & 94 & 18 \\
\hline I & 9 & 13 & 6 & 69 & 69 & 12 & 105 & 72 & 38 \\
\hline $\mathrm{P}$ & 4 & 4 & 3 & 56 & 53 & 3 & & & \\
\hline
\end{tabular}

índice de fixação total; bíndice de fixação dentro das populaçôes; 'Grau de divergência entre populações.

Pelo que se observa nesta tabela, na estimação de $F$, o aumento do número de locos é o fator mais importante para diminuir o erro associado a tal estimativa. Isso foi visto nos conjuntos de Reis (1996), Telles \& Coelho (1998), Ciampi (1999) e Sebbenn et al. (s.d.). Esse resultado está em concordância com os do item 4.2.2., pois, em todos os conjuntos, as maiores variâncias associadas às estimativas desse parâmetro ocorreram com a reamostragem de locos. Para os conjuntos de Seoane (1998) e Auler (2000), seria mais importante aumentar o número de indivíduos em discordância com os resultados obtidos em 4.2.2. Esse comportamento observado talvez possa ser justificado pelo fato de os quatro primeiros conjuntos apresentarem proporcionalmente número maior de indivíduos em relação ao número de locos que os últimos dois conjuntos.

Em relação aos erros das estimativas de $F$, o número de populações estudadas pode ser considerado suficiente apenas nas pesquisas de Telles \& Coelho (1998) e Ciampi (1998); nos demais trabalhos, esse número não foi suficiente.

O parâmetro $f$ apresentou comportamento idêntico ao de $F$ e as mesma comparações em relação ao item 4.2.2. podem ser incorporadas aqui. $\mathrm{O}$ número de locos também foi insuficiente para obter estimativas de $f$ com emos da ordem de 0,02 . Já o números de indivíduos e de populações foi suficiente tanto nos dados de Telles \& Coelho (1998) como nos de Ciampi (1999). 
Para estimar $\theta$ com desvio-padrão máximo de 0,02 , o número de locos foi suficiente para os dados de Reis (1996), Ciampi (1999) e Auler (2000). O número de indivíduos foi suficiente nesses mesmos conjuntos e também nos dados de Telles \& Coelho (1998) e Sebbenn et al. (s.d.) e o número de populaçōes foi suficiente em todos os casos, exceto na pesquisa de Seoane (1998), que precisaria de duas populações a mais do que as que foram amostradas.

Nas pesquisas de Seoane (1998) e Telles \& Coelho (1998), o número de locos utilizado foi insuficiente para obter estimativas de $\theta$ com a precisão desejada, sendo, portanto, necessário aumentá-lo. Para os demais conjuntos, se o número de indivíduos fosse maior do que o usado, as estimativas de $\theta$ seriam ainda mais precisas. No entanto, com o número de indivíduos empregado, o nível de precisão desejado para tais estimativas foi atingido.

Com os dados de Reis (1996), observou-se que, para obter desvios-padrão com a magnitude supra-mencionada, o número de locos, indivíduos e populações foram insuficientes para as estimativas de $F$ e $f$ em todos os níveis de reamostragem considerados; o contrário ocorreu na estimação do parâmetro $\theta$, em que os tamanhos amostrais foram suficientes. O mesmo padrão foi observado para os dados de Auler (2000). Na pesquisa de Seoane (1998) apenas o número de populações pode ser considerado suficiente para estimar $\theta$ com o nível de precisão desejado. Por outro lado, nesta mesma pesquisa, o número de locos, de indivíduos $e$ de populações foram insuficientes para estimar $F$ e $f$. No trabalho de Telles \& Coelho (1998), os números de indivíduos e populações foram adequados para estimar os três parâmetro, mas o número de locos poderia ter sido maior para estimá-los com a precisão desejada. Com os dados de Ciampi (1999), observou-se comportamento semelhante a esse. No entanto, o número de locos foi adequado para estimar $\theta$ e, em Sebbenn et al. (s.d.), o número de locos não foi adequado para estimar nenhum dos três parâmetros $e$ o número de indivíduos só foi suficiente para estimar $\theta$ com desvio-padrão igual ou inferior a 0,02 .

Algumas considerações gerais podem ser feitas ao observar a Tabela 15. Os conjuntos de Reis (1996) e Ciampi (1999) apresentam várias semelhanças entre si, pois tratam de espécies alógamas ( $\hat{f}$ não diferiu de zero), com baixa divergência entre 
populações ( $\hat{\theta}$ não diferiu de zero). O número de populações de Reis (1996) foi o dobro do de Ciampi (1999), porém o número de locos e o número médio de indivíduos (cerca de 24 por população, em média) foram praticamente iguais nos dois conjuntos. No entanto, o número de indivíduos e de populações usados por Ciampi (1999) foram suficientes para estimar todos os parâmetros com a precisão desejada, enquanto para os dados de Reis (1996) foram suficientes apenas para estimar a diversidade interpopulacional. O número de locos em ambos os casos foi suficiente apenas para estimar $\theta$ com a precisão determinada, mas, observa-se que para a pesquisa de Ciampi (1999) o número de locos necessário visando estimativas dos índices de fixação total $e$ intrapopulacional foi menor (20 locos) do que no caso de Reis (1996) (51 locos).

O fato de se ter encontrado um número menor de locos, populações e indivíduos, com os dados de Ciampi (1999), em comparação com os de Reis (1996), para atingir a precisão desejada, deve-se ao tipo de marcador empregado. Enquanto Ciampi (1999) usou microssatélites, em que o número de alelos por loco variou de 19 a 31, Reis (1996) empregou isoenzimas, em que esse nú mero foi de no máximo seis. Assim, não só o número de locos mas também o número de alelos parece determinante na estimação dos parâmetros $F, f$ e $\theta$ com boa precisão.

De modo geral, em espécies alógamas, sem divergência significativa entre populações, o número de locos isoenzimáticos, de indivíduos por população e de populações necessários para estimar $F, f$ e $\theta$, com a precisão estipulada neste trabalho foi, respectivamente, de 51,34 e 34 , enquanto que se fossem usados marcadores microssatélites com o número médio de alelos por loco utilizado por Ciampi (1999) estes números cairiam para 20 locos, 13 indivíduos por população e 4 populações.

A espécie estudada por Telles \& Coelho (1998) é alógama, como as duas anteriores, mas apresenta divergência entre populações relativamente alta. Também neste caso, o número de locos foi o fator crítico, o que era esperado, uma vez que apenas quatro locos foram usados. Observe-se que, embora o número de populações tenha sido intermediário ao utilizado por Reis (1996) e Ciampi (1999), e o número de indivíduos (30 por população) tenha sido um pouco superior ao usado por esses autores, com os dados de Telles \& Coelho (1998) todos os parâmetros foram estimados com a precisão estipulada, quando realizadas reamostragens de populações e de indivíduos. No entanto, 
seria necessário, numa situação como esta, usar 160 locos isoenzimáticos (ou menos, se fossem usados marcadores microssatélites), quatro indivíduos por população $e$ duas populações.

O conjunto de Seoane (1998) é referente a uma espécie alógama com baixa divergência entre populações. Pelo que se observa da Tabela 15, para conjuntos desse tipo, são necessários elevados números de populações, locos e principalmente de indivíduos. Em situações como esta, talvez o uso de locos microssatélites com muitos alelos, como no conjunto de Ciampi (1999), seja uma maneira de minimizar esses tamanhos amostrais. Sebbenn et al. (s.d.) também trabalhou com uma espécie alógama com baixa divergência entre populações. As mesmas considerações feitas para Seoane (1998) podem ser usadas aqui, porém, como só duas populaçōes foram amostradas, o número de locos e indivíduos deveria ser muito maior, cerca de 120 locos e 105 indivíduos para que todos os parâmetros fossem estimados com a precisão requerida. Obviamente, se possível, seria muito importante aumentar o número de populações utilizadas.

A espécie estudada por Auler (2000) é dióica, apresenta índices de fixação intrapopulacional $e$ total e divergência entre populações estatisticamente maiores que zero. Numa situação como essa, seriam necessários 51 locos isoenzimáticos, 69 indivíduos por população e 56 populações. Nesse conjunto, assim como no de Seoane (1998) e de Sebbenn et al. (s.d.) o polimorfismo não foi elevado, o que pode ter contribuído para que os tamanhos amostrais requeridos para obter estimativas dos parâmetros de interesse com erros baixos fossem tão grandes. Também nesse caso, o uso de marcadores microssatélites ou mesmo de locos isoenzimáticos mais polimórficos provavelmente levaria a uma redução desses tamanhos amostrais.

Nos casos estudados não é tarefa simples chegar a uma recomendação geral, pois, embora esistam algumas semelhanças entre alguns casos, os resultados são particulares de cada conjunto. Assim, seria importante fazer análises prévias do material a ser estudado, como as realizadas no presente trabalho, e então, se necessário, voltar ao campo e coletar mais material e/ou aumentar o número de locos usados na avaliação. Considerando o conjunto de Telles \& Coelho (1998), por exemplo, observou-se que o número de populações e indivíduos foi adequado, mas o de locos foi insuficiente. Assim, não seria 
necessário voltar ao campo e coletar mais material, mas apenas aumentar o número de locos analisados.

Uma consideração adicional deve ser feita. Espera-se que, ao aumentar o número de indivíduos, haja uma redução na magnitude dos erros associados às estimativas pontuais dos parâmetros em função das fontes de variação de locos e de populações, mesmo mantendo constantes o número de populações $e$ de locos. Ao variar concomitantemente o número de indivíduos e de populações para os dados de Reis (1996), por exemplo, observa-se da Figura 12, que, para um mesmo número de populações, quanto maior o número de indivíduos, menor a variância das estimativas de $F, f$ e $\theta$ devida à reamostragem conjunta de indivíduos e populações, principalmente para um número pequeno de populações. Esse comportamento prevalece para qualquer número de populações considerado. Observe-se que, com duas populações, se o número de indivíduos aumentar de dois para seis a variância se reduz a menos da metade da variância obtida com dois indivíduos, em todos os parâmetros. Nota-se também que as menores variâncias das estimativas de tais parâmetros ocorrem quando os números de populações e de indivíduos são máximos, o que era esperado.

Como foi dito, para um mesmo número de populações a variância dos parâmetro é menor se um número maior de indivíduos for utilizado. Esse comportamento é concordante com a conclusão de Petit \& Pons (1998) quanto ao fato de a variância oriunda da reamostragem de populações $e$ indivíduos conter a variância total (entre indivíduos e entre populações) e intrapopulacional. Intuitivamente pode-se antever que o componente de variância devido a indivíduos, ao participar da composição da variância devida à reamostragens de populações, deve ser inversamente proporcional ao número de indivíduos considerados $e$ assim, quanto maior este número, menor a influência desse componente na variância populacional. $\mathrm{O}$ mesmo raciocínio pode ser aplicado à variância oriunda da reamostragem de indivíduos e populações conjuntamente, pois o componente de variância intrapopulacional deve estar contido duas vezes, provavelmente em diferentes proporções, uma vez que a variância devida à reamostragem de populações também o contém.

Observa-se ainda que, para um mesmo número de indivíduos por população, com o aumento do número de populações há uma redução da variância oriunda da 
reamostragem de indivíduos e populações conjuntamente. Ao aumentar o número de populações, automaticamente o número de indivíduos também aumenta. Logo, os componentes dessa variância oriundos tanto de indivíduos quanto de populações devem sofrer uma redução em sua magnitude, inversamente proporcional ao aumento do número de indivíduos e populações, respectivamente.

Diante de tudo o que foi exposto, ressalta-se novamente a necessidade de obter expressões explícitas das estimativas de variância das estimativas dos parâmetros $F, f e$ $\theta$ oriundas da reamostragem de locos, indivíduos, populações e indivíduos e populações conjuntamente para que tais considerações possam ser melhor investigadas.

De uma visão geral dos resultados obtidos, é possivel afirnar que o número de locos isoenzimáticos que vem sendo utilizado nas pesquisas com populações naturais não foi suficiente. Amostrar maior número de populações, igualmente, é estratégia que deve ser adotada. É conveniente enfatizar que, ao aumentar o número de locos, haverá aumento concomitante do número total de alelos. Também, com incremento do número de populações, deverá crescer o número total de indivíduos amostrados. Esses detalhes são importantes e devem ser levados em conta para atingir desvios-padrão das estimativas dos parâmetros, que sejam compativeis e adequados. 


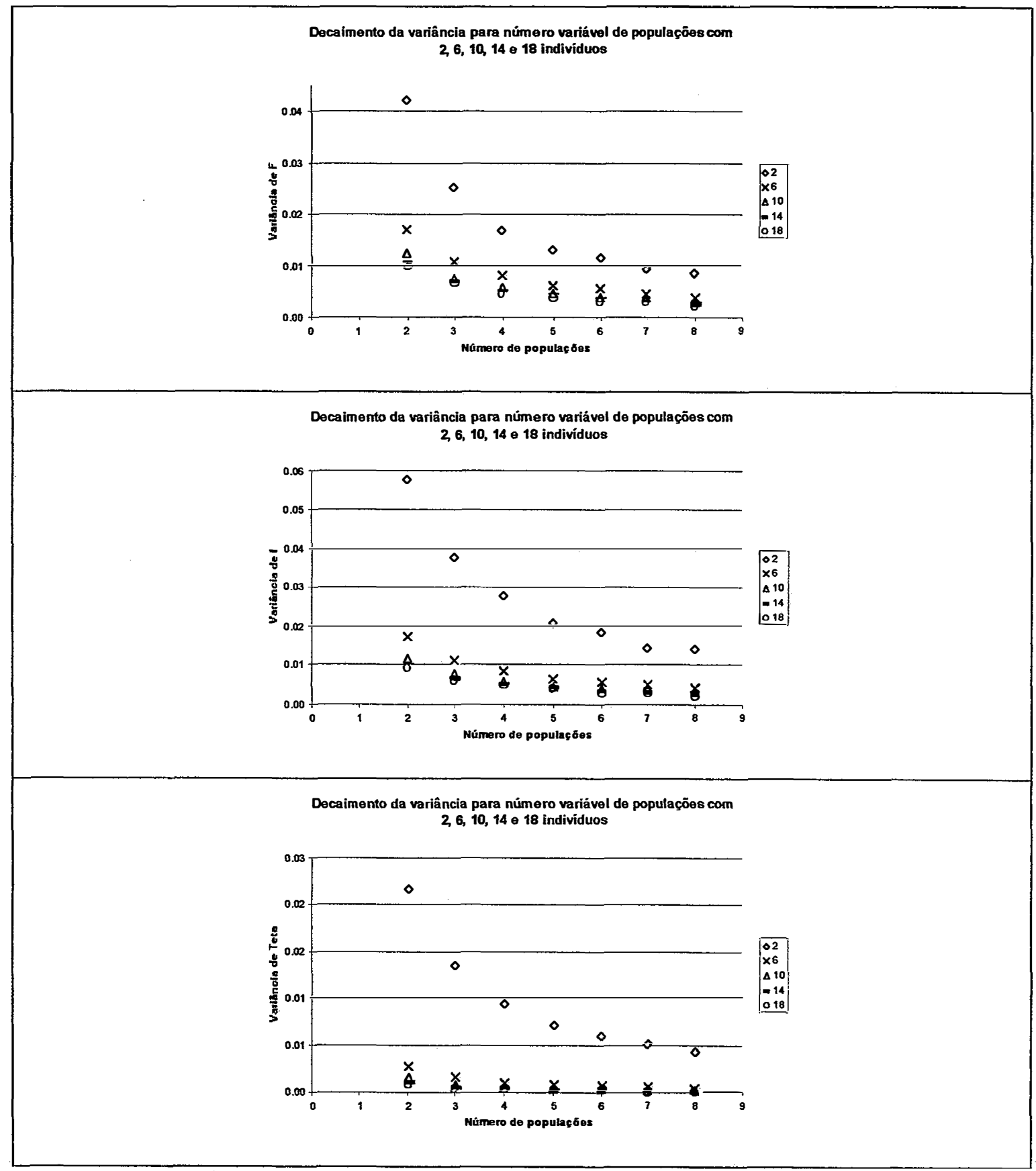

Figura 12. Decaimento das variâncias oriundas da reamostragem de indivíduos $e$ populações conjuntamente, em função do número variável de indivíduos para diversos números de populaçōes. Parâmetros considerados: índice de fixação geral $(F)$, índice de fixação dentro de populações $(f)$ e divergência entre populações $(\theta)$. Dados de Reis (1996). 


\subsubsection{Análise fatorial das estimativas bootstrap de variância}

Como descrito no item 4.3.1., foram feitos 1.000 bootstraps para cada combinação entre o número de populações $e$ o número de indivíduos. No entanto, na análise de variância foram concluídas somente as estimativa de variâncias das combinações com menos de $10 \%$ de bootstraps descartados. Assim, com os conjuntos de Auler (2000) e de Seoane (1998), o número mínimo de indivíduos considerados foi de cinco e seis, respectivamente. Também nesse item, os dados de Sebbenn et al. (s.d.) não foram considerados por serem constituídos de apenas duas populações.

Os resultados apresentados na Tabela 16 foram comparados aos apresentados no item 4.2.2. As comparações foram feitas desconsiderando os resultados obtidos para a fonte de variação de locos em tal item.

Tabela 16. Análise de variância das estimativas da variância bootstrap de ${ }^{\mathrm{a}} \hat{\boldsymbol{F}},{ }^{\mathrm{b}} \hat{\boldsymbol{f}} e^{\mathrm{c}} \hat{\boldsymbol{\theta}}$ oriundas da reamostragem conjunta de indivíduos (I) e populações (P), Valores de ${ }^{\mathrm{d}} R^{2}$. Dados de diversos autores.

\begin{tabular}{|c|c|c|c|c|c|c|c|c|c|c|c|}
\hline \multirow{2}{*}{\multicolumn{4}{|c|}{$\hat{F}$}} & \multicolumn{5}{|c|}{ Reis (1996) } & & \\
\hline & & & & \multicolumn{4}{|c|}{$\hat{f}$} & \multicolumn{4}{|c|}{$\hat{\theta}$} \\
\hline$F V$ & $G L$ & $S Q$ & $R^{2}$ & $F V$ & $G L$ & $S Q$ & $R^{2}$ & $F V$ & $G L$ & $S Q$ & $R^{2}$ \\
\hline I & 20 & $7,69.10^{-03}$ & 38,01 & I & 20 & $1,95.10^{-02}$ & 55,76 & $T$ & 20 & $3,25.10^{-8}$ & 64,86 \\
\hline $\mathrm{P}$ & 6 & $9,64.10^{-03}$ & 47,66 & $\mathrm{P}$ & 6 & $9,91 \cdot 10^{-03}$ & 28,32 & $\mathrm{P}$ & 6 & $4,91.10^{-04}$ & 9,80 \\
\hline $\operatorname{IxP}$ & 120 & $2,82.10^{-03}$ & 13,93 & $I * P$ & 120 & $5,49.10^{-03}$ & 15,68 & $I * P$ & 120 & $1,26.10^{-03}$ & 25,11 \\
\hline Resíduo & 588 & $8,23.10^{-05}$ & & Resíduo & 588 & $8,32.10^{-05}$ & & Resíduo & 588 & $1,18.10^{-05}$ & \\
\hline Total & 734 & $2,02.10^{-02}$ & & Total & 734 & $3,50.10^{-22}$ & & Total & 734 & $5,01.10^{-\infty}$ & \\
\hline \multicolumn{12}{|c|}{ Seoane (1998) } \\
\hline \multicolumn{4}{|c|}{$\hat{F}$} & \multicolumn{4}{|c|}{$\hat{f}$} & \multicolumn{4}{|c|}{$\hat{\theta}$} \\
\hline$F V$ & $G L$ & $S Q$ & $R^{2}$ & $F V$ & $G L$ & $S Q$ & $R^{2}$ & $F V$ & $G L$ & $S Q$ & $R^{2}$ \\
\hline I & 13 & $1,15.10^{-03}$ & 16,82 & I & 13 & $2,07.10^{-13}$ & 38,11 & $\mathrm{~T}$ & 13 & $2,45.10^{04}$ & 18,08 \\
\hline $\mathrm{P}$ & 2 & $5,45.10^{-03}$ & 79,55 & $P$ & 2 & $3,13.10^{-03}$ & 57,60 & $P$ & 2 & $1,07.10^{-03}$ & 79,38 \\
\hline $\operatorname{LxP}$ & 26 & $1,71.10^{-04}$ & 2,50 & $I^{*} \mathrm{P}$ & 26 & $1,77.10^{-04}$ & 3,26 & $I * P$ & 26 & $2,60.10^{-05}$ & 1,92 \\
\hline Resíduo & 168 & $7,73.10^{-05}$ & & Resíduo & 168 & $5,59.10^{-05}$ & & Resíduo & 168 & $8,30 \cdot 10^{-06}$ & \\
\hline Total & 209 & $6,85.10^{-03}$ & & Total & 209 & $5,43.10^{-03}$ & & Total & 209 & $1,35.10^{83}$ & \\
\hline
\end{tabular}


Continuação da Tabela 16. Análise de variância das estimativas da variância bootstrap de ${ }^{\mathrm{a}} \hat{F},{ }^{\mathrm{b}} \hat{\boldsymbol{f}} e^{\mathrm{c}} \hat{\boldsymbol{\theta}}$ oriundas da reamostragem conjunta de indivíduos (I) e populaçōes (P), Valores de ${ }^{\mathrm{d}} R^{2}$. Dados de diversos autores.

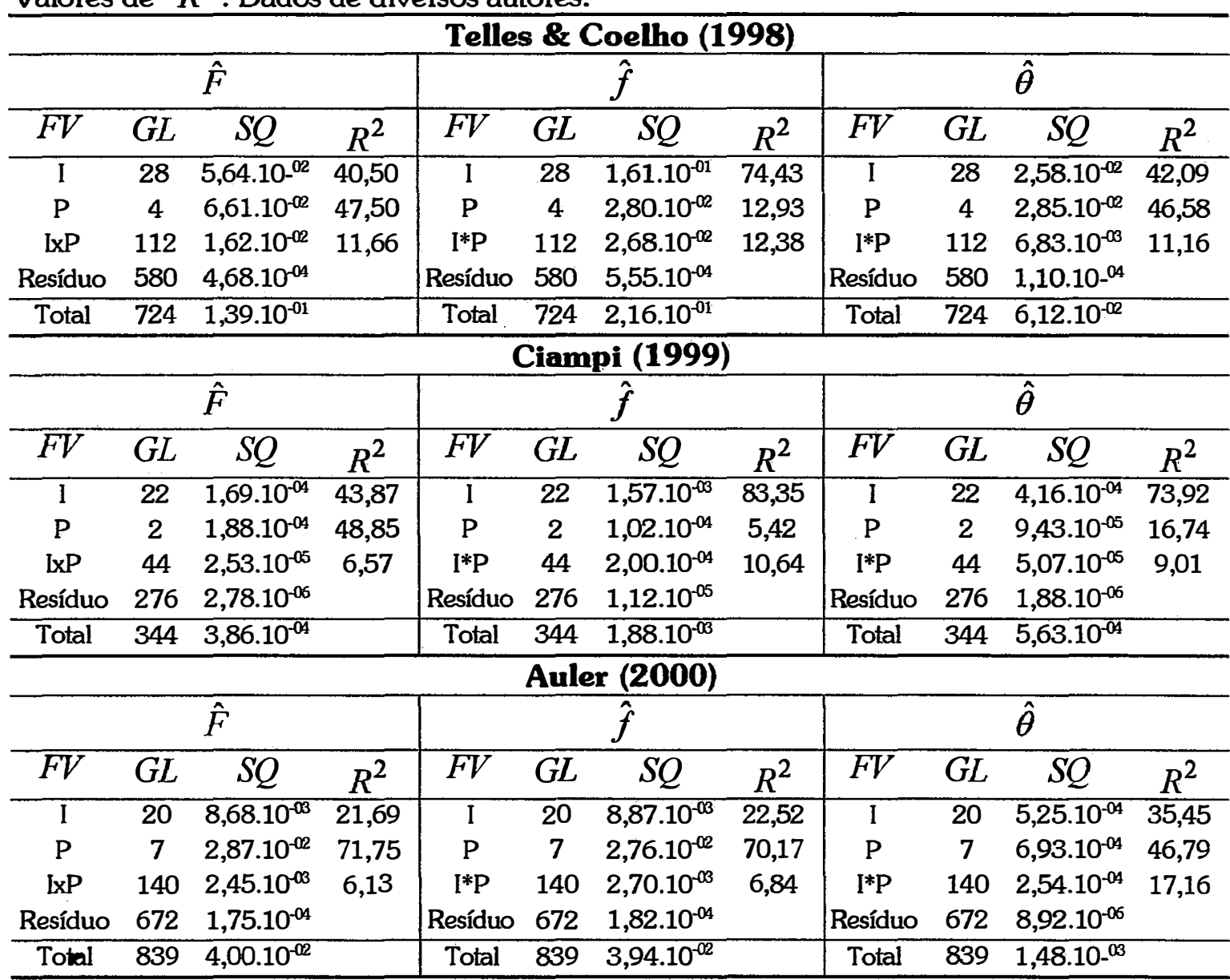

ándice de fixação total; 'índice de fixação dentro das populaçōes; 'Grau de divergência entre populaçōes; ${ }^{\mathrm{d}}$ coeficiente de deteminação (\%).

Da Tabela 16, observa-se pelos coeficiente de determinação $\left(R^{2}\right)$ que, para as estimativas do parâmetro $F$, as maiores variâncias foram provenientes do efeito de populações em todos os conjuntos, o que é concordante com os resultados obtidos em 4.2.2., pois, desconsiderando-se a fonte de variação de locos, as maiores variâncias foram observadas justamente quando foram reamostradas populações (Tabela 11).

Quanto ao parâmetro $f$, as maiores variâncias de suas estimativas decorreram do efeito de indivíduos, para os dados de Reis (1996), Telles \& Coelho (1998) e Ciampi (1999) e de populações para Seoane (1998) e Auler (2000) (Anexo A). Esses resultados 
foram concordantes com os do item 4.2.2. somente para os conjuntos de Seoane (1998), Telles \& Coelho (1998) e Auler (2000).

No caso das estimativas de $\theta$, as maiores variâncias estiveram associadas ao efeito de indivíduos, nos dados de Reis (1996) e Ciampi (1999) e de populações para os demais conjuntos (Tabela 11). Apenas para Auler (2000) esses resultados não foram concordantes com o item 4.2.2..

Com os dados de Reis (1996), para obter estimativas mais precisas de $F$, seria necessário aumentar o número de populações analisadas e para melhorar a precisão das estimativas de $f$ e de $\theta$ o número de indivíduos por população deveria ser maior. Comportamento idêntico foi observado com os dados de Ciampi (1999).

Estimativas mais precisas desses três parâmetros seriam obtidas para os dados de Seoane (1998) e Auler (2000) se o número de populações amostradas fosse maior nesses dois conjuntos. Na pesquisa de Telles \& Coelho (1998) seria necessário aumentar o número de populações para obter estimativas melhores de $F$ e $\theta$, e ampliar o número de indivíduos dentro de populações para que o desvio-padrão associado a $\hat{f}$ fosse menor.

De maneira geral, nota-se boa concordância entre os resultados obtidos com a reamostragem bootstrap com tamanhos constantes de amostra, sob modelo hierárquico $e$ os resultados obtidos com a reamostragem conjunta de indivíduos e populações em diversas repetiçōes, analisando em seguida as variâncias obtidas sob estrutura fatorial. Assim, esta seria uma metodologia alternativa proposta para verificar, através do coeficiente de determinação, quais fontes de variação são responsáveis por maiores variâncias associadas às estimativas de interesse. Esse método de análise também pode ser aplicado a quaisquer níveis de hierarquia, como por exemplo, quando se tem estrutura de subpopulações ou de progênies. A desvantagem é que não são feitas reamostragens concomitantes de locos, não sendo, portanto, obtidas informações sobre a variância associada a essa fonte de variação.

Pode-se concluir que este método se mostrou muito útil na determinação das importância relativa das fontes de variação de indivíduos e de populações na estimação dos parâmetros populacionais $F, f e \theta$. 


\section{CONCLUSÕES}

i. Ficou evidenciada a importância e a necessidade de, ao aplicar a reamostragem, levar em conta os diferentes níveis ou fontes de variação, a fim de melhor aquilatar o desvio-padrão das estimativas dos parâmetros;

ii. Os desvios-padrão das estimativas, decorrentes das várias fontes de variação, foram de grandezas diferentes. Esse fato deve ser considerado no planejamento da amostragem em pesquisas compopulações naturais, através de marcadores genéticos;

iii. Em relação aos parâmetros $F$ e $f$, os maiores desvios-padrão provieram da fonte de variação de locos e, em seguida, da de populações. Esta última também foi relevante como fonte de erro na estimação do parâmetro $\mathrm{Nm}$. No caso dos parâmetros $t_{a}$ e $N_{e}$, destacaram-se os erros provenientes da reamostragem de locos, em alguns casos e de indivíduos em outros. Isso realça os cuidado que se deve ter para encontrar uma amostragem adequada nas pesquisas;

iv. Os maiores erros foram obtidos na estimação de $F, f$ e $\mathrm{Nm}$ e os menores na estimação de $\theta$. Verificou-se, em termos gerais, que os tamanhos amostrais utilizados nas pesquisas aqui investigadas não foram suficientes, principalmente no que diz respeito ao número de locos $e$ de populações, que deveriam ter sido maiores;

v. Diante da existência de diferentes fontes de variação $e$, portanto, de diferentes intervalos de confiança para um mesmo parâmetro, a coincidência ou não desses intervalos deve ser levada em conta para fazer inferências a respeito do parâmetro em questão; 
vi. Em termos biométricos: a) somente as estimativas de $F$ e $f$ tenderam à normalidade, nos casos em que o número total de indivíduos foi elevado. Isso deve ser levado em conta ao fazer testes de hipóteses e reforça a importância da reamostragem, por bootstrap ou randomização, na realização desses testes; b) a aditividade das variâncias estimadas, quando se reamostra em diferentes níveis, facilitará muito a obtenção dessa variâncias para os vários níveis conjuntamente; c) tanto a análise hierárquica como a fatorial podem ser empregadas para mensurar a grandeza relativa das variâncias decorrentes das diferentes fontes de variação. 
ANEXOS 
Anexo A: Estimativas bootstrap de ${ }^{a} F,{ }^{b} f e^{c} \theta$ e de suas respectivas variâncias oriundas do método de reamostragem bootstrap com tamanhos de amostra variáveis de locos (L), indivíduos (I) e populações (P), para os conjuntos de dados avaliados.

\begin{tabular}{|c|c|c|c|c|c|c|c|}
\hline \multicolumn{8}{|c|}{ Reis (1996) - reamostragem de locos } \\
\hline & & \multicolumn{2}{|c|}{$\hat{F}$} & \multicolumn{2}{|c|}{$\hat{f}$} & \multicolumn{2}{|c|}{$\hat{\theta}$} \\
\hline $\mathrm{N}^{\circ}$ de locos & n.b.d." & Estimativa & Variância & Estimativa & Variância & Estimativa & Variância \\
\hline 1 & 0 & $-0,03983$ & 0,006997 & $-0,06062$ & 0,006326 & 0,01986 & 0,000241 \\
\hline 2 & 0 & $-0,03359$ & 0,005103 & $-0,05146$ & 0,004629 & 0,017199 & 0,000151 \\
\hline 3 & 0 & $-0,03539$ & 0,003912 & $-0,05279$ & 0,003524 & 0,016699 & 0,000102 \\
\hline 4 & 0 & $-0,03085$ & 0,002846 & $-0,04888$ & 0,002564 & 0,017319 & 0,000081 \\
\hline 5 & 0 & $-0,03198$ & 0,002403 & $-0,04958$ & 0,002140 & 0,016886 & 0,000067 \\
\hline 6 & 0 & $-0,03046$ & 0,001958 & $-0,04794$ & 0,001751 & 0,016778 & 0,000054 \\
\hline 7 & 0 & $-0,03309$ & 0,001598 & $-0,05034$ & 0,001442 & 0,016493 & 0,000046 \\
\hline \multicolumn{8}{|c|}{ Reis (1996) - reamostragem de indivíduos } \\
\hline & & \multicolumn{2}{|c|}{$\hat{F}$} & \multicolumn{2}{|c|}{$\hat{f}$} & \multicolumn{2}{|c|}{$\hat{\theta}$} \\
\hline $\mathrm{N}^{\circ}$ de indivíduos & n.b.d." & Estimativa & Variância & Estimativa & Variância & Estimativa & Variância \\
\hline 2 & 46 & $-0,023457$ & 0,006667 & $-0,065821$ & 0,012232 & 0,035207 & 0,004669 \\
\hline 3 & 3 & $-0,024989$ & 0,004426 & $-0,064486$ & 0,006703 & 0,035368 & 0,001774 \\
\hline 4 & 2 & $-0,028069$ & 0,003094 & $-0,069437$ & 0,004373 & 0,037767 & 0,000927 \\
\hline 5 & 0 & $-0,027918$ & 0,002731 & $-0,067271$ & 0,003420 & 0,036353 & 0,000606 \\
\hline 6 & 0 & $-0,026812$ & 0,002333 & $-0,067145$ & 0,002780 & 0,037478 & 0,000400 \\
\hline 7 & 0 & $-0,026170$ & 0,001942 & $-0,065664$ & 0,002308 & 0,036790 & 0,000345 \\
\hline 8 & 0 & $-0,028084$ & 0,001828 & $-0,066953$ & 0,002094 & 0,036246 & 0,000249 \\
\hline 9 & 0 & $-0,027807$ & 0,001537 & $-0,066589$ & 0,001744 & 0,036211 & 0,000214 \\
\hline 10 & 0 & $-0,028524$ & 0,001345 & $-0,067149$ & 0,001524 & 0,036077 & 0,000167 \\
\hline 11 & 0 & $-0,027316$ & 0,001203 & $-0,066153$ & 0,001384 & 0,036308 & 0,000155 \\
\hline 12 & 0 & $-0,025447$ & 0,001166 & $-0,063746$ & 0,001380 & 0,035872 & 0,000153 \\
\hline 13 & 0 & $-0,026350$ & 0,001080 & $-0,065533$ & 0,001259 & 0,036672 & 0,000120 \\
\hline 14 & 0 & $-0,027140$ & 0,000976 & $-0,066295$ & 0,001133 & 0,036630 & 0,000108 \\
\hline 15 & 0 & $-0,026277$ & 0,000902 & $-0,065364$ & 0,001043 & 0,036606 & 0,000101 \\
\hline 16 & 0 & $-0,027444$ & 0,000804 & $-0,066575$ & 0,000900 & 0,036627 & 0,000090 \\
\hline 17 & 0 & $-0,026399$ & 0,000806 & $-0,066059$ & 0,000908 & 0,037144 & 0,000082 \\
\hline 18 & 0 & $-0,026978$ & 0,000779 & $-0,065898$ & 0,000842 & 0,036472 & 0,000080 \\
\hline 19 & 0 & $-0,026944$ & 0,000727 & $-0,065737$ & 0,000843 & 0,036337 & 0,000073 \\
\hline 20 & 0 & $-0,025185$ & 0,000668 & $-0,064101$ & 0,000766 & 0,036516 & 0,000071 \\
\hline 21 & 0 & $-0,027073$ & 0,000590 & $-0,065834$ & 0,000659 & 0,036323 & 0,000065 \\
\hline 22 & 0 & $-0,027254$ & 0,000603 & $-0,065863$ & 0,000669 & 0,036185 & 0,000058 \\
\hline
\end{tabular}

\begin{tabular}{cccccccc}
\hline & \multicolumn{4}{c}{$\hat{F}$} & \multicolumn{2}{c}{$\hat{f}$} & \multicolumn{2}{c}{$\hat{\theta}$} \\
\hline $\mathrm{N}^{\circ}$ de populaçóes & n.b.d. & Estimativa & Variância & Estimativa & Variância & Estimativa & Variância \\
\hline 2 & 0 & $-0,021492$ & 0,007002 & $-0,033416$ & 0,006086 & 0,011841 & 0,000367 \\
3 & 0 & $-0,022445$. & 0,004676 & $-0,034542$ & 0,004078 & 0,011940 & 0,000146 \\
4 & 0 & $-0,023196$ & 0,003470 & $-0,034892$ & 0,003122 & 0,011452 & 0,000085 \\
5 & 0 & $-0,022096$ & 0,002635 & $-0,034114$ & 0,002382 & 0,011738 & 0,000054 \\
6 & 0 & $-0,022072$ & 0,002399 & $-0,033952$ & 0,002132 & 0,011612 & 0,000047
\end{tabular}


Continuação do Anexo A: Estimativas bootstrap de ${ }^{\mathrm{a}} F,{ }^{\mathrm{b}} f e^{\mathrm{c}} \boldsymbol{\theta}$ e de suas respectivas variâncias oriundas do método de reamostragem bootstrap com tamanhos de amostra variáveis de locos (L), indivíduos (I) e populações (P), para os conjuntos de dados avaliados.

\begin{tabular}{|c|c|c|c|c|c|c|c|}
\hline & & \multicolumn{2}{|c|}{$\hat{F}$} & \multicolumn{2}{|c|}{$\hat{f}$} & \multicolumn{2}{|c|}{$\hat{\theta}$} \\
\hline $\mathrm{N}^{\circ}$ de populações & n.b.d." & Estimativa & Variância & Estimativa & Variância & Estimativa & Variância \\
\hline 7 & 0 & $-0,024177$ & 0,002072 & $-0,035998$ & 0,001872 & 0,011507 & 0,000032 \\
\hline 8 & 0 & $-0,025106$ & 0,001627 & $-0,036734$ & 0,001496 & 0,011280 & 0,000026 \\
\hline \multicolumn{8}{|c|}{ Seoane (1998) - reamostragem de locos } \\
\hline & & \multicolumn{2}{|c|}{$\hat{F}$} & \multicolumn{2}{|c|}{$\hat{f}$} & \multicolumn{2}{|c|}{$\hat{\theta}$} \\
\hline $\mathrm{N}^{\circ}$ de locos & n.b.d. & Estimativa & Variância & Estimativa & Variância & Estimativa & Variância \\
\hline 1 & 0 & 0,271616 & 0,153293 & 0,183163 & 0,200184 & 0,079648 & 0,007149 \\
\hline 2 & $\mathbf{0}$ & 0,128453 & 0,049676 & 0,025140 & 0,064898 & 0,096778 & 0,004959 \\
\hline 3 & 0 & 0,095743 & 0,017477 & $-0,009680$ & 0,022899 & 0,100550 & 0,003688 \\
\hline 4 & 0 & 0,098865 & 0,008656 & $-0,002428$ & 0,012262 & 0,098360 & 0,002852 \\
\hline 5 & 0 & 0,088230 & 0,006252 & $-0,013093$ & 0,008748 & 0,098172 & 0,002202 \\
\hline \multicolumn{8}{|c|}{ Seoane (1998) - reamostragem de individuos } \\
\hline & & \multicolumn{2}{|c|}{$\hat{F}$} & \multicolumn{2}{|c|}{$\hat{f}$} & \multicolumn{2}{|c|}{$\hat{\theta}$} \\
\hline $\mathrm{N}^{\circ}$ de indivíduos & n.b.d." & Estimativa & Variância & Estimativa & Variância & Estimativa & Variância \\
\hline 2 & 579 & 0,030853 & 0,010780 & $-0,030768$ & 0,023002 & 0,048436 & 0,012410 \\
\hline 3 & 356 & 0,048717 & 0,011378 & $-0,042760$ & 0,019134 & 0,080817 & 0,009211 \\
\hline 4 & 232 & 0,063625 & 0,009308 & $-0,038233$ & 0,014153 & 0,093458 & 0,006708 \\
\hline 5 & 137 & 0,064079 & 0,008644 & $-0,046546$ & 0,011929 & 0,102842 & 0,004607 \\
\hline 6 & 84 & 0,068799 & 0,007262 & $-0,048127$ & 0,010799 & 0,108928 & 0,003654 \\
\hline 7 & 42 & 0,073346 & 0,006719 & $-0,050250$ & 0,009252 & 0,115905 & 0,002786 \\
\hline 8 & 15 & 0,078260 & 0,005469 & $-0,045707$ & 0,008164 & 0,116863 & 0,002214 \\
\hline 9 & 17 & 0,077270 & 0,005078 & $-0,046024$ & 0,007401 & 0,116520 & 0,001803 \\
\hline 10 & 8 & 0,073041 & 0,004417 & $-0,051003$ & 0,006445 & 0,116893 & 0,001452 \\
\hline 11 & 7 & 0,076747 & 0,003949 & $-0,047745$ & 0,005599 & 0,117851 & 0,001333 \\
\hline 12 & 3 & 0,074770 & 0,003866 & $-0,051025$ & 0,005398 & 0,118848 & 0,001202 \\
\hline 13 & 1 & 0,076181 & 0,003681 & $-0,052378$ & 0,004981 & 0,121406 & 0,001186 \\
\hline 14 & 2 & 0,075534 & 0,003029 & $-0,051653$ & 0,004487 & 0,120138 & 0,001020 \\
\hline 15 & 1 & 0,076914 & 0,002947 & $-0,049167$ & 0,003891 & 0,119623 & 0,000912 \\
\hline 16 & 1 & 0,078548 & 0,002881 & $-0,046601$ & 0,003968 & 0,119015 & 0,000821 \\
\hline 17 & 2 & 0,075848 & 0,002546 & $-0,049564$ & 0,003619 & 0,118874 & 0,000847 \\
\hline 18 & 0 & 0,074860 & 0,002374 & $-0,051521$ & 0,003416 & 0,119648 & 0,000712 \\
\hline 19 & 1 & 0,076559 & 0,002477 & $-0,048940$ & 0,003311 & 0,119191 & 0,000707 \\
\hline
\end{tabular}

Seoane (1998) - reamostragem de populaçóes

\begin{tabular}{cccccccc}
\hline & \multicolumn{2}{c}{$\hat{F}$} & \multicolumn{2}{c}{$\hat{f}$} & \multicolumn{2}{c}{$\hat{\theta}$} \\
\hline $\mathrm{N}^{\circ}$ de populações & n.b.d. & Estimativa & Variância & Estimativa & Variância & Estimativa & Variância \\
\hline 2 & 0 & 0,066800 & 0,012969 & $-0,000497$ & 0,008753 & 0,067146 & 0,005261 \\
3 & 0 & 0,069288 & 0,006719 & $-0,003535$ & 0,005785 & 0,072451 & 0,001770 \\
4 & 0 & 0,069183 & 0,004932 & $-0,003556$ & 0,004545 & 0,072399 & 0,001029
\end{tabular}


Continuação do Anexo A: Estimativas bootstrap de ${ }^{\mathrm{a}} F,{ }^{\mathrm{b}} f e^{\mathrm{c}} \theta$ e de suas respectivas variâncias oriundas do método de reamostragem bootstrap com tamanhos de amostra variáveis de locos (L), indivíduos (I) e populações (P), para os conjuntos de dados avaliados.

\begin{tabular}{|c|c|c|c|c|c|c|c|}
\hline \multicolumn{8}{|c|}{ Telles \& Coelho (1998) - reamostragem de locos } \\
\hline & & \multicolumn{2}{|c|}{$\hat{F}$} & \multicolumn{2}{|c|}{$\hat{f}$} & \multicolumn{2}{|c|}{$\hat{\theta}$} \\
\hline $\mathrm{N}^{\circ}$ de locos & n.b.d." & Estimativa & Variância & Estimativa & Variância & Estimativa & Variância \\
\hline 1 & 0 & 0,226862 & 0,017002 & 0,035086 & 0,011963 & 0,202302 & 0,004983 \\
\hline 2 & $\mathbf{0}$ & 0,227065 & 0,011265 & 0,023873 & 0,006814 & 0,211098 & 0,002908 \\
\hline 3 & 0 & 0,229618 & 0,008000 & 0,022423 & 0,004561 & 0,214150 & 0,002048 \\
\hline 4 & 0 & 0,227046 & 0,005945 & 0,018397 & 0,003336 & 0,214203 & 0,001511 \\
\hline \multicolumn{8}{|c|}{ Telles \& Coelho (1998) - reamostragem de individuos } \\
\hline & & \multicolumn{2}{|c|}{$\hat{F}$} & \multicolumn{2}{|c|}{$\hat{f}$} & \multicolumn{2}{|c|}{$\hat{\theta}$} \\
\hline $\mathrm{N}^{\circ}$ de indivíduos & n.b.d." & Estimativa & Variância & Estimativa & Variância & Estimativa & Variância \\
\hline 2 & 2 & 0,228060 & 0,020173 & $-0,028008$ & 0,045831 & 0,235920 & 0,014698 \\
\hline 3 & 0 & 0,232847 & 0,012431 & $-0,004982$ & 0,022757 & 0,231728 & 0,006707 \\
\hline 4 & 0 & 0,230677 & 0,008740 & 0,000478 & 0,015366 & 0,227442 & 0,003904 \\
\hline 5 & 0 & 0,228227 & 0,007625 & $-0,004713$ & 0,012338 & 0,230072 & 0,002949 \\
\hline 6 & 0 & 0,231530 & 0,006472 & $-0,000223$ & 0,009770 & 0,230536 & 0,002427 \\
\hline 7 & 0 & 0,230692 & 0,005743 & $-0,001304$ & 0,008878 & 0,230813 & 0,001836 \\
\hline 8 & 0 & 0,232346 & 0,004388 & 0,000701 & 0,006818 & 0,230989 & 0,001624 \\
\hline 9 & 0 & 0,229376 & 0,004058 & $-0,000848$ & 0,006437 & 0,229360 & 0,001259 \\
\hline 10 & 0 & 0,230918 & 0,003944 & 0,000204 & 0,006385 & 0,230123 & 0,001132 \\
\hline 11 & 0 & 0,233232 & 0,003576 & 0,001520 & 0,005397 & 0,231673 & 0,000981 \\
\hline 12 & 0 & 0,229177 & 0,003284 & $-0,001534$ & 0,004845 & 0,230046 & 0,000873 \\
\hline 13 & 0 & 0,229697 & 0,003001 & $-0,003258$ & 0,004831 & 0,231719 & 0,000894 \\
\hline 14 & 0 & 0,230444 & 0,002649 & $-0,000833$ & 0,003966 & 0,230803 & 0,000734 \\
\hline 15 & 0 & 0,231572 & 0,002432 & 0,001706 & 0,003691 & 0,229969 & 0,000689 \\
\hline 16 & 0 & 0,231277 & 0,002209 & $-0,000224$ & 0,003557 & 0,231127 & 0,000601 \\
\hline 17 & 0 & 0,229978 & 0,002021 & $-0,001895$ & 0,003167 & 0,231154 & 0,000591 \\
\hline 18 & 0 & 0,229542 & 0,002057 & $-0,001059$ & 0,002949 & 0,230132 & 0,000651 \\
\hline 19 & 0 & 0,230478 & 0,001973 & $-0,001667$ & 0,002932 & 0,231545 & 0,000573 \\
\hline 20 & 0 & 0,231329 & 0,001785 & 0,000392 & 0,002688 & 0,230807 & 0,000537 \\
\hline 21 & 0 & 0,230131 & 0,001800 & $-0,003227$ & 0,002624 & 0,232476 & 0,000461 \\
\hline 22 & 0 & 0,231288 & 0,001684 & 0,000193 & 0,002443 & 0,230977 & 0,000488 \\
\hline 23 & 0 & 0,232429 & 0,001548 & 0,000282 & 0,002280 & 0,232043 & 0,000472 \\
\hline 24 & 0 & 0,232797 & 0,001665 & 0,002137 & 0,002454 & 0,231001 & 0,000455 \\
\hline 25 & 0 & 0,231981 & 0,001505 & 0,001453 & 0,002306 & 0,230698 & 0,000397 \\
\hline 26 & 0 & 0,229820 & 0,001365 & $-0,000582$ & 0,002036 & 0,230107 & 0,000405 \\
\hline 27 & 0 & 0,233540 & 0,001318 & 0,003323 & 0,001988 & 0,230844 & 0,000357 \\
\hline 28 & 0 & 0,230366 & 0,001348 & 0,000058 & 0,002026 & 0,230185 & 0,000360 \\
\hline 29 & 0 & 0,231692 & 0,001391 & 0,000375 & 0,001973 & 0,231321 & 0,000356 \\
\hline 30 & 0 & 0,230926 & 0,001227 & $-0,000719$ & 0,001711 & 0,231388 & 0,000358 \\
\hline
\end{tabular}


Continuação do Anexo A: Estimativas bootstrap de ${ }^{a} F,{ }^{b} f e{ }^{c} \theta$ e de suas respectivas variâncias oriundas do método de reamostragem bootstrap com tamanhos de amostra variáveis de locos (L), indivíduos (I) e populações (P), para os conjuntos de dados avaliados.

Telles \& Coelho (1998) - reamostragem de populaçóes

\begin{tabular}{cccccccc}
\hline & \multicolumn{2}{c}{$\hat{F}$} & \multicolumn{2}{c}{$\hat{f}$} & \multicolumn{2}{c}{$\hat{\theta}$} \\
\hline$N^{\circ}$ de populações & n.b.d. & Estimativa & Variância & Estimativa & Variância & Estimativa & Variância \\
\hline 2 & 0 & 0,181805 & 0,018562 & 0,017554 & 0,005506 & 0,167720 & 0,014647 \\
3 & 0 & 0,192525 & 0,009051 & 0,018238 & 0,003443 & 0,177852 & 0,006596 \\
4 & 0 & 0,195058 & 0,006317 & 0,018820 & 0,002759 & 0,180124 & 0,003842 \\
5 & 0 & 0,201863 & 0,004507 & 0,019952 & 0,002039 & 0,185977 & 0,002697 \\
6 & 0 & 0,196853 & 0,003595 & 0,017530 & 0,001763 & 0,182856 & 0,001944 \\
\hline
\end{tabular}

Ciampi (1999) - reamostragem de locos

\begin{tabular}{|c|c|c|c|c|c|c|c|}
\hline & & \multicolumn{2}{|c|}{$\hat{F}$} & \multicolumn{2}{|c|}{$\hat{f}$} & \multicolumn{2}{|c|}{$\hat{\theta}$} \\
\hline $\mathrm{N}^{\circ}$ de locos & n.b.d. & Estimativa & Variância & Estimativa & Variância & Estimativa & Variância \\
\hline 1 & 0 & 0,030968 & 0,007525 & $-0,020477$ & 0,008704 & 0,050201 & 0,000111 \\
\hline 2 & 0 & 0,033123 & 0,003664 & $-0,018283$ & 0,004188 & 0,050397 & 0,000054 \\
\hline 3 & 0 & 0,031363 & 0,002411 & $-0,020148$ & 0,002813 & 0,050414 & 0,000035 \\
\hline 4 & 0 & 0,033847 & 0,001893 & $-0,017613$ & 0,002199 & 0,050511 & 0,000025 \\
\hline 5 & 0 & 0,033223 & 0,001324 & $-0,018088$ & 0,001520 & 0,050365 & 0,000022 \\
\hline 6 & 0 & 0,033724 & 0,001178 & $-0,017462$ & 0,001350 & 0,050278 & 0,000018 \\
\hline 7 & 0 & 0,036113 & 0,000954 & $-0,015075$ & 0,001098 & 0,050402 & 0,000014 \\
\hline 8 & 0 & 0,034467 & 0,000917 & $-0,016921$ & 0,001052 & 0,050511 & 0,000013 \\
\hline \multicolumn{8}{|c|}{ Ciampi (1999) - reamostragem de individuos } \\
\hline & & \multicolumn{2}{|c|}{$\hat{F}$} & \multicolumn{2}{|c|}{$\hat{f}$} & \multicolumn{2}{|c|}{$\hat{\theta}$} \\
\hline $\mathrm{N}^{\circ}$ de indivíduos & n.b.d." & Estimativa & Variância & Estimativa & Variância & Estimativa & Variância \\
\hline 2 & 0 & 0,035873 & 0,001719 & $-0,043148$ & 0,006495 & 0,072034 & 0,003360 \\
\hline 3 & 0 & 0,035463 & 0,001269 & $-0,038052$ & 0,002729 & 0,069673 & 0,001131 \\
\hline 4 & 0 & 0,036770 & 0,000868 & $-0,035581$ & 0,001599 & 0,069273 & 0,000625 \\
\hline 5 & 0 & 0,034248 & 0,000700 & $-0,038190$ & 0,001202 & 0,069396 & 0,000388 \\
\hline 6 & 0 & 0,036142 & 0,000593 & $-0,036869$ & 0,000935 & 0,070155 & 0,000284 \\
\hline 7 & 0 & 0,036589 & 0,000513 & $-0,035998$ & 0,000725 & 0,069907 & 0,000190 \\
\hline 8 & 0 & 0,035762 & 0,000459 & $-0,037157$ & 0,000642 & 0,070175 & 0,000156 \\
\hline 9 & 0 & 0,033434 & 0,000380 & $-0,039060$ & 0,000552 & 0,069649 & 0,000134 \\
\hline 10 & 0 & 0,035141 & 0,000358 & $-0,037463$ & 0,000527 & 0,069869 & 0,000119 \\
\hline 11 & 0 & 0,034816 & 0,000305 & $-0,037734$ & 0,000435 & 0,069825 & 0,000097 \\
\hline 12 & 0 & 0,035451 & 0,000298 & $-0,037213$ & 0,000398 & 0,069988 & 0,000085 \\
\hline 13 & 0 & 0,034617 & 0,000269 & $-0,038071$ & 0,000342 & 0,069973 & 0,000067 \\
\hline 14 & 0 & 0,035538 & 0,000280 & $-0,036912$ & 0,000334 & 0,069835 & 0,000059 \\
\hline 15 & 0 & 0,034580 & 0,000210 & $-0,037539$ & 0,000276 & 0,069464 & 0,000058 \\
\hline 16 & 0 & 0,035331 & 0,000216 & $-0,036912$ & 0,000274 & 0,069633 & 0,000052 \\
\hline 17 & 0 & 0,035267 & 0,000218 & $-0,037598$ & 0,000271 & 0,070191 & 0,000048 \\
\hline 18 & 0 & 0,035868 & 0,000198 & $-0,036640$ & 0,000249 & 0,069912 & 0,000044 \\
\hline 19 & 0 & 0,036074 & 0,000192 & $-0,036474$ & 0,000242 & 0,069964 & 0,000042 \\
\hline 20 & 0 & 0,036125 & 0,000181 & $-0,036085$ & 0,000217 & 0,069670 & 0,000040 \\
\hline 21 & 0 & 0,035149 & 0,000171 & $-0,037746$ & 0,000218 & 0,070216 & 0,000036 \\
\hline 22 & 0 & 0,036179 & 0,000180 & $-0,036008$ & 0,000217 & 0,069656 & 0,000034 \\
\hline
\end{tabular}


Continuação do Anexo A: Estimativas bootstrap de ${ }^{\mathrm{a}} F,{ }^{\mathrm{b}} f e^{\mathrm{c}} \theta$ e de suas respectivas variâncias oriundas do método de reamostragem bootstrap com tamanhos de amostra variáveis de locos (L), indivíduos (I) e populaçōes (P), para os conjuntos de dados avaliados.

\begin{tabular}{|c|c|c|c|c|c|c|c|}
\hline & & \multicolumn{2}{|c|}{$\hat{F}$} & \multicolumn{2}{|c|}{$\hat{f}$} & \multicolumn{2}{|c|}{$\hat{\theta}$} \\
\hline $\mathrm{N}^{\circ}$ de indivíduos & n.b.d." & Estimativa & Variância & Estimativa & Variância & Estimativa & Variância \\
\hline 23 & 0 & 0,035332 & 0,000155 & $-0,037274$ & 0,000194 & 0,069975 & 0,000029 \\
\hline 24 & 0 & 0,035297 & 0,000154 & $-0,037123$ & 0,000182 & 0,069811 & 0,000029 \\
\hline \multicolumn{8}{|c|}{ Ciampi (1999) - reamostragem de populaçóes } \\
\hline & & \multicolumn{2}{|c|}{$\hat{F}$} & \multicolumn{2}{|c|}{$\hat{f}$} & \multicolumn{2}{|c|}{$\hat{\theta}$} \\
\hline $\mathrm{N}^{\circ}$ de populações & n.b.d." & Estimativa & Variância & Estimativa & Variância & Estimativa & Variância \\
\hline 2 & $\mathbf{0}$ & 0,015548 & 0,001745 & $-0,016171$ & 0,000717 & 0,031185 & 0,001057 \\
\hline 3 & $\mathbf{0}$ & 0,018384 & 0,000642 & $-0,016222$ & 0,000463 & 0,033984 & 0,000329 \\
\hline 4 & $\mathbf{0}$ & 0,018225 & 0,000432 & $-0,015888$ & 0,000347 & 0,033539 & 0,000174 \\
\hline \multicolumn{8}{|c|}{ Auler (2000) - reamostragem de locos } \\
\hline & & \multicolumn{2}{|c|}{$\hat{F}$} & \multicolumn{2}{|c|}{$\hat{f}$} & \multicolumn{2}{|c|}{$\hat{\theta}$} \\
\hline $\mathrm{N}^{\circ}$ de locos & n.b.d." & Estimativa & Variância & Estimativa & Variância & Estimativa & Variância \\
\hline 1 & 0 & 0,307364 & 0,132601 & 0,286562 & 0,140316 & 0,028774 & 0,000274 \\
\hline 2 & $\mathbf{0}$ & 0,226420 & 0,047347 & 0,201292 & 0,050006 & 0,032248 & 0,000101 \\
\hline 3 & $\mathbf{0}$ & 0,202041 & 0,025595 & 0,176131 & 0,026915 & 0,032002 & 0,000063 \\
\hline 4 & 0 & 0,201168 & 0,018270 & 0,174920 & 0,019131 & 0,032219 & 0,000042 \\
\hline 5 & 0 & 0,193100 & 0,009559 & 0,166712 & 0,009913 & 0,031906 & 0,000032 \\
\hline 6 & 0 & 0,195598 & 0,009875 & 0,169399 & 0,010329 & 0,031726 & 0,000024 \\
\hline 7 & 0 & 0,188361 & 0,008354 & 0,161816 & 0,008673 & 0,031883 & 0,000022 \\
\hline 8 & 0 & 0,184474 & 0,005889 & 0,157674 & 0,006145 & 0,031925 & 0,000017 \\
\hline 9 & 0 & 0,184396 & 0,004888 & 0,157726 & 0,005091 & 0,031760 & 0,000015 \\
\hline 10 & 0 & 0,184858 & 0,004219 & 0,158129 & 0,004365 & 0,031852 & 0,000013 \\
\hline 11 & 0 & 0,180009 & 0,003832 & 0,153327 & 0,003962 & 0,031608 & 0,000012 \\
\hline \multirow[t]{3}{*}{12} & 0 & 0,182006 & 0,003532 & 0,155315 & 0,003657 & 0,031680 & 0,000011 \\
\hline & \multicolumn{5}{|c|}{ Auler $(2000)$ - reamostragem de individuos } & & \\
\hline & & \multicolumn{2}{|c|}{$\hat{F}$} & \multicolumn{2}{|c|}{$\hat{f}$} & \multicolumn{2}{|c|}{$\hat{\theta}$} \\
\hline $\mathrm{N}^{\circ}$ de indivíduos & n.b.d." & Estimativa & Variância & Estimativa & Variância & Estimativa & Variância \\
\hline 2 & 763 & 0,036997 & 0,008470 & 0,028001 & 0,007530 & 0,008639 & 0,002442 \\
\hline 3 & 366 & 0,108097 & 0,013255 & 0,081412 & 0,011389 & 0,029143 & 0,002790 \\
\hline 4 & 155 & 0,145393 & 0,010846 & 0,110403 & 0,009622 & 0,039548 & 0,001941 \\
\hline 5 & 99 & 0,159198 & 0,008875 & 0,119974 & 0,008008 & 0,044730 & 0,001623 \\
\hline 6 & 55 & 0,166317 & 0,006746 & 0,126630 & 0,006273 & 0,045506 & 0,001128 \\
\hline 7 & 25 & 0,175859 & 0,005065 & 0,133864 & 0,004838 & 0,048494 & 0,000859 \\
\hline 8 & 18 & 0,180469 & 0,004556 & 0,139307 & 0,004398 & 0,047858 & 0,000659 \\
\hline 9 & 19 & 0,177811 & 0,004018 & 0,137097 & 0,003808 & 0,047270 & 0,000576 \\
\hline 10 & 4 & 0,178934 & 0,003331 & 0,138033 & 0,003262 & 0,047485 & 0,000425 \\
\hline 11 & 4 & 0,179686 & 0,002927 & 0,138376 & 0,002755 & 0,048025 & 0,000414 \\
\hline 12 & 1 & 0,180388 & 0,002832 & 0,138958 & 0,002769 & $0 ; 048166$ & 0,000337 \\
\hline 13 & 1 & 0,178785 & 0,002672 & 0,136952 & 0,002553 & 0,048555 & 0,000330 \\
\hline 14 & 0 & 0,182822 & 0,002338 & 0,140841 & 0,002252 & 0,048935 & 0,000270 \\
\hline 15 & 0 & 0,181591 & 0,002171 & 0,139527 & 0,002034 & 0,048993 & 0,000246 \\
\hline
\end{tabular}


Continuação do Anexo A: Estimativas bootstrap de ${ }^{a} F,{ }^{b} f e^{c} \theta$ e de suas respectivas variâncias oriundas do método de reamostragem bootstrap com tamanhos de amostra variáveis de locos (L), indivíduos (I) e populações (P), para os conjuntos de dados avaliados.

\begin{tabular}{|c|c|c|c|c|c|c|c|}
\hline & & \multicolumn{2}{|c|}{$\hat{F}$} & \multicolumn{2}{|c|}{$\hat{f}$} & \multicolumn{2}{|c|}{$\hat{\theta}$} \\
\hline $\mathrm{N}^{\circ}$ de indivíduos & n.b.d." & Estimativa & Variância & Estimativa & Variância & Estimativa & Variância \\
\hline 16 & 0 & 0,184349 & 0,002153 & 0,141701 & 0,002121 & 0,049737 & 0,000231 \\
\hline 17 & 0 & 0,182546 & 0,001835 & 0,140321 & 0,001743 & 0,049181 & 0,000234 \\
\hline 18 & 0 & 0,182881 & 0,001914 & 0,140545 & 0,001835 & 0,049332 & 0,000214 \\
\hline & & \multicolumn{2}{|c|}{$\hat{F}$} & \multicolumn{2}{|c|}{$\hat{f}$} & \multicolumn{2}{|c|}{$\hat{\theta}$} \\
\hline 19 & 0 & 0,180963 & 0,001727 & 0,139405 & 0,001707 & 0,048323 & 0,000184 \\
\hline 20 & 0 & 0,181028 & 0,001546 & 0,139168 & 0,001484 & 0,048684 & 0,000171 \\
\hline 21 & 0 & 0,181395 & 0,001400 & 0,138793 & 0,001386 & 0,049490 & 0,000158 \\
\hline 22 & 0 & 0,181532 & 0,001589 & 0,139247 & 0,001521 & 0,049194 & 0,000158 \\
\hline 23 & 0 & 0,181085 & 0,001505 & 0,139076 & 0,001421 & 0,048873 & 0,000148 \\
\hline 24 & 0 & 0,182956 & 0,001412 & 0,140997 & 0,001364 & 0,048908 & 0,000126 \\
\hline 25 & 0 & 0,183167 & 0,001283 & 0,141069 & 0,001249 & 0,049059 & 0,000122 \\
\hline \multicolumn{8}{|c|}{ Auler (2000) - reamostragem de populaçóes } \\
\hline & & \multicolumn{2}{|c|}{$\hat{F}$} & \multicolumn{2}{|c|}{$\hat{f}$} & \multicolumn{2}{|c|}{$\hat{\theta}$} \\
\hline $\mathrm{N}^{\circ}$ de populações & n.b.d. & Estimativa & Variância & Estimativa & Variância & Estimativa & Variância \\
\hline 2 & 0 & 0,184037 & 0,010129 & 0,163513 & 0,008409 & 0,025642 & 0,000916 \\
\hline 3 & 0 & 0,185544 & 0,007017 & 0,164646 & 0,006016 & 0,025782 & 0,000353 \\
\hline 4 & 0 & 0,184799 & 0,005625 & 0,163525 & 0,004895 & 0,026040 & 0,000206 \\
\hline 5 & 0 & 0,178131 & 0,004320 & 0,157444 & 0,003788 & 0,024994 & 0,000149 \\
\hline 6 & 0 & 0,183061 & 0,003606 & 0,161973 & 0,003172 & 0,025539 & 0,000103 \\
\hline 7 & 0 & 0,183129 & 0,003101 & 0,161973 & 0,002715 & 0,025584 & 0,000087 \\
\hline 8 & 0 & 0,183768 & 0,002616 & 0,162275 & 0,002316 & 0,025922 & 0,000066 \\
\hline 9 & 0 & 0,183738 & 0,002333 & 0,162449 & 0,002055 & 0,025667 & 0,000056 \\
\hline \multicolumn{8}{|c|}{ Sebbenn et al. (s.d.) - reamostragem de locos } \\
\hline & & \multicolumn{2}{|c|}{$\hat{F}$} & \multicolumn{2}{|c|}{$\hat{f}$} & \multicolumn{2}{|c|}{$\hat{\theta}_{P}$} \\
\hline $\mathrm{N}^{\circ}$ de locos & n.b.d." & Estimativa & Variância & Estimativa & Variância & Estimativa & Variância \\
\hline 1 & 0 & 0,115136 & 0,032684 & 0,038659 & 0,020558 & 0,084098 & 0,008400 \\
\hline 2 & 0 & 0,102556 & 0,017837 & 0,030356 & 0,011618 & 0,076738 & 0,004190 \\
\hline 3 & 0 & 0,104100 & 0,012779 & 0,033368 & 0,008642 & 0,074829 & 0,002577 \\
\hline 4 & 0 & 0,110194 & 0,009768 & 0,037778 & 0,006841 & 0,076457 & 0,001971 \\
\hline 5 & 0 & 0,104709 & 0,007729 & 0,036431 & 0,005282 & 0,071881 & 0,001488 \\
\hline 6 & 0 & 0,106321 & 0,006176 & 0,034846 & 0,004342 & 0,074767 & 0,001323 \\
\hline 7 & 0 & 0,107135 & 0,005448 & 0,036488 & 0,003720 & 0,074030 & 0,001096 \\
\hline 8 & 0 & 0,108871 & 0,004741 & 0,039590 & 0,003486 & 0,072698 & 0,000837 \\
\hline 9 & 0 & 0,107296 & 0,004420 & 0,034973 & 0,003122 & 0,075515 & 0,000815 \\
\hline 10 & 0 & 0,105869 & 0,004062 & 0,035741 & 0,002822 & 0,073259 & 0,000766 \\
\hline 11 & 0 & 0,109054 & 0,003817 & 0,038996 & 0,002632 & 0,073450 & 0,000660 \\
\hline 12 & 0 & 0,108909 & 0,003292 & 0,038116 & 0,002404 & 0,074001 & 0,000578 \\
\hline
\end{tabular}


Continuação do Anexo A: Estimativas bootstrap de ${ }^{a} F,{ }^{b} f e^{c} \theta$ e de suas respectivas variâncias oriundas do método de reamostragem bootstrap com tamanhos de amostra variáveis de locos (L), indivíduos (I) e populações (P), para os conjuntos de dados avaliados.

\begin{tabular}{|c|c|c|c|c|c|c|c|}
\hline \multicolumn{8}{|c|}{ Sebbenn et al. (s.d.) - reamostragem de individuos } \\
\hline \multirow[b]{2}{*}{$\mathrm{N}^{\circ}$ de indivíduos } & \multirow[b]{2}{*}{ n.b.d. } & \multicolumn{2}{|c|}{$\hat{F}$} & \multicolumn{2}{|c|}{$\hat{f}$} & \multicolumn{2}{|c|}{$\hat{\theta}$} \\
\hline & & Estimativa & Variância & Estimativa & Variância & Estimativa & Variância \\
\hline 2 & 310 & 0,088257 & 0,018782 & 0,020800 & 0,022598 & 0,057493 & 0,019597 \\
\hline 3 & 44 & 0,100537 & 0,015737 & 0,017664 & 0,018562 & 0,077431 & 0,012219 \\
\hline 4 & 11 & 0,105866 & 0,011322 & 0,018901 & 0,011247 & 0,085681 & 0,007237 \\
\hline 5 & 6 & 0,098128 & 0,009245 & 0,022002 & 0,008237 & 0,076392 & 0,004826 \\
\hline 6 & 0 & 0,097148 & 0,008041 & 0,019131 & 0,006665 & 0,078738 & 0,003779 \\
\hline 7 & 0 & 0,103934 & 0,006205 & 0,023614 & 0,005481 & 0,081538 & 0,002931 \\
\hline 8 & 0 & 0,105836 & 0,005386 & 0,023778 & 0,004668 & 0,083432 & 0,002601 \\
\hline 9 & 0 & 0,105391 & 0,004695 & 0,024585 & 0,003890 & 0,082549 & 0,001986 \\
\hline 10 & 0 & 0,102528 & 0,004468 & 0,023738 & 0,003666 & 0,080456 & 0,001859 \\
\hline 11 & 0 & 0,101989 & 0,004142 & 0,021708 & 0,003276 & 0,081925 & 0,001645 \\
\hline 12 & 0 & 0,106040 & 0,003358 & 0,023911 & 0,002829 & 0,083832 & 0,001562 \\
\hline 13 & 0 & 0,104445 & 0,003198 & 0,022774 & 0,002517 & 0,083425 & 0,001364 \\
\hline 14 & 0. & 0,109308 & 0,003059 & 0,026078 & 0,002411 & 0,085318 & 0,001311 \\
\hline 15 & 0 & 0,104430 & 0,002968 & 0,023257 & 0,002289 & 0,083057 & 0,001158 \\
\hline 16 & 0 & 0,104572 & 0,002856 & 0,025470 & 0,002180 & 0,081151 & 0,001089 \\
\hline 17 & 0 & 0,105727 & 0,002758 & 0,024713 & 0,002141 & 0,083044 & 0,001026 \\
\hline 18 & 0 & 0,103402 & 0,002286 & 0,023595 & 0,001917 & 0,081640 & 0,000866 \\
\hline 19 & 0 & 0,105462 & 0,002192 & 0,023800 & 0,001646 & 0,083637 & 0,000863 \\
\hline 20 & 0 & 0,105653 & 0,002314 & 0,026302 & 0,001740 & 0,081501 & 0,000864 \\
\hline 21 & 0 & 0,106927 & 0,002039 & 0,024581 & 0,001549 & 0,084386 & 0,000825 \\
\hline 22 & 0 & 0,105033 & 0,002089 & 0,023867 & 0,001462 & 0,083199 & 0,000793 \\
\hline 23 & 0 & 0,105251 & 0,001721 & 0,023825 & 0,001305 & 0,083395 & 0,000685 \\
\hline 24 & 0 & 0,106672 & 0,001761 & 0,023841 & 0,001346 & 0,084840 & 0,000682 \\
\hline 25 & 0 & 0,102557 & 0,001695 & 0,022967 & 0,001428 & 0,081425 & 0,000575 \\
\hline 26 & 0 & 0,107449 & 0,001612 & 0,026631 & 0,001252 & 0,083038 & 0,000570 \\
\hline 27 & 0 & 0,103632 & 0,001645 & 0,023535 & 0,001231 & 0,082038 & 0,000610 \\
\hline 28 & 0 & 0,108639 & 0,001424 & 0,026115 & 0,001108 & 0,084687 & 0,000611 \\
\hline 29 & 0 & 0,106685 & 0,001435 & 0,024887 & 0,001051 & 0,083904 & 0,000546 \\
\hline 30 & 0 & 0,106837 & 0,001359 & 0,025154 & 0,001066 & 0,083762 & 0,000536 \\
\hline 31 & 0 & 0,106191 & 0,001571 & 0,024047 & 0,001042 & 0,084244 & 0,000587 \\
\hline 32 & 0 & 0,104810 & 0,001273 & 0,024002 & 0,001001 & 0,082783 & 0,000467 \\
\hline 33 & 0 & 0,105799 & 0,001197 & 0,023693 & 0,000973 & 0,084075 & 0,000441 \\
\hline 34 & 0 & 0,104605 & 0,001233 & 0,023741 & 0,000876 & 0,082837 & 0,000500 \\
\hline 35 & 0 & 0,107237 & 0,001237 & 0,024810 & 0,000912 & 0,084549 & 0,000447 \\
\hline 36 & 0 & 0,106989 & 0,001207 & 0,025177 & 0,000887 & 0,083949 & 0,000437 \\
\hline 37 & 0 & 0,105446 & 0,001185 & 0,024005 & 0,000883 & 0,083465 & 0,000422 \\
\hline 38 & 0 & 0,106918 & 0,001120 & 0,023913 & 0,000847 & 0,085049 & 0,000411 \\
\hline 39 & 0 & 0,105413 & 0,001211 & 0,024250 & 0,000858 & 0,083231 & 0,000421 \\
\hline 40 & 0 & 0,105775 & 0,001030 & 0,024818 & 0,000758 & 0,083029 & 0,000387 \\
\hline 41 & 0 & 0,107306 & 0,001069 & 0,026276 & 0,000801 & 0,083218 & 0,000409 \\
\hline 42 & 0 & 0,106577 & 0,001150 & 0,024881 & 0,000832 & 0,083810 & 0,000419 \\
\hline
\end{tabular}


Continuação do Anexo A: Estimativas bootstrap de ${ }^{\mathrm{a}} F,{ }^{\mathrm{b}} f e^{\mathrm{c}} \boldsymbol{\theta}$ e de suas respectivas variâncias oriundas do método de reamostragem bootstrap com tamanhos de amostra variáveis de locos (L), indivíduos (I) e populações (P), para os conjuntos de dados avaliados.

\begin{tabular}{cccccccc}
\hline \multicolumn{6}{c}{ Sebbenn et al. (s.d.) - reamostragem de indivíduos } \\
\hline \multicolumn{6}{c}{$\hat{\boldsymbol{F}}$} & \multicolumn{2}{c}{$\hat{f}$} \\
$\mathrm{~N}^{\circ}$ de indivíduos & n.b.d. & Estimativa & Variância & Estimativa & Variância & Estimativa & Variância \\
\hline 43 & 0 & 0,107269 & 0,000974 & 0,025897 & 0,000752 & 0,083528 & 0,000372 \\
44 & 0 & 0,105961 & 0,000939 & 0,025011 & 0,000682 & 0,083057 & 0,000329 \\
45 & 0 & 0,106211 & 0,000989 & 0,025259 & 0,000710 & 0,083083 & 0,000351 \\
\hline
\end{tabular}

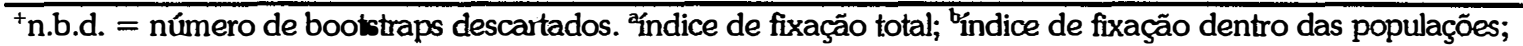
'grau de divergência entre populações. 
Anexo B: Histogramas e Boxplots

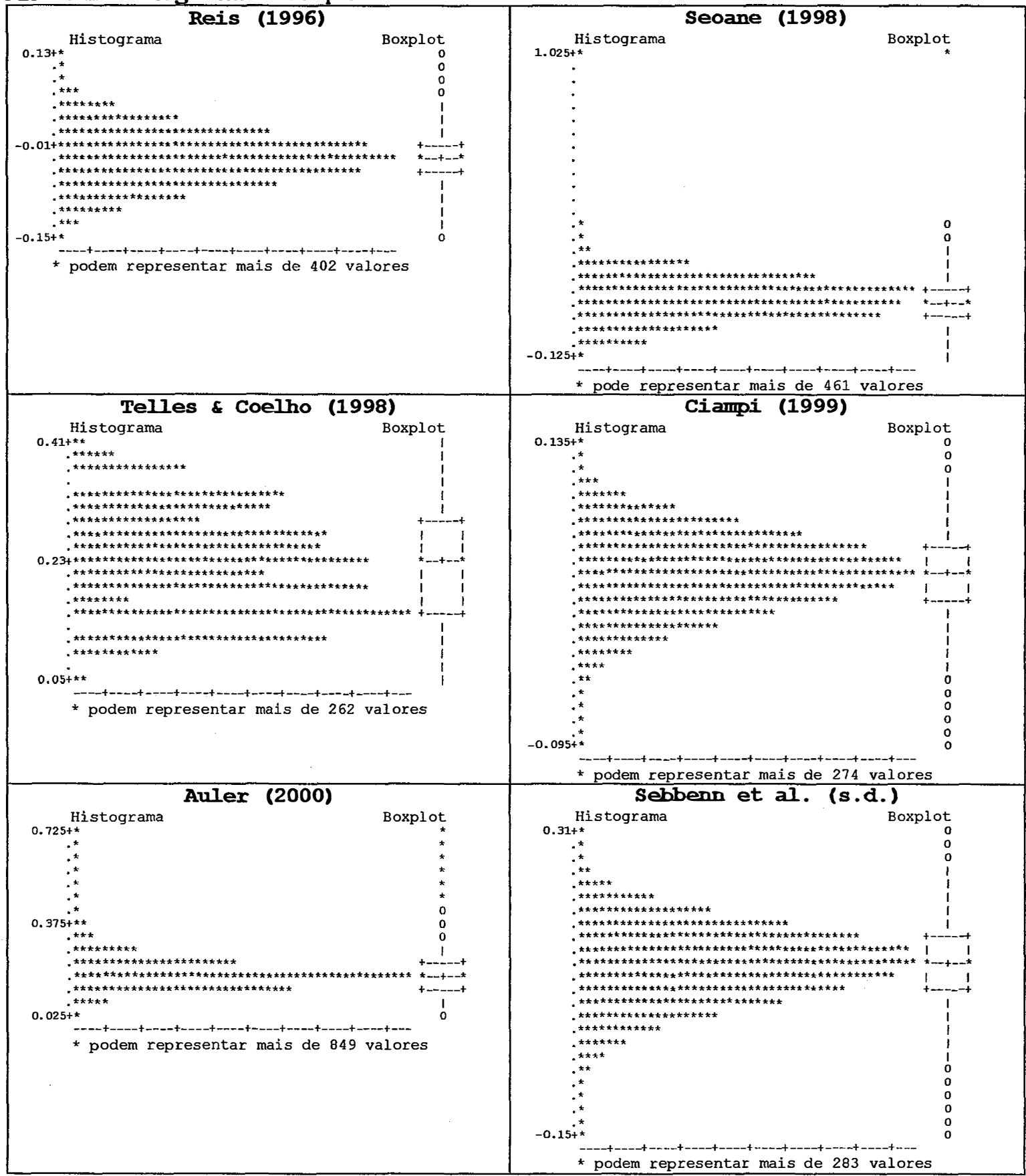

Histogramas e boxplot das estimativas do índice de fixação total $(F)$, obtidas a partir da reamostragem de locos, para os conjuntos estudados. 
Continuação do Anexo B: Histogramas e Boxplots

\begin{tabular}{|c|c|}
\hline 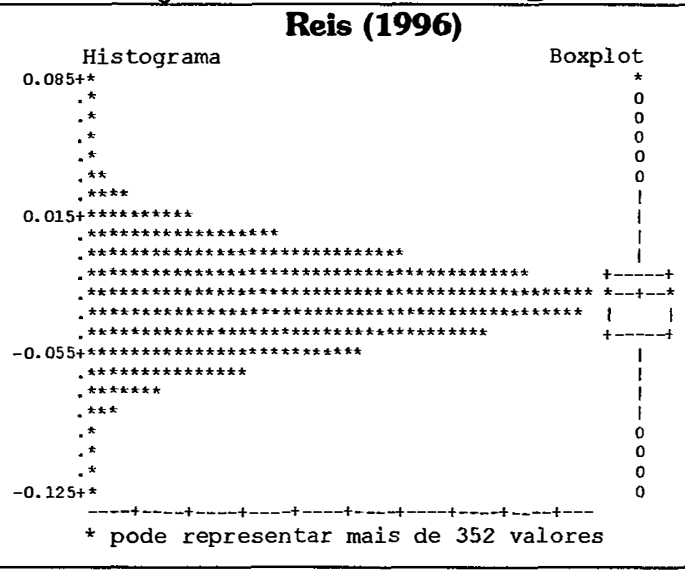 & 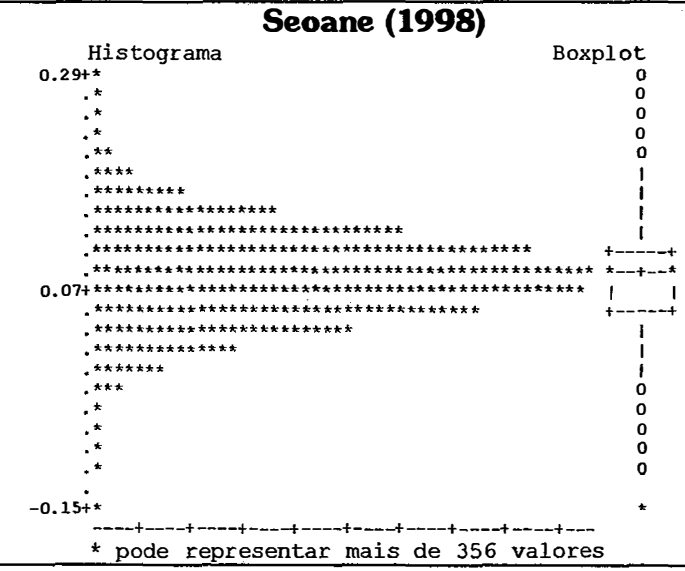 \\
\hline 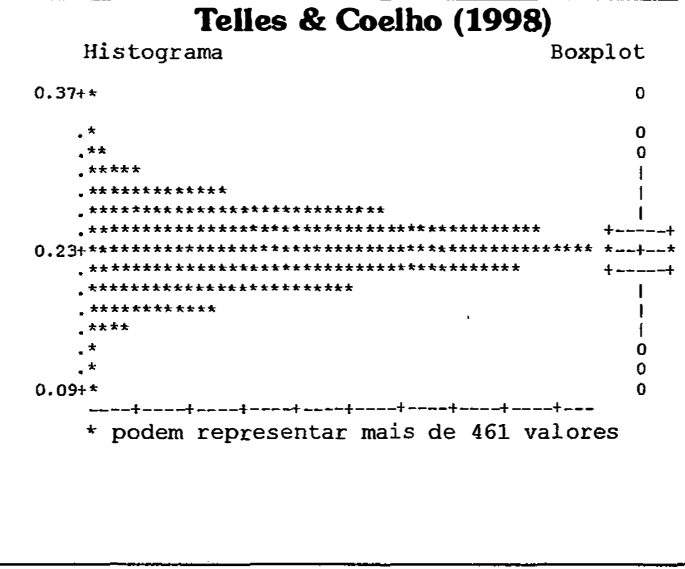 & 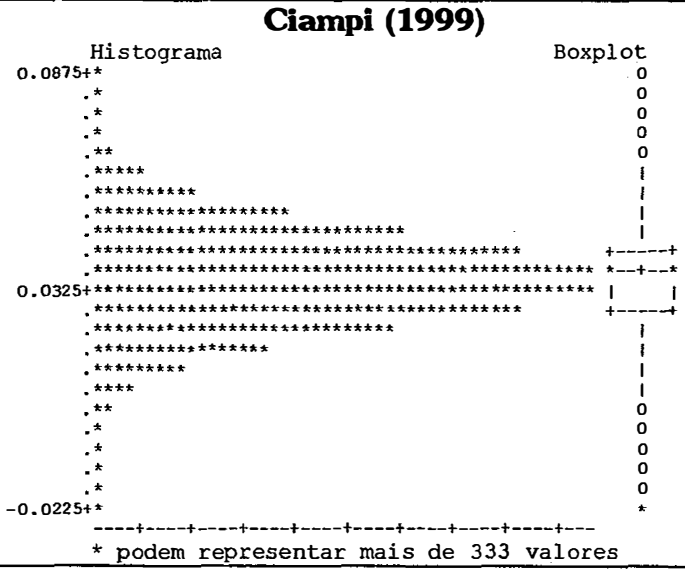 \\
\hline 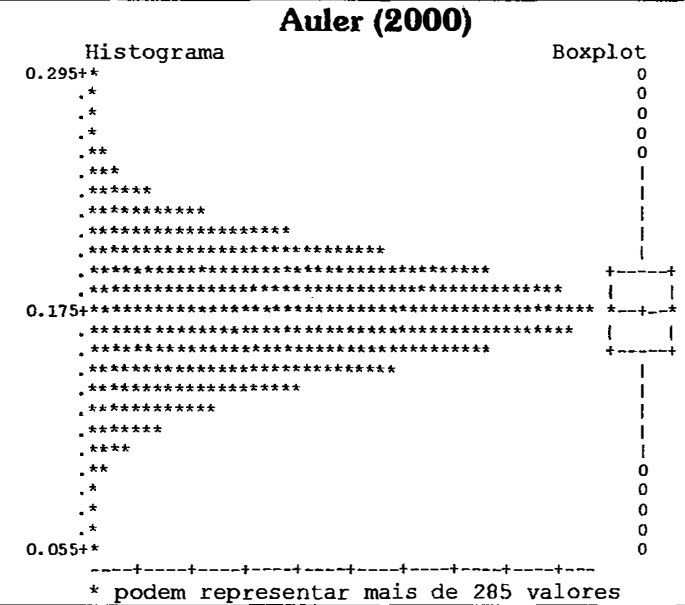 & 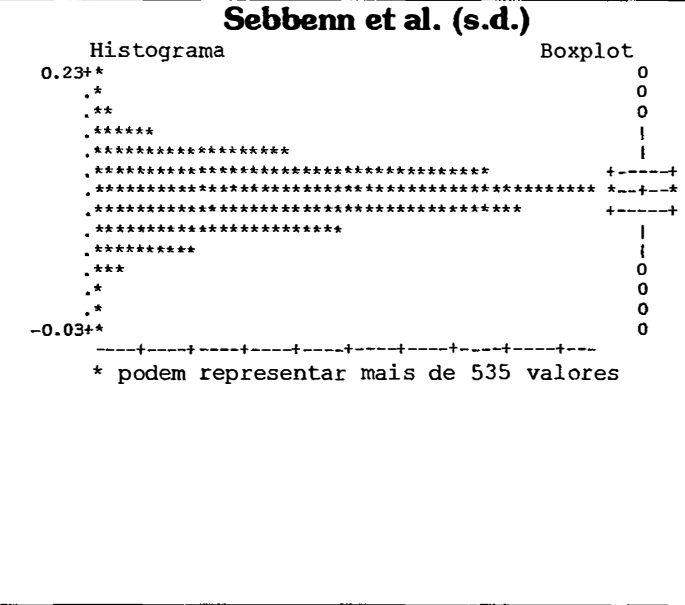 \\
\hline
\end{tabular}

Histogramas e boxplot das estimativas do índice de fixação total $(F)$, obtidas a partir da reamostragem de indivíduos, para os conjuntos estudados. 
Continuacão do Anexo B: Histogramas e Boxplots

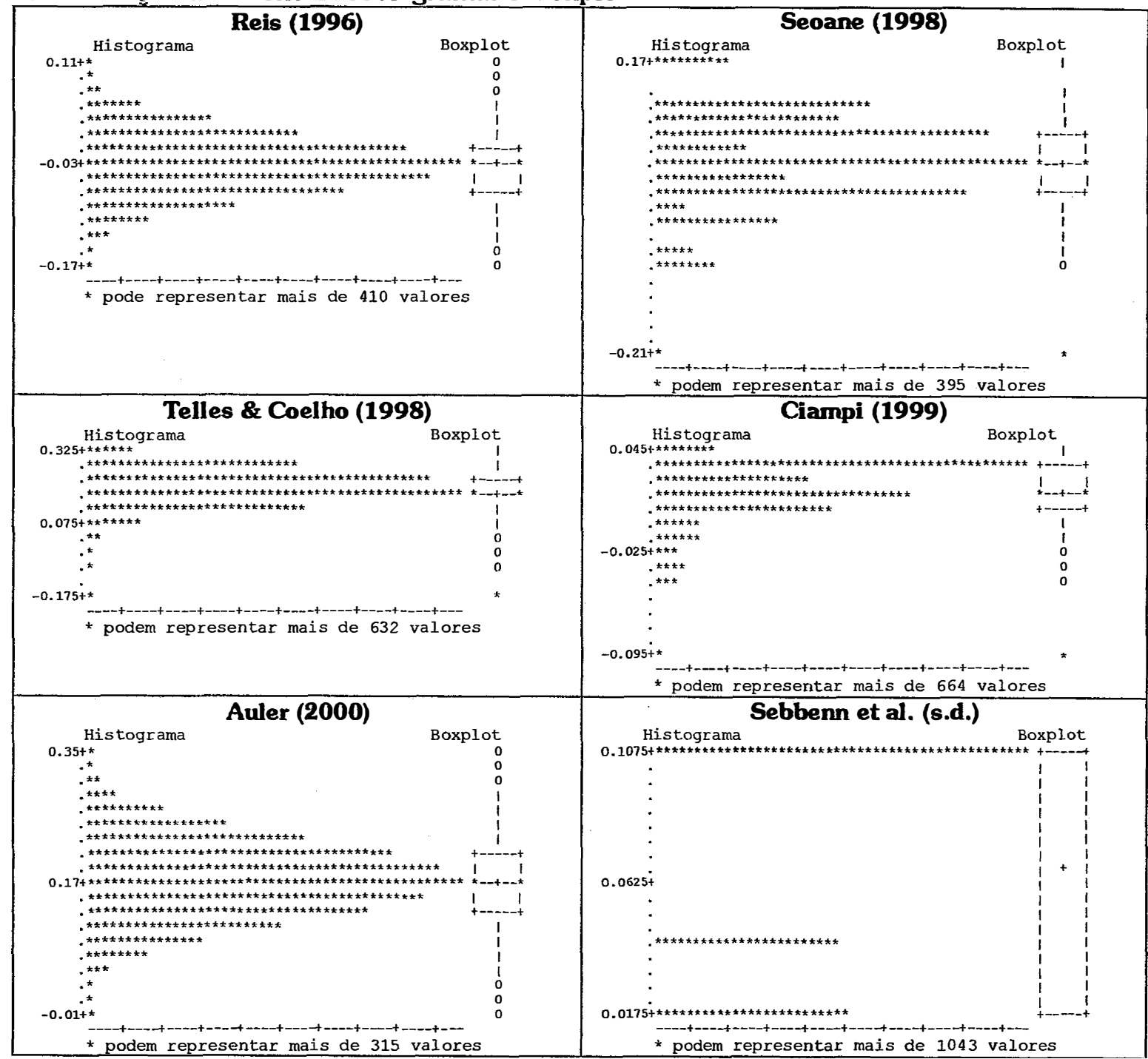

Histogramas e boxplot das estimativas do índice de fixação total $(F)$, obtidas a partir da reamostragem de populaçōes, para os conjuntos estudados. 
Continuação do Anexo B: Histogramas e Boxplots

\begin{tabular}{|c|c|}
\hline Reis (1996) & Seoane (1998) \\
\hline Histograma & Histograma \\
\hline $0.15+*$ & $0.325+ \pm$ \\
\hline 0.107 & $* *$ \\
\hline$\because * *$ & 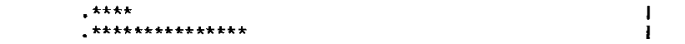 \\
\hline 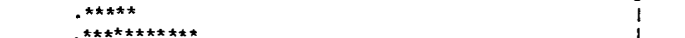 & 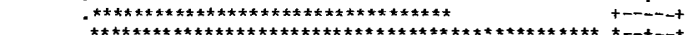 \\
\hline 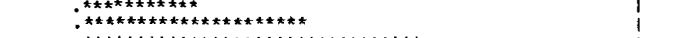 & 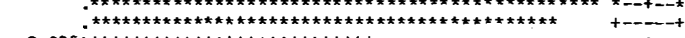 \\
\hline 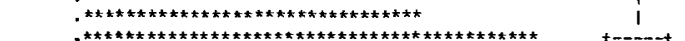 & 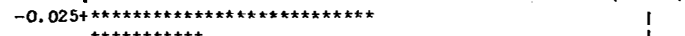 \\
\hline 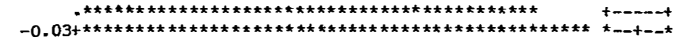 & $\begin{array}{l}: \star \star \star \star \star \star \star \star \star \star \star \star \star \star \\
: \star \star \star \star \star\end{array}$ \\
\hline 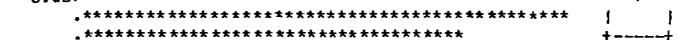 & $\because *$ \\
\hline 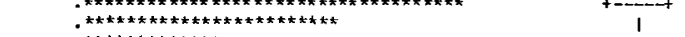 & $\because *$ \\
\hline 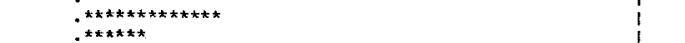 & $-0.375 \div *$ \\
\hline 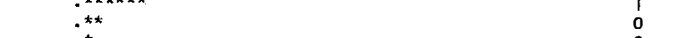 & -0.375+t \\
\hline$\because *$ & * podem representar mais de 536 valores \\
\hline$-0.21+* \pi$ & \\
\hline \multicolumn{2}{|l|}{ 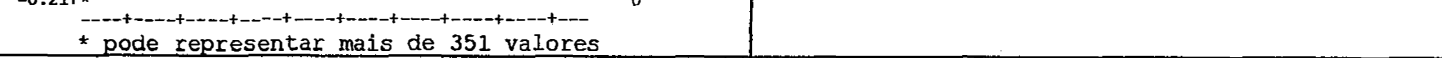 } \\
\hline & Ciampi (1999) \\
\hline $\begin{array}{l}\text { Telles \& Coelho (1998) } \\
\text { Histograma }\end{array}$ & \multirow{18}{*}{ 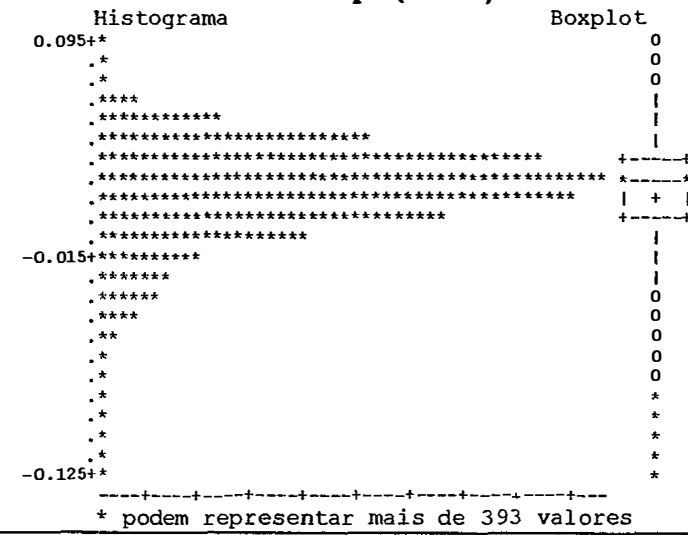 } \\
\hline $0.475+\star$ & \\
\hline${ }_{* *}^{*}$ & \\
\hline 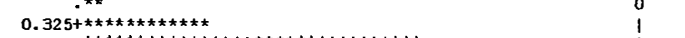 & \\
\hline 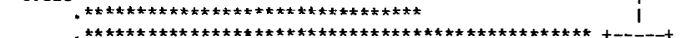 & \\
\hline 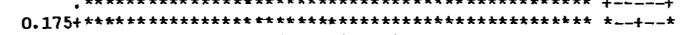 & \\
\hline 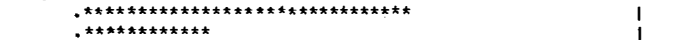 & \\
\hline 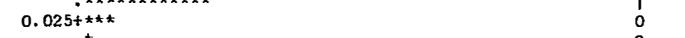 & \\
\hline.$_{*}^{\star}$ & \\
\hline$-0.125+*$ & \\
\hline$: *$ & \\
\hline$-0.275+*$ & \\
\hline \multirow{5}{*}{ * podem representar mais de 539 valores } & \\
\hline & \\
\hline & \\
\hline & \\
\hline & \\
\hline \multirow{2}{*}{ Auler (2000) } & \\
\hline & Sebbenn et al. (s.d.) \\
\hline$\underset{0.41+^{\star}}{\text { Histograma }}$ & $\underset{0}{\text { Histograma }}$ \\
\hline $\begin{array}{ll}0.41+\star \\
. *\end{array}$ & 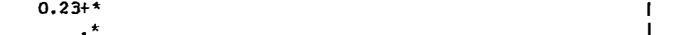 \\
\hline & 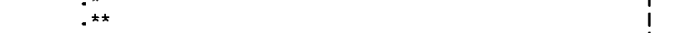 \\
\hline$\stackrel{. *}{* \star}$ & 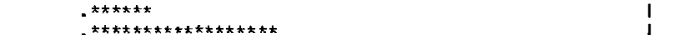 \\
\hline : & $:=$ \\
\hline 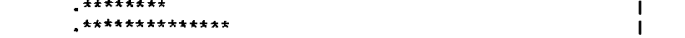 & 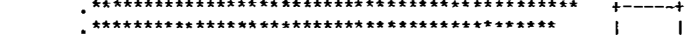 \\
\hline 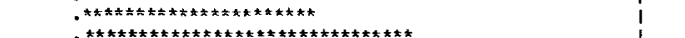 & 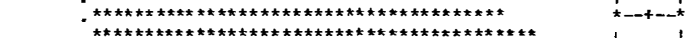 \\
\hline 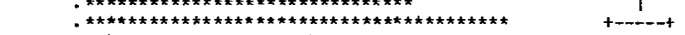 & 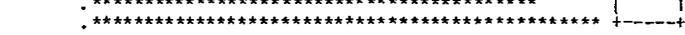 \\
\hline 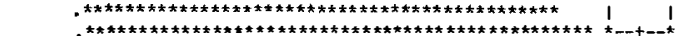 & 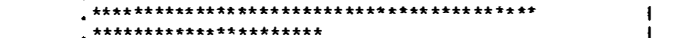 \\
\hline 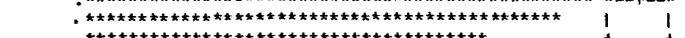 & 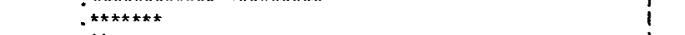 \\
\hline 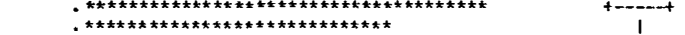 & 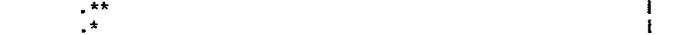 \\
\hline 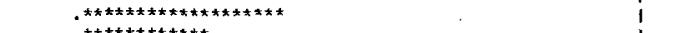 & $\therefore{ }^{*}$ \\
\hline 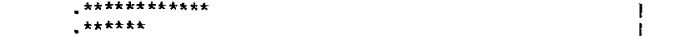 & $-0.11+*$ \\
\hline $2 * * *$ & * podem representar mais de 290 valores \\
\hline$\because *$ & \\
\hline$-0.05+*$ & \\
\hline 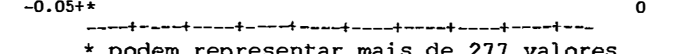 & \\
\hline
\end{tabular}

Histogramas e boxplot das estimativas do índice de fixação total $(F)$, obtidas a partir da reamostragem de indivíduos e populações, para os conjuntos estudados. 
Continuação do Anexo B: Histogramas e Boxplots

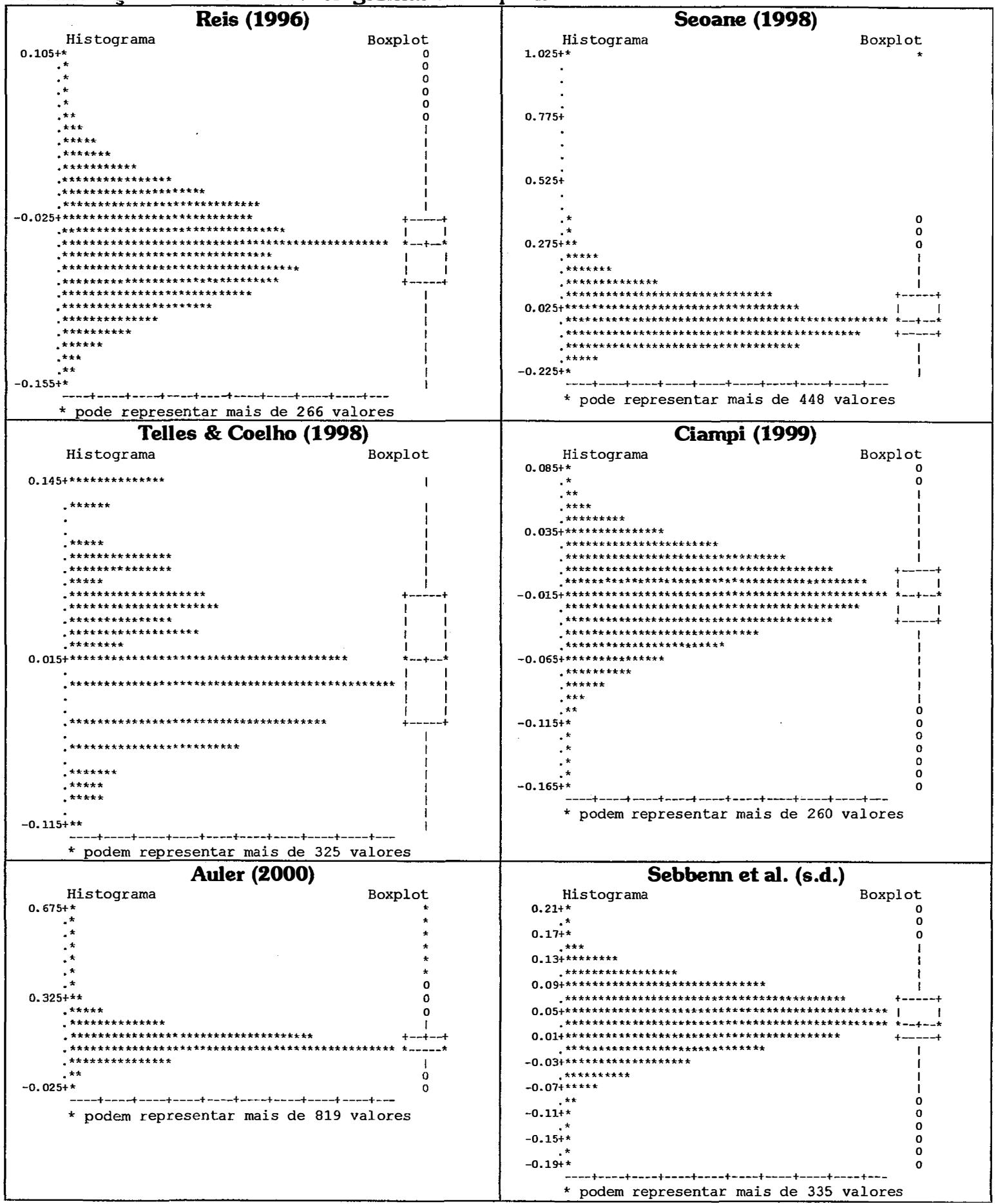

Histogramas e boxplot das estimativas do índice de fixação dentro de populações $(f)$, obtidas a partir da reamostragem de locos, para os conjuntos estudados. 
Continuação do Anexo B: Histogramas e Boxplots

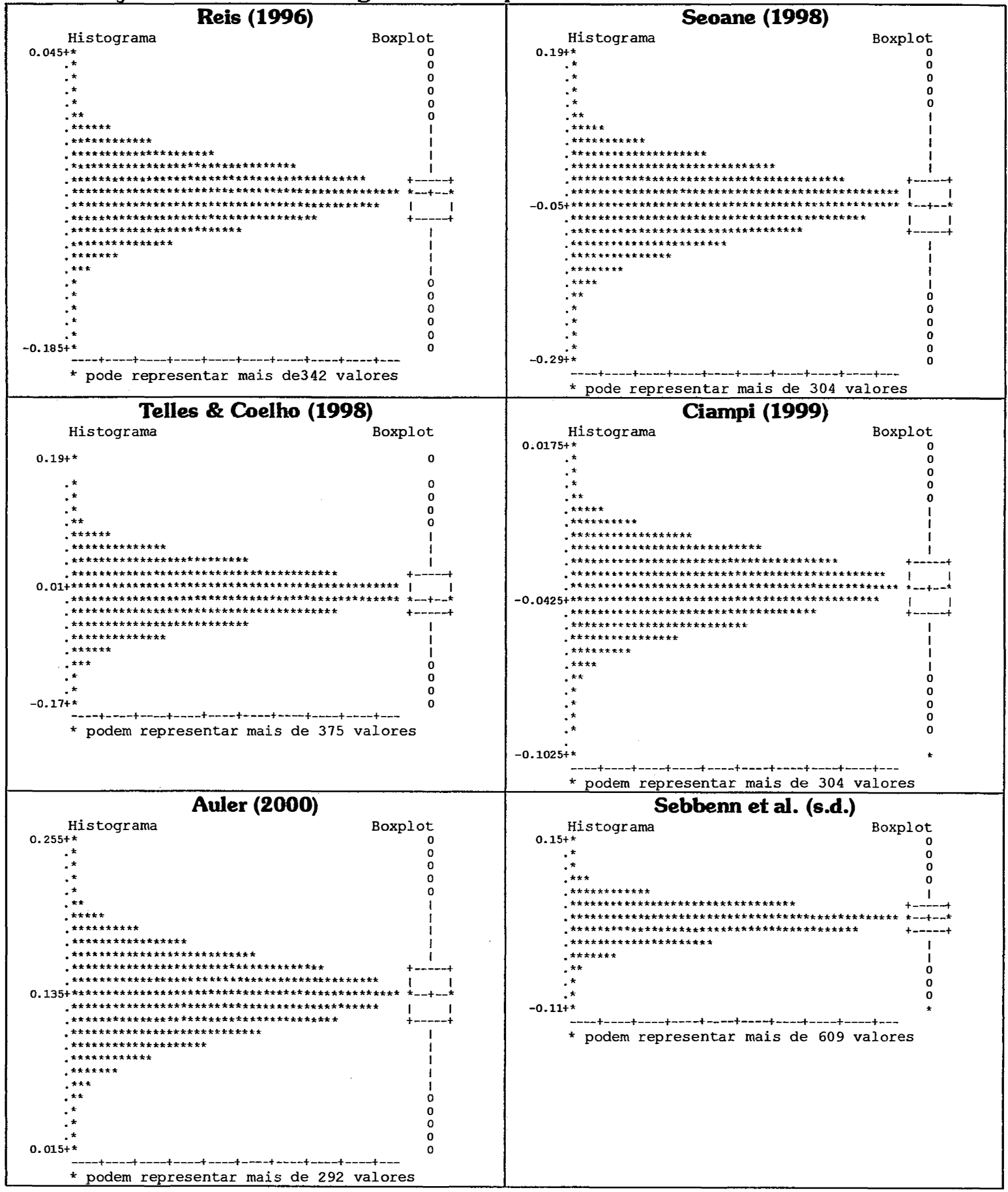

Histogramas e boxplot das estimativas do índice de fixação dentro de populações $(f)$, obtidas a partir da reamostragem de indivíduos, para os conjuntos estudados. 
Continuação do Anexo B: Histogramas e Boxplots

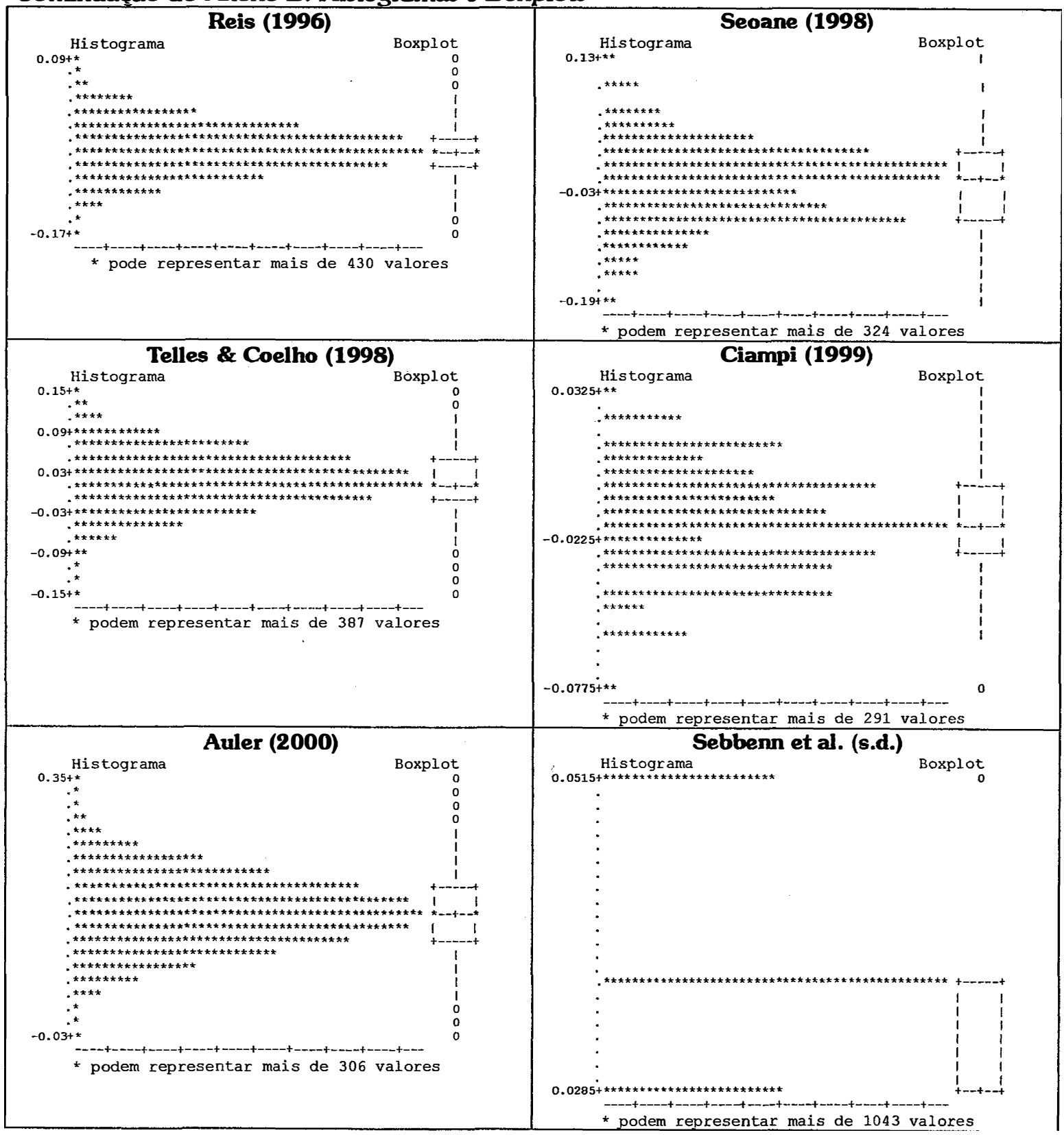

Histogramas e boxplot das estimativas do índice de fixação dentro de populações $(f)$, obtidas a partir da reamostragem de populações, para os conjuntos estudados. 
Continuação do Anexo B: Histogramas e Boxplots

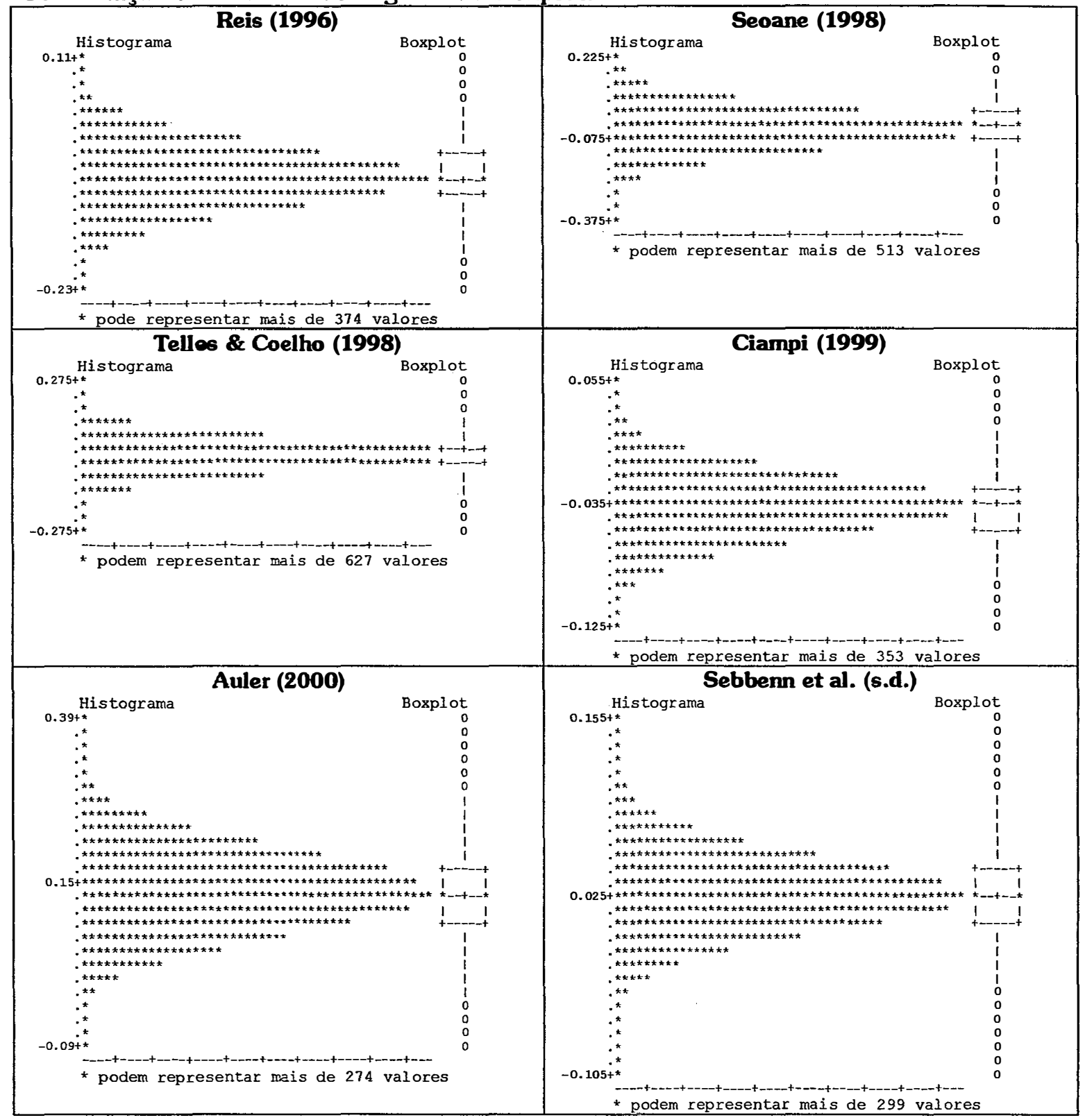

Histogramas e boxplot das estimativas do índice de fixação dentro de populações $(f)$, obtidas a partir da reamostragem de indivíduos e populações, para os conjuntos estudados. 
Continuação do Anexo B: Histogramas e Boxplots

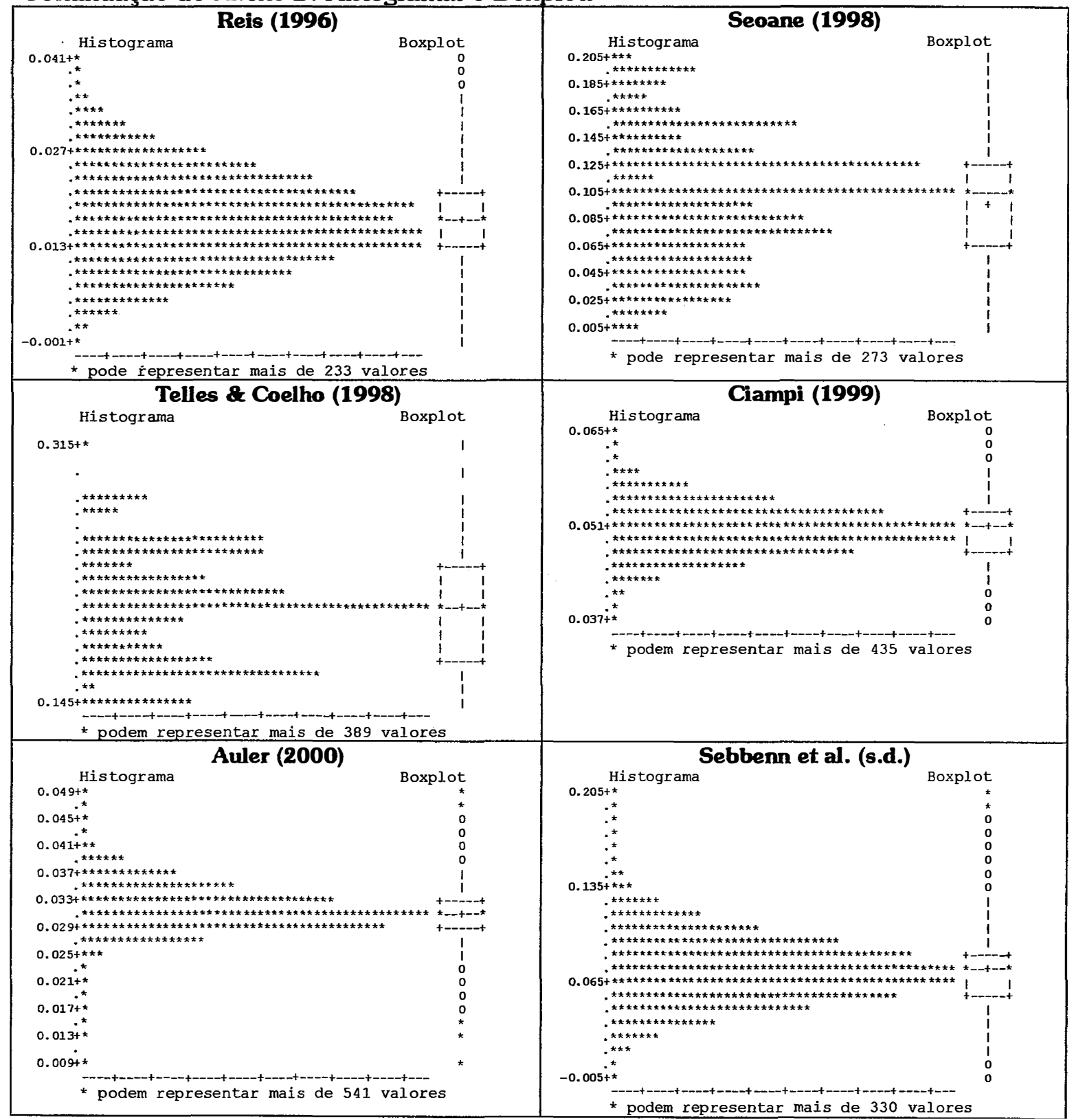

Histogramas e boxplot das estimativas da diversidade entre populações $(\theta)$, obtidas a partir da reamostragem de locos, para os conjuntos estudados. 
Continuação do Anexo B: Histogramas e Boxplots

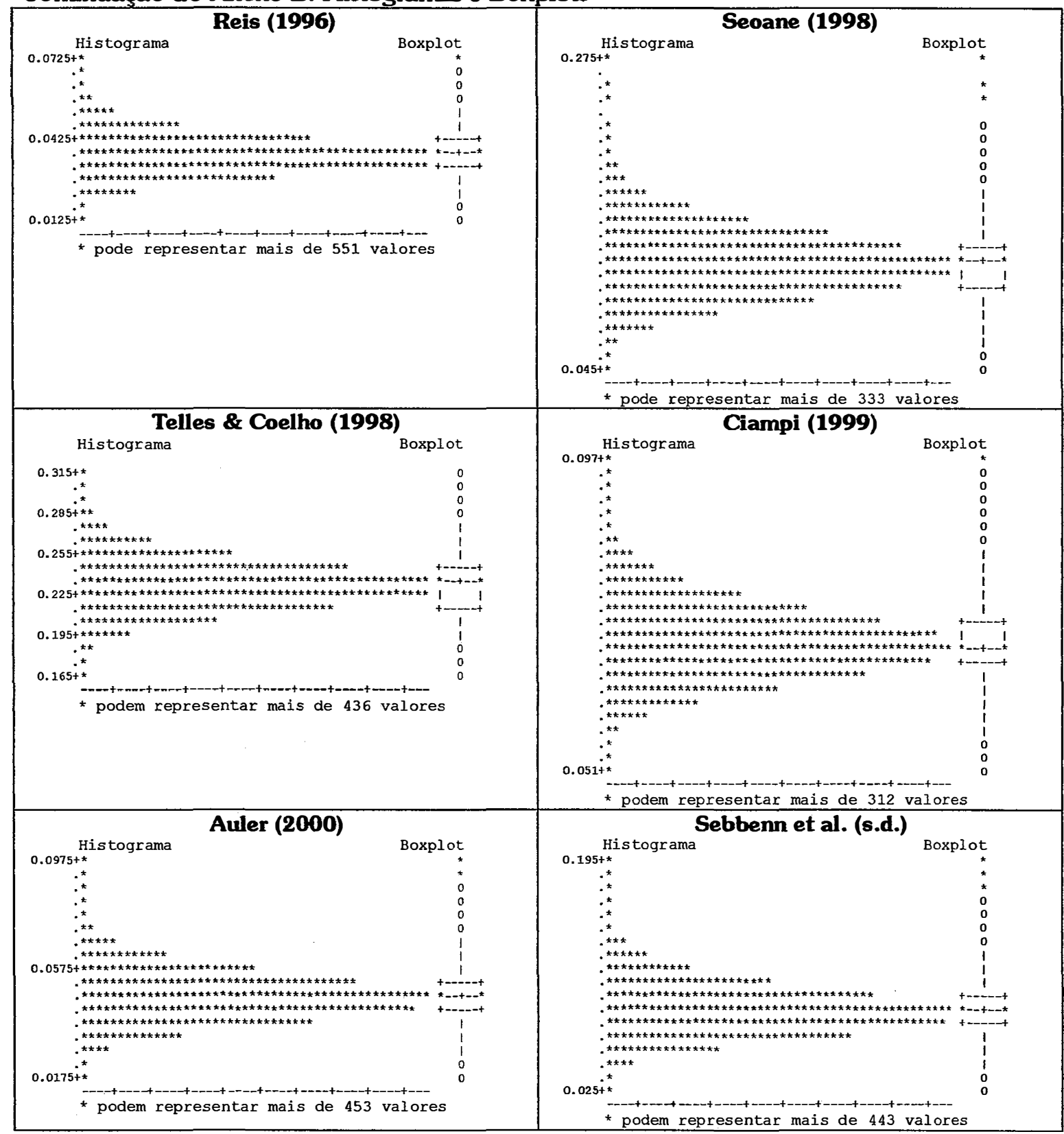

Histogramas e boxplot das estimativas da diversidade entre populaçōes $(\theta)$, obtidas a partir da reamostragem de indivíduos, para os conjuntos estudados. 
Continuação do Anexo B: Histogramas e Boxplots

\begin{tabular}{|c|c|}
\hline Reis (1996) & Seoane (1998) \\
\hline$\underset{0.025+\star \star}{H i s t o g r a m a} \quad$ Boxplot & 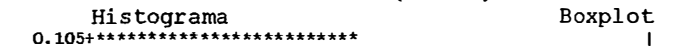 \\
\hline 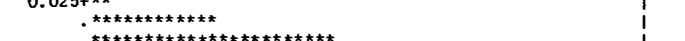 & 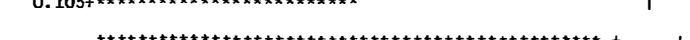 \\
\hline 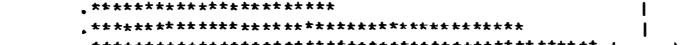 & 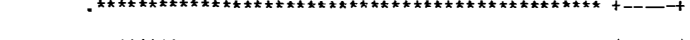 \\
\hline 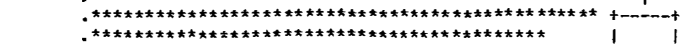 & $\begin{array}{l}-\star \star \star \star \star \star \star \star \star \star \\
: \star \star \star \star \star \star \star \star \star \star \star \star \star \star \star \star \star \star \star \star \star \star \star \star \star \star \star \star \star \star \star\end{array}$ \\
\hline 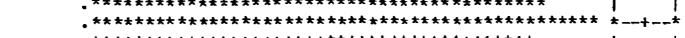 & 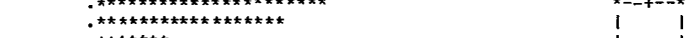 \\
\hline 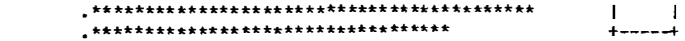 & 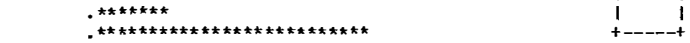 \\
\hline 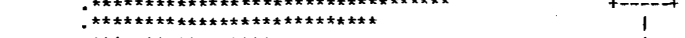 & 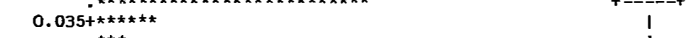 \\
\hline 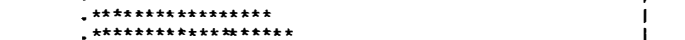 &.$* \star \star$ \\
\hline 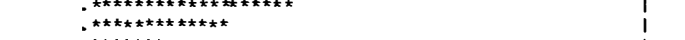 & $:$ \\
\hline 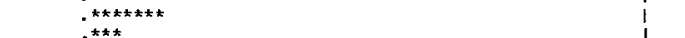 & 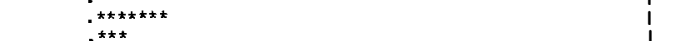 \\
\hline $\begin{array}{ll}: * \star \star * & 1 \\
* & 0\end{array}$ & 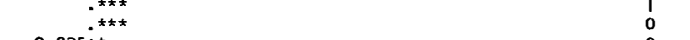 \\
\hline$\because *$ & $-0.035+\star$ \\
\hline 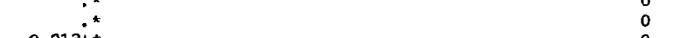 & * podem representar mais de 587 valores \\
\hline $\begin{array}{l}-0.013+* \\
\text { * pode representar mais de } 268 \text { valores }\end{array}$ & 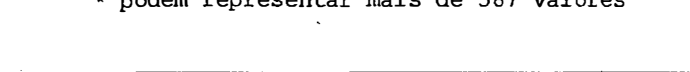 \\
\hline Telles \& Coelho (1998) & Ciampi (1999) \\
\hline $\begin{array}{l}\text { Histograma Boxplot } \\
0.29+\star\end{array}$ & 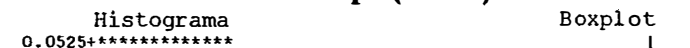 \\
\hline 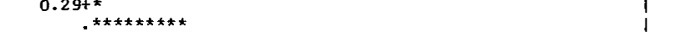 & 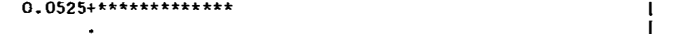 \\
\hline 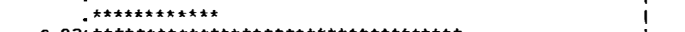 & 每 \\
\hline 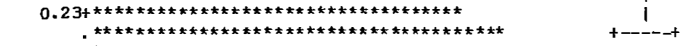 & 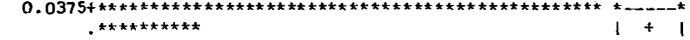 \\
\hline 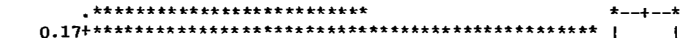 & 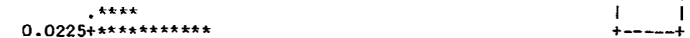 \\
\hline 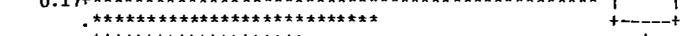 & 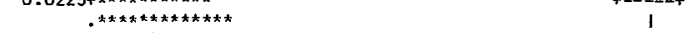 \\
\hline 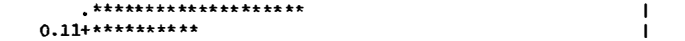 & 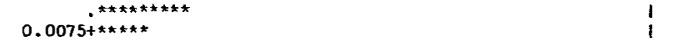 \\
\hline.$\star \star \star \star \star \star \star \Delta$ & . \\
\hline $0.05 t^{* \star}$ & $-0.0075+$ \\
\hline$\cdot{ }_{*}^{*}$ & $\sigma_{*}$ \\
\hline$-0.01+*$ & 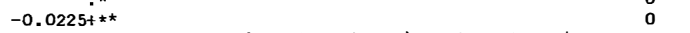 \\
\hline * podem representar mais de 434 valores & * podem representar mais de 730 valores \\
\hline Auler (2000) & Sebbenn et al. (s.d.) \\
\hline Histograma & Histograma \\
\hline $0.0625+\star$ & $0.0725+\star \star \star \star \star \star \star \star \star \star \star \star \star \star \star \star \star$, \\
\hline.$*$ & • \\
\hline $0.0475+\star * \star$ & i \\
\hline 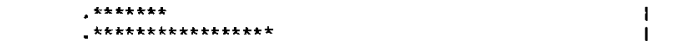 & 1 \\
\hline 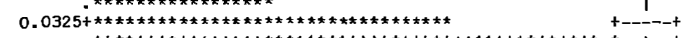 & $i$ \\
\hline 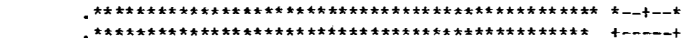 & $i$ \\
\hline 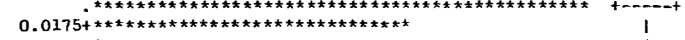 & i \\
\hline 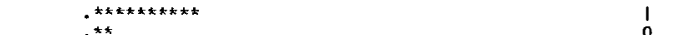 & . \\
\hline $0.0025+\star *$ & 1 \\
\hline :* & 1 \\
\hline$-0.0125+*$ & 1 \\
\hline * podem representar mais de 518 valores & 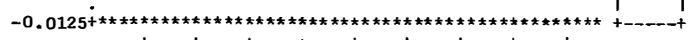 \\
\hline & * podem representar mais de 1043 valores \\
\hline
\end{tabular}

Histogramas e boxplot das estimativas da diversidade entre populações $(\theta)$, obtidas a partir da reamostragem de populações, para os conjuntos estudados. 
Continuação do Anexo B: Histogramas e Boxplots

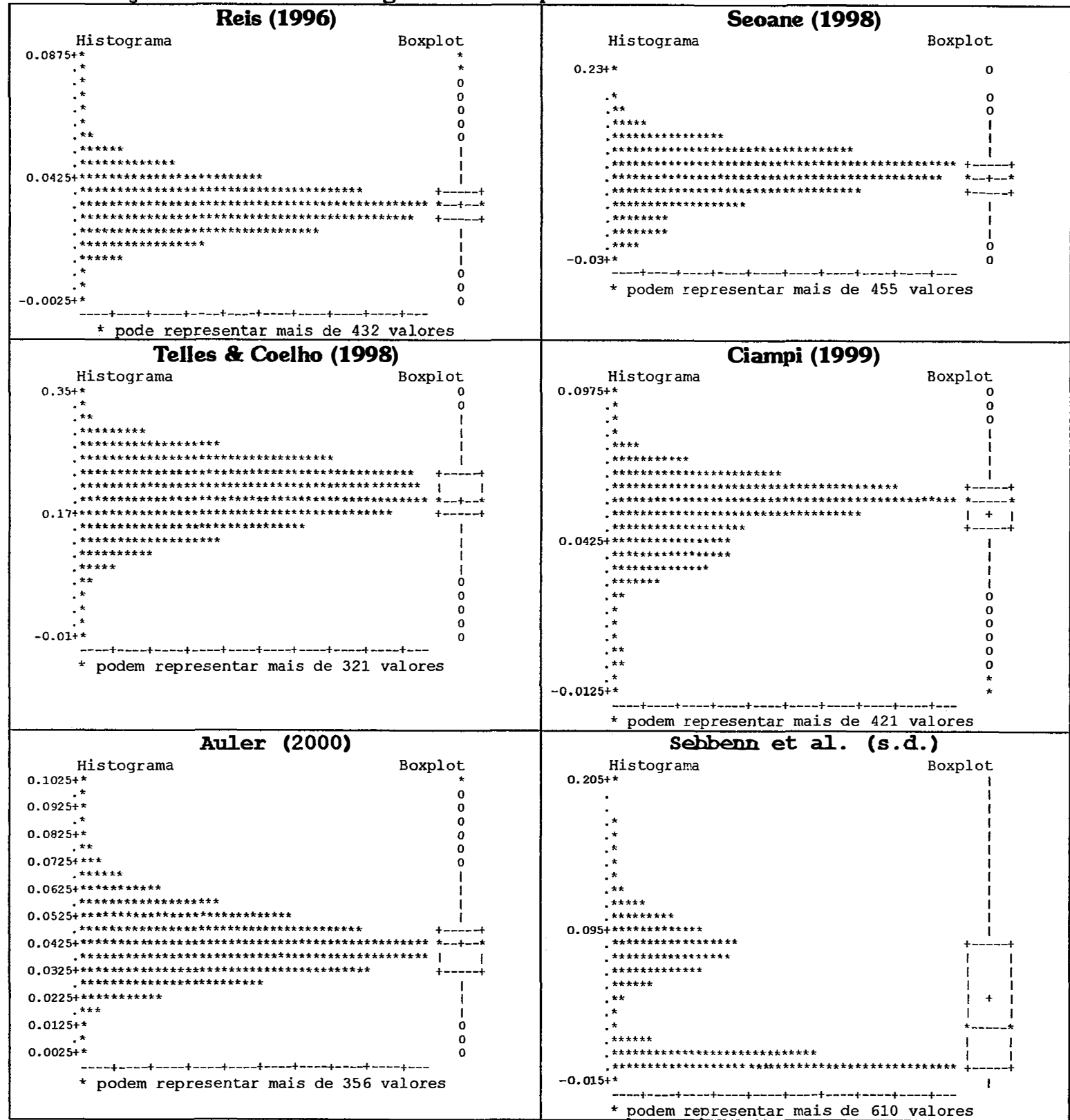

Histogramas e boxplot das estimativas da diversidade entre populações $(\theta)$, obtidas a partir da reamostragem de indivíduos e populações, para os conjuntos estudados. 
Continuação do Anexo B: Histogramas e Boxplots

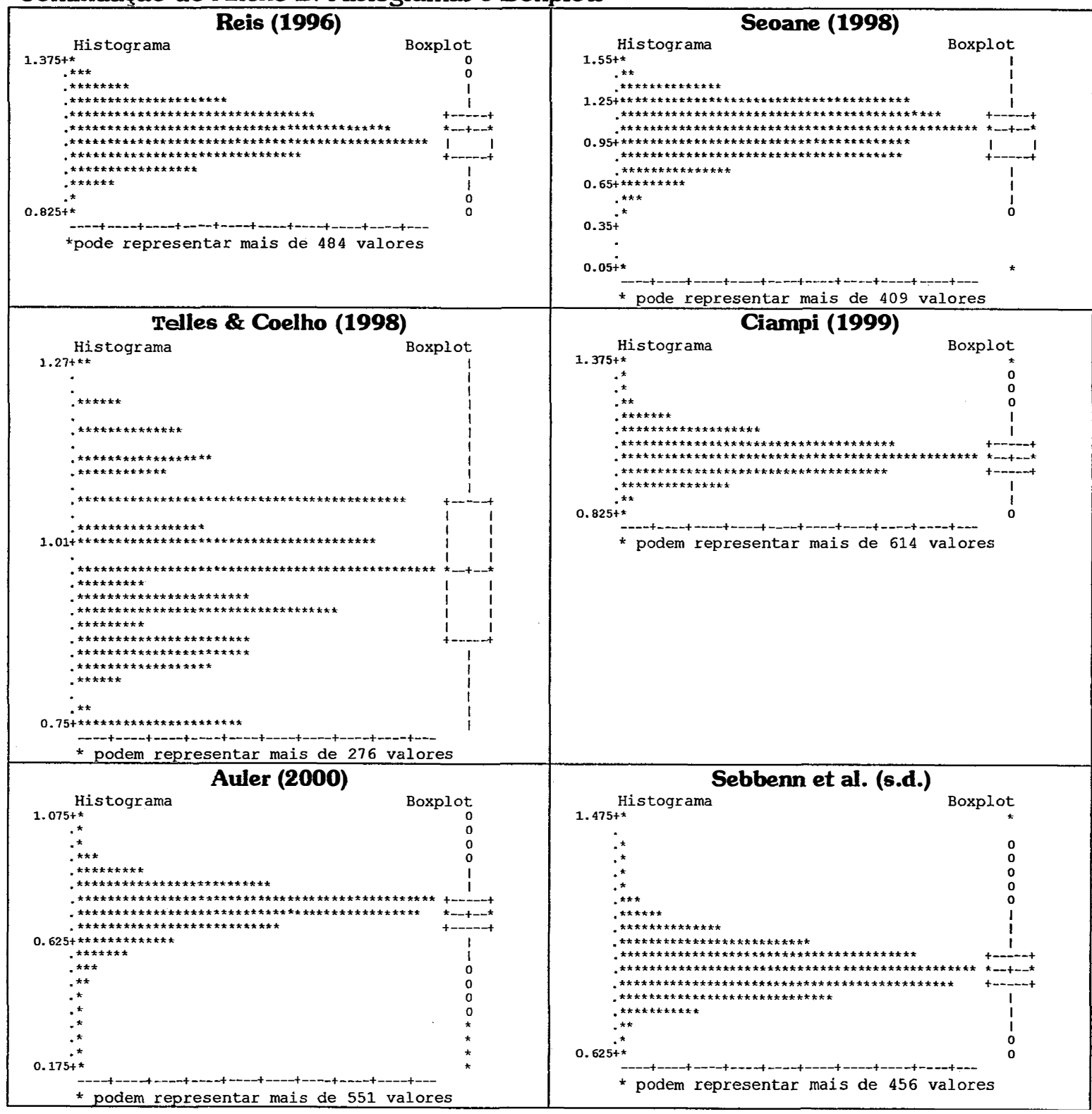

Histogramas e boxplot das estimativas da taxa aparente de cruzamento $\left(t_{a}\right)$, obtidas a partir da reamostragem de locos, para os conjuntos estudados. 
Continuação do Anexo B: Histogramas e Boxplots

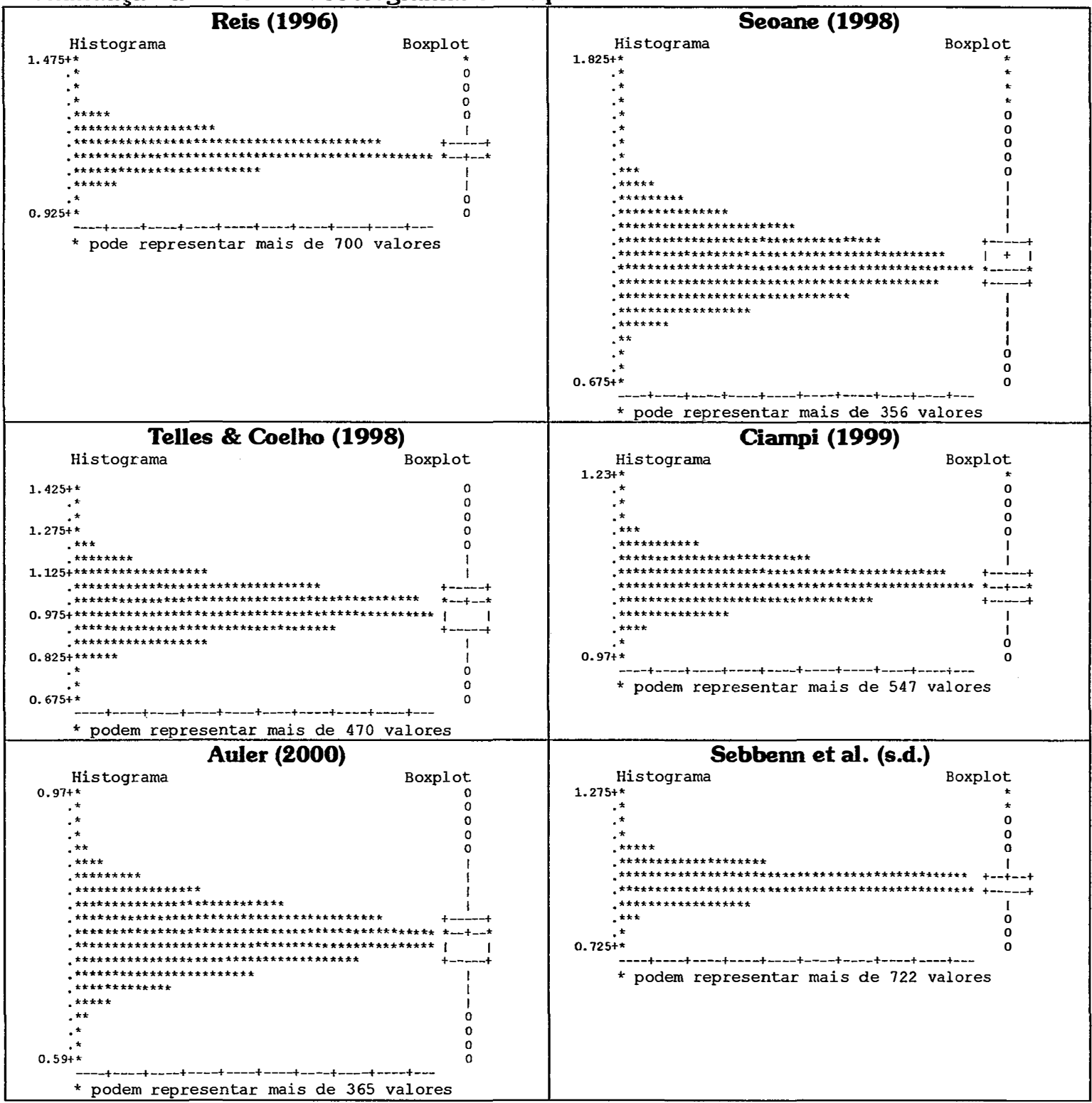

Histogramas e boxplot das estimativas da taxa aparente de cruzamento $\left(t_{a}\right)$, obtidas a partir da reamostragem de indivíduos, para os conjuntos estudados. 
Continuação do Anexo B: Histogramas e Boxplots

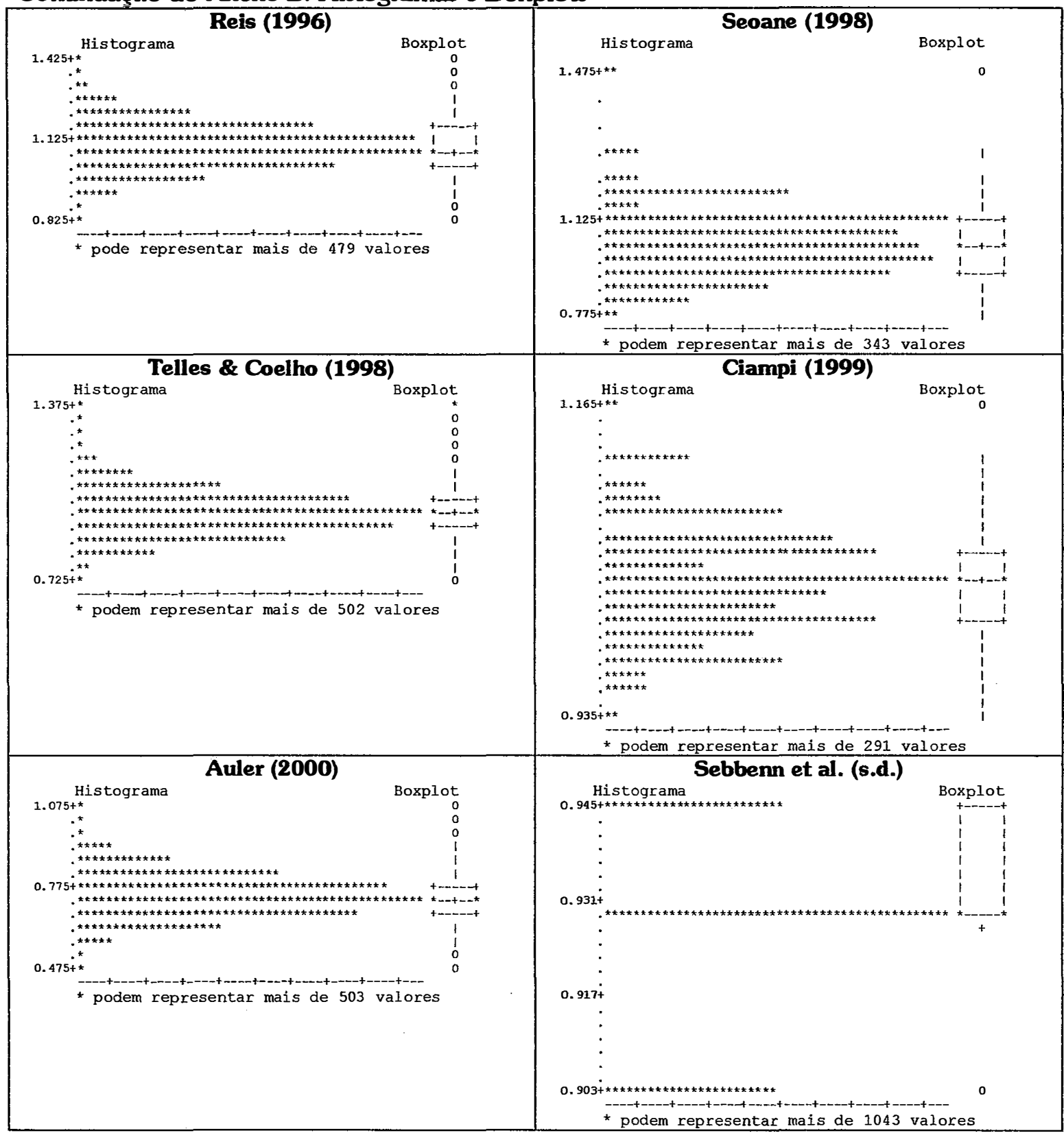

Histogramas e boxplot das estimativas da taxa aparente de cruzamento $\left(t_{a}\right)$, obtidas a partir da reamostragem de populações, para os conjuntos estudados. 
Continuação do Anexo B: Histogramas e Boxplots

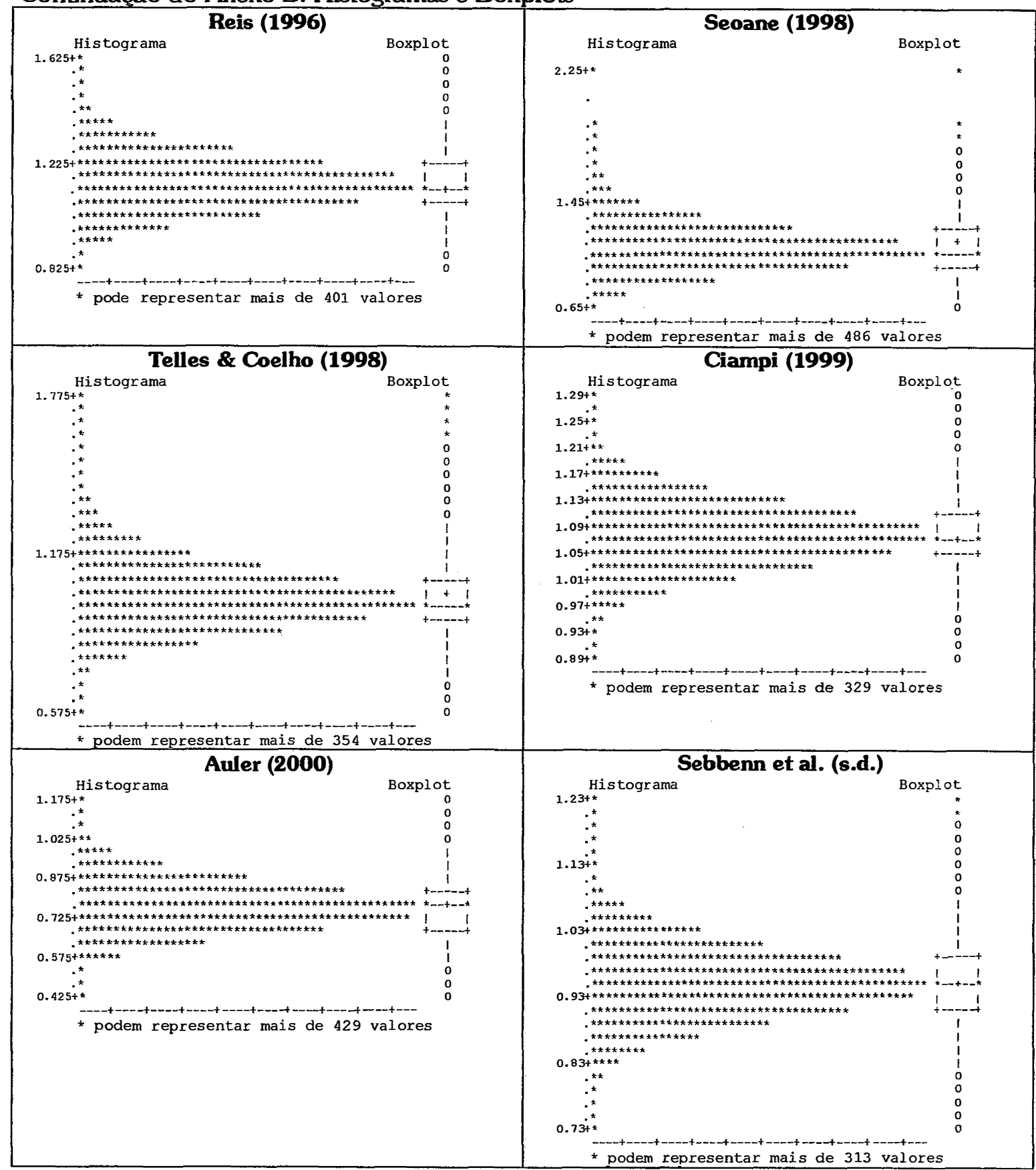

Histogramas e boxplot das estimativas da taxa aparente de cruzamento $\left(t_{a}\right)$, obtidas a partir da reamostragem de indivíduos e populaçōes, para os conjuntos estudados. 
Continuação do Anexo B: Histogramas e Boxplots

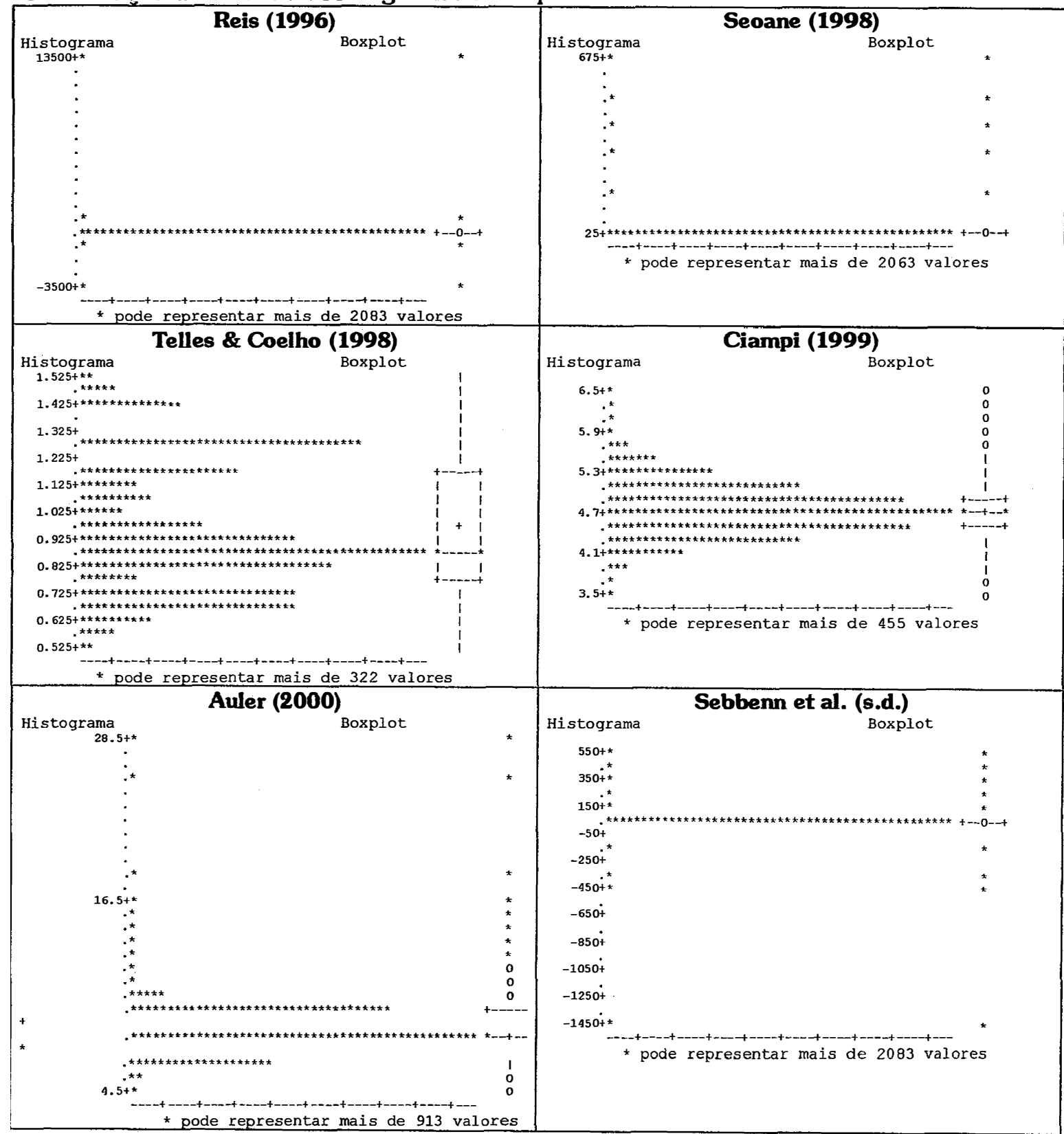

Histogramas e boxplot das estimativas do fluxo de genes entre populações $(\mathrm{Nm})$, obtidas a partir da reamostragem de locos, para os conjuntos estudados. 
Continuação do Anexo B: Histogramas e Boxplots

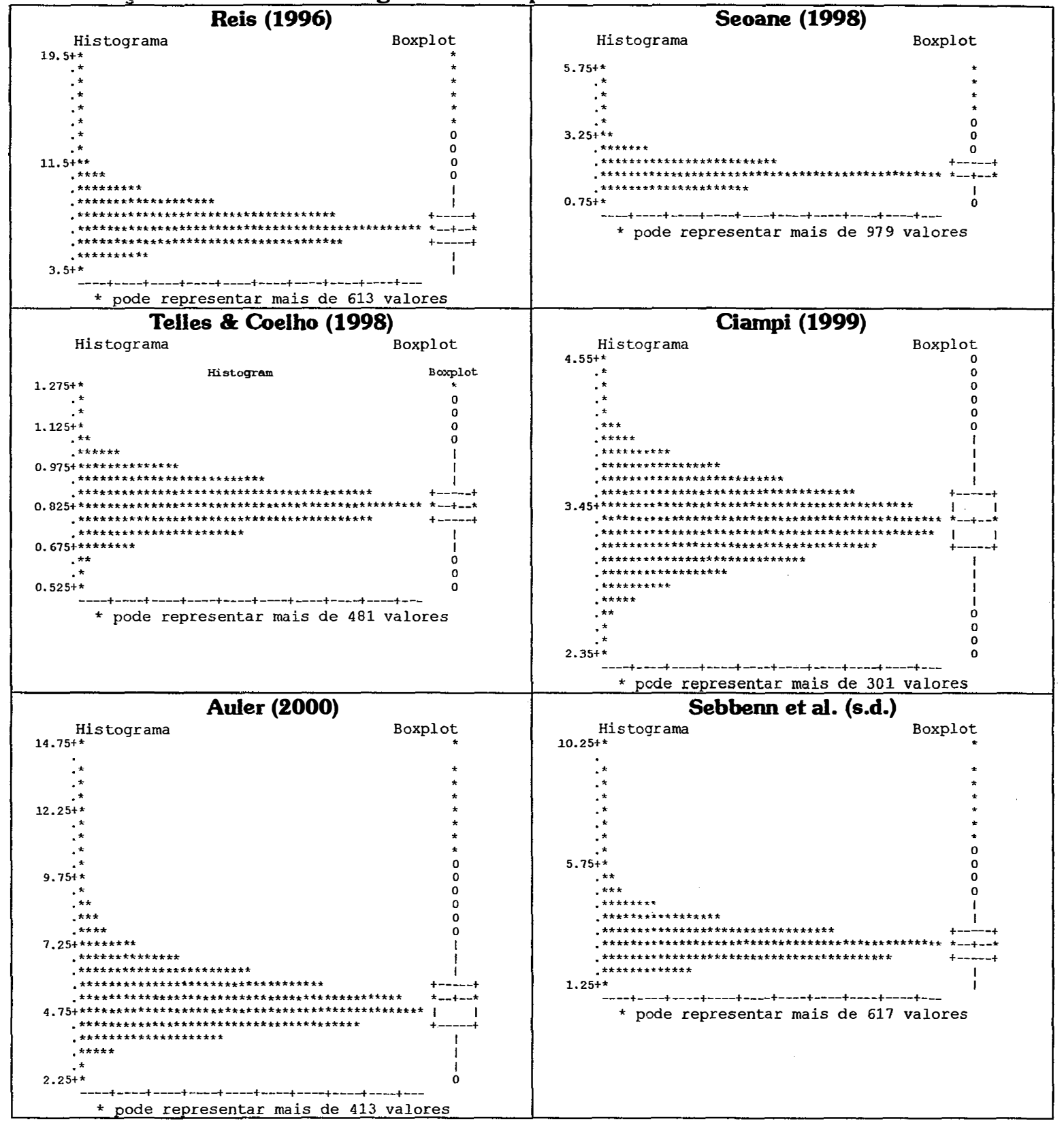

Histogramas e boxplot das estimativas do fluxo de genes entre populações $(\mathrm{Nm})$, obtidas a partir da reamostragem de indivíduos, para os conjuntos estudados. 
Continuação do Anexo B: Histogramas e Boxplots

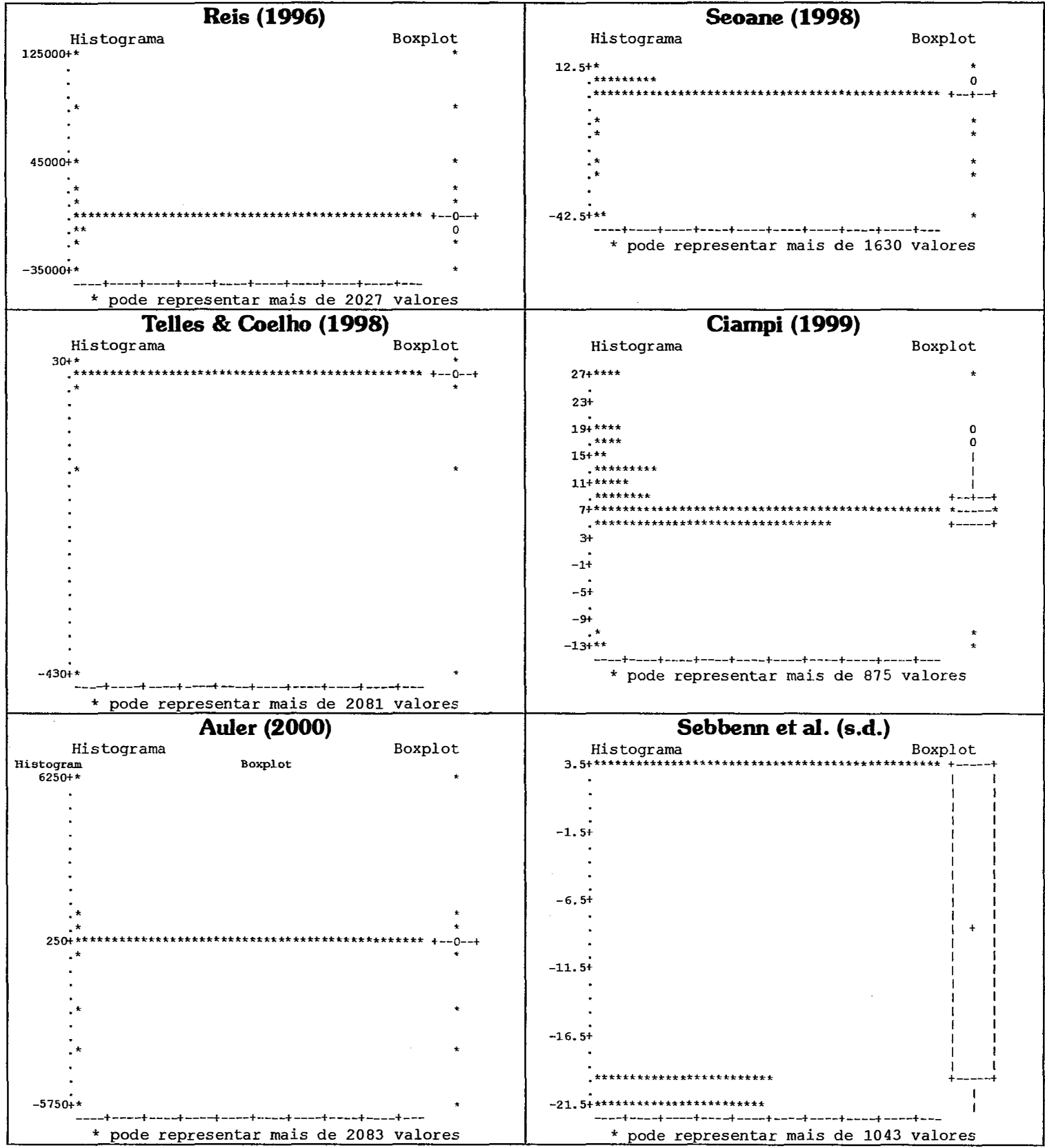

Histogramas e boxplot das estimativas do fluxo de genes entre populações $(\mathrm{Nm})$, obtidas a partir da reamostragem de populações, para os conjuntos estudados. 
Continuação do Anexo B: Histogramas e Boxplots

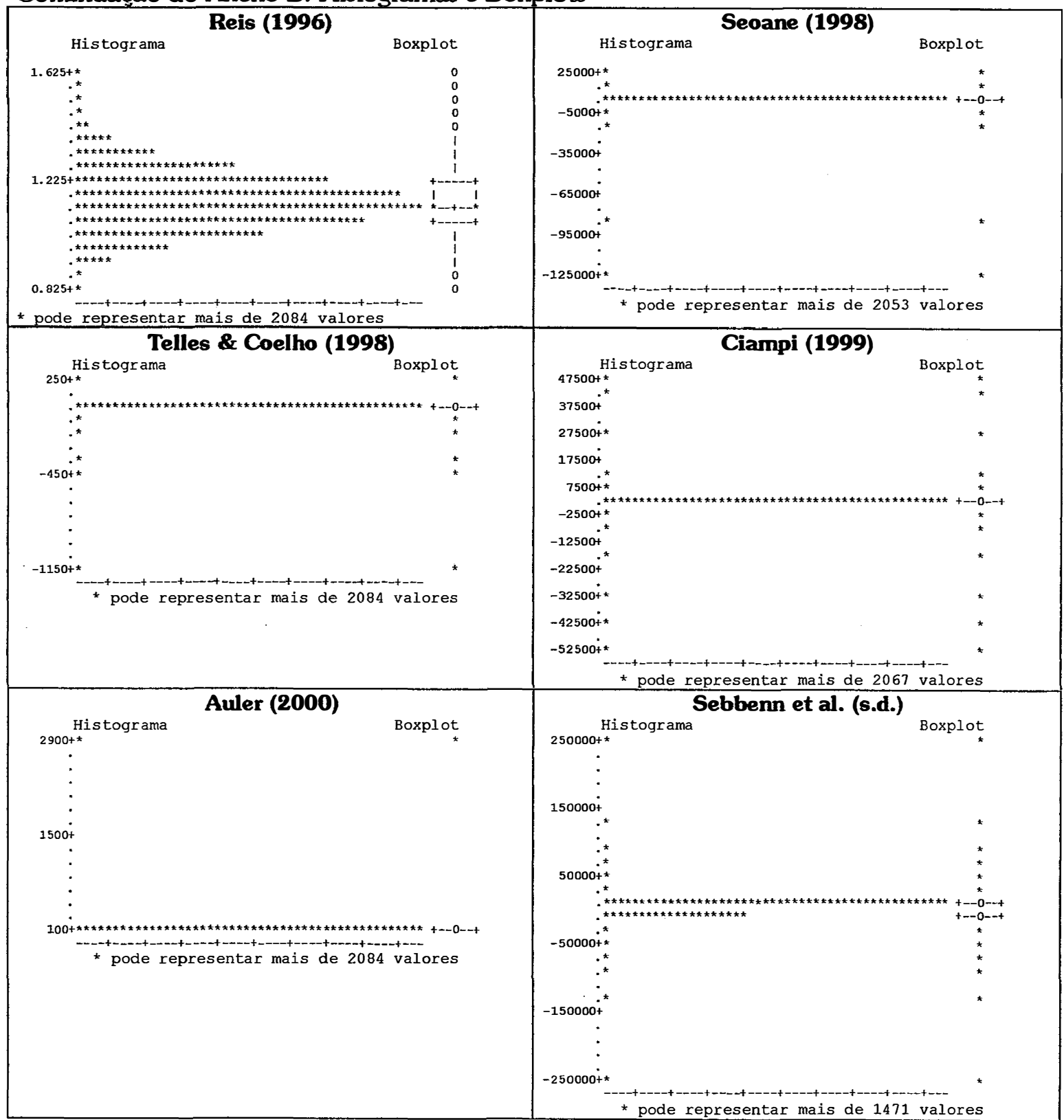

Histogramas e boxplot das estimativas do fluxo de genes entre populações $(\mathrm{Nm})$, obtidas a partir da reamostragem de indivíduos e populações, para os conjuntos estudados. 
Continuação do Anexo B: Histogramas e Boxplots

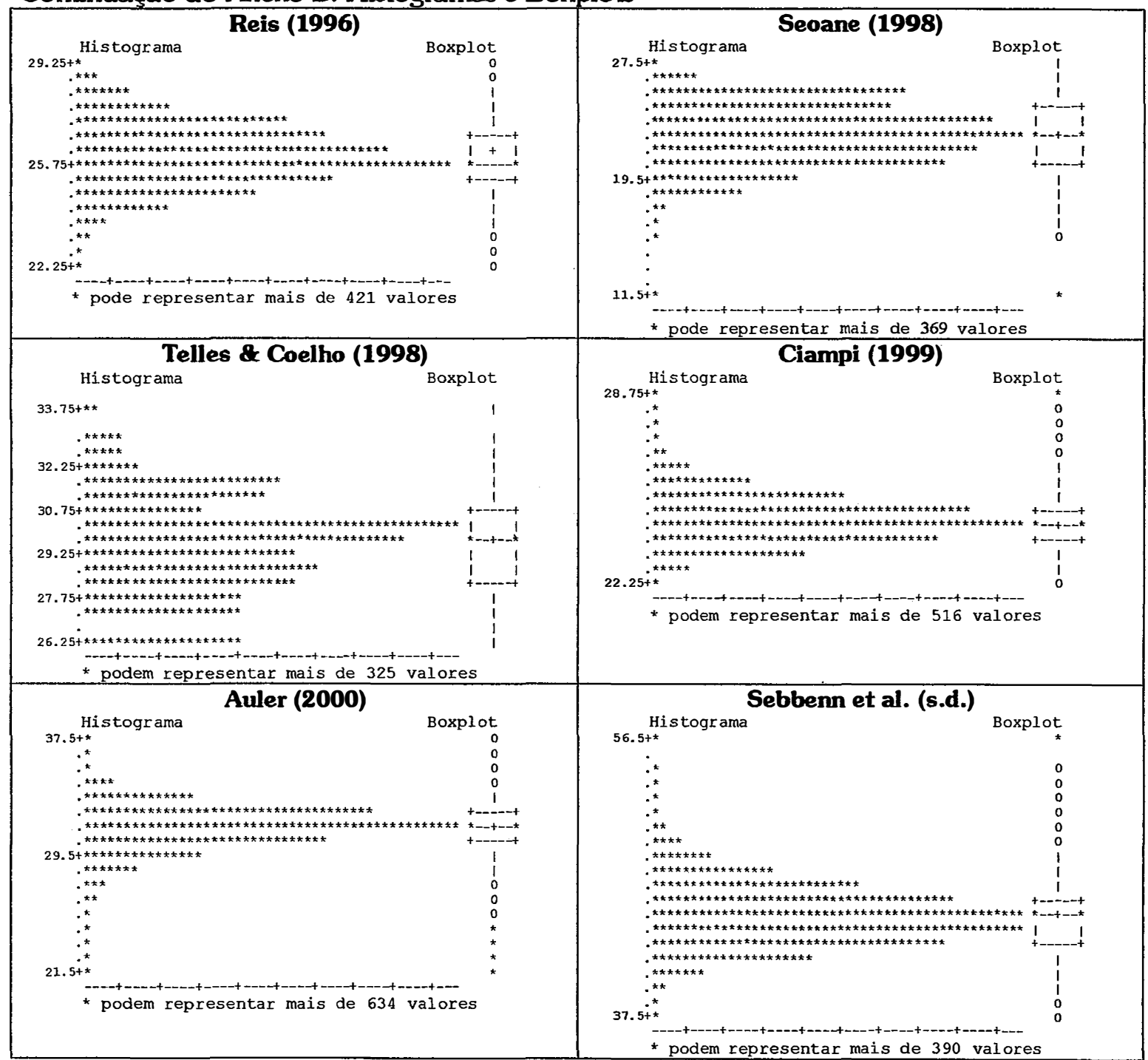

Histogramas e boxplot das estimativas do tamanho efetivo populacional $\left(N_{e}\right)$, obtidas a partir da reamostragem de locos, para os conjuntos estudados. 
Continuacão do Anexo B: Histogramas e Boxplots

\begin{tabular}{|c|c|}
\hline Reis (1996) & Seoane (1998) \\
\hline Histograma & Histograma \\
\hline $30.25+ \pm$ & $31.25+\star$ \\
\hline$\ddot{. *}$ & $\stackrel{. *}{. *}$ \\
\hline 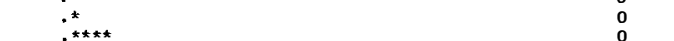 & $\because \approx$ \\
\hline 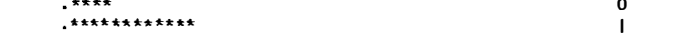 & $28.75+*$ \\
\hline. & $\begin{aligned} 28.13+x \\
. *\end{aligned}$ \\
\hline 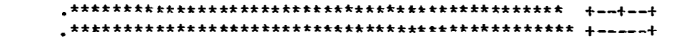 & $\because *$ \\
\hline 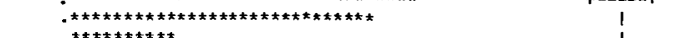 & $\ddot{0 *}$ \\
\hline 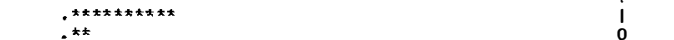 & 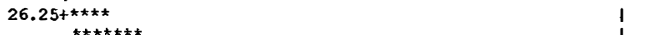 \\
\hline$: * x^{* *}+$ & 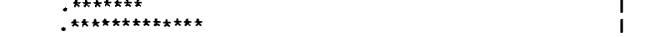 \\
\hline $23.75+*$ & 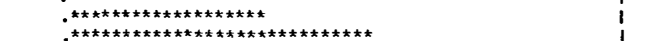 \\
\hline * pode representar mais de 559 valores & 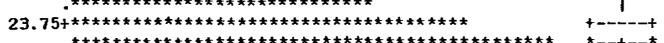 \\
\hline & 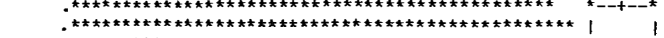 \\
\hline & 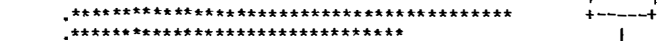 \\
\hline & 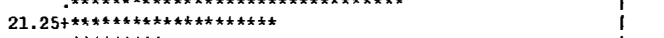 \\
\hline & 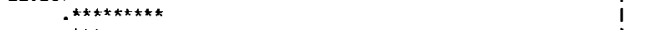 \\
\hline &.$\star \star \star \star \Delta$ \\
\hline & $\stackrel{*}{*}$ \\
\hline & $\begin{array}{l}18.75+* \\
* \text { pode representar mai.s de } 323 \text { valores }\end{array}$ \\
\hline Telles \& Coelho (1998) & Ciampi (1999) \\
\hline Histograma $\quad$ Boxplot & Histograma \\
\hline $36.25+*$ & $26.7+*$ \\
\hline$\therefore *$ & $\ddot{*}$ \\
\hline.$*$ & 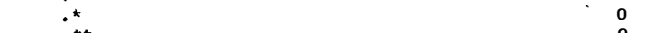 \\
\hline$\stackrel{. \star}{\star \star \star}$ & $i_{\star * *}^{* * \pi}$ \\
\hline$\ddot{: \star \star \star * t}$ & 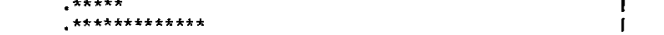 \\
\hline 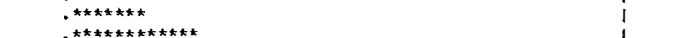 & 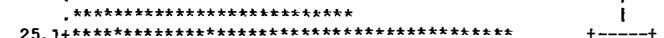 \\
\hline 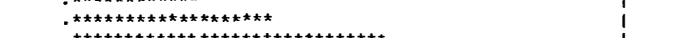 & 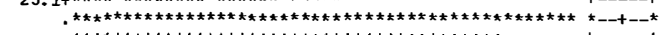 \\
\hline 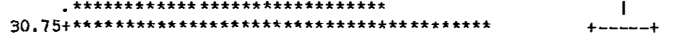 & 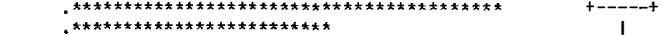 \\
\hline 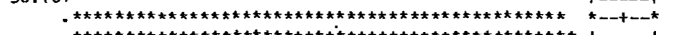 & 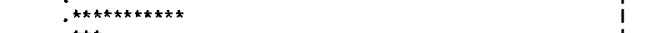 \\
\hline 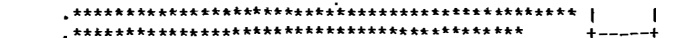 &.$* * *$ \\
\hline 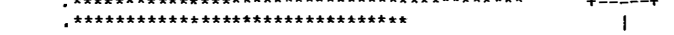 & $\stackrel{* *}{*}$ \\
\hline 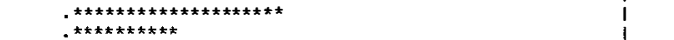 & 23.5+* \\
\hline 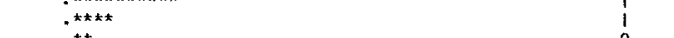 & * podem representar mais de 467 valores \\
\hline $\begin{array}{ll}: \star * & 0 \\
* & 0\end{array}$ & \\
\hline $\begin{array}{rl}: * & 0 \\
25.25 * * & 0\end{array}$ & \\
\hline 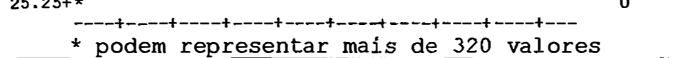 & \\
\hline Auler (2000) & Sebbenn et al. (s.d.) \\
\hline Histograma & Histograma \\
\hline $35.75 t^{\star}$ & $52.25+*$ \\
\hline.$*$ &.$*$ \\
\hline$\because * *$ & ;* \\
\hline 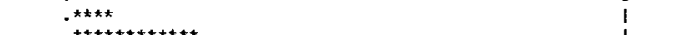 & $\because *$ \\
\hline 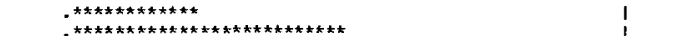 &.$*$ \\
\hline 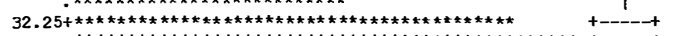 & 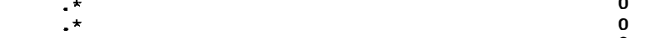 \\
\hline 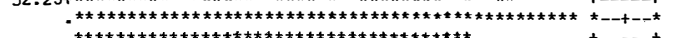 & $: * \star *$ \\
\hline 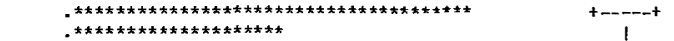 & 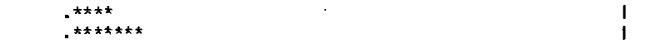 \\
\hline 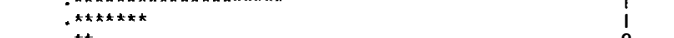 & 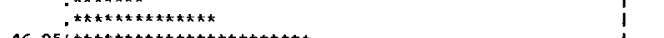 \\
\hline$\stackrel{. * *}{: *}$ & 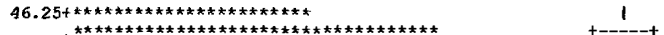 \\
\hline $28.75+\star \pm \quad 0$ & 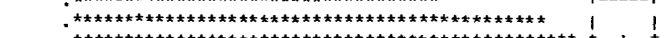 \\
\hline * podem representar mais de 509 valores & 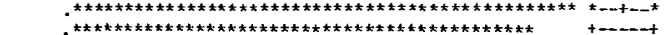 \\
\hline podem Lepresental mals de sug valores & 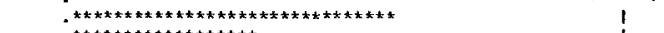 \\
\hline & 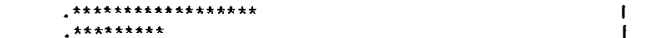 \\
\hline & 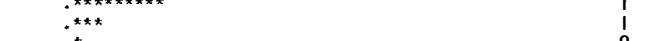 \\
\hline & $\therefore *$ \\
\hline & $\ddot{*}$ \\
\hline & $40.25+*$ \\
\hline & * podem representar mais de 358 valores \\
\hline
\end{tabular}

Histogramas e boxplot das estimativas do tamanho efetivo populacional $\left(N_{e}\right)$, obtidas a partir da reamostragem de indivíduos, para os conjuntos estudados. 
Continuação do Anexo B: Histogramas e Boxplots

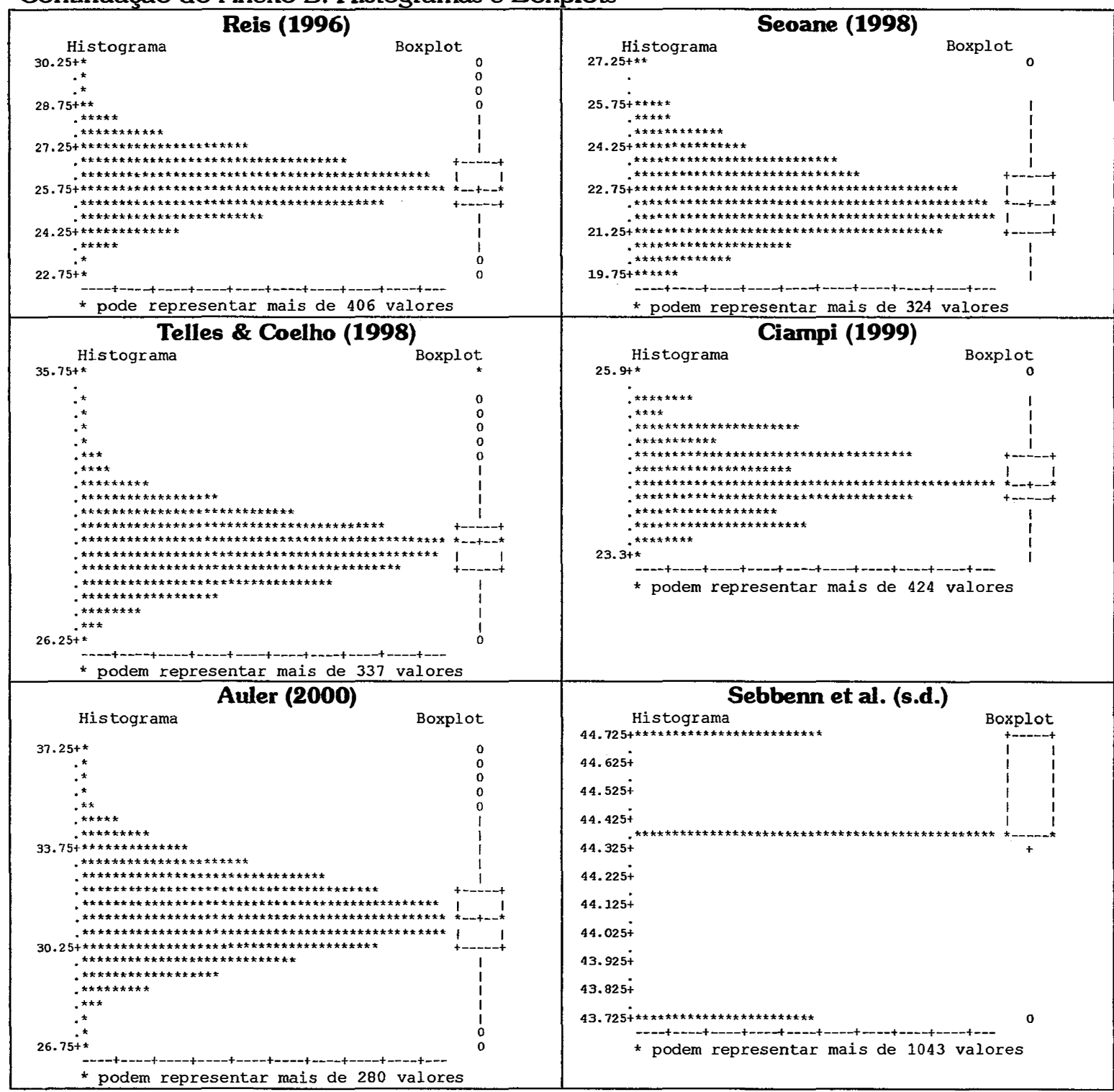

Histogramas e boxplot das estimativas do tamanho efetivo populacional $\left(N_{e}\right)$, obtidas a partir da reamostragem de populações, para os conjuntos estudados. 
Continuação do Anexo B: Histogramas e Boxplots

\begin{tabular}{|c|c|}
\hline Reis (1996) & Seoane (1998) \\
\hline 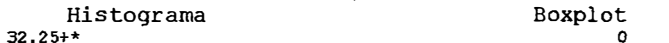 & $\underset{36.5+\star}{\text { Histograma }}$ \\
\hline $\begin{array}{ll}32.25+\star \\
. * & \vdots\end{array}$ & $36.5+\star$ \\
\hline $31.25+*$ & $:$ \\
\hline $30.25+* *$ & $\because *$ \\
\hline 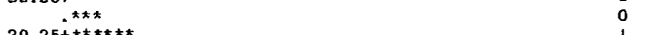 & $\because *$ \\
\hline 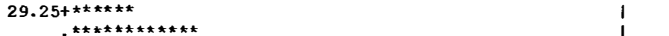 & $\therefore$ \\
\hline 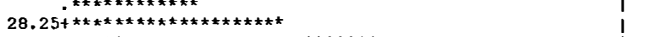 & $\because * *$ \\
\hline . & $\because \star \star \star \star \star \star \Delta$ \\
\hline 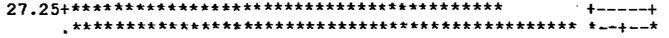 & 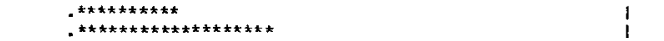 \\
\hline 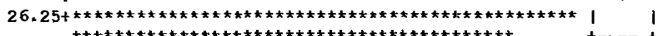 & 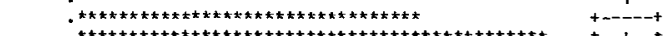 \\
\hline 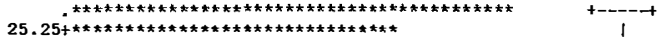 & 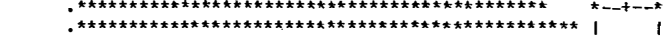 \\
\hline 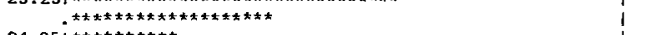 & 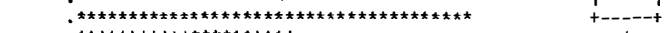 \\
\hline 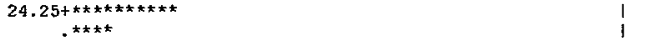 & 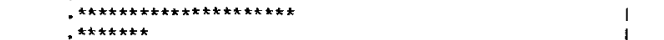 \\
\hline 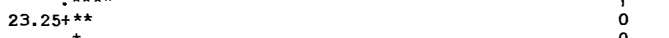 & 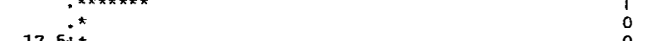 \\
\hline 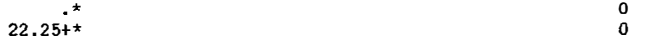 & $17.5+\star *$ \\
\hline$*$ pode representar mais de 320 valores & * podem representar mais de 444 valores \\
\hline Telles \& Coelho (1998) & Ciampi (1999) \\
\hline Histograma Boxplot & Histograma \\
\hline $41.5+*$ & 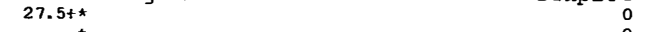 \\
\hline$\stackrel{*}{*}$ & $\because *$ \\
\hline$\therefore$ & $\because *$ \\
\hline.$*$ &.$*$ \\
\hline$\stackrel{*}{* \pm \pi}$ & 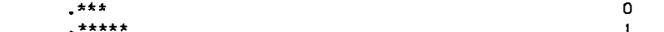 \\
\hline 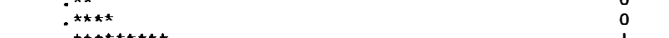 & $-* \pm * \pm \pm \pm * \pm * \pm$ \\
\hline 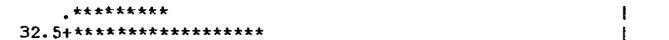 & 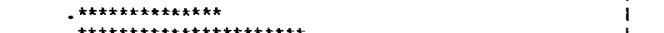 \\
\hline 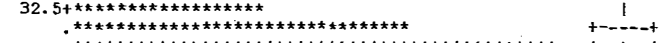 & 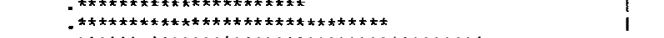 \\
\hline 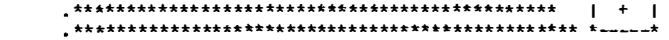 & 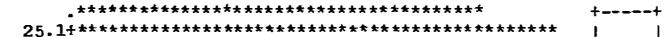 \\
\hline 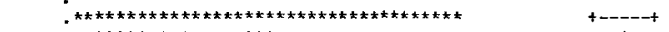 & 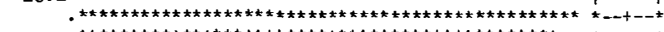 \\
\hline 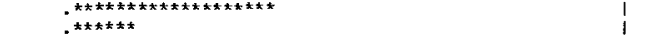 & 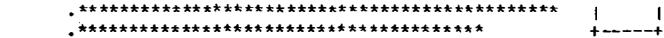 \\
\hline $\begin{array}{ll}. * & 0 \\
: * & 0\end{array}$ & 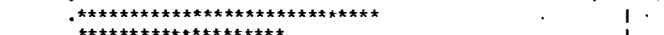 \\
\hline 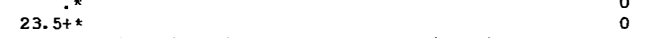 & 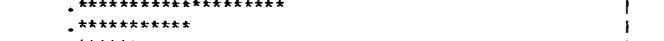 \\
\hline +and & 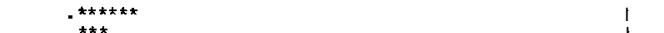 \\
\hline * podem representar mais de 459 valores & $\because * *$ \\
\hline & $\because *$ \\
\hline & $22 . \dot{7+\star}$ \\
\hline & * podem representar mais de 275 valores \\
\hline Auler (2000) & Sebbenn et al. (s.d.) \\
\hline (5) & Histograma \\
\hline $39.5+\star$ & $51.25+\star$ \\
\hline.$_{*}^{*}$ & $: *$ \\
\hline$\ddot{* * *}$ & $\because *$ \\
\hline 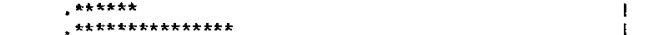 & $\because *$ \\
\hline 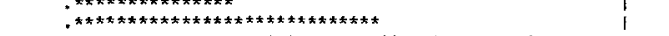 & $::_{\star \star *}^{*}$ \\
\hline 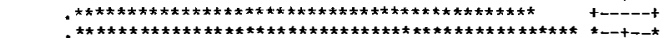 & 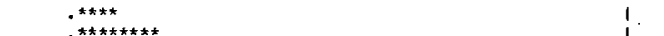 \\
\hline 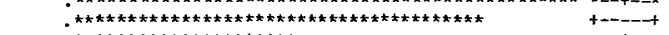 & 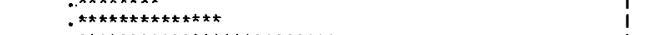 \\
\hline 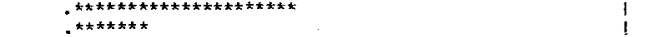 & 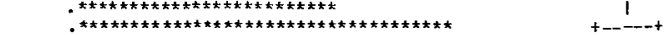 \\
\hline$\therefore 0^{*}$ & 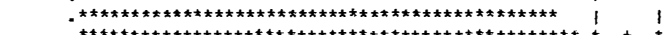 \\
\hline $26.5+\star$ - & 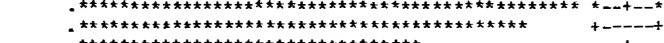 \\
\hline * podem representar mais de 481 valores & 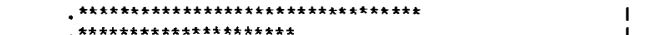 \\
\hline & 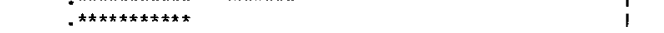 \\
\hline & 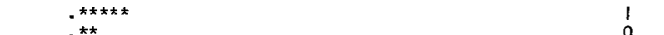 \\
\hline & 0 \\
\hline & $\begin{array}{l}0 \\
0\end{array}$ \\
\hline & $39.75 \div *$ \\
\hline & * podem representar mais de 340 valores \\
\hline
\end{tabular}

Histogramas e boxplot das estimativas do tamanho efetivo populacional $\left(N_{e}\right)$, obtidas a partir da reamostragem de indivíduos e populações, para os conjuntos estudados. 


\section{REFERÊNCIAS BIBLIOGRÁFICAS}

ANDERBERG, M. R. Clustering analysis for applications. London: Academic Press, 1973. $359 \mathrm{p}$.

AULER, N.M.F. Caracterização da estrutura genética de populações naturais de Araucaria angustifolia (Bert) O. Ktze. no Estado de Santa Catarina. Florianópolis, 2000. 93 p. Dissertação. Universidade Federal de Santa Catarina.

BALANOUSKAYA, E.V. \& NURBAEV, S.D. Selective structure of the gene pool: III. Estimation from FST-statistics with the use of numerical resampling. Genetika, v.34, n.10, p.1434-1446, 1998.

BARROS, L. M. caracterização morfológica e isoenzimática do cajueiro (Anacardium occidentalis L.), tipos comuns e anão, por meio de técnicas multivariadas. Piracicaba, 1991. 256 p.Tese (Doutorado) - Escola Superior de Agricultura "Luiz de Queiroz".

BENDER, L. C.; ROLOFF, G. J.; HAUFLER, J. B. Evaluating confidence intervals for habitat suitability models. Wildlife Society Bulletin, v.24, n.2, p.347-352; 1996.

BERTORELLE, G.; BUCCHINI, L.; PILASTRO, A.; MATESSI, C. DNA fingerprinting data and the analysis of population genetic structure by comparing band-sharing patterns. Molecular Ecology, v.8, n. 11, p. 1851-1866, 1999.

BUCKLAND, S.T. Monte Carlo confidence intervals. Biometrics, v.38, p. 469-477, 1984.BUSO, G. S. C.; RANGEL, P. H.; FERREIRA, M. E. Analysis of genetic variability of South American wild rice (Oryza glumaepatula) with isozymes and RAPD markers. Molecular Ecology, v. 7, n.1. p. 107-117, 1998. 
BUSSAB, W. de O.; MAZAKI, E. S.; ANDRADE, D. F. Introdução à análise de agrupamentos. São Paulo: Associação Brasileira de Estatística, 1990. 105 p.

CHALWATZIS, N; HAUF, J; PEER, Y. VAN-DE; KINZELABACH, R; ZIMMERMANN, F. K. $18 \mathrm{~S}$ ribosomal RNA genes of insects: primary structure of the genes and molecular phylogeny of the Holometabola. Annals of the Entomological Society of America, v.89, n.6, p.788-803; 1996.

CHATFIELD, C.; COLLINS, A. J. Introduction to multivariate analysis. Chapman \& Hall., 1980. 246p.

CHIKUNI, K; MORI, Y; TABATA, T; SAITO, M; MONMA, M; KOSUGIYAMA, M. Molecular phylogeny based on the kappa-casein and cytochrome $\mathrm{b}$ sequences in the mammalian suborder Ruminantia. Journal of Molecular Evolution, v. 41, n.6, p.859-866; 1995

CIAMPI, A.Y. Desenvolvimento e utilização de marcadores microsatélites, AFLP e seqüênciamento de cpDNA, no estudo da estrutura genética e parentesco em populações de copaíba (Copaifera langsdorffii) em matas de galeria no cerrado. Botucatu, 1999. 204p.Tese (Doutorado) - Universidade Estadual Paulista "Júlio de Mesquita Filho".

CLIFFORD, H. T. \& STEPHENSON, W. An Introduction to Numerical Taxonomy. London; Academic Press, 1975. 229p.

COCKERHAM C. C. Variance of gene frequencies. Evolution, v.23, p. 72-84, 1969.

COCKERHAM, C. C. Analysis of gene frequencies. Genetics, v. 74, p. 679-700, 1973.

COELHO, A.S.G. Programa EG: Análise de estrutura genética de populações pelo método da análise de variância (software). Universidade Federal de Goiânia, Instituto de Ciências Biológicas, Departamento de Biologia Geral, Goiânia, Goiás, 2000a.

COELHO, A.S.G. Programa EGBV: Análise de estrutura genética de populações pelo método da análise de variância, com a utilização de bootstraps com amostras de tamanho variável (software). Universidade Federal de Goiânia, Instituto de Ciências Biológicas, Departamento de Biologia Geral, Goiânia, Goiás, $2000 \mathrm{~b}$. 
CROWLEY, P.H. Resampling methods for computation-intensive data analysis in ecology nand evolution. Annual Review of Ecology and Systematics, v. 23, p. 405-447, 1992.

DAVIDSON, A.C.; HINKIEY, D.V. Bootstrap methods and their application. Cambridge University Press, 1997. 582p.

DOPAZO, J. Estimating erros and confidence intervals for branch lenghts in phylogenetic trees by a bootstrap approach. Journal of Molecular Evolution, v. 38, p. 300-304, 1994.

DUNN, G.; EVERITT, B. S. An Introduction to Mathematical Taxonomy. Cambrige University Press, 1980. 152 p.

EFRON, B. Bootstrap methods: another look at jackknife. Annals of Statistics, v. 7, p. 1-26, 1979.

EFRON, B. Better bootstrap confidence intervals. Journal of the American Statistical Association, v.82, p. 171-185, 1987.

EFRON, B. \& TIBSHIRANI, R. J. An Introduction to the Bootstrap. Chapman \& Hall, 1993. 436p.

EXCOFFIER, L.; SMOUSES, P. E.; QUATTRO, J. M. Analysis of molecular variance inferred from metric distances among DNA Haplotypes: application to human mitocondrial DNA restriction data. Genetics, v.131, p. 479-491, 1992.

FALCONER, D.S.; MACKAY, T.F.C. Introduction to Quantitative Genetics. $4^{\text {th }}$ ed. Longman Group Ltd, 1996. 464p.

FANIZZA, G.; COLONNA, G.; RESTA, P.; FERRARA, G. The effect of the number of RAPD markers on the evaluation of genotypic distances in Vitis vinifera. Euphytica, v.107, n.1, p.45-50, 1999.

FARALDO, M. I. F. Caracterização isoenzimática e diversidade de etnovariedades de mandioca (Manihot esculenta Crantz). Piracicaba, 1994. 91 p. Dissertação - Escola Superior de Agricultura "Luiz de Queiroz". 
FELSENSTEIN, J. Confidence limits on phylogenies: a justification. Evolution, v. 39, p. 783-791, 1985.

FERREIRA, M. E. e GRATTAPAGLIA, D. Introdução ao Uso de Marcadores Moleculares em Análise Genética. Brasilia: EMBRAPA, 1996. 220 p.

FUTUYMA, D.J. Biologia Evolutiva. $2^{\text {a }}$ ed. 1992. 631p.

GANG, D. R.; WEBER, D. J. Genetic variability and relationsip among ten populations of rubber rabbitbrush (Chrysothamnus nauseous ssp. hololeucus) determined by RAPD analysis of bulked genomic DNA samples. Bot. Bull. Acad. Sin., v. 36, p. 1-8, 1995.

GILIES, A. C. M.; CORNEUUS, J. P.; NEWTON, A. C.; NAVARRO, C.; HERNANDEZ, M.; WILSON, J. Genetic variation in Costa Rican populations of the tropicla timber species Cedrela odorata L., assessed using RAPDs. Molecular Ecology, v.6, n.12, p. 1133-1145, 1997.

GRIFFITHS, A.J.F.; MILER, J.H.; SUZUKI, D.T.; LEWONTIN, R.C.; GELBART, W.M. An Introduction to Genetics a Analysis. $6^{\text {th }}$ ed. New York: W.H. Freeman and Company, 1996. 916p.

HAL, P. The Bootstrap and Edgeworth Expansion. New York: Springer-Verlag, 1992.

HAUDÉN, C.; NILSSON, N. O.; RADING, I. M.; SÄLL, T. Evaluation of RFLP and RAPD markers in a comparison of Brassica napus breeding lines. Theoretical and Applied Genetics, v. 88, p. 123-128, 1994.

HUFF, D. R.; PEAKALL, R. SMOUSE, P. E. RAPD variation within and among natural populations of outcrossing buffalograss [Buchloë dactyloides (Nutt.) Engelm.]. Theoretical and Applied Genetics, v. 86, p. 927-934, 1993.

JAMES, F.C.; MCCULLOCH, C.E. Multivariate analysis in ecology and systematics: panacea or Pandora's box? Annual Review of Ecol. Systematics, v. 21, p.129-166, 1990.

JOHNSON, R. A. \& WICHERN, D. W. Applied Multivariate Statistical Analysis. $3^{\text {rd }}$ ed. New Jersey: Prantice Hall, 1992. 642 p. 
KAWAGUICI, C.B. Variação genética em três grupos de indivíduos (adultos, jovens e plântulas) de Calophyllum brasiliense Camb. (Clusiaceae), em mata de galeria. Piracicaba, 1999. 98p. Dissertação - Escola Superior de Agricultura "Luiz de Queiroz".

KEIGHTLEY, P.D. \& KNOTT, S. Testing the correspondence between map positions of quantitative trait loci. Genetical-Research, v.74, n.3, p. 323-328, 1999.

KEMPTHORNE, O.; DOEFLER, T.E. The behaviour of some significance tests under experimental randomization. Biometrika, v.56, p.231-248, 1969.

KEFUEY, S. C. \& JANSEN, R. K. Chloroplast DNA restriction site variation in the Vernonieae (Asteraceae), na initial appraisal of the relationship of New and Old World taxa and th monophyly of Vernonia. Plant Systematics and Evolution, v. 193, p. 249-265, 1994.

KORMAN, A.K.; MALIET, J.; GOODENOUGH, J.L.; GRAVES, J.B.; HAYES, J.L.; HENDRICKS,D.E.; LUTIREU, R.; PARI, S.D.; WALL, M. Population structure in Heliothis virescens (Lepidoptera: Noctuidae): na estimate of gene flow. Annals of theEntomological Society of America, v. 86, n.2, p.182-188, 1993.

LI, C. C. Population Genetics. The University of Chicago Press, 1954. 366 p.

LI, C. C. First Course in Population Genetics. The Boxwood Press, 1976. 631 p

LU, B. H.; KNAPP, S. J.; BIRKES, D. Sampling distributions, biases, variances, and confidence intervals for genetic correlations. Theoretical and Applied Genetics., v.94, n.1, p.8-19; 1997.

LYNCH, M. \& MILLIGAN, B. G. Analysis of population genetic structure with RAPD markers. Molecular Ecology, v. 3, p. 91-99, 1994.

MALÉCOT, g. Les Mathématiques de L'Hérédité. Paris: Masson et Cie. Éditeurs, 1948. 63p.

MANLY, B. F. J. Multivariate Statistical Methods: A Primer. 2 ed. Chapman \& Hall, 1994. $215 \mathrm{p}$.

MANLY, B. F. J. Randomization, Bootstrap and Monte Carlo Methods in Biology. $2^{a}$ ed. Chapman \& Hall, 1997. 399 p. 
MARCON, G. estrutura genética de populações de Stylosanthes humilis H.B.K. (Leguminoseae) de três regiões ecogeográficas do Estado de Pernambuco. Piracicaba, março, 1988. 179 p. Tese (Doutorado) - Escola Superior de Agricultura "Luiz de Queiroz".

MARDIA, K. V.; KENT, J. T. BIBBY, J. M. Multivariate Analysis. London: Academic Press, 1979. $520 \mathrm{p}$.

MCDONALD, D.B.; POTTS, W.K; FITZPATRICK, J.W.; WOOLFENDEN,G.E. Contrasting genetic structures in sister species of North American scrub. Proceedings of the Royal Society Biological Sciences, Series B, v.266, n. 1424, p. 1117-1125, 1999.

MICHALAKIS, Y. \& EXCOFFIER, L. A generic estimation of population subdivision using distances between allesles with special reference to microstellite loci. Genetics, v. 142, n.3, p. 1061-1064, 1997.

MITCHEL L, B.D.; GHOSH, S.; WATANABE, R.M.; SUFER, S.H. Identifying influential individuals in linkage analysis: Application to a quantitative trait locus detected in the COGA data. Genetic Epidemiology, v. 17, supl. 1, p. 259-264, 1999.

MORAES, P.L.R. Estrutura genética de populações de Cryptocaria moschata Nees e Martius Ex Nees (Lauraceae). Rio Claro, 1997. 197p. Tese (Doutorado) Universidade Estadual Paulista.

MORI, E.S. Variabilidade genética isoenzimática em uma população de Eucaliptus grandis Hill ex Maiden submetida a diferentes intensidades de seleção. Piracicaba, 1993. 119 p. Tese (Doutorado) - Escola Superior de Agricultura "Luiz de Queiroz".

MORRISON, D. F. Multivariate statistical methods. 2 ed. McGraw-Hill Book Company, 1976. 415p.

MUNIZ, J.A. Inferência sobre parâmetros relativos à estrutura genética de populações com dados de freqúências gênicas. Piracicaba, 1994. 224p. Tese (Doutorado) - Escola Superior de Agricultura "Luiz de Queiroz".

NEI, M. Analysis of gene diversity in subdivided populations. Proceedings of Natural Academy Science, v. 70, n. 12, p.3321-3323, 1973. 
NEI, M. Estimation of average heterozygosity and genetic distance from a small number of individuals. Genetics, v. 89, p. 583-590, 1978.

NEI, M. Genetic distance between populations. American Naturalist, v.106, p. 283292, 1972.

NEI, M. Analysis of gene diversity in subdivided populations. Proceedings of Natural Academic Science, v.70, n.12, p.3321-3323, 1973a.

NEI, M. The theory and estimation of genetic distance. In: MORTON, N.E. Genetic Structure of Populations. Honolulu: University Hawaii Press, 1973b. p.45-54.

NEI, M. F-statistics and analysis of gene diversity in subdivided population. Ann. Human Genet., v.41, p. 225-233, 1977.

NEI, M. Estimation of average heterozygosity and genetic distance from a small number of individuals. Genetics, v. 89, p. 583-590, 1978.

NEI, M. Molecular Evolutionary Genetics. New York, 1987. 512 p.

NETER, J.; WASSERMAN, W.; KUINER, M.H. Applied linear regression models. $3^{\text {rd }}$ ed., 1990. $1181 \mathrm{p}$.

NETTLETON, D. \& DOERGE, R.W. Accounting for variability in the use of permutation testing to detect quantitative trait loci. Biometrics, v. 56, n.1, p. 52-58, 2000.

PETIT, R. J. \& PONS, O. Bootstrap variance of diversity and differentiation estimators in a subdiveded population. Heredity, v. 80, p. 56-61, 1998.

PONS. O. \& PETIT, R. J. Estimation variance and optimal sampling of gene diversity. I. Haploid locus. Theoretical and Applied Genetics., v.90, p. 462-470; 1995.

PRIMMER, C.R.; AHO, T.; PIIRONEN, J; ESTOUP, A.; CORNUET, J.M.; RANTA, E. Microsatellite analysis of hatchery stocks and natural populations of Arctic charr, Salvelinus alpinus Lund. from the Nondic region: Implications for conservation. Hereditas, v.130, n.3, p. 277-289, 1999.

QUENOUILLE, M. Approximations tests of correlation in time series. Journal of $\mathbf{R}$. Statist. Society B, v. 11, n. 18-84, 1949 
REIS, M.S. Distribuição e dinâmica da variabilidade genética em populações naturais de palmiteiro (Euterpe edulis Martius). Piracicaba, 1996. 210 p. Tese (Doutorado) - Escola Superior de Agricultura "Luiz de Queiroz".

REMINGTON, D.L.; WHETTEN, R.W.; LIU, B.H.; O'MAUUEY, D.M. Construction of an AFLP genetic map with nearly complete genome coverage in Pinus taeda. Theoretical and Applied Genetics, v.98, n.8, p. 1279-1292, 1999.

RITLAND, K; JAIN, S. A model for the estimation of outcrossing rate and gene frequencies using $n$ independente loci. Heredity, v.47, n.1, p.35-52, 1981.

ROFF, D.A. \& PREZIOSI, R. the estimation of the genetic correlation: the use of the jackknife. Heredity, v. 74, p. 544-548, 1994

SANTOS, E. M. G. Ecologia da polinização, fluxo de pólen e taxa de cruzamento em Bauhinia forficata Link. 1994.

SEBBENN, A.M. Estrutura genética de subpopulações de Genipa americana L. (Rubiaceae) a partir de isoenzimas. Piracicaba, 1997. 107 p. Dissertação - Escola Superior de Agricultura "Luiz de Queiroz".

SANTOS, M. M. Polimorfismo isoenzimático de população subespontânea de dendê (Elaeis guineensis Jacq.) do Estado da Bahia e sua relação genética com seis procedências africanas. Campinas, 1991. Tese de (Doutorado) - UNICAMP.

SEBBENN, A.M.; SEOANE, C.ES.; KAGEYAMA, P.Y.; VENCOUSKY, R. Efeitos do manejo no comportamento genético de populações de caixeta - Tabebuia cassinoides (LAM.) D.C. Scientia florestalis, 2000. No prelo/.

SEBBENN, A.M.; SEOANE, C.E.S.; KAGEYAMA, P.Y. ; LACERDA, C.B. Estrutura genética de populações de Tabebuia cassinoides: implicações para o manejo e a conservação genética, s.d. /Dados não publicados/.

SEOANE, C.E.S. Efeitos da fragmentação florestal sobre a estrutura genética de populações de Esenbeckia leiocarpa Engl. - guarantã - um exemplo de espécie arbória tropical climácica de distribuição agregada. Campinas, 1998. 80 p. Dissertação - Universidade Estadual de Campinas. 
SHAO, J. \& TU, D. The Jackknife and Bootstrap. Springer Series in Statistics. Springer, 1995. $516 \mathrm{p}$.

SLATKIN, M. A measure of subdivision based on micrsatellite allele frequencies. Genetics, v.139, p.457-462, 1995.

SNEATH, P. H.; SOKAL, R. R. Numerical taxonomy: the principles and practice of numerical classification. San Francisco: W.H. Freeman and Company, 1973. 573p.

SOKAL, R.R.; ROHLF, F.J. Biometry: the principles and practice of statistics in biolofical research. $3^{\text {rd }}$ ed. New York: W.H. Freeman and Company, 1995. 887p.

STEEL, R.G.D. \& TORRIE, J.H. Principles and Procedures of Statistics: a biometrical aproach. $2^{\text {th }}$ ed. McGraw-Hill Book Company, 1980. 633p.

TEI_IES M.P.C. \& COEIHO, A.S.G. Caracterização genética de populações naturais de araticum (Anonna crassiflora). Programa e Resumos do $44^{\circ}$ Congresso Nacional de Genética. Genetic and Molecular Biology, v.21, n. 3 (Supplement), p. 199. Águas de Lindóia, SP, 1998.

TELIES, M.P.C. Diversidade genética e estrutura populacional de cagaiteira (Eugenia dysenterica DC.) do sudeste de Goiás. Goiânia, 2000. 129 p. Dissertação Universidade Federal de Goiás.

TIVANG, J. G.; NIENHUIS, J.; SMITH, O. S. Estimation of samplimg variance os molecular marker data using the bootstrap procedure. Theoretical Applied Genetics, v. 89, p. 259-264, 1994.

TOSTAIN, S. Isozymic classification of peqrl millet (Pennisetum glaucum, Poaceae) ladraces from Niger (West Africa). Plant Systematics and Evolution, v. 193, p. 8193, 1994.

TRAVIS, S. E. ; MASCHINSKY, J.; KEIM, P. Na analysis of genetic variation in Astragalus cremnophylax var. cremnophylax, a critically endangered plant, using AFLP markers. Molecular Ecology, v.5, n.6, p. 735-745, 1996.

TUKEY, J.W. Bias and confidence in nota quite large samples. Annals of Mathematical Statistics, n.29, p.614, 1958. 
VAN DONGEN, S. How should we bootstrap allozyme data? Heredity, v. 74, p. 445447, 1995.

VAN DONGAN, S. \& BACKELJAU, T. One- and two-sample tests for single-locus inbreeding coefficients using the bootstrap. Heredity, v. 74, p. 129-135, 1995.

VENCOVSKY, R. Effective size of monoicious populations submitted to artificial selection. Revista Brasileira de Genética, v.I, n. 3, p. 191-191, 1978.

VENCOVSKY, R. Análise de variância de freqüências alélicas. Revista Brasileira de Genética, v. 15, n. 1, p.53-60, 1992.

VENCOVSKY, R.; DIAS, C. T. S.; DEMÉTRIO, C. G. B.; LEANDRO, R. A.; PIEDADE, S. M. S. Reamostragem por "bootstrap" na estimação de parâmetros baseados em marcadores genéticos. Anais do $14^{\circ}$ Encontro sobre Temas de Genética e Melhoramento, v. 14, p. 59-72, 1997.

VISSCHER, P. M.; THOMPSON, R.; HALEY, C. S. Confidence intervals in QTL mapping by bootstrapping. Genetics, v. 143, p. 1013-1020, 1996.

WEIR, B. S. Genetic Data Analysis 1I. $2^{\text {nd }}$ ed. Sunderland: Sinauer Associates, Inc. Publishers, 1996. $445 \mathrm{p}$.

WEIR, B.S.; COCKERHAM, C.C. Estimating F-statistics for the analysis of population structure. Evolution, v.38, n.6, p. 1358-1370, 1984.

WRIGHT, S. Systems of mating. Genetics, v.6, p. 111-178, 1921.

WRIGHT, S. Coefficients of inbreeding and relationship. American Naturalist, v. 56, p. 330-338, 1922.

WRIGHT, S.. The genetical structure of population. Ann. Eugenics, v. 15, 323-354, 1951.

WRIGHT, S. The interpretation of population structure by F-statistics with special regard to systems of mating. Evolution, v. 19, p. 395-420, 1965. 
ZHAO, H.; SHEFFILD, L.J.; PAKSTIS, A.J.; KNAUERT, M.P.; KIDD, K.K. A more powerful method to evaluate p-values in GENEHUNIER. Genetic Epidemiology, v. 17, Supl. 1; p.415-420, 1999.

ZHU, J. \& WEIR, B.S. Diallel analisys for sex-linked and maternal effects. Theoretical Apllied Genetics, v. 92, p. 1-9, 1996. 